\title{
Experimental Characterization and Modelling of a Heat Pump Water Heater
}

\author{
by \\ Kevin Khalaf, B.Eng., Mechanical Engineering \\ Carleton University
}

A thesis submitted to the Faculty of Graduate and Postdoctoral Affairs in partial fulfillment of the requirements for the degree of Master of Applied Science

In

Mechanical Engineering

Carleton University

Ottawa, Ontario

(C) 2017, Kevin Khalaf 


\section{Abstract}

Canada plays a leading role in the initiative to divert energy sources from greenhouse gas (GHG) emissive power sources to renewable and sustainable energy sources. Through the Clean Energy Act, Canada is subjected to introduce a reduction in electricity demand by $66 \%$, and GHG emission reduction by $80 \%$, from the levels achieved in 2007 , by 2020 . This thesis investigated the use of heat pump water heater technology to assist in the reduction of GHG emissions and energy in domestic water heating for the residential sector. Heat pump water heaters (HPWHs) have had great success in the warm, humid climates of the US, Europe and Asia. However, due to the longer heating season in Canada, a conventional HPWH installed in a residential basement can increase the space heating demand in the winter. Models have been used to study heat pumps and thermal storage as separate components. However, few modelling studies have been conducted on HPWHs with condensers as wrap-around coils on the outside wall of the water storage tank. This study involved the development of a new HPWH model in the TRNSYS simulation software, based on Types 938 (heat pump water heater) and 534 (water storage tank), to investigate the effect of a HPWH unit on the space heating and cooling requirements of a house. The model was verified by experiment using a commercially available HPWH unit in a laboratory setting. The experimental set-up consisted of an air-source heat pump connected to a controlled air supply that provided constant temperature, flow rate, relative humidity to the unit, as well as a draw system for hourly water draws. A performance map was experimentally obtained through monitoring the air temperature, relative humidity, and water temperature as the independent variables, while the total and sensible cooling capacity, compressor power and heat delivery were the dependent variables. The result of the study showed that humidity has a negative effect on the performance of the unit at low temperatures. 
The study of the effect of the HPWH unit on the space heating and cooling systems was conducted in multiple Canadian locations. It was found that the unit's performance was independent of the ambient temperature when installed in a basement. The unit had a maximum coefficient of performance (COP) of 3.07 and minimum of 2.46 for a basement temperature held at $18^{\circ} \mathrm{C}$. It was found the HPWH unit is not cost effective in comparison to a natural gas water heater. However, the HPWH significantly reduces house emissions. Furthermore, the HPWH was shown to have a payback period of 4 years in Ontario in comparison to a 12 and 9 year payback period in Quebec and British Columbia, respectively. This was due to the higher electricity rates. These payback periods were shown to be much higher when the effect of the space heating and cooling is considered. 


\section{Acknowledgements}

I would like to thank my supervisor, Dr. Cynthia Cruickshank, for the support, guidance, and patience she has provided for the last 2 years.

I would like to thank my colleagues within the Solar Energy Systems Laboratory who have provided friendship, guidance, and mentorship over the duration of my thesis. These people include, but are not limited to, Adam Wills, Alex Hayes, Brock Conley, Chris Baldwin, Curtis Meister, David Ouellette, Dylan Bardy, Nina Dmytrenko, Patrick Smith, and Sarah Wert.

I would like to thank my friends for their continuous support. These people include, but are not limited to, Adel Jawhary, Ahmed Farag, Clinton D’Silva, Evelyn Tennant, Juan Posada, Leon Lewis, Mohamed Emara, Navi Randhawa and Tejas Sawant.

I would like to acknowledge the financial support I have received from the Natural Sciences and Engineering Research Council (NSERC) Smart Net-zero Energy Buildings Strategic Research Network and NSERC.

Finally, I would like to thank my family for their support throughout my journey. Without the support and love of my Mother Samar, Father Majid, I would not be where I am today. 


\section{Table of Contents}

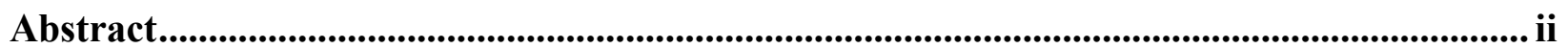

Acknowledgements ........................................................................................................................... iv

List of Figures............................................................................................................................................. viii

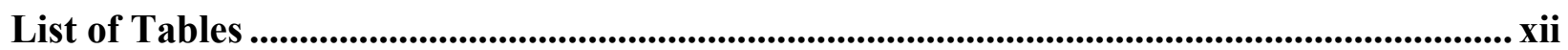

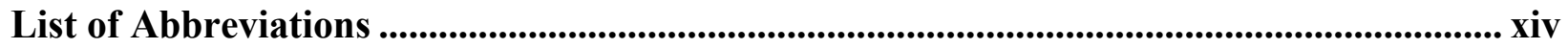

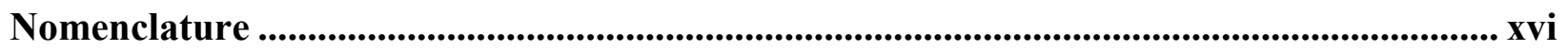

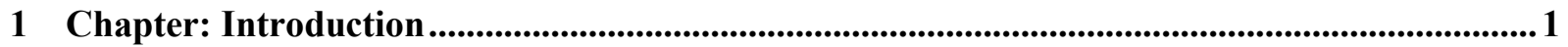

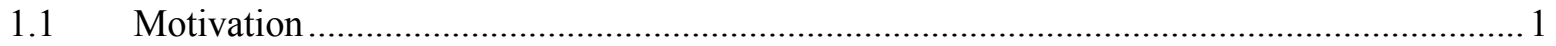

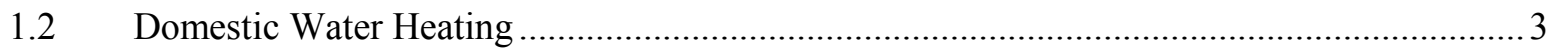

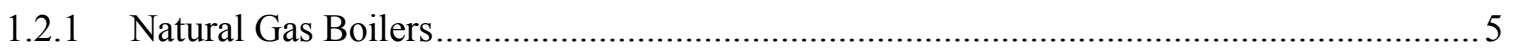

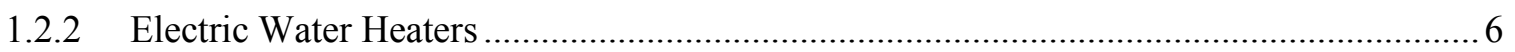

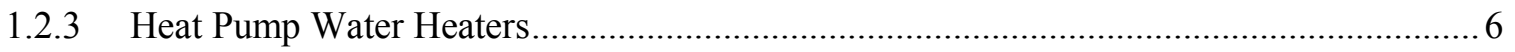

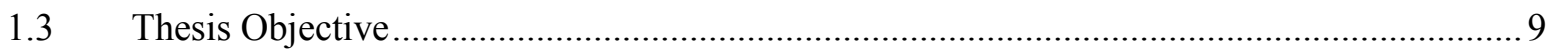

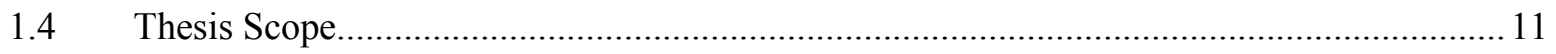

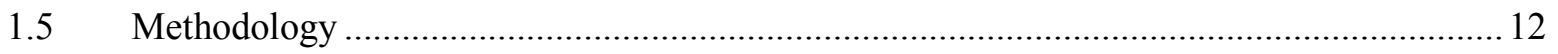

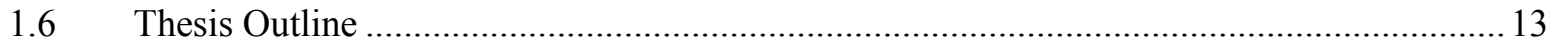

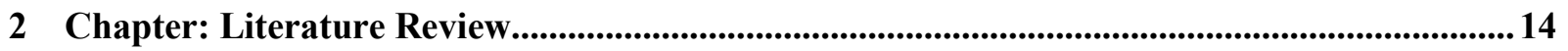

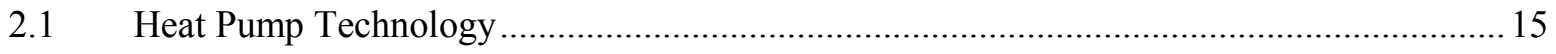

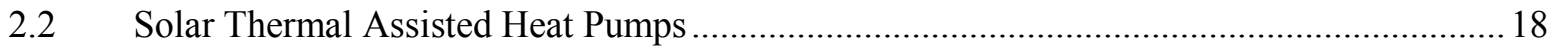

2.3 Photovoltaic-Thermal Heat Pump Water Heater............................................................... 21

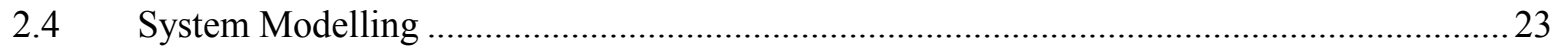

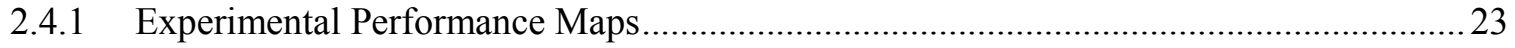

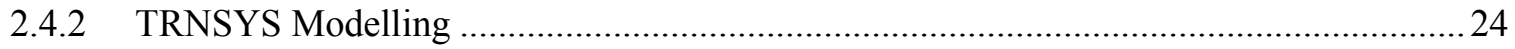

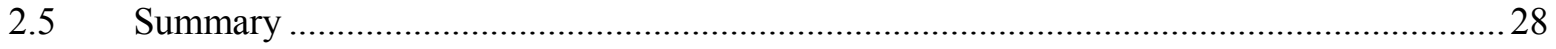




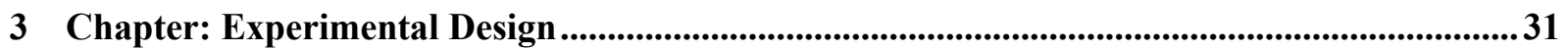

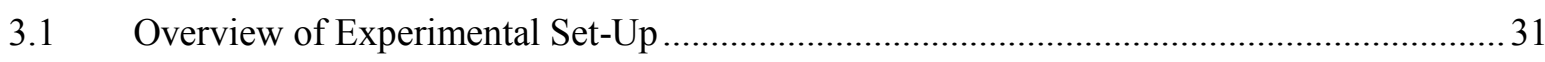

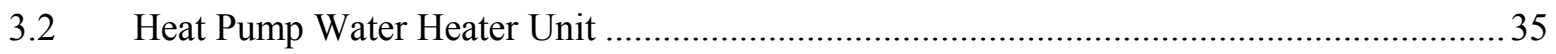

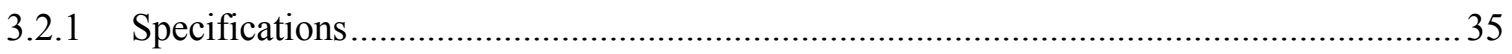

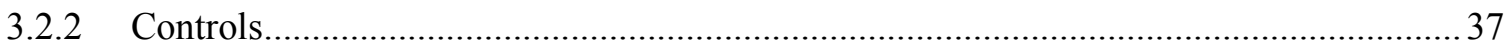

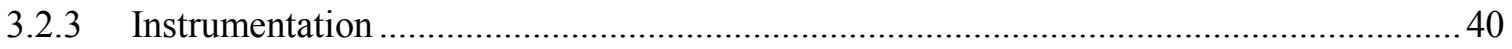

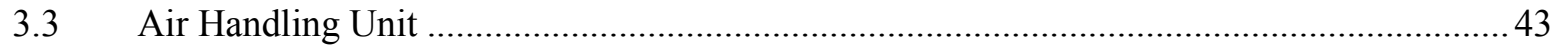

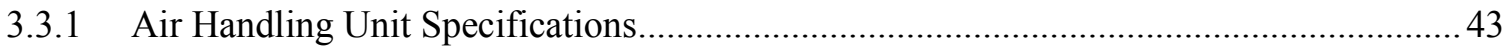

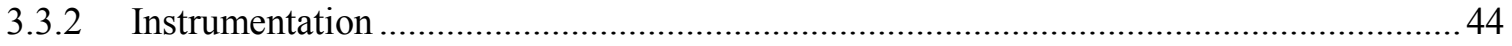

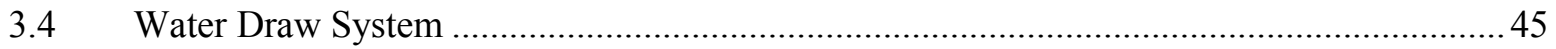

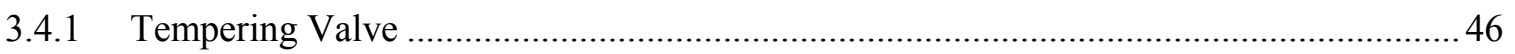

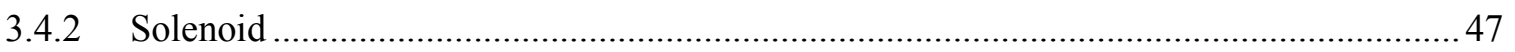

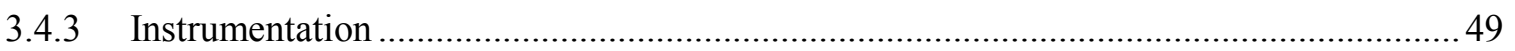

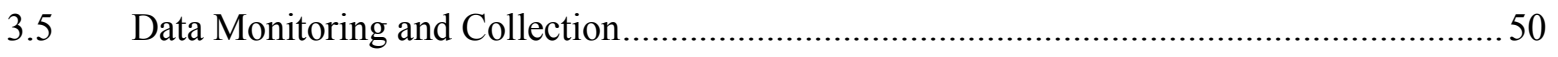

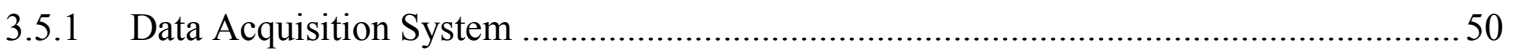

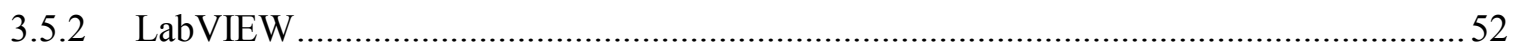

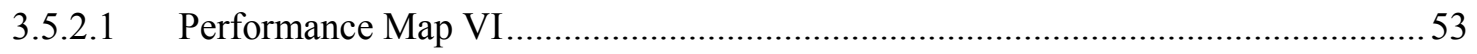

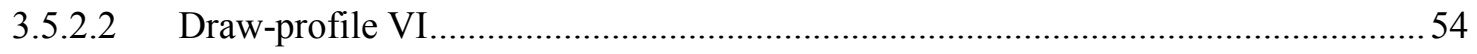

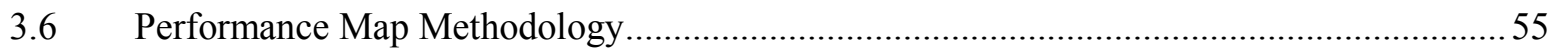

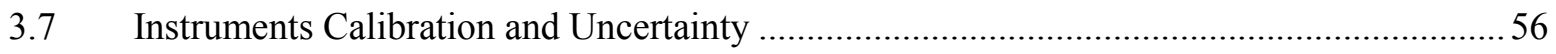

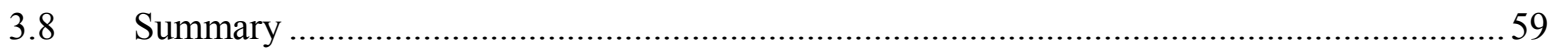

4 Chapter: System Modelling …..........................................................................................................6 61

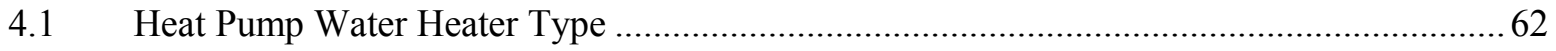

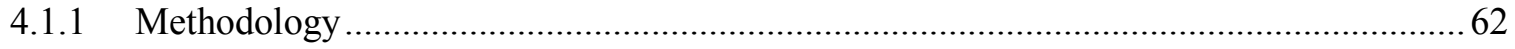

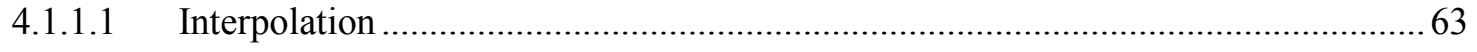




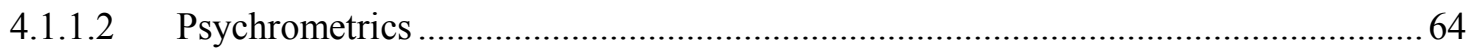

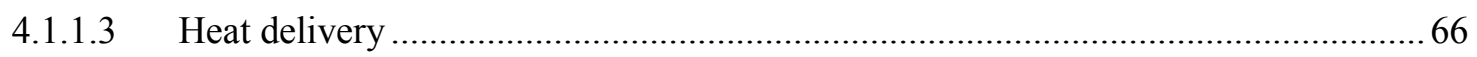

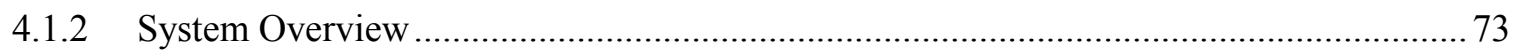

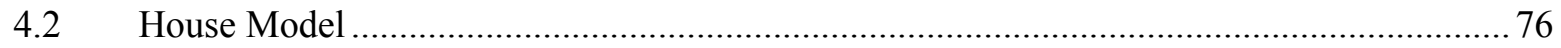

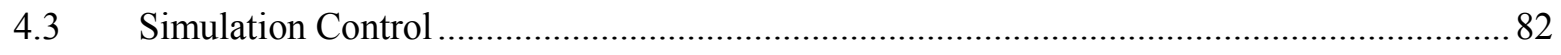

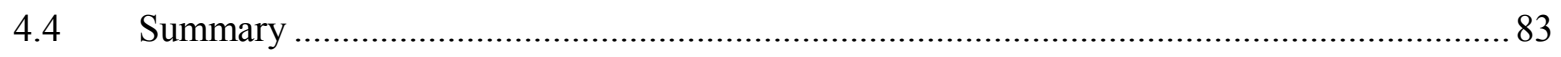

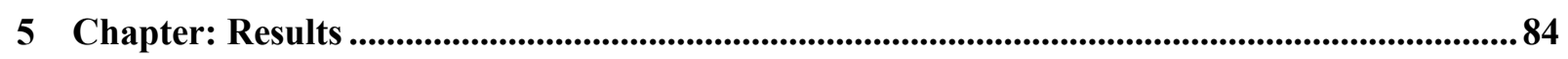

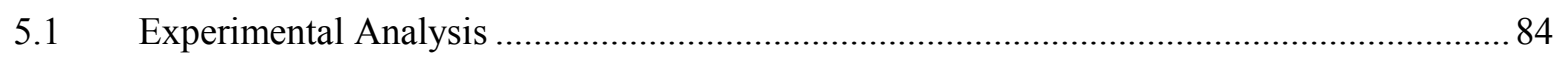

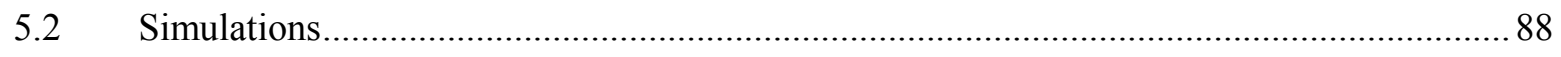

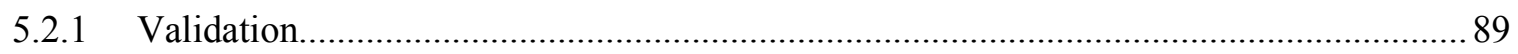

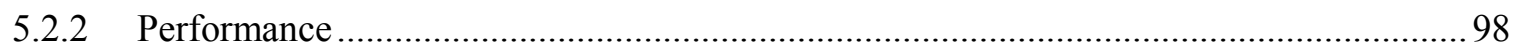

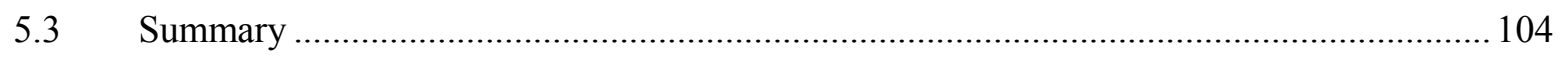

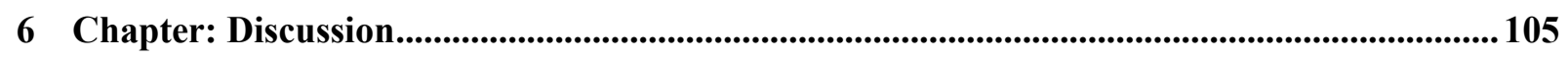

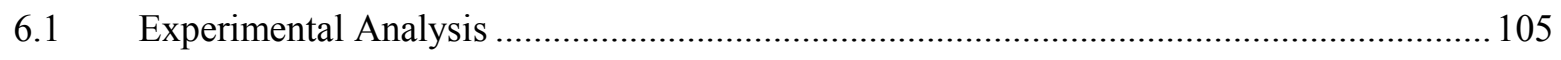

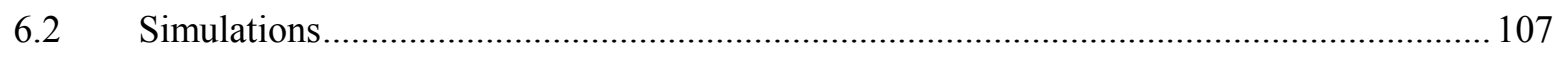

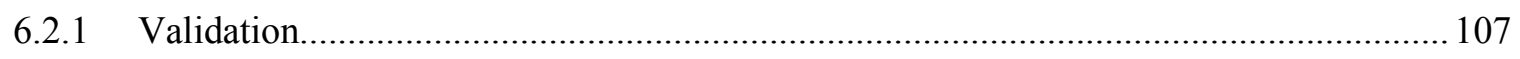

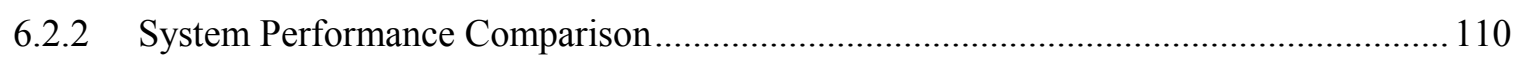

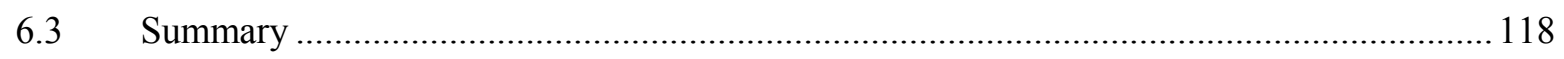

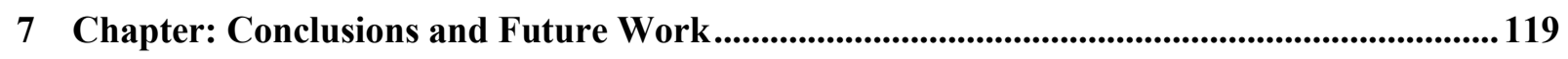

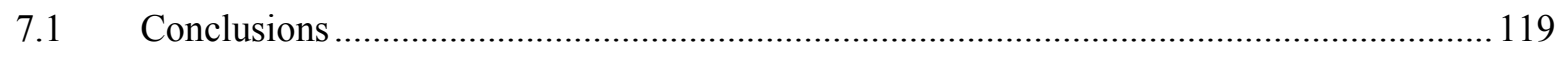

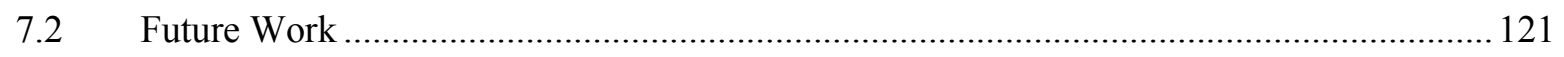

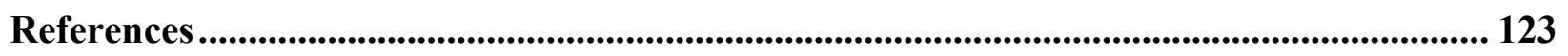

Appendix A Heat Pump Water Heater Performance Map................................................... 131

Appendix B Type 240 Heat Pump Water Heater FORTRAN Code................................. 134 


\section{List of Figures}

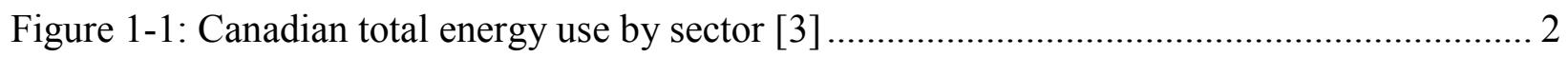

Figure 1-2: Canadian energy consumption by end-use in the residential sector [3] ..................... 2

Figure 1-3: Domestic water heater market share in Canada [3] ............................................... 4

Figure 1-4: Market share by year for water heating units: (top) Natural gas (middle) Electric

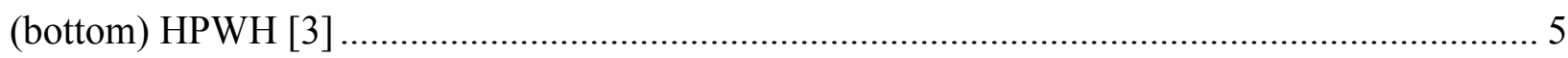

Figure 1-5: Summer average ambient temperature across Canada [8] ……………………..... 8

Figure 1-6: Winter average ambient temperature across Canada [8] ........................................ 8

Figure 1-7: Experimental set-up as installed in-situ : (a) HPWH tank inlet and outlet connection

to pre-heat tank and the water draw system, (b) AHU and HPWH unit connection .................... 10

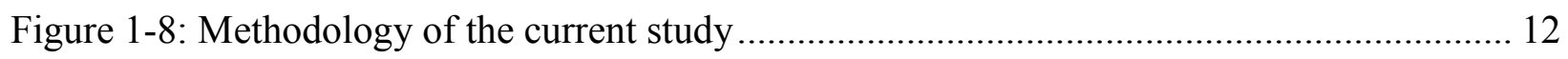

Figure 2-1: Air-to-water heat pump cycle: (a) refrigerant thermal cycle (b) heat pump

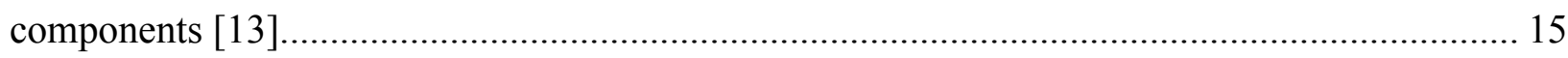

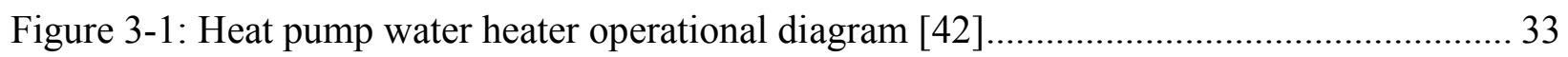

Figure 3-2: Air handling unit schematics for the unit's components and controls ....................... 34

Figure 3-3: System diagram for the HPWH experimental apparatus (excluding the AHU) ........ 34

Figure 3-4: Geospring Hybrid Electric Water Heater: (a) actual unit, (b) components of the unit

[43]

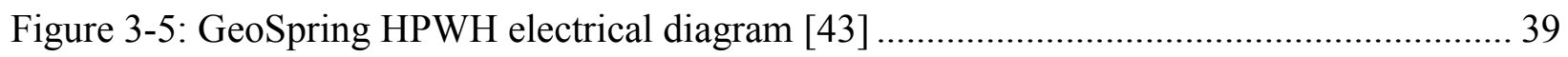

Figure 3-6: Wiring of the HPWH external relays controlling and power monitoring system...... 40

Figure 3-7: Heat pump water heater air exhaust instrumentation showing the "X" placement of

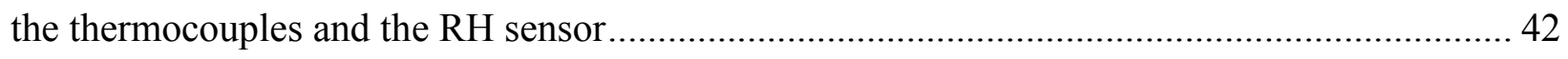

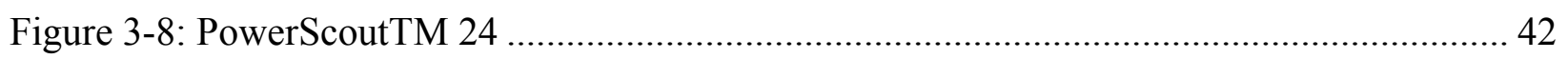




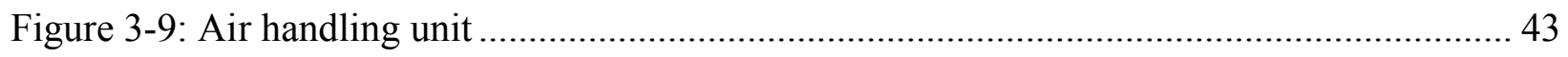

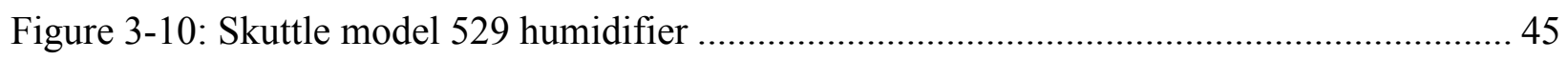

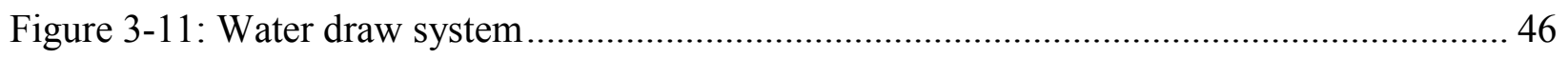

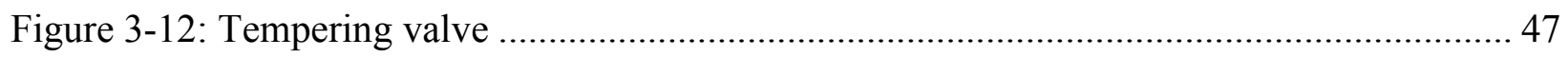

Figure 3-13: Water solenoid for water draw-profile initiation ................................................... 48

Figure 3-14: Recirculation loop for tank water de-stratification ................................................ 48

Figure 3-15: Thermowell for fluid stream temperature measurements ........................................ 49

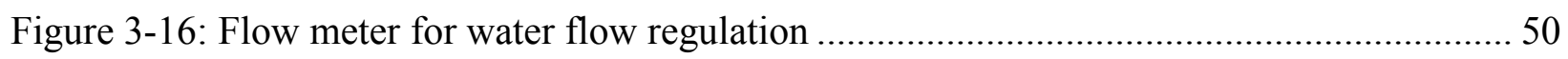

Figure 3-17: Data acquisition system and I/O cards for the HPWH apparatus ........................... 52

Figure 3-18: LabVIEW VI for performance map data collection................................................ 54

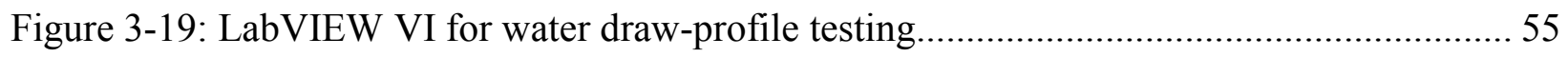

Figure 4-1: Stratification test conducted to determine the length of the wrap-around coil .......... 67

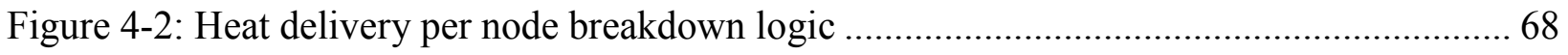

Figure 4-3: Schematic for a storage tank model and energy balance on a node (adopted from

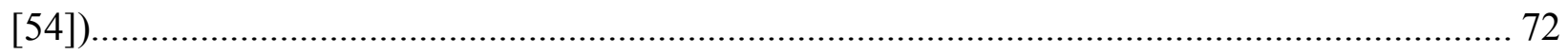

Figure 4-4: TRNSYS model for the HPWH experimental apparatus validation......................... 75

Figure 4-5: TRNSYS model for the HPWH integrated into a house Type ................................ 81

Figure 5-1: Heat delivery to water for a $20^{\circ} \mathrm{C}$ supply air temperature at varying humidities....... 86

Figure 5-2: Compressor power for a $20^{\circ} \mathrm{C}$ supply air temperature at varying humidities............ 86

Figure 5-3: Heat delivery to water at a supply air relative humidity of $20 \%$ for varying

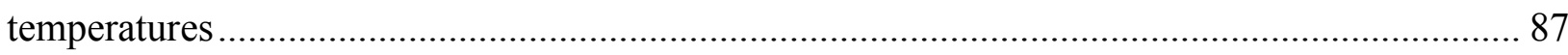

Figure 5-4: Compressor power at a supply air relative humidity of $20 \%$ for varying temperatures 
Figure 5-5: Heat delivery to water for an supply air temperature of $20^{\circ} \mathrm{C}$ and a relative humidity of $20 \%$ at varying flowrates 88

Figure 5-6: Compressor power for an supply air temperature of $20^{\circ} \mathrm{C}$ and a relative humidity of $20 \%$ at varying flowrates 88

Figure 5-7: Charging test comparison between the experimental and model results for Nodes 1 through 10 90

Figure 5-8: Experimental heat delivery per node during the charging procedure 91

Figure 5-9: Charging test comparison between the experimental and model results for heat delivery to the water for Node 1

Figure 5-10: Charging test comparison between the experimental and model results for heat delivery to the water for Node 5

Figure 5-11: Charging test comparison between the experimental and model results for heat delivery to the water for Node 8 93

Figure 5-12: Charging test comparison between the experimental and model results for heat delivery to the water for Node 10 93

Figure 5-13: Discharging test comparison between the experimental and model results for Nodes 1 through 10 94

Figure 5-14: Charging-discharging test comparison between the experimental and model results for Nodes 1 through 10 97

Figure 5-15: Draw profile test comparison between the experimental and model results for Nodes 1 through 10, the power consumption of the compressor, and the resulting instantaneous COP. 97 Figure 5-16: Comparison between the experimental and model results for the exhaust air temperature 98 
Figure 5-17: Performance of the HPWH in a basement set-up outlining the COP of the unit, the exhaust air temperature of the unit, the water supply temperature and the storage water temperature profile. 101

Figure 5-18: Effect of HPWH unit operation on the temperature of the basement in October .. 102 Figure 5-19: Space heating and cooling energy consumption comparison between a heat pump space heating operated house operating with and without a HPWH unit for two day period in October

Figure 6-1: Annual cost and GHG emissions results for different house set-ups in Ottawa...... 113

Figure 6-2: Annual cost and emissions results for different house set-ups in Toronto

Figure 6-3: Annual cost and emissions results for different house set-ups in Montreal............ 115

Figure 6-4: Annual cost and emissions results for different house set-ups in Vancouver....... 116 


\section{List of Tables}

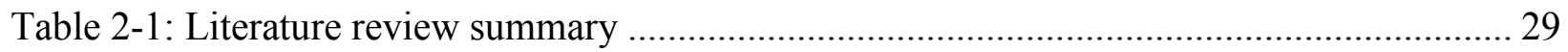

Table 3-1: GeoSpring HPWH unit sizing per household size [43] ......................................... 36

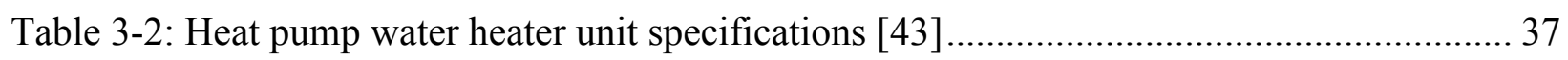

Table 3-3: Safety features for the GeoSpring HPWH unit ......................................................... 38

Table 3-4: Current transformers size used to monitor the power consumption of the HPWH

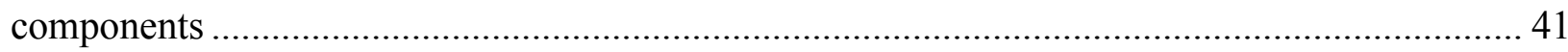

Table 3-5: Specification of the AHU heating and cooling coils ..................................................... 44

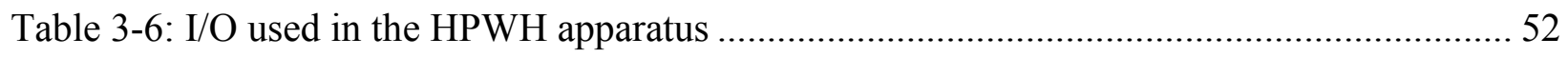

Table 3-7: Summary of measurement and calibration error for temperature readings $\left({ }^{\circ} \mathrm{C}\right) \ldots \ldots \ldots . . .58$

Table 3-8: Summary of the control equipment in the experimental apparatus and their I/O list . 60

Table 4-1: Loss coefficient to the environment per node [53] ................................................ 70

Table 4-2: CSA-F379.1 DHW draws schedule (for different level of occupancy) ( [56],

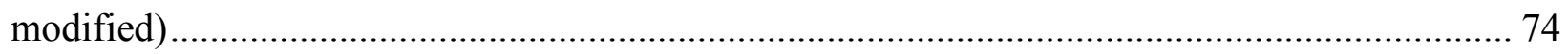

Table 4-3: Thermal resistances used in TRNSYS house model [58] ........................................ 77

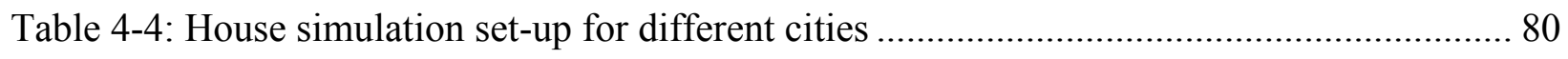

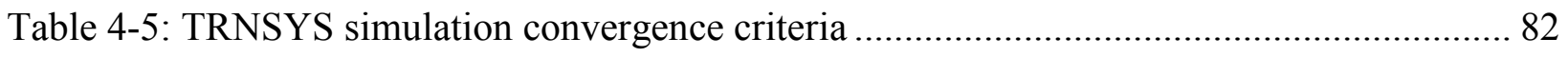

Table 5-1: Summary of the effect of the HPWH operation on the space heating and cooling for

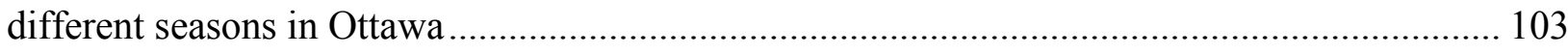

Table 6-1: Payback period summary for different Canadian cities ........................................... 117

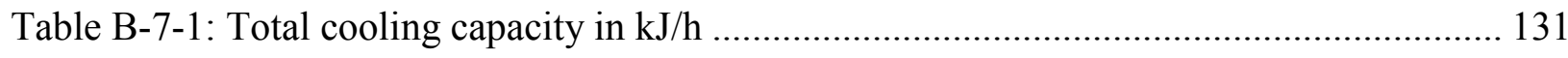

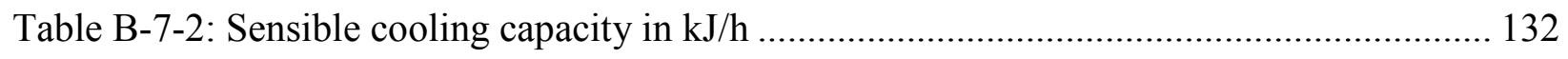

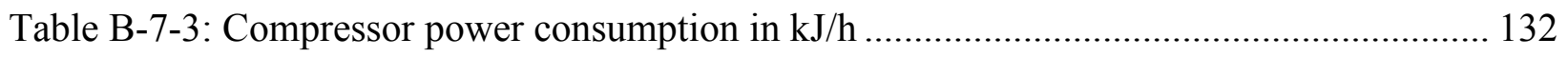




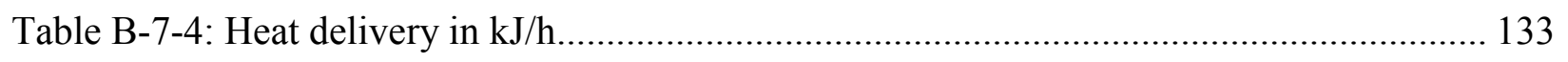




\section{List of Abbreviations}

\begin{tabular}{|c|c|}
\hline AHU & Air Handling Unit \\
\hline $\mathrm{AO}$ & Analog Output \\
\hline $\mathrm{BIPV} / \mathrm{T}$ & Building Integrated Photovoltaic/Thermal \\
\hline $\mathrm{BO}$ & Binary Output \\
\hline cDAQ & Compact Data Acquisition System \\
\hline CSA & Canadian Standards Association \\
\hline $\mathrm{COP}$ & Coefficient of Performance \\
\hline $\mathrm{CT}$ & Current Transformers \\
\hline DAQ & Data Acquisition System \\
\hline DLB & Double Line Breaker \\
\hline DHW & Domestic Hot Water \\
\hline DVC & Digital Valve Control \\
\hline DX-SAHP & Direct-Expansion Solar-Assisted Heat Pump \\
\hline $\mathrm{EF}$ & Efficiency Factor \\
\hline ESA & Electrical Standard Association \\
\hline EWH & Electric Water Heater \\
\hline GHG & Green House Gases \\
\hline HPWH & Heat Pump Water Heater \\
\hline IASHPWH & $\begin{array}{l}\text { Instantaneous-heating Air Source Heat Pump } \\
\text { Water Heater }\end{array}$ \\
\hline IDX-SAHP & $\begin{array}{l}\text { Indirect Expansion Solar Assisted Heat Pump } \\
\text { Systems }\end{array}$ \\
\hline $\mathrm{I} / \mathrm{O}$ & Input/Output \\
\hline NREL & National Renewable Energy Laboratory \\
\hline
\end{tabular}


PID

PV

$\mathrm{PV} / \mathrm{T}$

RH

RTD

SAHP

TC

TCO

TESS

TMY

TRNSYS

VAV

VI
Proportional Integral Derivative

Photovoltaic

Photovoltaic/Thermal

Relative Humidity

Resistance Temperature Detector

Solar-Assisted Heat Pumps

Thermocouple

Thermal Cut Off

Thermal Energy Systems Specialists

Typical Meteorological Year

TRaNsient SYstem Simulation

Variable Air Volume

Virtual Interface 


\section{Nomenclature}

Symbol

$T$

$R_{\mathrm{RTD}}$

V

CJC

$L U$

$n I N D$

$n X$

$n Y$

$X$

Y

$\dot{m}$

$\dot{V}$

$\rho$

$Q_{\text {sens }}$

$C_{\mathrm{p}}$

$T_{\text {in }}$

$T_{\text {out }}$

$Q_{\text {total }}$

$h_{\text {in }}$

$h_{\text {out }}$

$\phi$

$v$

$p$

$p_{\mathrm{w}}$

$W$

$W_{\mathrm{s}}$

$\mu$

Vol

$t$

$T_{\mathrm{t}}$

$T_{\mathrm{t}-1}$

$H R$

E

$M_{\mathrm{i}}$

k
Description

Units

Temperature

Resistance of RTD

Voltage

Cold junction temperature

FORTRAN logic unit number

Number of independent variables

Number of values for each independent variable

Number of values for each dependent variable

Independent variable input

Dependent variable output

Mass flowrate

Volumetric flowrate

Density

Sensible cooling capacity

Specific heat

Inlet air temperature

Exhaust air temperature

Total cooling capacity

Inlet air enthalpy

Exhaust air enthalpy

Relative humidity

Specific volume of dry air

Atmospheric pressure

Partial pressure of water vapor

Humidity ratio

Saturation humidity ratio

Degree of saturation

Volume

Time-step

Temperature of the node at the current time-step

Temperature of the node at the previous

Heat delivery to the water node

Energy stored in a water node at a specific time-step

Mass of a node

Thermal conductivity
${ }^{\circ} \mathrm{C}$

ohms

$\mathrm{mV}$

${ }^{\circ} \mathrm{C}$

$-$

$-$

$-$

$-$

-

-

$\mathrm{kg} / \mathrm{s}$

$\mathrm{m}^{3} / \mathrm{s}$

$\mathrm{kg} / \mathrm{m}^{3}$

$\mathrm{kJ} / \mathrm{h}$

$\mathrm{kJ} / \mathrm{kg} . \mathrm{K}$

$\mathrm{K}$

$\mathrm{K}$

$\mathrm{kJ} / \mathrm{h}$

$\mathrm{kJ} / \mathrm{kg}$

$\mathrm{kJ} / \mathrm{kg}$

$\mathrm{m}^{3} / \mathrm{kg}$

$\mathrm{kPa}$

$\mathrm{kPa}$

$\mathrm{kg}_{\text {water }} / \mathrm{kg}_{\text {dryair }}$

$\mathrm{kg}_{\text {water }} / \mathrm{kg}_{\text {dryair }}$

-

$\mathrm{m}^{3}$

seconds

${ }^{\circ} \mathrm{C}$

${ }^{\circ} \mathrm{C}$

$\mathrm{kJ} / \mathrm{s}$

$\mathrm{kJ}$

$\mathrm{kg}$

$\mathrm{W} / \mathrm{mK}$ 


$\begin{array}{clc}A_{\mathrm{s}, \mathrm{i}} & \text { Surface area of a node } & \mathrm{m}^{2} \\ A_{\mathrm{c}, \mathrm{i}} & \text { Cross-sectional area of a node } & \mathrm{m}^{2} \\ U_{\mathrm{i}} & \text { Heat loss coefficient per unit area of a node } & \mathrm{W} / \mathrm{m}^{2} \mathrm{~K} \\ Q_{\mathrm{aux}} & \text { Auxiliary heat } & \mathrm{kJ} / \mathrm{h} \\ H R_{\text {total }} & \text { Total heat delivery } & \mathrm{kJ} / \mathrm{h} \\ P_{\text {fan }} & \text { Fan power } & \mathrm{kJ} / \mathrm{h} \\ P_{\text {compressor }} & \text { Compressor power } & \mathrm{kJ} / \mathrm{h} \\ P_{\text {controls }} & \text { Controls power } & \mathrm{kJ} / \mathrm{h} \\ T_{\text {mains }} & \text { Mains water temperature } & { }^{\circ} \mathrm{C} \\ \bar{T}_{\text {amb }} & \text { Annual average ambient temperature } & { }^{\circ} \mathrm{C} \\ R & \text { Ratio of the ground temperature at which the mains water } & -\end{array}$




\section{Chapter: Introduction}

\subsection{Motivation}

Canada plays a leading role in the initiative to divert energy sources from greenhouse gas (GHG) emissive power sources to renewable and sustainable energy sources. Through the Clean Energy Act, Canada is subjected to introduce a reduction in electricity demand by $66 \%$, and GHG emission reduction by $33 \%$, from the levels achieved in 2007 , by 2020 [1]. The recent introduction of carbon tax by the government of Ontario represents a significant opportunity to adapt renewable energy sources in all sectors and to encourage the reduction of fuel usage [2]. The residential sector represents $16 \%$ of the total energy use in Canada (Figure 1-1), representing a significant opportunity for cost savings and GHG emission reductions [3]. Further, eighty six percent of the total energy use within the residential sector is dominated by natural gas and electricity. In 2007, the total energy use accounted for 1447.2 PJ with GHG emissions of 74.3 Mt [3]. The residential energy consumption by end-use at a national level is shown in Figure 1-2, where space and water heating are the second largest uses of energy consumption in Canada at $63 \%$ and $19 \%$, respectively [4]. Although the space cooling load represents $1 \%$ of the energy use in Canada, this is not necessarily the case at provincial levels. Many of the southern provinces can benefit from energy reduction in space cooling during the cooling season, as this load usually occurs at the same time as peak loading on the utility grid. 


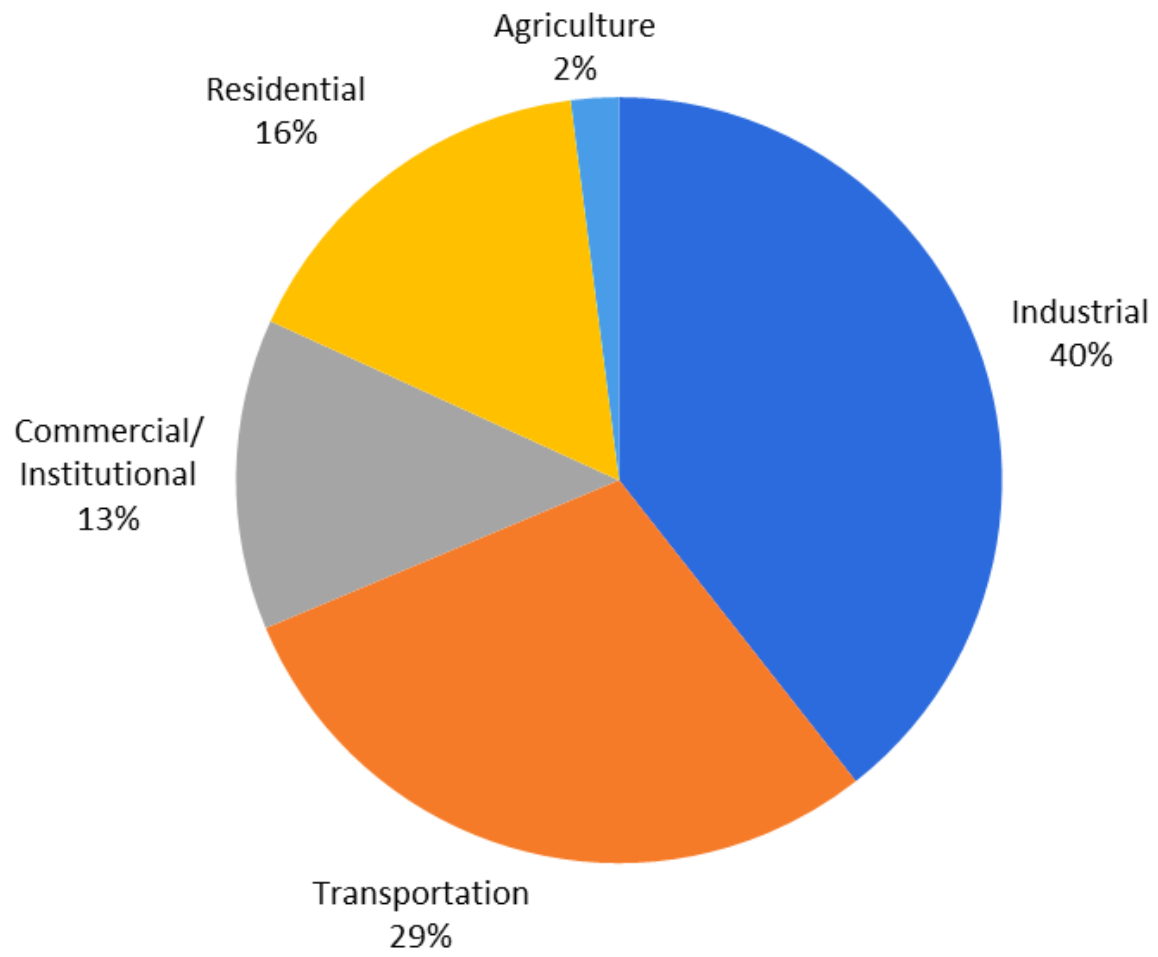

Figure 1-1: Canadian total energy use by sector [3]

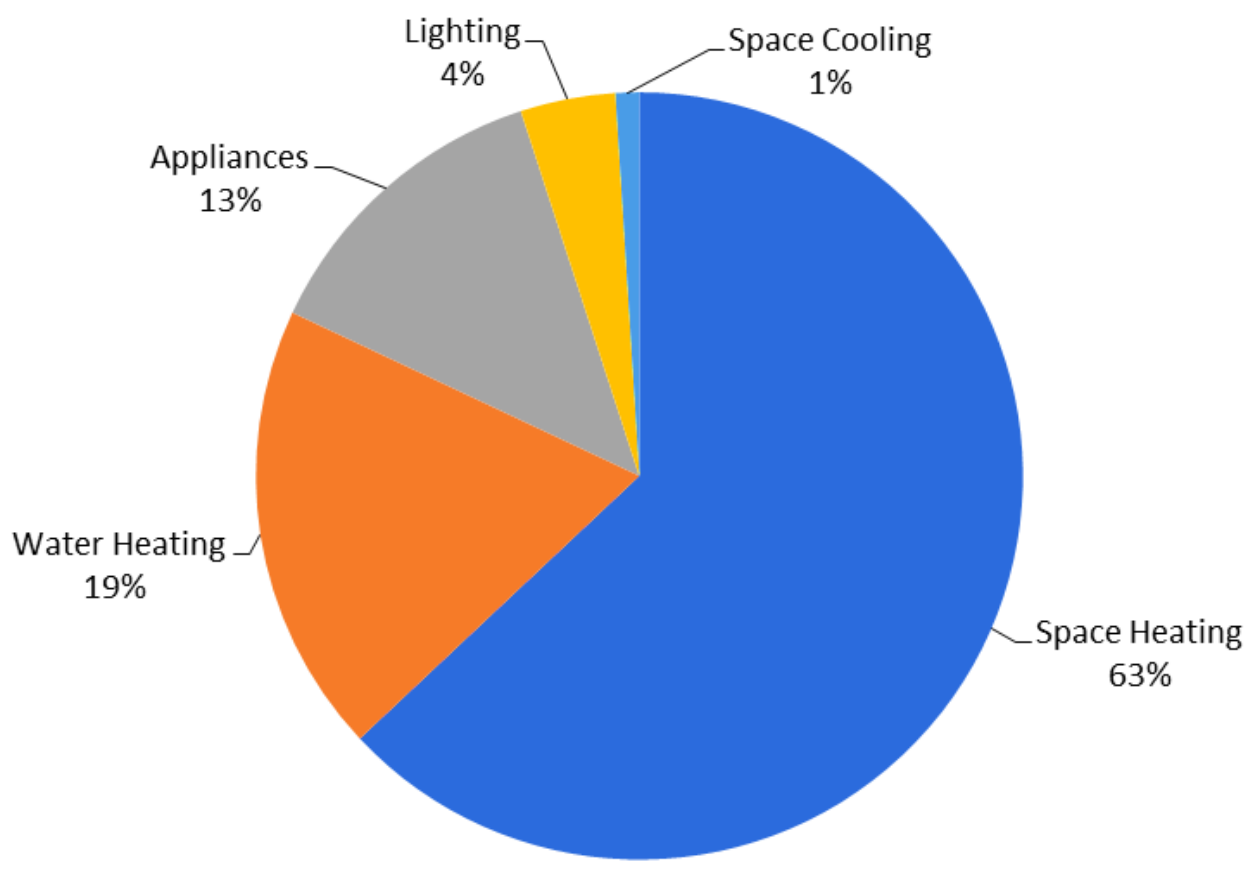

Figure 1-2: Canadian energy consumption by end-use in the residential sector [3] 


\subsection{Domestic Water Heating}

In Canada, natural gas is the dominant energy source for domestic water heating (DWH) systems, at $50.5 \%$, followed by electric sources at $44.3 \%$. The breakdown for the market share of these systems is shown in Figure 1-3. The main reason for the high demand for natural gas systems is due to the low cost and high efficiency of these systems with the additional low cost of natural gas. Similarly, electric water heaters also have a high efficiency and low capital cost. However, these units have not been utilized as abundantly as natural gas water heaters due to higher electricity costs in most provinces. The 'Other' category which accounts for less than $0.4 \%$ of the market share, represents the use of renewable energy sources for water heating, as of 2013 [4]. Figure 1-4 illustrates the market share per year for water heating units. The figure shows that a decreasing trend in market share exists for electricity-based DWH systems and an increase trend in market share exists for natural gas DWH systems. This is because of the rise in electricity prices and drop in natural gas prices, respectively. It is also observed that the trend for 'Other' or renewable energy sources is also increasing. The trend for natural gas is expected to decrease due to the implementation of the carbon tax, and the government's Clean Energy Act. This Act is expected to lead to a significant increase in the market share of renewable energy systems as Canada is projected to reduce GHG emissions by $80 \%$ by the year 2050 [1]. 


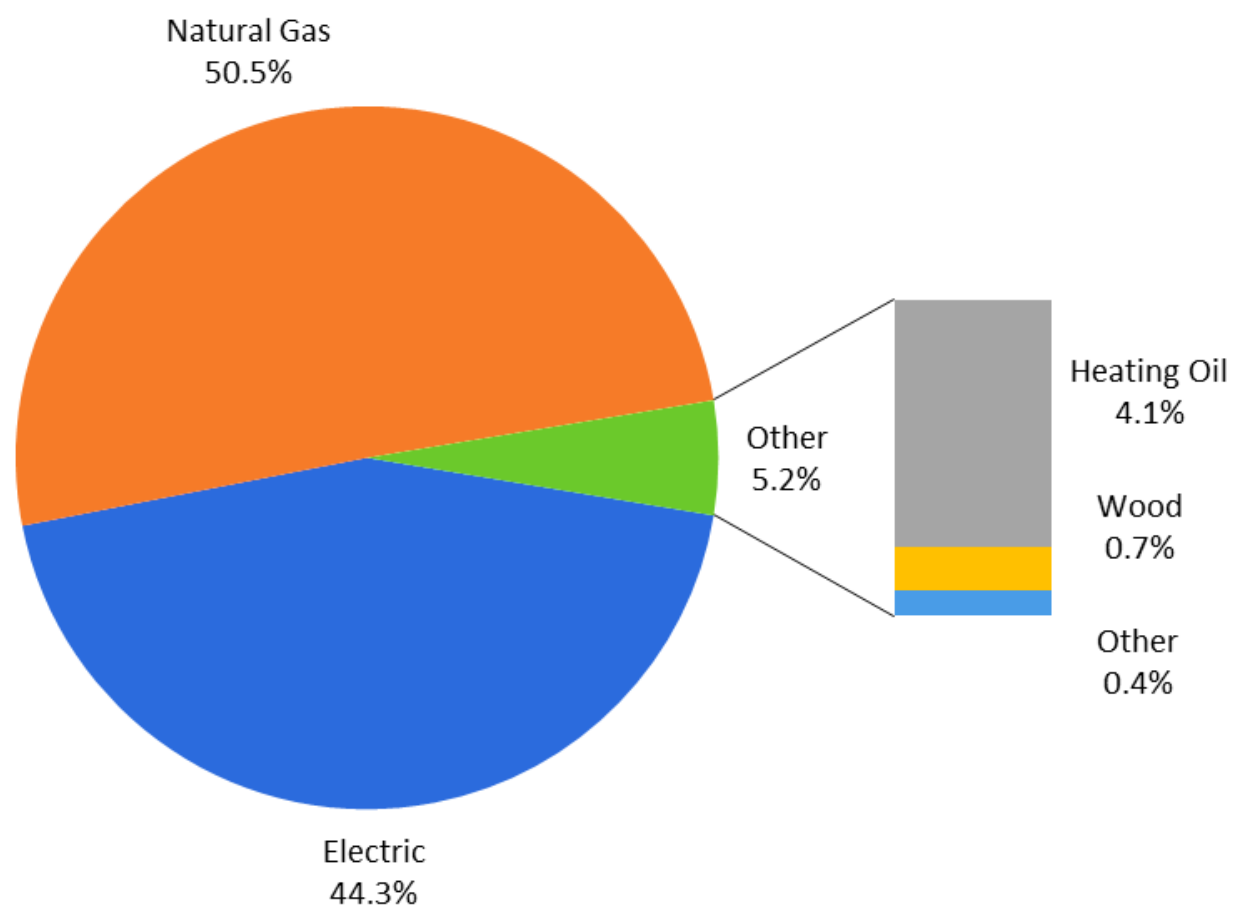

Figure 1-3: Domestic water heater market share in Canada [3] 

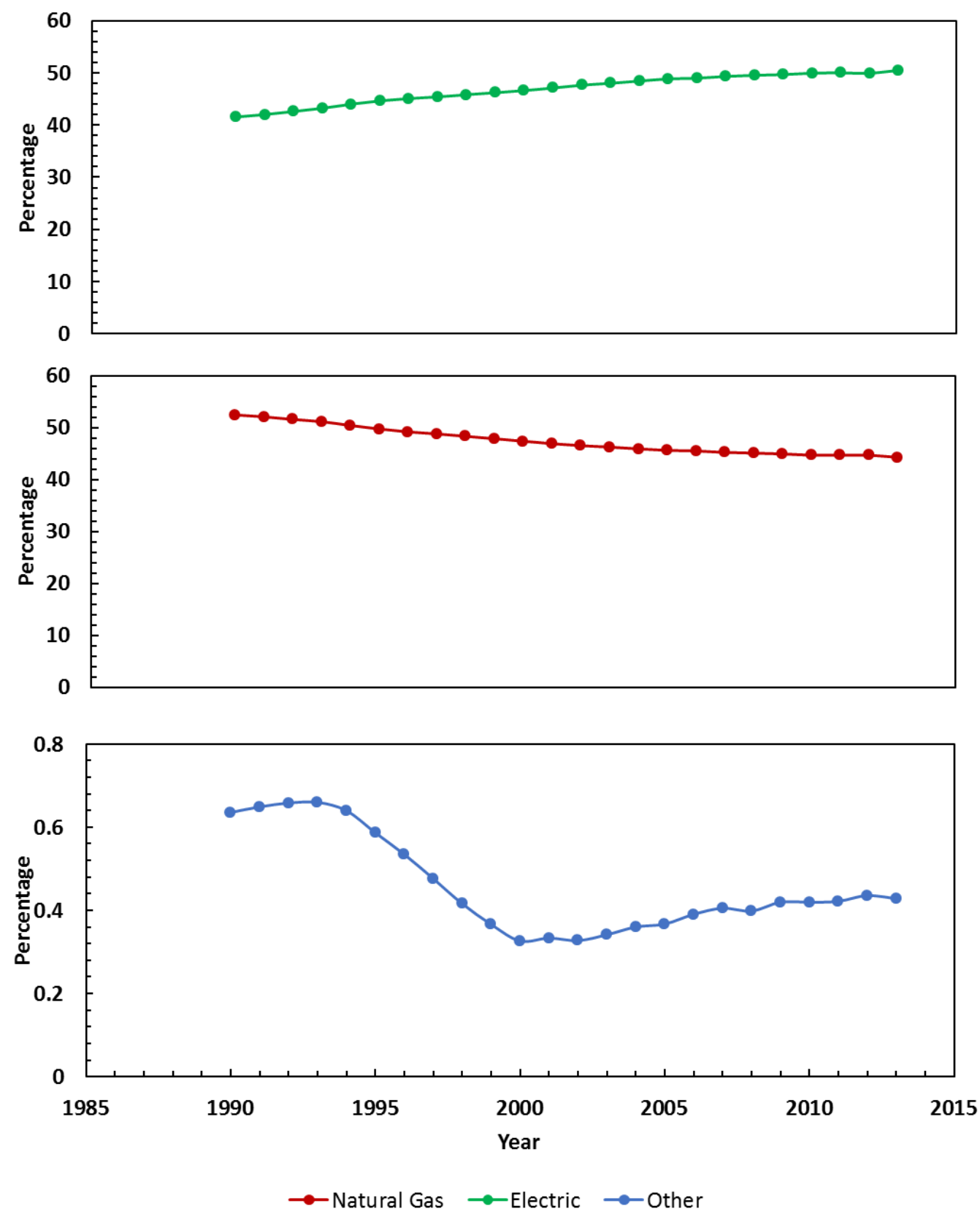

Figure 1-4: Market share by year for water heating units: (top) Natural gas (middle) Electric (bottom) HPWH [3]

The following sections compare common DWH systems which exist in Canada [5].

\subsubsection{Natural Gas Boilers}

Natural gas boilers are most common in provinces where the cost of electricity is high, and the cost of natural gas is low. These units burn natural gas in a combustion chamber located 
below a storage tank. Existing units have an energy factor (EF) of 0.62-0.67. The EF is defined as the overall efficiency of a unit based on the amount of hot water produced per unit of fuel consumption [5]. Due to their low cost, ranging between $\$ 400$ and $\$ 600$ per unit, these units have had major success in the market share in the past two decades [5]. Venting is generally required in order to dispose of the combustion products produced through combustion inefficiency. As a result, these units contribute to the GHG emissions in the residential sector, along with furnace space heating systems.

\subsubsection{Electric Water Heaters}

Electric water heater units are highly efficient at $0.9 \mathrm{EF}$ in comparison to natural gas boilers at 0.65 average EF. These units work according to a master-slave relationship between two electrical elements, where the top element ensures a fast response to water heating demands, and the bottom element is used for larger demand backup. The energy factor for these units is close to 1 and the main source of inefficiency in these units is the storage tank losses. The potential of cost saving on DWH in comparison to gas boilers is dependent on the cost of electricity in the region in which they are implemented [5]. Although the units do not produce any GHG emissions when being used, their electricity source must be considered in the analysis when considering GHG emissions.

\subsubsection{Heat Pump Water Heaters}

Heat pump water heater technology uses a vapor compression heat pump cycle which extracts energy from the surrounding air, upgrades the energy and then transfers this energy to a water storage tank. Developed in the 1950s, HPWHs use wrap-around coil condensers to achieve small compact units. In comparison to electric water heaters (EWHs) and natural gas water heaters, HPWH units are significantly more efficient with an EF of 2-2.5. Generally, HPWH 
units are manufactured to operate in a hybrid mode along with electric heating elements. This is done in order to offset high hot water demands, due to the heat pump's low recovery rate. The recovery rate is defined as the rate at which the water storage tank restores the water temperature to the required set-point temperature during water draw operation. The main downfall or setback of the HPWH is its high initial cost which can reach up to three times that of an electric or gas boiler water heater's initial cost [5]. However, due to the high energy saving potential of HPWHs, the market share in North America has seen a large expansion in the warm and humid areas of the US [6]. Computer simulations conducted by the National Renewable Energy Laboratory in Golden, Colorado has shown that switching from electric water heaters to HPWHs has a great economic advantage in cities such as Chicago and Illinois [7]. This was mainly due to the high utility cost in these states. HPWHs also affect their regional environment or surrounding conditions which can, in some cases, increase the conditioning load of the home. For example, as energy is removed from the surrounding space to heat the hot water, cold air is returned to the surroundings, which can increase the space heating load of the residence during the heating season. However, this same process in the cooling season will reduce the cooling energy or space conditioning required. HPWHs are similar to electric water heaters in the sense that they both have a low energy requirement and that the GHG emissions associated with these water heaters occur at the generation plant and are based on the electricity source.

Although on average, the heating season in Canada is eight months long, the ambient temperature throughout the year will vary significantly per province, as shown in Figure 1-5 and Figure 1-6. The west coast provinces experience relatively higher temperatures in comparison to the rest of Canada. When considering the suitability of HPWHs in Canada, it is important to understand the regulations, incentives and energy costs that may exist in each province and study 
the effect that HPWHs may have on space heating and cooling, as well as examining their payback periods.

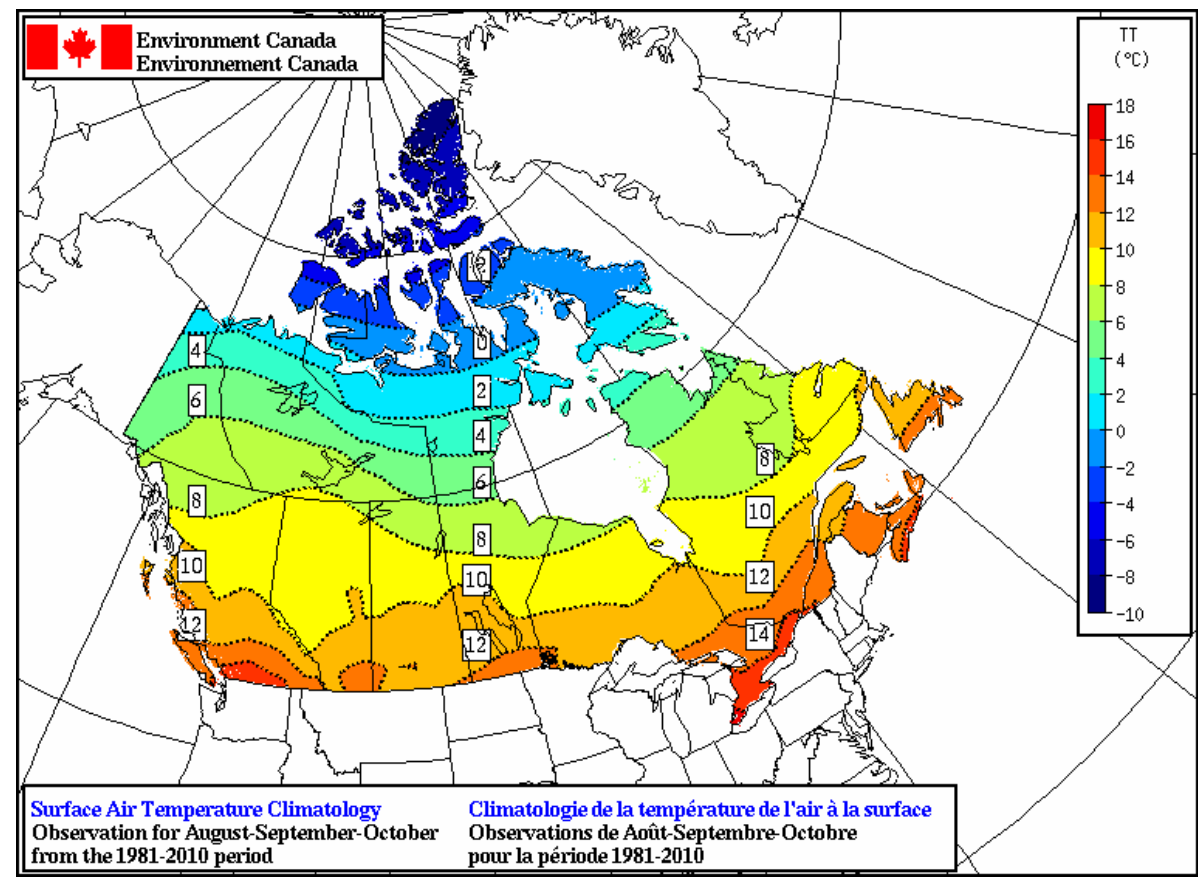

Figure 1-5: Summer average ambient temperature across Canada [8]

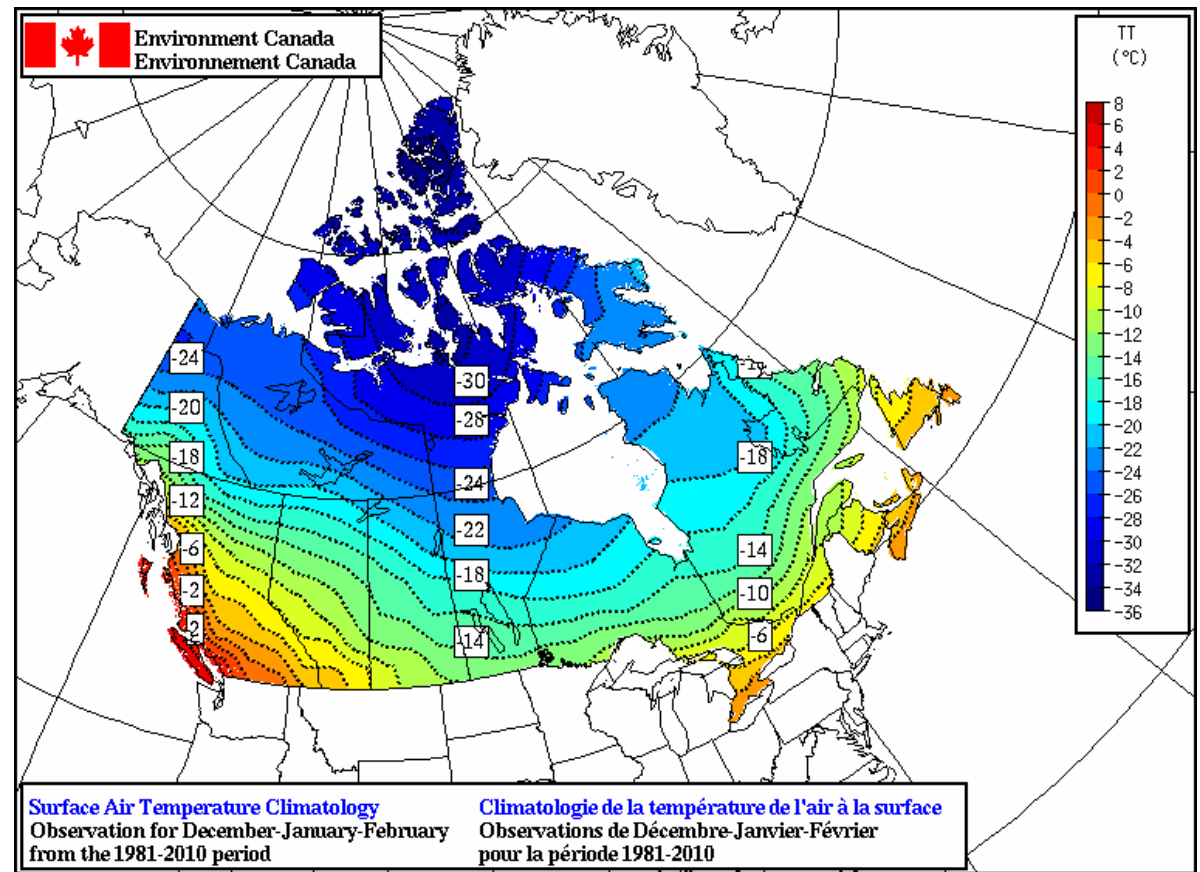

Figure 1-6: Winter average ambient temperature across Canada [8] 


\subsection{Thesis Objective}

This thesis investigated the use of heat pump water heater technology to assist in the reduction of GHG emissions and energy in domestic water heating for the residential sector. Heat pump water heaters have had great success in the warm, humid climates of the US, Europe and Asia. However, due to the longer heating season in Canada, a conventional HPWH installed in residential basements can increase the space heating demand in the winter. Models have been used to study heat pumps and thermal storage as separate components. However, few modelling studies have been conducted on HPWHs with condensers as wrap-around coils on the outside wall of the water storage tank. This study involved the development of a new HPWH model in the TRNSYS (TRaNsient SYstem Simulation) simulation software, based on Types 938 (heat pump water heater) and 534 (water storage tank), to investigate the effect of a HPWH unit on the space heating and cooling requirements of a house. The TRNSYS simulation software is a graphical-based environment used to simulate the behaviour of transient systems [9]. The thermal performance of the HPWH was also compared to that of an electric water heater and gas water heater for four Canadian cities, operating under a domestic hot water load of $150 \mathrm{~L} /$ day. The model was verified by experiment using a commercially available HPWH unit in a laboratory setting. The experimental set-up consisted of an air-source heat pump connected to a controlled air supply that provided constant temperature, flow rate, relative humidity to the unit, as well as a draw system for hourly water draws. The experimental apparatus is shown in Figure 1-7a and Figure 1-7b. A performance map was experimentally obtained through monitoring the air temperature, relative humidity, and water temperature as the independent variables, while the total and sensible cooling capacity, compressor power and heat delivery were the dependent variable 


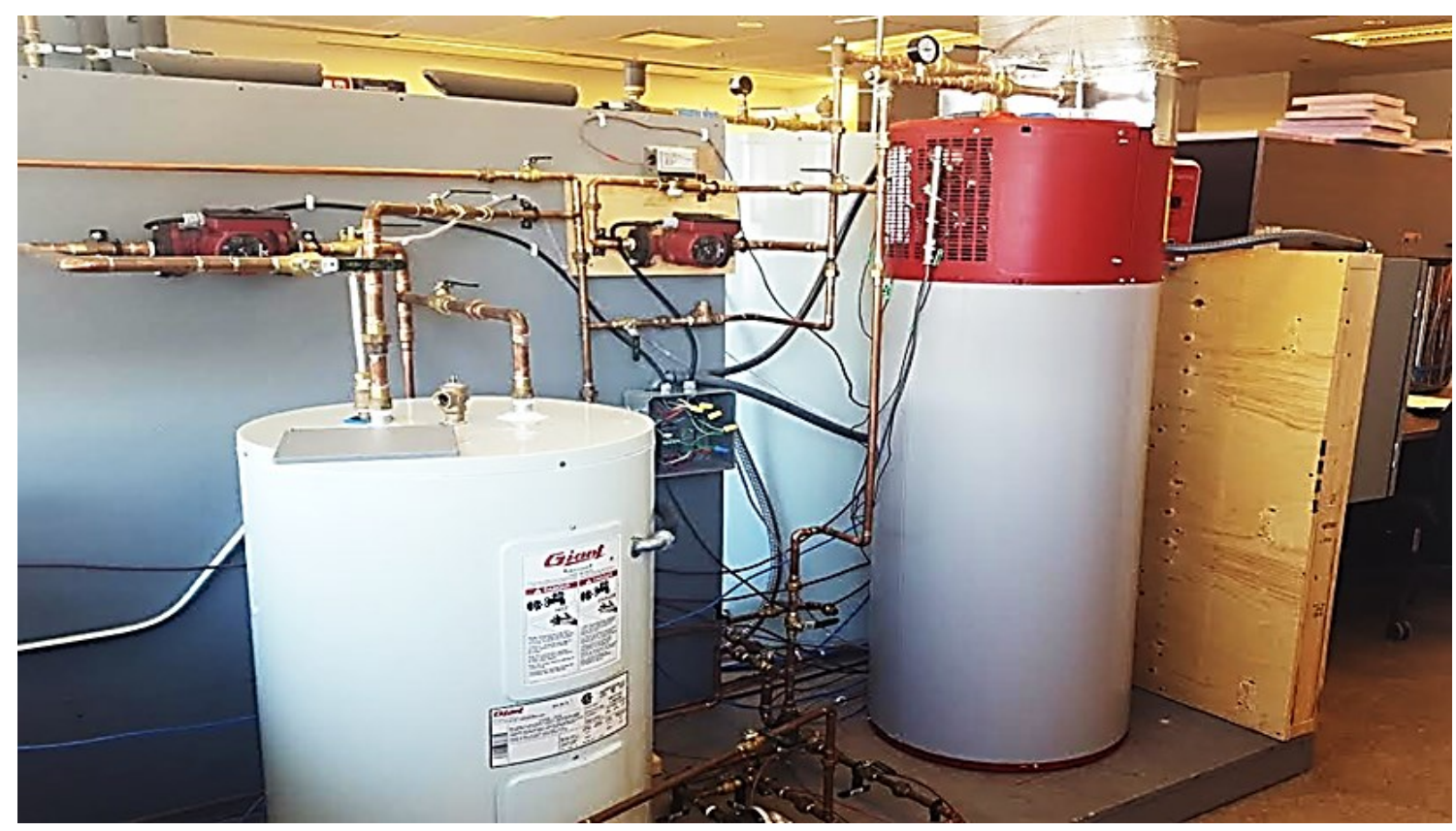

(a)

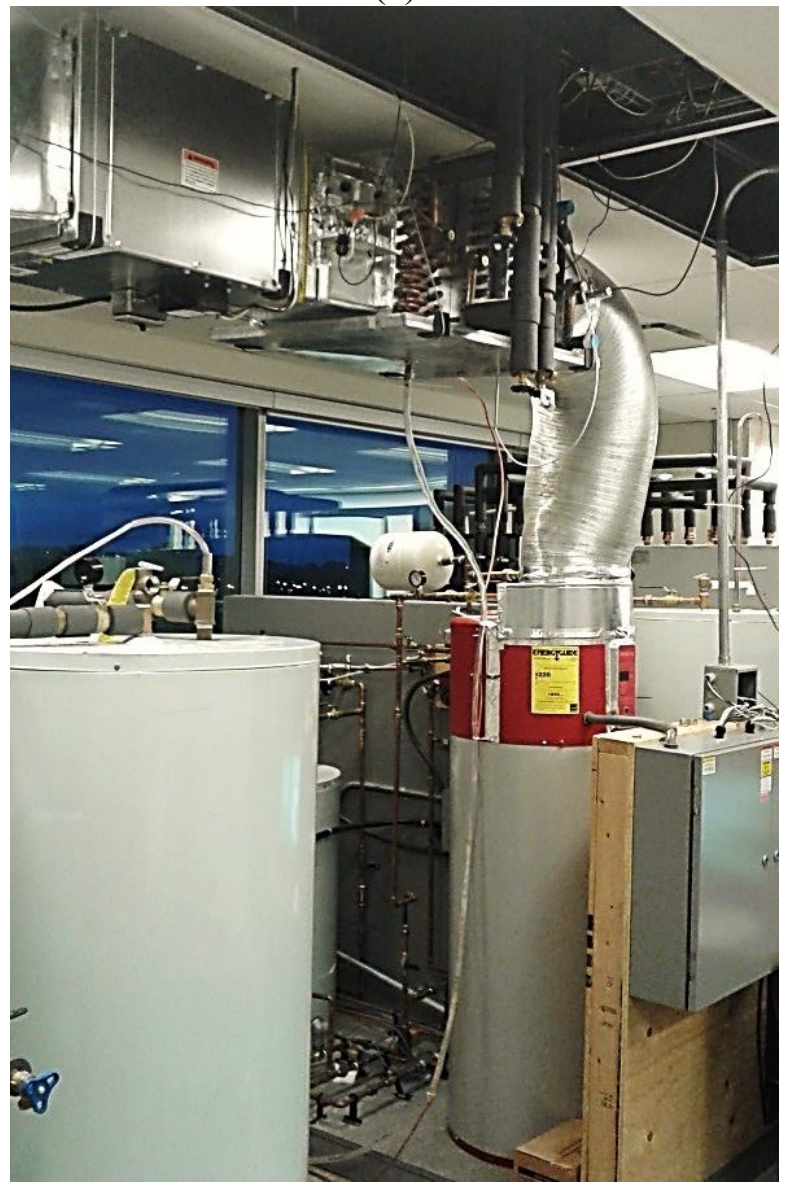

(b)

Figure 1-7: Experimental set-up as installed in-situ : (a) HPWH tank inlet and outlet connection to pre-heat tank and the water draw system, (b) AHU and HPWH unit connection 


\subsection{Thesis Scope}

The scope of the research included:

- Modifying the controls of a commercially available HPWH in order to manually control the unit's operating modes;

- Fully instrumenting the HPWH unit to test its performance at given operating conditions;

- Designing an experimental test set-up for the HPWH unit, including a water draw system that simulates water draw-profiles;

- Designing and instrumenting an air handling unit to alter and control the testing conditions for the HPHW;

- Creating a virtual control platform using LabVIEW and a data acquisition system;

- Developing a performance map to determine the performance of the HPWH at certain operating conditions;

- Creating a new TRNSYS Type for the HPWH unit with a wrap-around coil;

- Calibrating, verifying and validating the TRNSYS model based on experimental findings;

- Modifying a house model in TRNSYS with space heating and cooling in order test the HPWH model in basement conditions;

- Running annual simulations to evaluate the performance of a HPWH installed in the basement of the house model; and

- Comparing the cost and GHG emissions between the HPHW, EWH and natural gas water heater for different house space heating systems (furnace, electrical baseboard and heat pump) for various Canadian locations. 


\subsection{Methodology}

An overview of the study methodology is shown in Figure 1-8.

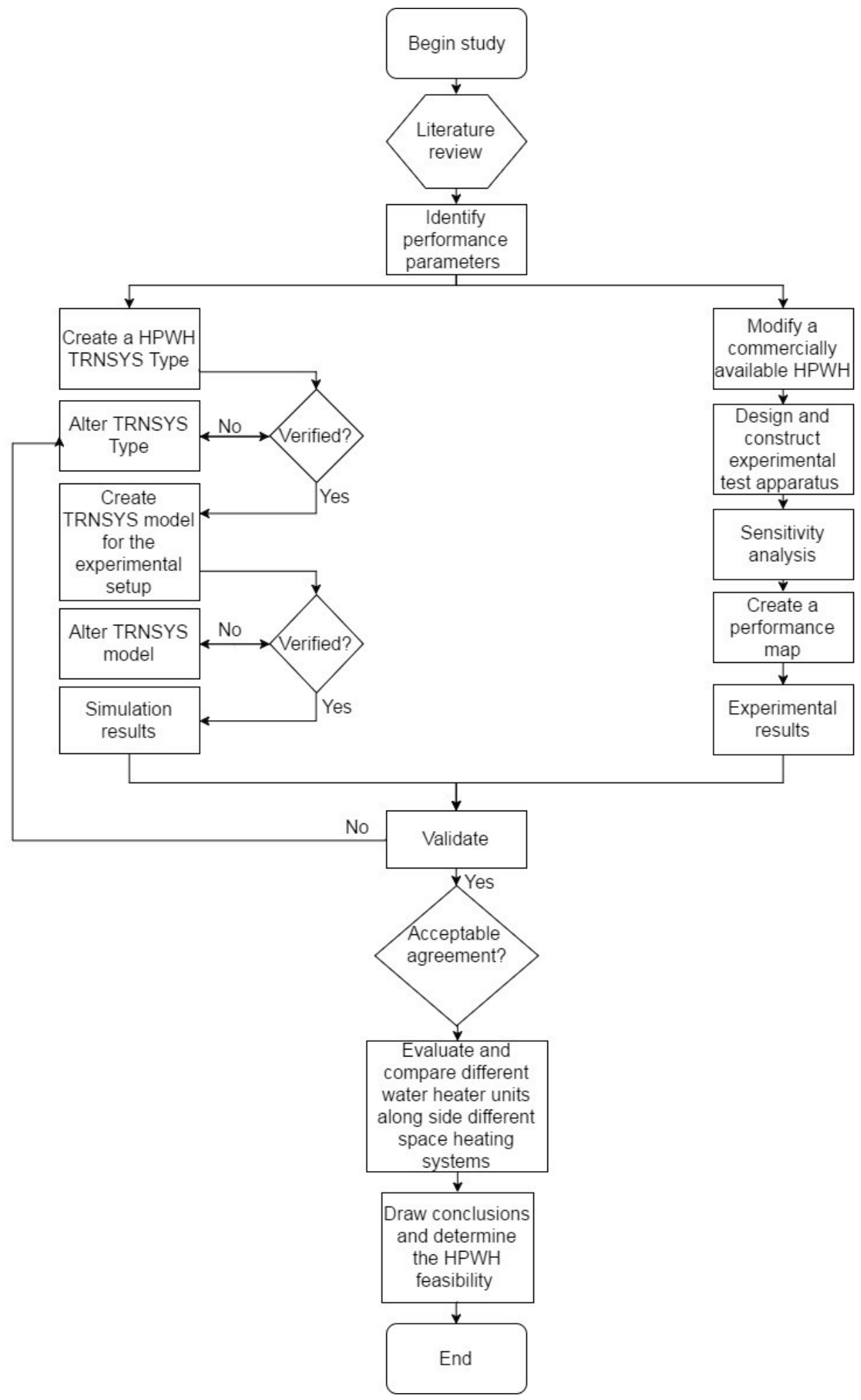

Figure 1-8: Methodology of the current study 


\subsection{Thesis Outline}

The thesis is divided into the following chapters:

- Chapter 1 - Introduction: Provides the motivation for the thesis and background information on HPWHs and other DWH systems, and outlines the objectives and scope of the study.

- Chapter 2 - Literature Review: A review of previous work on DWH energy reduction, HPWH performance improvement and alternative water heating systems. Furthermore, TRNSYS studies for similar applications are covered.

- Chapter 3 - Experimental Design: A detailed description of the test apparatus and a description of the equipment and sensors installed.

- Chapter 4 - System Modelling: An outline of the methodology of the HPWH TRNSYS Type and the description of the house model with the DWH unit.

- Chapter 5 - Results: A summary of the experimental results and the computer model validation.

- Chapter 6 - Discussion: Outlines the significance of the experimental and modelling results and provides a detailed analysis on the comparison of energy savings for three different residential house heating systems operating alongside three different water heating systems in various Canadian locations.

- Chapter 7 - Conclusion and Future Work: A summary of the research findings and future work. 


\section{Chapter: Literature Review}

The increased awareness of the world's limited energy resources has caused many governments and the scientific community to re-examine energy conversion devices and develop new techniques to better utilize existing finite resources and reduce GHG emissions [10].

Heat pump technology offers the opportunity to reduce energy consumption and GHG emissions within the residential sector in Canada by meeting the residential water heating demand with a lower electricity requirement. Heat pump water heaters have had great success in the warm, humid climates of the US, Europe and Asia. However, these systems have failed to penetrate into the Canadian market due to their significant reduction in performance at lower ambient air temperatures. This thesis examines the performance of a HPWH for a conditioned space (basement) for cold climates, and examines the effect of these units on the space heating and cooling loads.

Literature relevant to HPWH technology optimization for cold climates was reviewed with a focus on the following: heat pump domestic water heating, solar thermal heat pump water heaters, photovoltaic-thermal heat pump water heater, and experimental and TRNSYS simulation studies. 


\subsection{Heat Pump Technology}

Heat pumps function on the transfer of thermal energy from a low-temperature heat source through a vapor compression cycle to meet the load side heating demands [6]. The upgrade of energy through the compression cycle is demonstrated in Figure 2-1, showing the Pressure-Enthalpy diagram of the working fluid throughout the cycle. Heat pumps can achieve a high coefficient of performance due to the upgrade of energy through the compressor, generated with a minimal amount of electricity in comparison to a conventional electric water heating system [11]. Heat pump performance is strongly dependent on the load temperature requirements, source temperature and operational patterns, according to Vieira et al. [12]. Vieira's study showed that, there was a significant deterioration in the COP of the heat pump as the temperature of the source decreased and that the heat pump struggled to produce a high COP that normally can be achieved in hot humid environments. Many studies are currently being conducted in order to enhance the performance of heat pumps and HPWHs in cold environments through control optimization strategies.

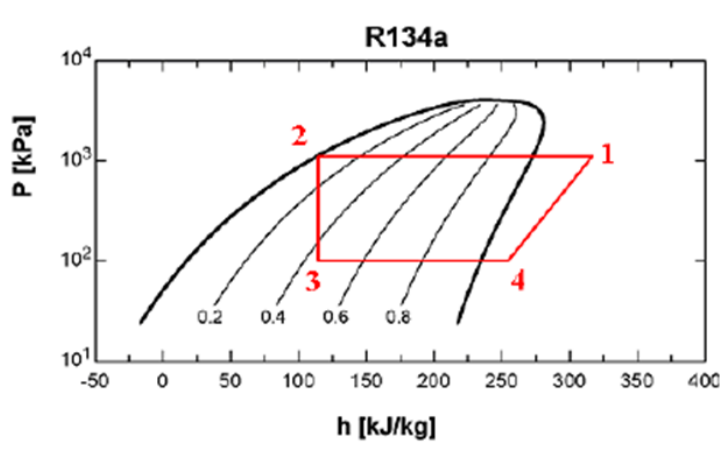

(a)

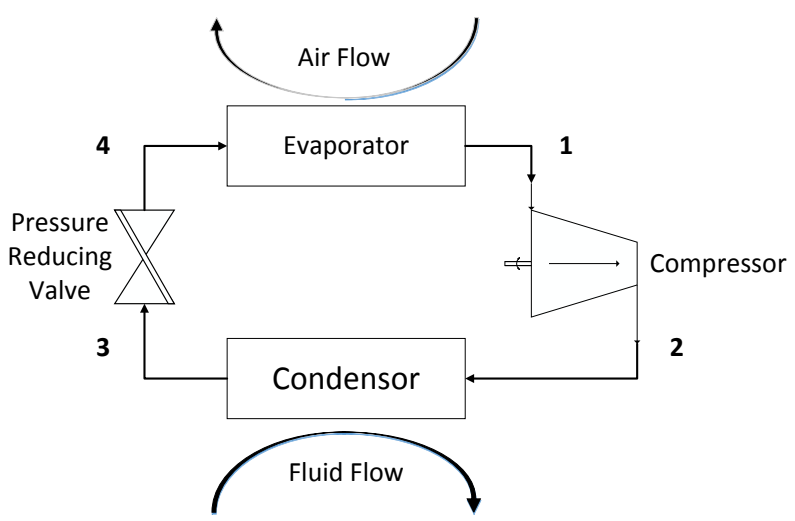

(b)

Figure 2-1: Air-to-water heat pump cycle: (a) refrigerant thermal cycle (b) heat pump components [13] 
Hudon et al. [14] and Spran et al. [15] performed a number of experimental and modelling studies at the U.S. National Renewable Energy laboratory on multiple commercially available HPWH units to determine the limitations and energy saving potential for numerous climates and operational conditions. Computer models for the HPWH units were developed in EnergyPlus and TRNSYS for the purpose of conducting annual simulations on the units to determine the impact on the space heating and cooling systems with the introduction of the HPWH. The study concluded that the saving potential of the units differs based on the control strategy of the unit and the installation location of the unit both geographically and locally.

Widder et al. [16] conducted a field study on a commercially available HPWH at the Pacific Northwest National Laboratory to examine the interaction between the HPWH and the heating and cooling systems of the tested space for three exhaust set-ups: full ducting, exhaust ducting and no ducting. It was concluded that the HPWH performance enhancement in a conditioned space is compromised by the increased demands for the heating system of the residence. Furthermore, the HPWH performance was significantly improved when used under higher load periods than generated power.

Roth et al. [17] presented a number of cold climate optimization strategies for the operation of heat pumps in cold climates. These strategies were: sizing the heat pump based on heating loads, introducing the use of multiple variable speed compressors, using low boiling temperature refrigerants and increasing the evaporator coil capacity. These strategies were tested and optimized by Bursill [18], who studied the performance of a HPWH by experiment and modelling for Canadian climates. In Bursill's study, multiple draw profiles were tested for various set-points, using the ambient room temperature as the heat source for the HPWH. It was found that by keeping the set-point within $5^{\circ} \mathrm{C}$ between the electric booster and the heat pump, 
the COP of the unit was significantly improved. In other words, the electric booster is triggered if the set-point of the tank drops $5^{\circ} \mathrm{C}$ below the set-point. This regime improved the performance of the heat pump, causing the unit to operate at a $\mathrm{COP}$ of 2.5 , in comparison to other regimes which provided a COP of between 1.5 and 2. Also, this regime would reduce the operating time of heating equipment, through the reduction of unnecessary stratified regimes.

Lei et al. [19] designed and tested an instantaneous-heating air source heat pump water heater (IASHPWH) with a temperature stratified tank, using R410A refrigerant. The IASHPWH operated using three modes: condenser heating for a source temperature over $20^{\circ} \mathrm{C}$, water tank heating for a source temperature below $20^{\circ} \mathrm{C}$ and condenser-water tank joint heating. The study concluded that the COP of the unit was $2.76,4.5$ and 12.7 for ambient temperatures of $-7,20$ and $43^{\circ} \mathrm{C}$, respectively. The unit was capable of generating a domestic hot water of $42^{\circ} \mathrm{C}$ at a draw rate of $6 \mathrm{~L} / \mathrm{min}$.

Bursill's study [18] also concluded that the heat pump water heater's performance was highly dependent on utility costs during the heating season. Since the heat pump rejects cold air through the exhaust, after transferring energy to the refrigerant, the residence space heating system must compensate for the heat loss, causing a higher energy demand to heat the space, which hinders the overall performance of the heat pump. In other words, although the COP of the system reaches a satisfactory level, the extra energy required for space heating must be included in the COP calculations of the heat pump. As a result of this study and others, there has been an increased research effort on conditioning the source temperature through the introduction of HPWH combined systems, such as solar thermal collector coupling. 


\subsection{Solar Thermal Assisted Heat Pumps}

That study of solar-assisted heat pumps (SAHPs) began in 1955. It was shown that the integration of solar heating technology with heat pumps, through direct expansion, can improve the COP of heat pumps and increase the utilization of solar energy using thermal storage [20]. Many studies introduced the concept of SAHP systems, which led to more research studies on SAHP designs and combinations for all type of climates.

In the early 1980, Chnadarshekar et al. [21] studied six types of solar assisted heat pump systems for space and water heating, in multiple Canadian cities, using the WATSUN computer program, to analyze their feasibility. The results of the study demonstrated a significant advantage to using SAHP systems over conventional heat pump water heaters with electric back-up for multiplex dwelling units. However, it was found that this was not the case for all single-family dwellings [21].

An experimental analysis for a direct expansion solar-assisted heat pump (DX-SAHP) was performed by Li et al. [22] in Shanghai. The set-up consisted of a $4.20 \mathrm{~m}^{2}$ solar collector (acting as the evaporator) with R-22 as the working fluid and a rotary type hermetic compressor (with a rated power of $0.75 \mathrm{~kW}$ ) and a $60 \mathrm{~m}$ copper coil condenser immersed in a $150 \mathrm{~L}$ water tank. The DX-SAHP was capable of achieving a COP of 6.61 at an average ambient temperature of $20.6^{\circ} \mathrm{C}$. It was also shown that the COP of the system was 3.11 on rainy day with an average ambient temperature of $17.1^{\circ} \mathrm{C}$.

Although DX-SAHP systems have shown to work well in warmer climates, the working fluid in DX-SAHP systems is susceptible to freezing at colder temperatures. Thus, indirect expansion solar assisted heat pump systems (IDX-SAHPs) are typically used in colder climates in order to separate the solar heating loop from that of the domestic hot water (DHW) tank. In 
this case, the solar heating loop contains an anti-freeze solution which is heated and this energy is transferred to the DHW tank using an external heat exchanger [23]. The increase in the number of components increases the capital cost of the system. Sterling and Collins [24] conducted a feasibility study on a dual tank IDX-SAHP system for domestic water heating. The study involved modelling an electric DHW system, a traditional SDHW system and a dual tank IDX-SAHP within the TRNSYS simulation software. Results showed that although the IDX-SAHP system is the most complicated and has more components, it used the least amount of electrical energy in comparison to the other two systems. The IDX-SAHP system also gained the most solar energy with a solar fraction of 0.67 , compared to the 0.58 and 0 for the traditional SAHP and electrical heating systems, respectively. The solar fraction is the fraction of energy produced by solar technology to assist the total energy required by a system [25].

Whether the SAHP has a direct or indirect configuration, it has been shown that thermal stratification in the storage tank can enhance overall performance and lead to a higher COP, due to the lower entering working fluid temperature in the collector, which improves its efficiency [6]. Hollands and Lightstone [26] stated that a $17 \%$ improvement can be achieved on solar energy delivery of a system on low-flow systems due to the introduction of high stratification. Chu [25] investigated a dual tank IDX-SAHP system for both space and domestic water heating which consisted of a float tank connected to solar thermal panels and a heat pump that circulated heat between the float tank and DHW storage tank. The result of the study showed that when a high flow rate of $10 \mathrm{~L} / \mathrm{min}$ circulated through the heat pump, the COP of the system was shown to reach 5 initially (the highest $\mathrm{COP}$ during the test), and then decreased to an average COP of 3.76 shortly after. At a flow rate of $3 \mathrm{~L} / \mathrm{min}$, the COP was calculated to be 3.77 . From this work, it was concluded that $3 \mathrm{~L} / \mathrm{min}$ was a more suitable flow rate due to the low stratification level in 
the tank in comparison to a flowrate of $10 \mathrm{~L} / \mathrm{min}$ where mixing in the tank occurred due to the higher incoming water velocity.

Freeman et al. [27] evaluated three SAHP systems (parallel, series and dual) combinations using TRNSYS for two different climates, Wisconsin and New Mexico. The solar fraction for the three SAHP systems was compared to a conventional solar domestic water heating system and a conventional air source heat pump. The simulation results showed that the parallel system acquired the highest solar fraction, although it had the smallest COP when compared to the other systems. The COP of the three systems was shown to be 2.0, 2.5 and 2.8 for parallel, series and dual system, respectively.

The choice of the working fluid circulating through the solar heating loop in a SAHP system is important as it determines the performance capability of the system. Li et al. [28] ran a comparative analysis for different working fluids in China for a solar-air hybrid heat source HPWH: R22, R134a and R744. The solar-air hybrid heat source HPWH consisted of a IDX-SAHP coupled to spiral-finned tubes and was evaluated both experimentally and by mathematical model. The COP, heating capacity, power consumption and water outlet temperature for the three refrigerants were monitored at an ambient temperature of $30^{\circ} \mathrm{C}$ ambient temperature and for a solar radiation of $355 \mathrm{~W} / \mathrm{m}^{2}$. Results showed that when using refrigerant $\mathrm{R} 22$, the highest COP was reached, which was followed closely by the R134a according to the four monitored parameters. The R744 system had the lowest COP due to the relatively longer heating process, and therefore higher power consumption. However, it was found that this same system experienced a significant boost at temperatures lower than $13^{\circ} \mathrm{C}$, giving it a superiority over the other two systems. 


\subsection{Photovoltaic-Thermal Heat Pump Water Heater}

Research on photoelectric effects dates back to 1839; Bacquerel, a French physicist, found that some material, such as crystalline silicon, has the ability to produce electric current when exposed to light. This material was then modified in 1976 to produce the first photovoltaic (PV) cells from selenium with an efficiency of 1-2\% [29]. One major disadvantage, pointed out by Bazilian et al. [30], is that the PV cell has a low efficiency due to the low conversion rate between incident radiation and electrical energy production, at approximately $8 \%$. Much of the energy received by the PV cell is either reflected or converted into heat. Therefore, in order to increase the efficiency of PV cells, their temperature must be kept low. This led to the concept of PV-thermal or PV/T systems, which produce both electricity and thermal energy while keeping the temperature of the cells low and increase the electrical efficiency of the PV cells. Zondag et al. [31] performed a numerical study for four PV-thermal collectors, which confirmed the cooling effect on PV cells in relation to their increase in efficiency. Gang et al. [32] conducted a modelling study on a PV/T evaporator coupled with a heat pump Rankine cycle system for a subtropical region in south middle China. Results from the study showed that the PV/T efficiency for a collector area of $6 \mathrm{~m}^{2}$ varies between $15.4 \%$ and $13.7 \%$ for morning and afternoon conditions, respectively. These results agreed with previous studies, stating that the efficiency of the PV cells is typically higher in the morning when the solar radiation is lower and decreases over the course of the day when the solar radiation level increases, resulting in higher collector temperatures. When Gang et al. examined the performance of the heat pump, they found that the heat pump significantly improved over the course of the day due to its higher COP at higher evaporator temperatures. 
Kamel and Fung [33] modelled the performance of a building integrated PV/T (BIPV/T) system with an air source heat pump for space heating of the Archetype Sustainable House in Toronto using the TRYNSYS simulation software. The system under study consisted of a two-stage variable capacity air to air source heat pump, which delivers a load to the house through a direct expansion air handling unit. The heat pump was coupled with a natural gas boiler to act as a backup during peak load demands. Furthermore, the system used a heat recovery system to utilize the exhaust air in order to condition the air for the heat pump. The study showed that the seasonal electricity consumption of the heat pump was $6522 \mathrm{kWh}$, which resulted in a seasonal COP of 2.74 for the heating season. The house model was then modified by adding BIPV/T system, which consisted of $251.66 \mathrm{~m} \times 1.00 \mathrm{~m} \mathrm{PV} / \mathrm{T}$ poly-crystalline cells. The seasonal heating COP showed an improvement, giving a value of 3.35. Kamel and Fung further concluded that based on the hourly electricity consumption of the system and time-of-use pricing for Toronto, the annual cost of electricity required to operate the heat pump system and the BIPV/T couple heat pump system was $\$ 1024.25$ and $\$ 837.8$, respectively. [33].

Recently, Berger and Harrison [34] performed a modelling comparative analysis of PV, solar thermal and PV/T domestic hot water systems. The study was conducted on a 270L tank with a 250 L daily draw, based on the CSA F379-M1982 standards, using the TRNSYS simulation software. The modelled PV system consisted of a water tank with an electrical resistant element connect to PV panels through a AC/DC converter. The PV panel specifications were based on the TSM-180D module from TrinaSolar. The modelled solar thermal system consisted of a water tank coupled with solar thermal panels, based on the SOL +20 flat plate solar thermal collector manufactured by Dimas and used a heat exchanger with 50/50 glycol solution (by volume) as the working fluid to prevent freezing in the solar loop. Finally, the modelled PVT 
system was a combination of both the solar thermal and PV systems. Hot water loads and collector areas were varied for the all three systems. At a collector area of $6.25 \mathrm{~m}^{2}$, it was observed that the solar thermal system had a higher exergy and total efficiency. However, when comparing the three systems based on solar fraction, operation costs and primary energy saving efficiency, the results favored the PV/T system. The primary energy saving efficiency is the efficiency of the PV cell divided by the efficiency of the local power plant and added to the efficiency of the thermal component [35]. When comparing the total energy efficiency, the solar thermal system produced a higher efficiency to that of the PV/T, i.e., $65 \%$ and $48 \%$, respectively. However, when the electricity production of the PV/T panels was included in the energy efficiency calculation, the PV/T system's total energy efficiency was increase to $73 \%$. Similarly, the $\mathrm{PV} / \mathrm{T}$ system gave an $18 \%$ higher primary energy saving efficiency compared to solar thermal. Berger and Harrison concluded that the PV/T system is suitable option for domestic how water applications.

\subsection{System Modelling}

\subsubsection{Experimental Performance Maps}

Performance maps are often developed and incorporated in modelling software in order to represent and simulate a physical component within a system. Baldwin and Cruickshank [36] developed a performance map for a water-to-water heat pump (with 50/50 propylene glycol solution (by volume) on the source side of the heat pump), which was subsequently incorporated in Type 927 within the TRNSYS simulation software. The performance map included the temperatures and flowrates of the source and load sides of the heat pump as independent variables and the heating transfer rate on the source and load sides and the electrical consumption of the unit as the dependent variables. One hundred and eighty test runs were 
conducted in order to cover the performance range of the heat pump; each test was 10 minutes long at 30 second data logging intervals. The authors concluded that the model accurately represented the experimental system using the steady state performance map, and that the transient effect of the heat pump could be neglected in the TRNSYS model.

\subsubsection{TRNSYS Modelling}

Bursill [18] adapted and modified Type 1237-1 from the TESS [13] component library in TRNSYS was used to represent the HPWH. The Type model was modified in order to incorporate a thermal storage tank with wrap around coil. However, when comparing to his experimental results from his HPWH test set-up, the results of the model did not agree. Bursill concluded that the significant difference between the modelling and the experimental results was generated due to the complex geometry of the tank and the thermal interaction simplifications within the condenser. This discrepancy was addressed by introducing a subroutine that used experimental data to specify the fraction of total heat delivery into each node [37].

Baldwin and Cruickshank [36] conducted a modelling study to compare three storage tank subroutines in TRNSYS (Types 4, 60 and 534) for cold thermal storage applications. Results from the modelling study were then verified by experiment. They observed similar discrepancies between all the model Types and experiment when comparing the rate of temperature change within the storage tank. It was observed that the temperature change in the storage tank models was significantly slower than that of the physical system. This is due to the assumption that each node within the storage tank models is at uniform temperature and that each node takes up a certain volume within the tank. This is not the case for the physical system where temperature measurements were recorded at discrete locations within the tank (i.e., spot measured). Baldwin and Cruickshank subsequently performed a node sensitivity analysis to 
determine the number of nodes needed to produce an acceptable level of accuracy for a $270 \mathrm{~L}$ tank. The study compare using 12 nodes to 100 nodes, which varied the node sizes from $22.5 \mathrm{~L}$ to $2.7 \mathrm{~L}$, respectively, for a $270 \mathrm{~L}$ tank. Results showed that increasing the number of nodes in the tank increased the rate of temperature change in the tank due to the decrease in the volume of water for each node. The study concluded that although a change from 50 to 100 nodes would result in a small improvement in the rate of temperature change, the improvement is insignificant and can be neglected in order to save computation time when performing system simulations [36].

A similar study was performed by Allard et al. [38] where five electric water heater models in TRNSYS were compared (Types 38, 4, 60, 340 and 534) to determine their modelling capabilities for different application purposes. The experimental set-up to validate the five TRNSYS Types was implemented using a $270 \mathrm{~L}$ standard electric water heater storage tank with two $4.2 \mathrm{~kW}$ rated heating elements. Thermocouples were installed on the storage tank wall between the steel tank and the insulation layer. A standby test was conducted in which the tank was initially heated to a high temperature and left to cool down through thermal losses to the ambient temperature, while periodically being heated by the electrical heating elements. This test was used to determine the total heat loss coefficient for the TRNSYS storage tank Types. The results of the test gave a storage tank overall heat transfer coefficient value of $1.05 \mathrm{~W} / \mathrm{m}^{2} \mathrm{~K}$, while the heat loss rate at steady state was calculated to be $93 \mathrm{~W}$. Discharge tests were also carried out for various hot water draw-profiles (220, 235 and $450 \mathrm{~L} /$ day). These water draws were achieved through the use of a control valve that draws water from the storage tank at a rate of $10 \mathrm{~L} / \mathrm{min}$. The number of nodes selected was based on the ratio between the daily water draw to the total tank volume, resulting in the TRNSYS Types requiring 58 nodes per Type. The 
study showed that the simulation time step was an important factor in the simulation study. Type 4 obtained significant errors in the tank energy balance when the fluid at any node was completely replaced within a given time-step. Therefore, it was found that the maximum acceptable time-step was 28 seconds. The results for the water draw concluded that the TRNSYS models represent the de-stratification phenomenon, similar to the temperature-profiles obtained experimentally. However, it was shown that Type 4 does not support de-stratification, due to thermal conduction. The thermal conduction in Type 4 resulted in a dead zone at the bottom of the tank, at a much lower temperature than the rest of the tank. It was also observed that a phenomenon called temperature inversion occurred when the cold-water inlet was not located near the bottom of the water storage tank Type and the temperature of the cold-water inlet was lower than the temperature below. Although this phenomenon did not occur in the physical system, the TRNSYS Types handle this situation through mixing the colder node with the node immediately below, until no inversion is taking place in the tank. Allard et al. concluded that the temperature inversion was only significant after a draw when the tank was being supplied with cold water. A comparison between Type 534 with an instantaneous mixing flow routine and Type 340 with a default mixing flowrate value showed that the vertical temperature distribution of the tank was the same to that of the experimental results. Allard et al. stated that Type 534 is the only model capable of reducing the error in the mixing zone through the introduction of a fractional inlet zone where the user can distribute the water entering the tank over multiple nodes and also the use of high number of heating elements to represent the uniform heat distribution during water draws.

The assumption of using a 1-D temperature profile to represent the temperature distribution within a storage tank was verified by experiment by Cruickshank and Harrison [39]. 
Experiments consisting of cool-down and heat diffusion tests were performed for a $270 \mathrm{~L}$ storage tank to investigate the validity of this assumption. Horizontal and vertical temperature measurements were recorded using temperature probes to examine the temperature gradient within the tank. The vertical probe consisted of nine thermocouples, $0.15 \mathrm{~m}$ apart, for a total length of $1.50 \mathrm{~m}$, and the horizontal probe consisted of 10 thermocouples, $0.05 \mathrm{~m}$ apart, for a total length of $0.45 \mathrm{~m}$. The cool-down and heat diffusion tests were carried out over a 48 hour period. Tests were initialized by charging the storage tank to a uniform tank temperature of $54^{\circ} \mathrm{C}$ and logging data at 3 minute intervals for the horizontal and vertical temperature variations, as the tank lost heat to the surroundings. The surrounding temperature for the duration of the test was approximately $20^{\circ} \mathrm{C}$. The results of the tests indicated that the bottom of the tank lost energy to the environment at a faster rate than the top of the tank. The authors concluded that this was due to the lack of insulation at the bottom on the tank. It was also observed that there were negligible changes in temperature along the length of the storage tank walls, i.e., no significant two-dimensional effects. The authors concluded that the 1-D profile assumption was reasonable.

Finally, Tran et al. [40] conducted a study on the improvement of HPWH modelling and concluded that storage tank stratification and water draws are the main sources of error in wrap around coil condenser modelling. The solution proposed for these sources of error was to refrain from using the average tank water temperature for modelling the heat delivery to the tank, and to instead only use the water temperature covered by the coil. 


\subsection{Summary}

Chapter 2 presented a review of previous work on DWH energy reduction, HPWH performance improvement and alternative water heating systems. Furthermore, TRNSYS studies for similar applications were covered. The literature shows that HPWH technology has failed to penetrate in colder climates due to its reduction in performance at lower ambient air temperatures. The literature also highlighted that there is a lack of understanding related to how HPWHs affect space heating and cooling loads of conditioned spaces. The literature also indicated that computer models can be used to study the suitability and annual performance of HPWHs for different climates, and that electricity sources, energy cost and water loads have a significant effect on their economic advantage. Finally, the literature highlighted some of the challenges associated with modelling HPWHs, including the difficulties that exist in modelling the heat delivery from the condenser, using the TRNSYS models that are currently available. A summary of the highlights of this literature review is given in Table 2-1. 
Table 2-1: Literature review summary

\begin{tabular}{|c|c|}
\hline Authors & Conclusions \\
\hline K. Hudon et al. [14] and Spran et al. [15] & $\begin{array}{l}\text { HPWH's capability of meeting high load } \\
\text { demands at high efficiency is dependent on } \\
\text { the size of the storage tank and the control } \\
\text { logic of the unit. It was shown that installing } \\
\text { HPWH units in conditioned spaces could } \\
\text { result in savings in source energy of over } 38 \% \\
\text { in comparison to electric water heating when } \\
\text { the impact on the space heating and cooling is } \\
\text { considered over different states in the US. }\end{array}$ \\
\hline Vieira et al. [12] & $\begin{array}{l}\text { The HPWH performance is dependent on the } \\
\text { load temperature requirements, source } \\
\text { temperature and operational patterns. It was } \\
\text { shown that a significant deterioration in the } \\
\text { COP of the heat pump as the temperature of } \\
\text { the source decreased and that the heat pump } \\
\text { struggled to produce a high COP that } \\
\text { normally can be achieved in hot humid } \\
\text { environments }\end{array}$ \\
\hline Li et al. [28] & $\begin{array}{l}\text { Three working fluids for IDX-SAHP HPWH: } \\
\text { R22, R134a and R744, were tested under } \\
\text { various temperatures. The results show that } \\
\text { the R22 produced the highest COP, followed } \\
\text { closely by R } 134 \mathrm{a} \text { at } 30^{\circ} \mathrm{C} \text { ambient } \\
\text { temperature. However, the COP of the R134a } \\
\text { unit was superior to the other two working } \\
\text { fluids when the ambient temperature dropped } \\
\text { below } 13^{\circ} \mathrm{C} \text {. }\end{array}$ \\
\hline J. Bursill [37] & $\begin{array}{l}\text { Optimization study for HPWH in Canadian } \\
\text { cities showed significant enhancement in the } \\
\text { performance by reducing the size of the } \\
\text { storage tank and decreasing the set-point of } \\
\text { the unit, while maintaining high enough } \\
\text { temperature to control legionella growth. }\end{array}$ \\
\hline
\end{tabular}




\begin{tabular}{l|l}
\hline Authors & Conclusions \\
\hline C. Tran et al. [40] & $\begin{array}{l}\text { Study on the performance of HPWH } \\
\text { concluded that the main sources of error with } \\
\text { modelling a wrap-around condenser coil are } \\
\text { the tank stratification and water draws. It was } \\
\text { suggested that the best practice to reducing } \\
\text { computational error is to use the water } \\
\text { temperature average for the area covered by } \\
\text { the condenser. }\end{array}$ \\
\hline J. Berger and S. J. Harrison [34] [41] & $\begin{array}{l}\text { Water heating energy demands were } \\
\text { significantly reduced through the introduction } \\
\text { of solar coupled systems. A comparison } \\
\text { between solar thermal, PV and PV/T } \\
\text { technology with a back-up auxiliary heating } \\
\text { showed that PV/T heating system can } \\
\text { outperform stand-along solar thermal and PV } \\
\text { systems, and are suitable in most Canadian } \\
\text { cities. }\end{array}$ \\
\hline C. Baldwin and C. A. Cruickshank [36] & $\begin{array}{l}\text { TRNSYS storage tank models require a large } \\
\text { number of nodes (50+) in order to accurately } \\
\text { predict the behavior of a physical system } \\
\text { accurately, due to the characteristics of a node } \\
\text { which measures the water volume as opposed } \\
\text { to a discrete temperature point. }\end{array}$ \\
\hline
\end{tabular}




\section{Chapter: Experimental Design}

This chapter describes the experimental apparatus which was used in this study to develop a heat pump performance map, which was subsequently used to create a new TRNSYS subroutine to model and evaluate the performance of HPWHs for different Canadian cities.

The chapter begins with an overall description and schematics of the experimental set-up, followed by a detailed description of the major components installed within the system. This chapter also provides information about the data acquisition system and the sensors installed within the system.

\subsection{Overview of Experimental Set-Up}

The experimental set-up, located at Carleton University, included a HPWH tank, a preheat tank, a tempering valve, a flow meter and a solenoid. In order to allow a consistent mains water temperature entering the HPWH tank, a 136 L (30 US Gal) electric hot water tank was used to preheat the water. A water draw system was installed at the outlet of the HPWH tank to simulate hot water draw-profiles for residential houses. The water draw system consisted of a tempering valve to maintain the water draw at $55^{\circ} \mathrm{C}$, a flow meter to measure the flowrate of the water draw, and a solenoid to regulate the volume of the water draw.

The 189 L (50 US Gal) HPWH unit by GeoSpring consisted of an evaporator, a compressor, a wrap-around condenser, an electric expansion valve, two heating elements and a storage hot water tank. An illustrative diagram of the HPWH is shown in Figure 3-1. The experimental setup was designed such that the water would sequentially pass through the preheat tank, the HPWH, through the draw system, and finally discharge through the drain. A water circulation loop controlled by a second solenoid was installed to allow the exiting hot water to be 
recirculated through the cold-water inlet. The purpose of this loop is to reinitialize the tank to a uniform temperature at the end of each test.

In addition to the HPWH tank, an air handling unit was installed to the air inlet of the HPWH, which consists of a fan, a set of cooling coils, a set of heating coils, and a second set of cooling coils (glycol cooling coils). An illustrative diagram of the HPWH is shown in Figure 3-2. The purpose of the air handling unit is to condition the temperature and humidity of the air delivered to the heat pump, in order to achieve a controlled testing environment. Figure 3-3 outlines all the components and connections between all the major components and the location of the sensors used to monitor the system.

A laboratory Virtual Instrument Engineering Workbench (LabVIEW) was used for the data acquisition system due to the availability and interoperability with existing systems within the laboratory. LabVIEW was used for component controls such as turning on and off the heat pump and creating virtual proportional integral derivative (PID) loops to allow control automation. Furthermore, it was used for data monitoring and collection during testing periods.

The following sections outline the details of the HPWH installation and controls, air handling unit controls, and the installation of the main components in the system. 


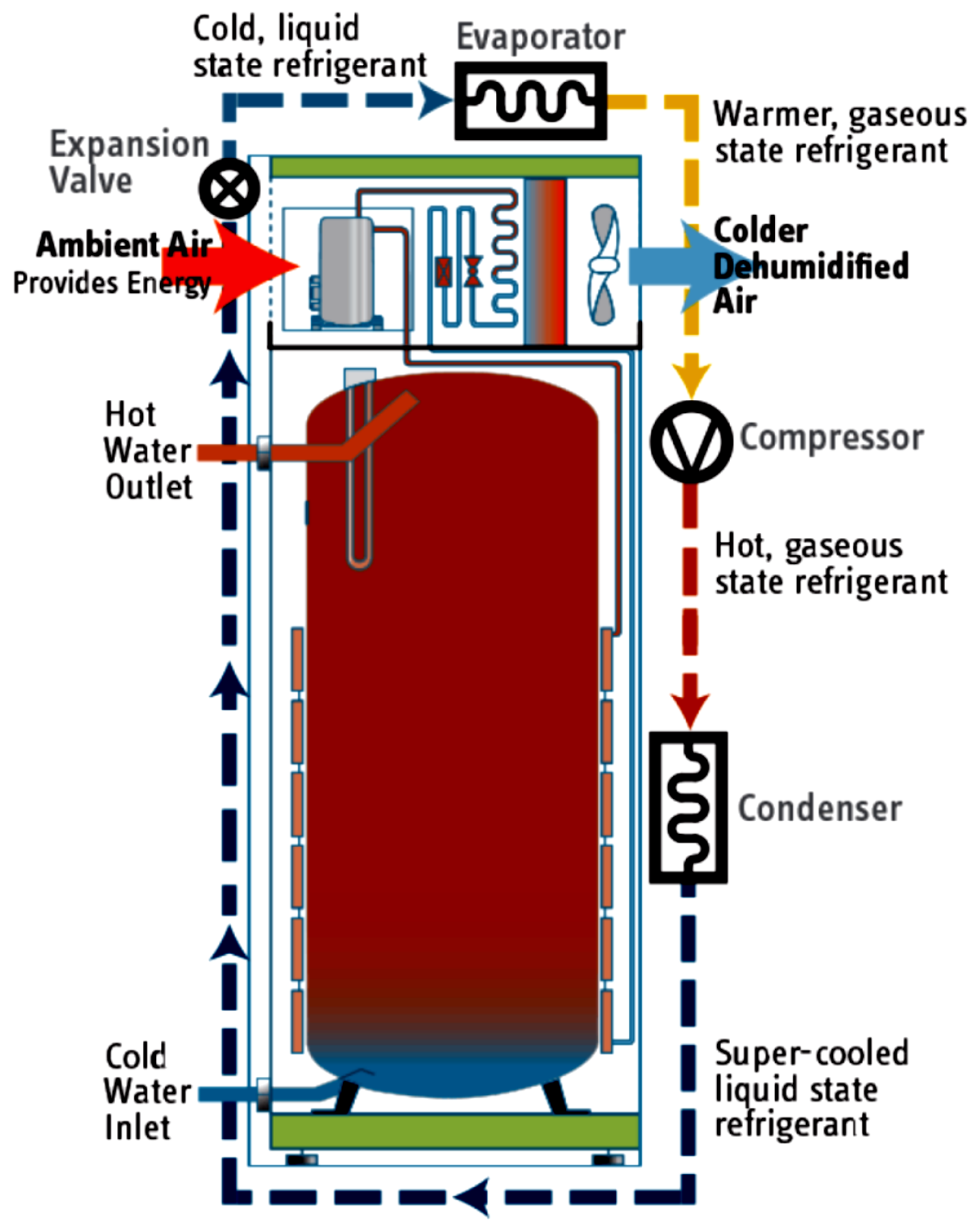

Figure 3-1: Heat pump water heater operational diagram [42] 


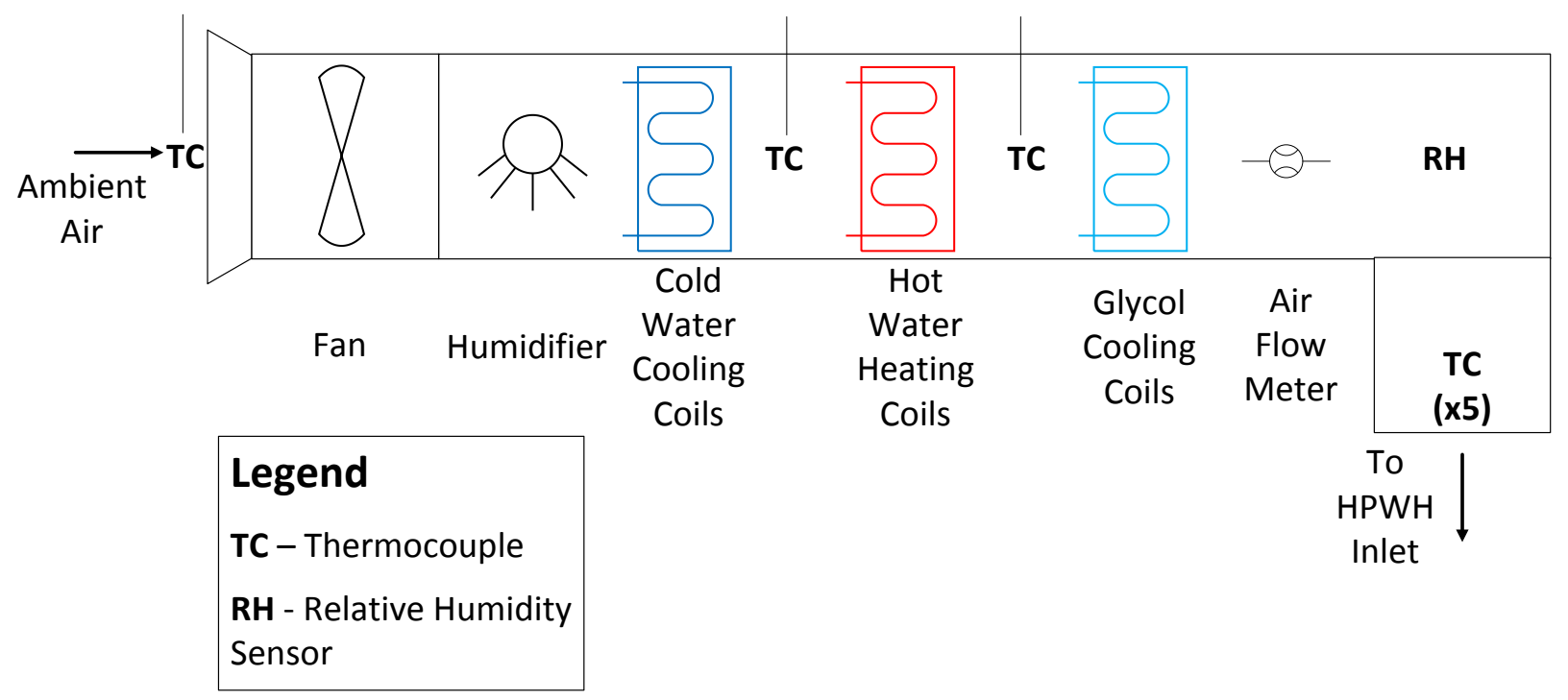

Figure 3-2: Air handling unit schematics for the unit's components and controls

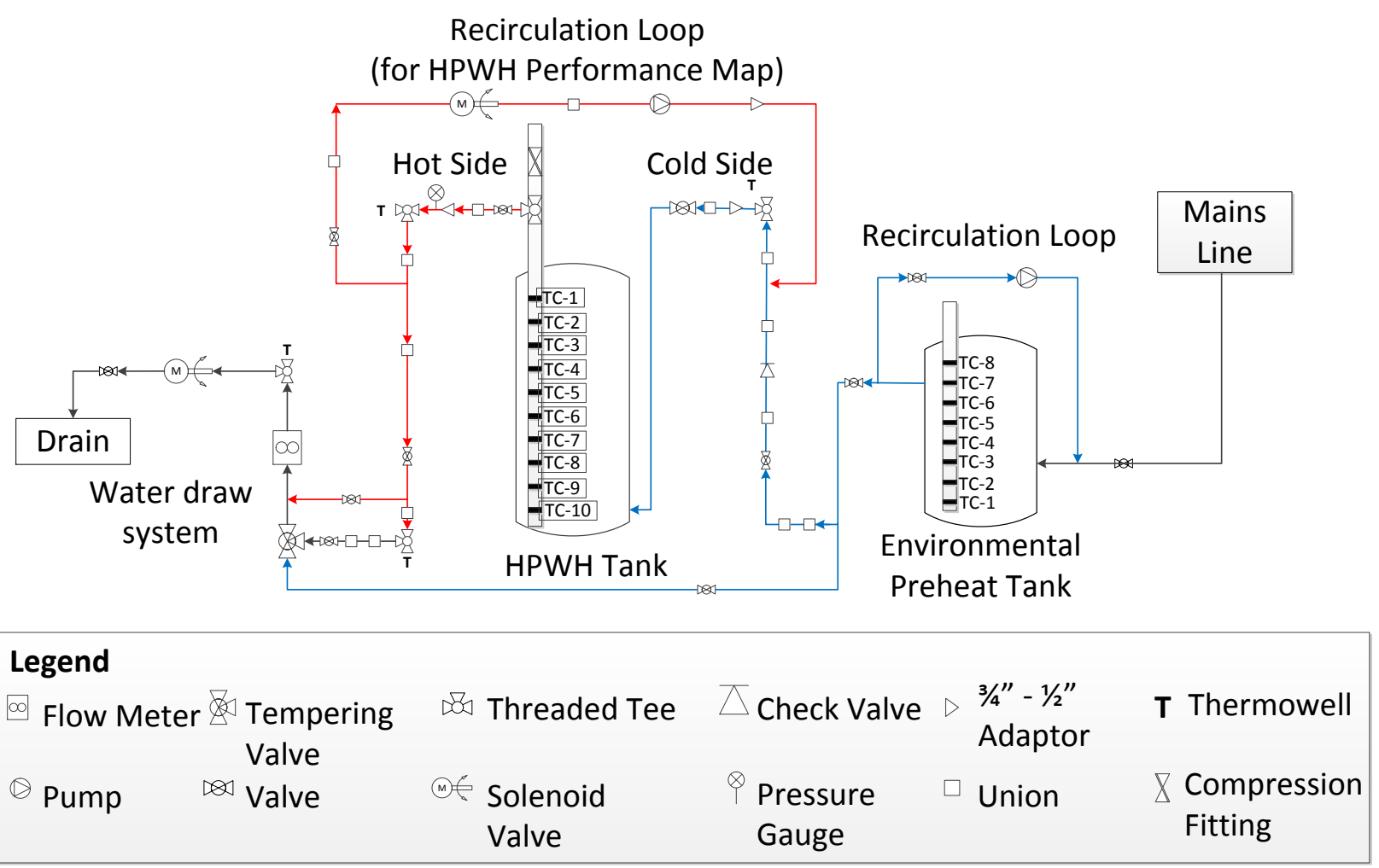

Figure 3-3: System diagram for the HPWH experimental apparatus (excluding the AHU) 


\subsection{Heat Pump Water Heater Unit}

\subsubsection{Specifications}

For this research, the GeoSpring hybrid electric water heater was installed and tested in the laboratory. The unit is $1.5 \mathrm{~m}$ (59") high and $53 \mathrm{~cm}\left(21^{\prime \prime}\right)$ in diameter and has a temperature set-point range of 38 to $60^{\circ} \mathrm{C}\left(100\right.$ to $\left.140^{\circ} \mathrm{F}\right)$. This temperature set-point range can be achieved through multiple heating modes, including: heat pump only, hybrid, high demand/boost, electric/standard (fan off), and vacation. According to the GeoSpring unit sizing guide, the 189 L unit capacity is recommended for a 2-4 family size household as outlined in Table 3-1. Therefore, in order to evaluate the performance of the unit properly, the water draw profile used for this study focused on this range.

Figure 3-4a is a picture of the actual GeoSpring HPWH unit and Figure 3-4b is an isometric view of the unit (provided from the user manual), which illustrates the heat pump components and the water storage tank. 
Table 3-1: GeoSpring HPWH unit sizing per household size [43]

\begin{tabular}{|l|l|l|l|}
\hline \multicolumn{2}{|c|}{ Residential Water Heater Sizing Guide } \\
\hline \multirow{2}{*}{ Family Size } & \multirow{2}{*}{ Demand } & \multicolumn{2}{|c|}{ Gallon Capacity Recommended (Litres) } \\
\cline { 3 - 4 } & & \multicolumn{1}{|c|}{ Electric or GeoSpring } & \multicolumn{1}{c|}{ Gas } \\
\hline \multirow{2}{*}{$5+$} & High & $378.5)$ & 283.9 \\
\cline { 2 - 4 } & Average to low & 302.8 & 189.3 \\
\hline \multirow{2}{*}{3 to 4} & High & $302.8)$ & $189.3-283.9$ \\
\cline { 2 - 4 } & Average to low & 189.3 & 151.4 \\
\hline \multirow{2}{*}{2 to 3} & High & 189.3 & $151.4-189.3$ \\
\cline { 2 - 4 } 1 to 2 & Average to low & 151.4 & 151.4 \\
\hline & High & $151.4-189.3$ & $151.4-189.3$ \\
\cline { 2 - 4 } & Average to low & 113.6 & 113.6 \\
\hline
\end{tabular}

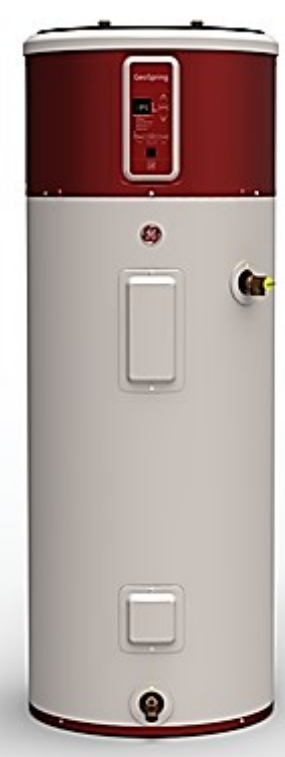

(a)

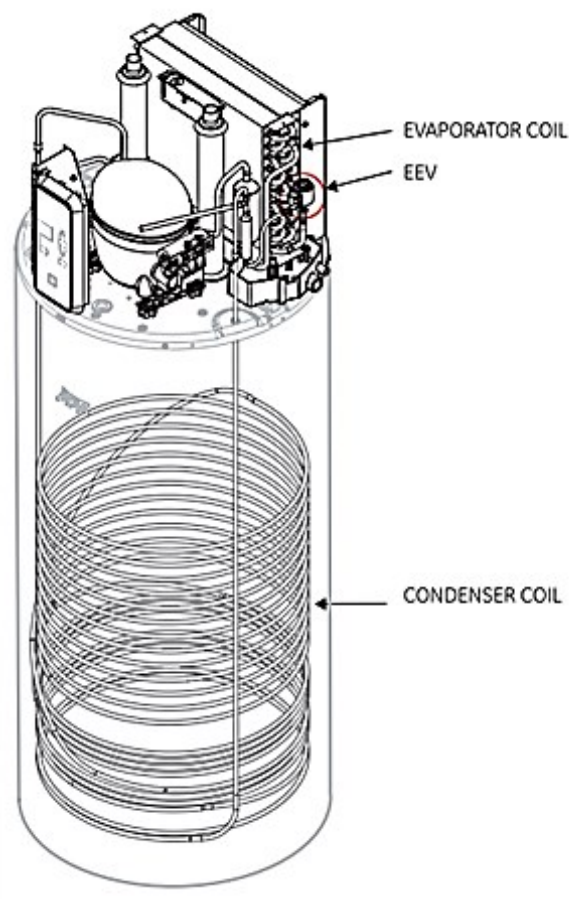

(b)

Figure 3-4: Geospring Hybrid Electric Water Heater: (a) actual unit, (b) components of the unit [43] 
The HPWH technical specifications are summarized in Table 3-2 as listed in the installation manual [43]. These specifications were used for installation and instrumentation purposes, but most importantly for manually overriding the controls.

Table 3-2: Heat pump water heater unit specifications [43]

\begin{tabular}{|l|l|}
\hline HPWH Property & Value \\
\hline Tank Volume & $189 \mathrm{~L}$ \\
\hline Tank Height & $1.5 \mathrm{~m}$ \\
\hline Tank Diameter & $0.5 \mathrm{~m}$ \\
\hline Electrical Power Requirement & $208 \mathrm{VAC} 60 \mathrm{~Hz}$ \\
\hline Air Flowrate & $150 \mathrm{~L} / \mathrm{s}$ \\
\hline Tank Max Working Pressure & $1.034 \times 10^{6} \mathrm{~Pa}(150 \mathrm{PSI})$ \\
\hline Circuit Breaker & $30 \mathrm{~A}$ \\
\hline Elements Rated Power & $4500 \mathrm{~W}$ \\
\hline Compressor Rated Power & $600 \mathrm{~W}$ \\
\hline Compressor LRA & $21.0 \mathrm{~A}$ \\
\hline Compressor LRA with Capacitor & $19.6 \mathrm{~A}$ \\
\hline Compressor RLA & $3.0 \mathrm{~A}$ \\
\hline Compressor RLA with Capacitor & $4.5 \mathrm{~A}$ \\
\hline Refrigerant Charge (R134a) & $0.78 \mathrm{~kg}$ \\
\hline
\end{tabular}

\subsubsection{Controls}

In order to have full control of the heat pump and its components during operation, the controls of the GeoSpring HPWH unit were manually adjusted (without compromising the built-in safety features, listed in Table 3-3. Overriding the controls was achieved by disconnecting the K202 and K204 relays found in Figure 3-5, while keeping and modifying the K203 and K201 relays. The disconnected relays were replaced by external relays placed in an electrical box. These external relays allowed full control of the fan, compressor, and upper and lower elements within the heat pump water heater unit. All the modifications on the HPWH 
unit's controls were inspected and approved in accordance with Carleton University's standards and the Electrical Standard Association (ESA) standards.

Table 3-3: Safety features for the GeoSpring HPWH unit

\begin{tabular}{|l|l|}
\hline Safety Feature & Function \\
\hline Double Line Breaker (DLB) & $\begin{array}{l}\text { Creates an open circuit if the current supplied } \\
\text { to the unit exceeds 30 A }\end{array}$ \\
\hline Thermal Cut Off (TCO) & $\begin{array}{l}\text { Opens the circuit if the temperature of the tank } \\
\text { exceeds } 77^{\circ} \mathrm{C}\left(170^{\circ} \mathrm{F}\right)\end{array}$ \\
\hline External Compressor Overload & $\begin{array}{l}\text { Opens at } 14 \text { A or if temperature exceeds } \\
70^{\circ} \mathrm{C}\left(158^{\circ} \mathrm{F}\right)\end{array}$ \\
\hline
\end{tabular}

The modification on the electrical diagram shown in Figure 3-5 was accomplished by creating a closed circuit with the external electrical box through the use of terminal blocks connected to the L1 and the L2 power lines. This was done, in order to pull power from the unit to feed the external relays.

Figure 3-6 provides an overview of the electrical box connections used to modify the HPWH unit's controls. Fifteen amp fuses were added between the HPWH controls and the electrical box for extra protection on excess current as an additional safety feature. 


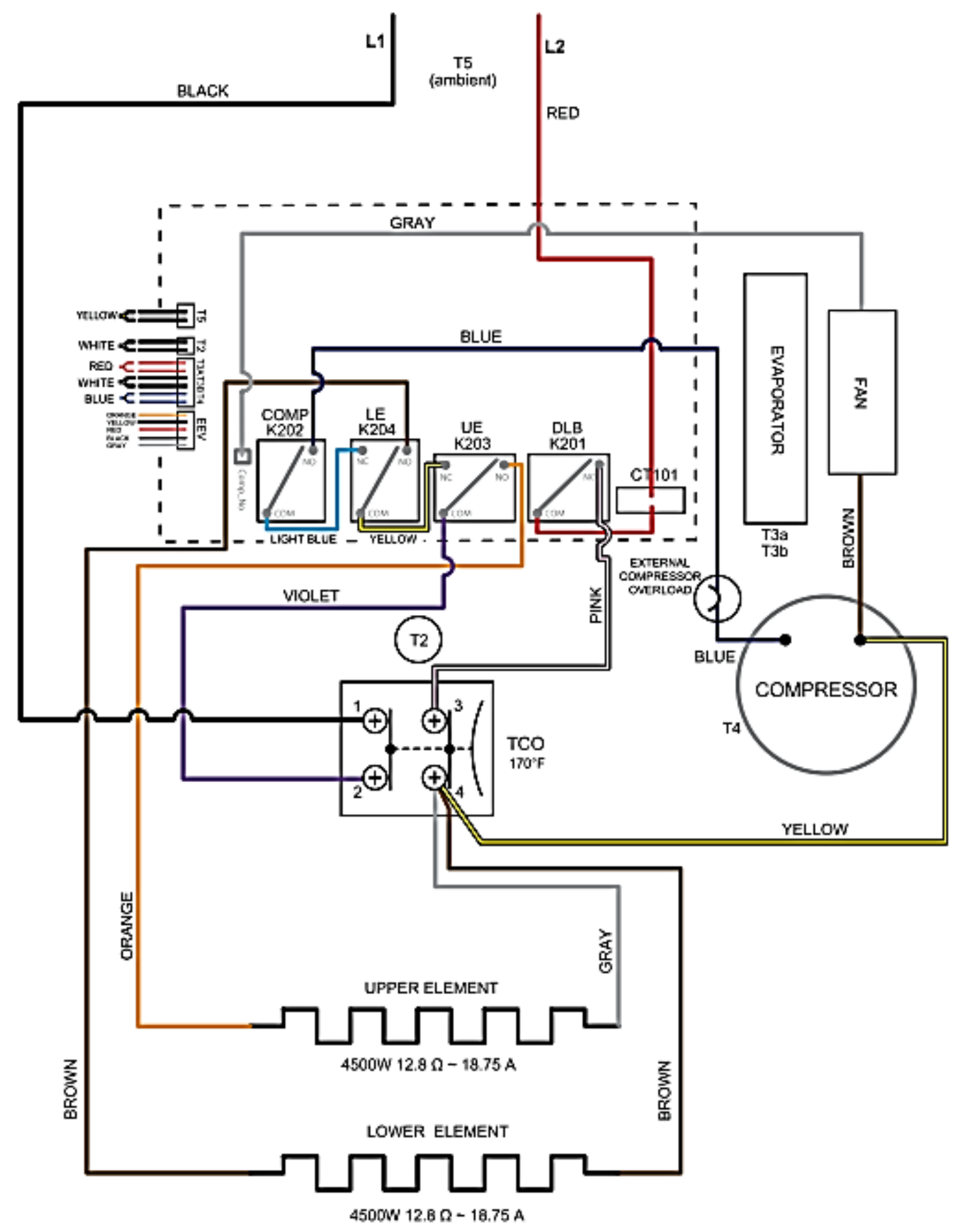

Figure 3-5: GeoSpring HPWH electrical diagram [43] 


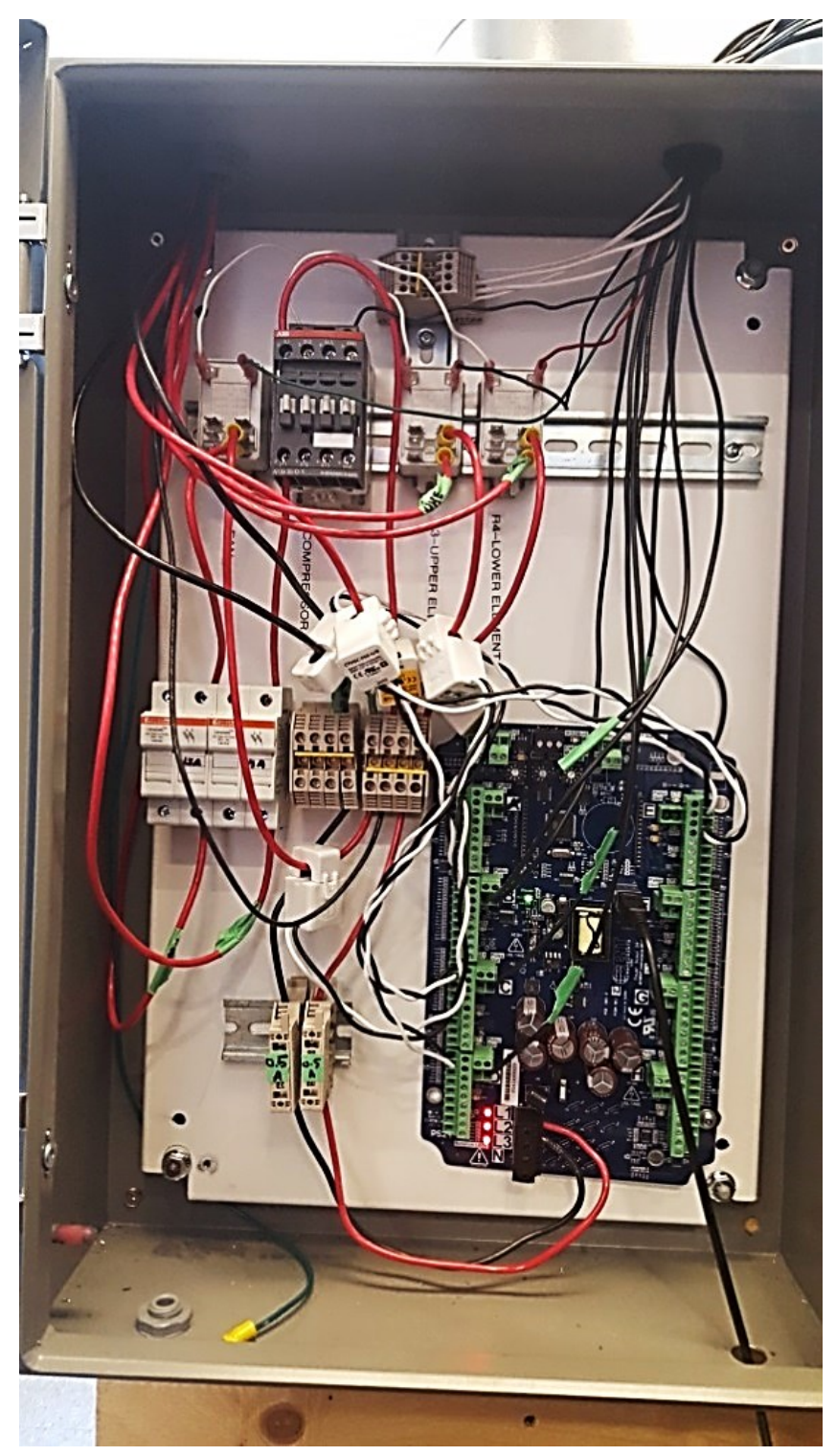

Figure 3-6: Wiring of the HPWH external relays controlling and power monitoring system

\subsubsection{Instrumentation}

The water storage was instrumented with 10 equally spaced Type $\mathrm{T}$ thermocouples (0.1 m apart) to measure the temperature change along the length of the tank. The air temperature at the inlet and exhaust of the heat pump were also measured using an array of 5 thermocouples placed in an " $\mathrm{X}$ " configuration. The relative humidity was measured using a "HX94A Series RH/Temperature Transmitter" by Omega at the inlet and exhaust of the HPWH. The humidity sensors had an accuracy of $2.5 \%$ at $22^{\circ} \mathrm{C}$ from 20 to $80 \% \mathrm{RH}$ [44]. The temperature and relative 
humidity of air were used to develop the performance map and calculate the total and sensible cooling capacity of the evaporator. The temperature and relative humidity readings were sampled at 60 second intervals. Furthermore, these measurements were used to define the controls of the AHU. The set-up of the RH sensor and thermocouples are shown in Figure 3-7.

The total power of the HPWH unit and its individual components were monitored using a power monitoring system PowerSout ${ }^{\mathrm{TM}} 24$ by Dent Instruments [45]. The power monitoring system converts the current flow through current transformers to pulses which are communicated to a binary input card, which is then converted in the LabVIEW software into an average power reading. The pulse readings were sampled at 30 second intervals. Once the pulses were converted to power readings, the power of the compressor at a specific water temperature was determined by taking the average reading at $\pm 1^{\circ} \mathrm{C}$ interval. Therefore, three current transformers (CTs) were installed in the electric box on the connection between the terminal block and the four on/off relays for the fan, compressor, and upper and lower elements. The CT size depends on the current draw of the component being monitored. Therefore, different sizes of CTs were chosen based on the component's specification provided by the HPWH unit's technical manual.

Table 3-4 summarized the CTs used on the HPWH unit. The PowerScout ${ }^{\mathrm{TM}} 24$ uses the total power of the HPWH unit through the L1 and L2 lines which extend from the terminal blocks to generate pulses. The PowerScout ${ }^{\mathrm{TM}} 24$ circuit layout is shown in Figure 3-8.

Table 3-4: Current transformers size used to monitor the power consumption of the HPWH components

\begin{tabular}{|c|c|c|c|}
\hline Component & Model & CT Size & \multirow{2}{*}{ Accuracy } \\
\hline Heat Pump & Dent CT-HSC-050-U & $50 \mathrm{~A}$ & $0.5 \%$ \\
\hline Fan & Dent CT-HSC-020-U & $20 \mathrm{~A}$ & \\
\hline $\begin{array}{c}\text { Compressor } \\
\text { Upper Element }\end{array}$ & Dent CT-HSC-020-U & $20 \mathrm{~A}$ & \\
\hline
\end{tabular}




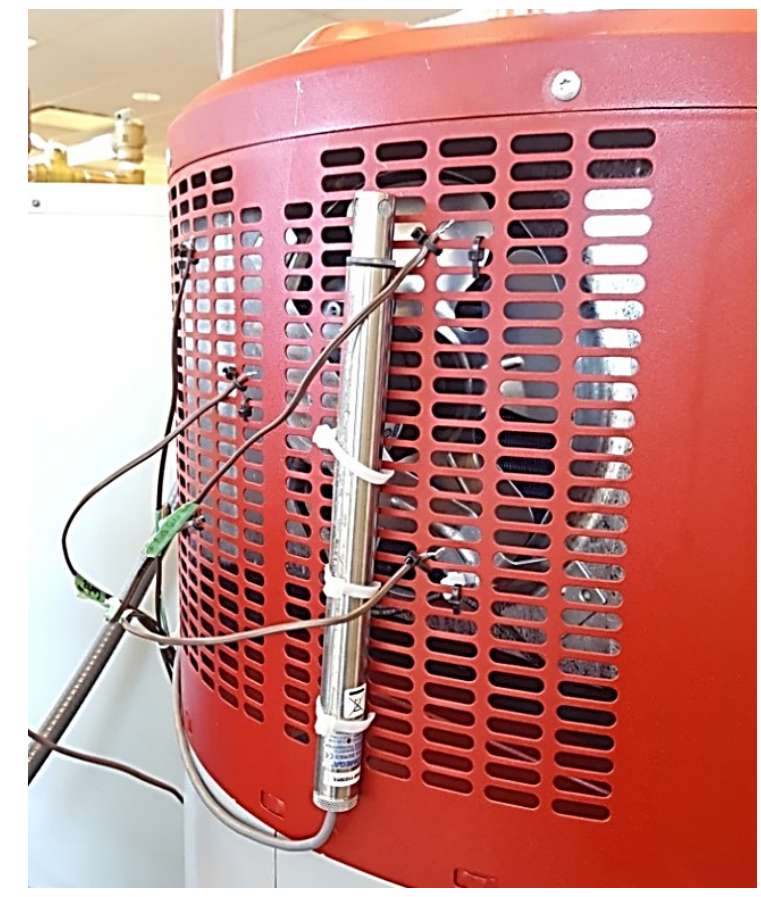

Figure 3-7: Heat pump water heater air exhaust instrumentation showing the " $X$ " placement of the thermocouples and the RH sensor

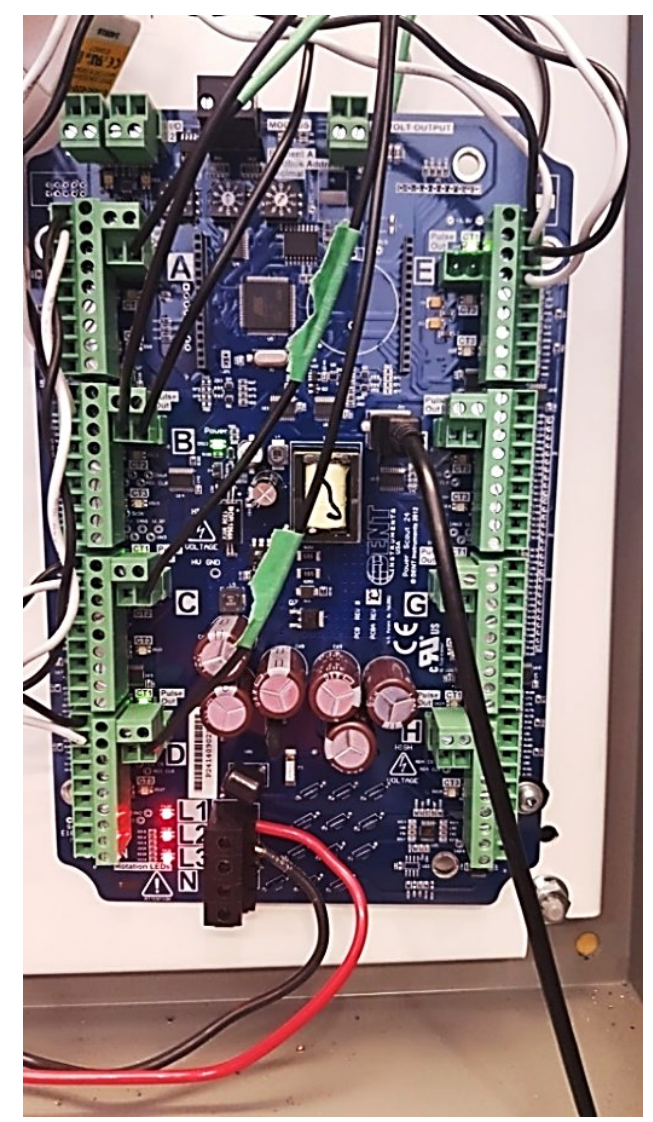

Figure 3-8: PowerScoutTM 24 


\subsection{Air Handling Unit}

An air handling unit was designed, manufactured and installed in the laboratory to condition the supply air to the heat pump. Using the AHU, it was possible to heat and cool the supply air, as well as humidify and dehumidify the supply air. The supply air temperatures and relative humidities were measured during each test to develop the performance map which was later used in the TRNSYS simulation program to model the HPWH.

\subsubsection{Air Handling Unit Specifications}

The AHU consisted of a variable air volume (VAV) fan followed by a set of cooling coils, a set of heating coils and a secondary set of cooling coils (glycol cooling coils). The reason for the order of the coils was to allow the dehumidification of air. The secondary cooling coils allow further cooling of air since the chilled water lines could only cool down to $10^{\circ} \mathrm{C}$. The air handling unit and the connection to the HPWH is shown in Figure 3-9. The air handling unit's heating and cooling coils were designed and sized to meet the temperature and relative humidity requirements for the performance characterization tests and any operational conditions of interest. The unit's design specifications are outlined in Table 3-5.

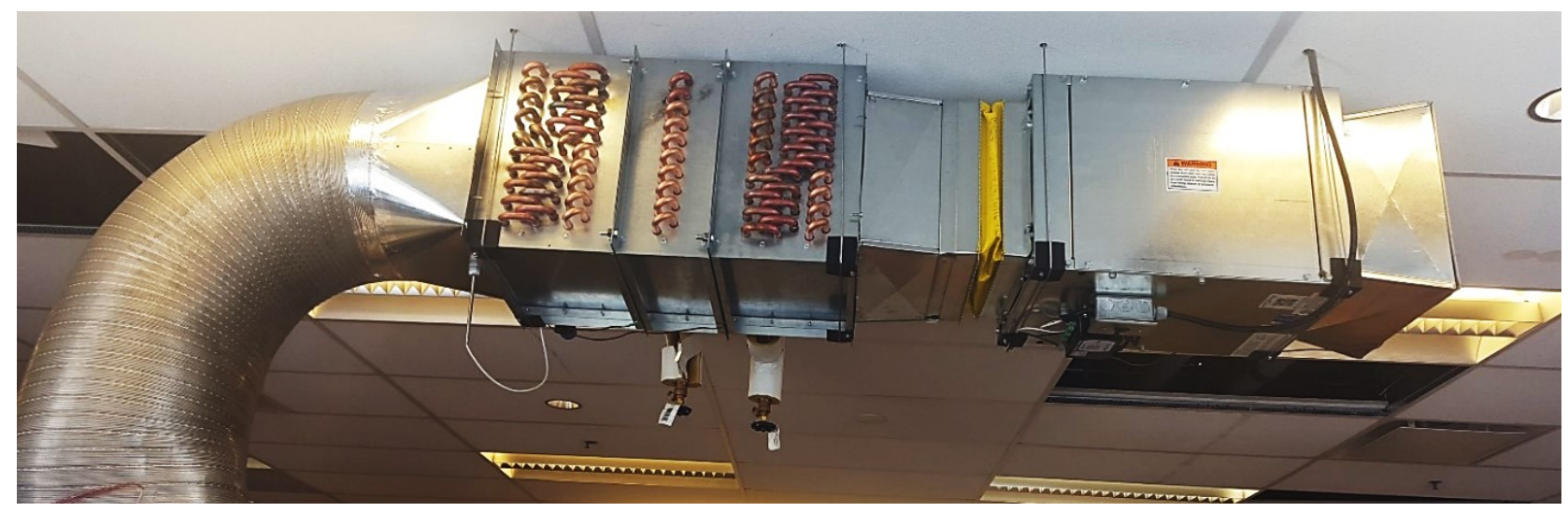

Figure 3-9: Air handling unit 
Table 3-5: Specification of the AHU heating and cooling coils

\begin{tabular}{|l|c|c|c|}
\hline Tag & Cooling Coil & Heating Coil & Super-Cooling Coil \\
\hline Model & $\begin{array}{c}\text { CW12C06S12- } \\
12.5 \times 14-R H\end{array}$ & $\begin{array}{c}\text { HW12C02A11- } \\
12.5 \times 14-R H\end{array}$ & $\begin{array}{c}\text { CW12C06S12- } \\
12.5 \times 14-R H\end{array}$ \\
\hline Total capacity (kW) & 3.7 & 8.7 & 4.7 \\
\hline Sensible capacity (kW) & 3.7 & - & 2.5 \\
\hline Fluid & Water & Water & $50 \%$ Glycol/Water \\
\hline Fluid flow rate $\left(\mathbf{m}^{3} / \mathbf{s}\right)$ & $1.6 \times 10^{-4}$ & $1.3 \times 10^{-4}$ & $1.7 \times 10^{-4}$ \\
\hline $\begin{array}{l}\text { Air Pressure Drop } \\
\text { (Pa) }\end{array}$ & 54.7 & 20 & 109.5 \\
\hline
\end{tabular}

\subsubsection{Instrumentation}

The AHU was fully instrumented. The fan and the proportional control valves were controlled through virtual PID loops created in LabVIEW. Three thermocouples were installed at various locations throughout the AHU to be used as feedback for the PID loops. This was used to control the flowrate of hot and chilled water through the heating and cooling coils. The first thermocouple was installed at the inlet of the air handling unit fan to monitor the room air temperature. The rest of the thermocouples were installed on a fishing line between the fan and the cooling coils, and between the cooling coils and heating coils. Additionally, the ability to humidify the air was required to understand how the effect of moisture in the supplied air affects the performance of the heat pump. Therefore, a fine mist Skuttle model 529 humidifier [46] was installed at the AHU section between the fan box and the cooling coil. This installation location, shown in Figure 3-10, allowed the air to become fully saturated, which was used to dehumidify the air through the cooling coils to the required set-point.

An air flow meter was installed at the end of the air handling unit which provided feedback for the virtual PID controller. This allowed full control over the incoming flow rate to the air handling unit. The flow rate was used to adjust the temperature of incoming air to the HPWH unit. This option was not used during the performance map data collection. 
Finally, a humidity sensor was installed at the exit of the air handling unit to monitor the incoming relative humidity to the HPWH unit. The humidity sensors were used when developing the performance maps as well as used for PID loop feedback in order to adjust the incoming humidity through manipulating the air temperature throughout the air handling unit. The implementation of the PID loops and control strategies for obtaining the humidity and temperature set-points will be explained further in Section 3.5.2: LabVIEW.

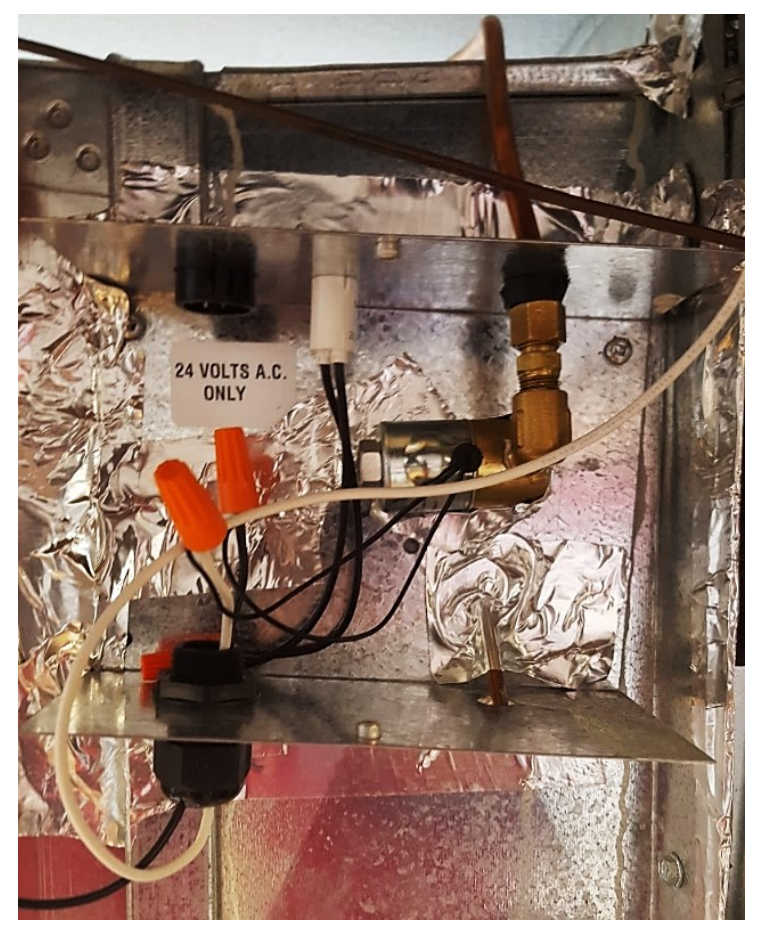

Figure 3-10: Skuttle model 529 humidifier

\subsection{Water Draw System}

A water draw system, Figure 3-11, was connected to the experimental set-up to simulate draw-profiles that represent a family water draw usage, according to the CSA-F379.1 standards. The water draw system consisted of a tempering valve, flowmeter and a solenoid. 


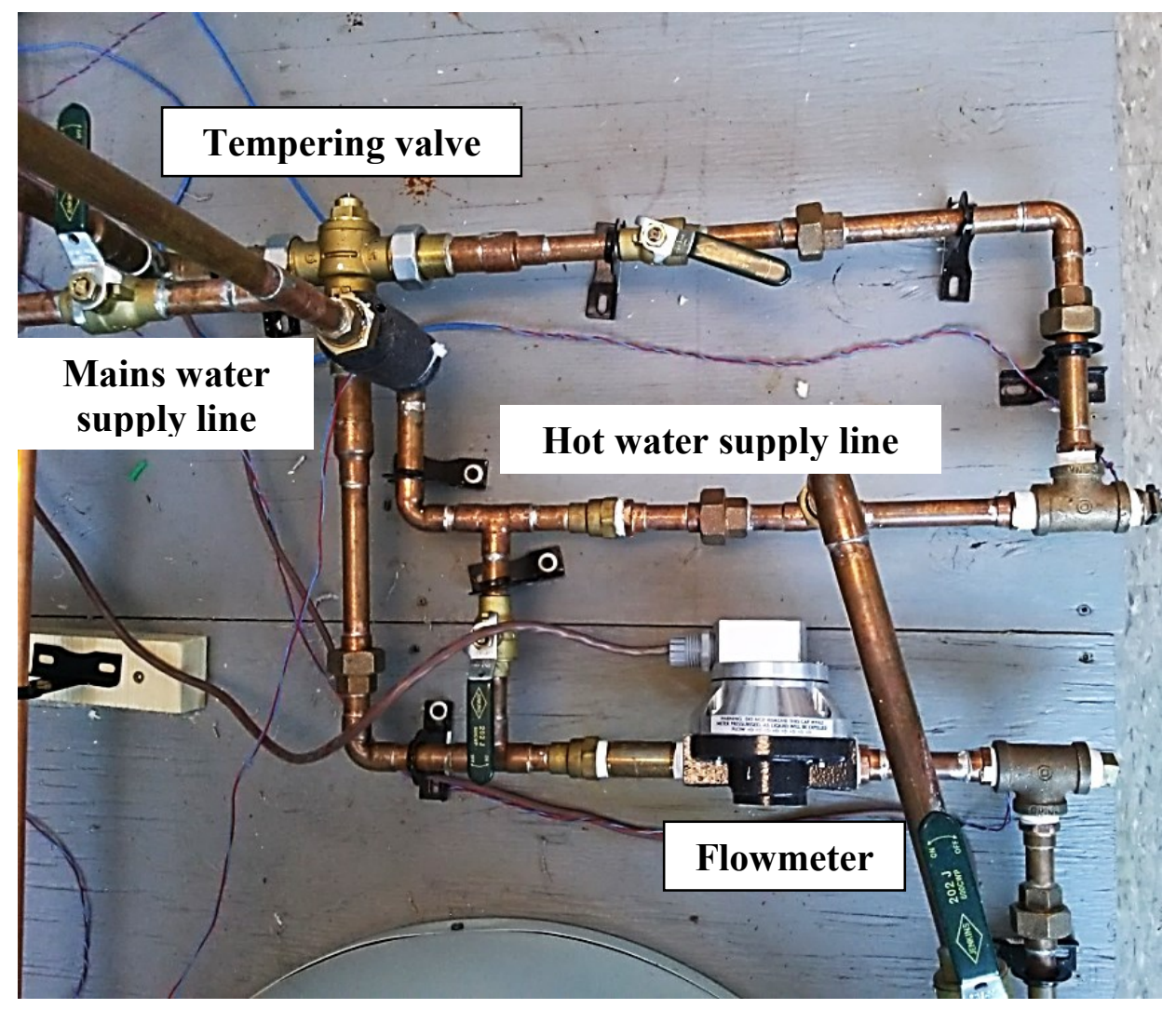

Figure 3-11: Water draw system

\subsubsection{Tempering Valve}

A tempering valve (or mixing valve) was installed at the outlet of the HPWH to maintain a safe and constant water draw temperature. A Heatguard HG110-HX tempering valve was used to allow mixing of the outlet hot water from the HPWH and the preheat tank water. The preheat tank was used to maintain the mains water temperature delivery at a constant temperature. The mixed water was then discharged to the drain line through a solenoid. The tempering valve is shown in Figure 3-12. 


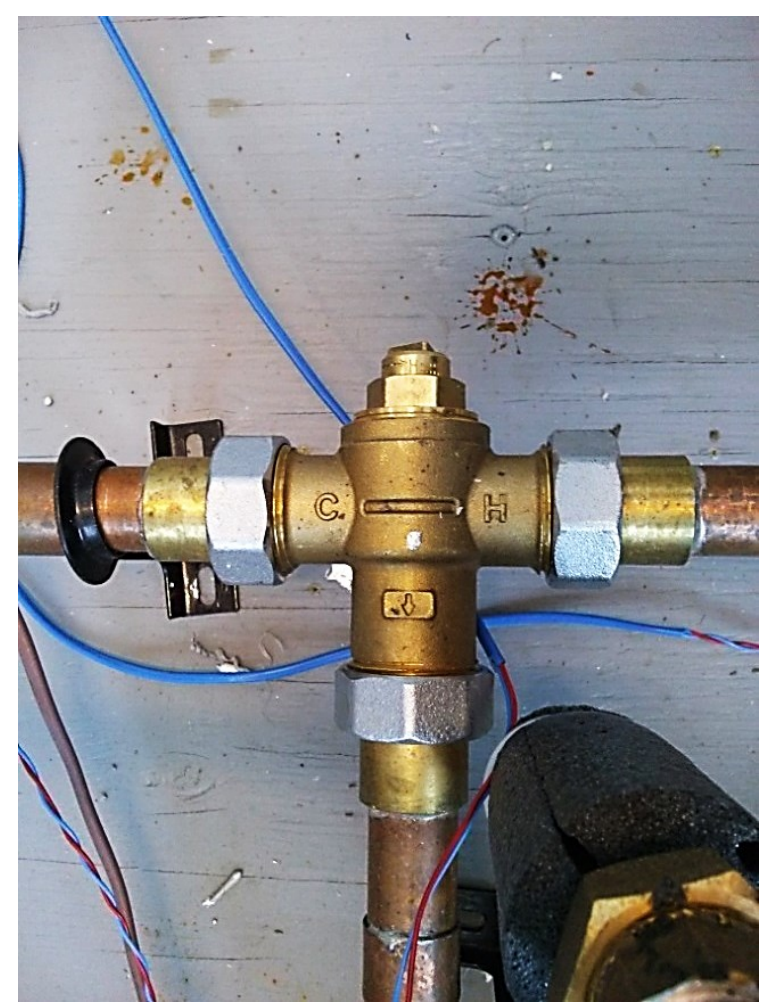

Figure 3-12: Tempering valve

\subsubsection{Solenoid}

A Schneider AG13A020 solenoid, shown in Figure 3-13, was installed at two locations on the experimental apparatus to control the draw off the DHW tank. The first solenoid was location at the outlet of the water tank (referred to as the draw line) to initiate the water draw. This solenoid and a throttling valve were used to control the volume draw according to the CSA-F379.1 draw profiles. These components also allowed for bringing the tank water temperature down to a uniform temperature before the start of a new test when performing a performance map test. The second solenoid was installed at the recirculation loop between the outlet and inlet of the HPWH tank. The purpose of this solenoid was to allow the mixing of the top and bottom of the tank to eliminate stratification. This was only used to initialize the tank during performance map testing, since each test started at a uniform tank temperature. The recirculation assembly consisted of a recirculation pump and a solenoid, shown in Figure 3-14. 


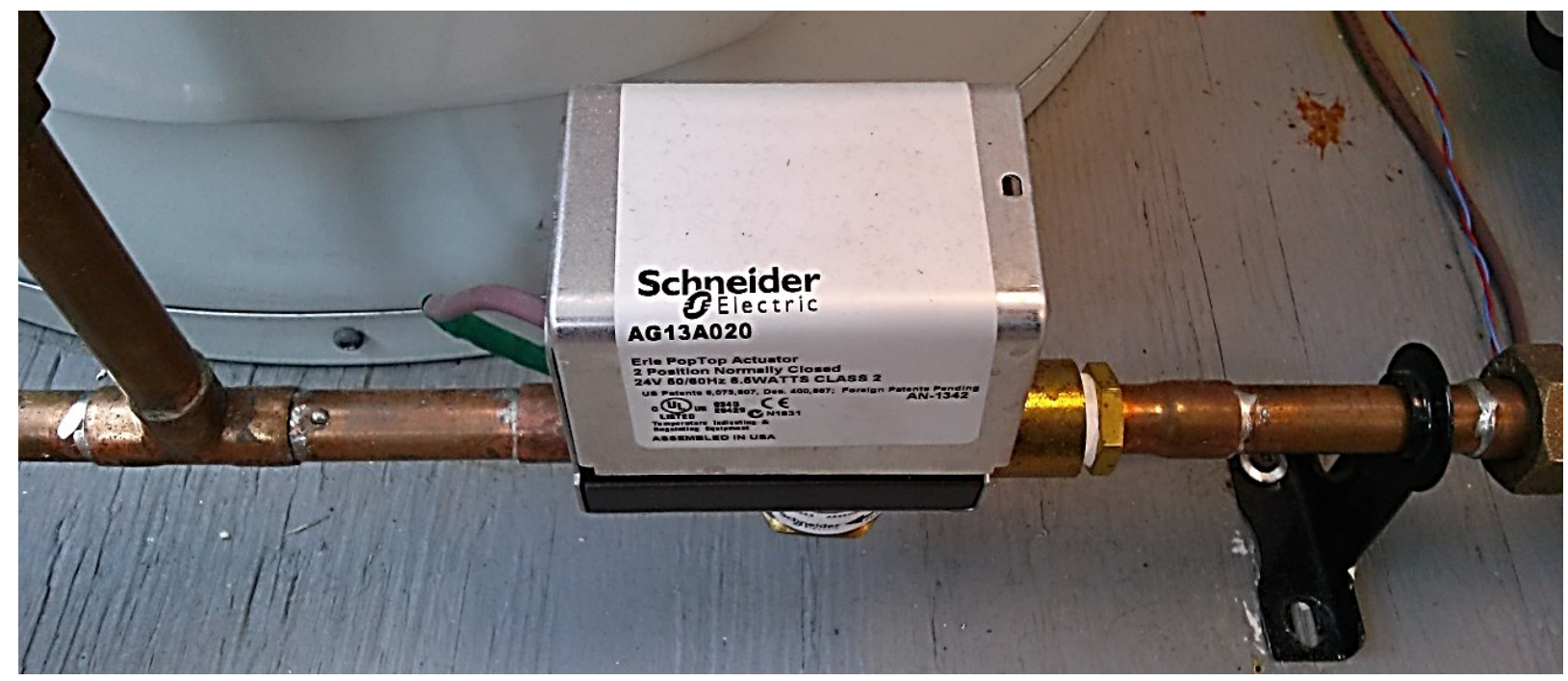

Figure 3-13: Water solenoid for water draw-profile initiation

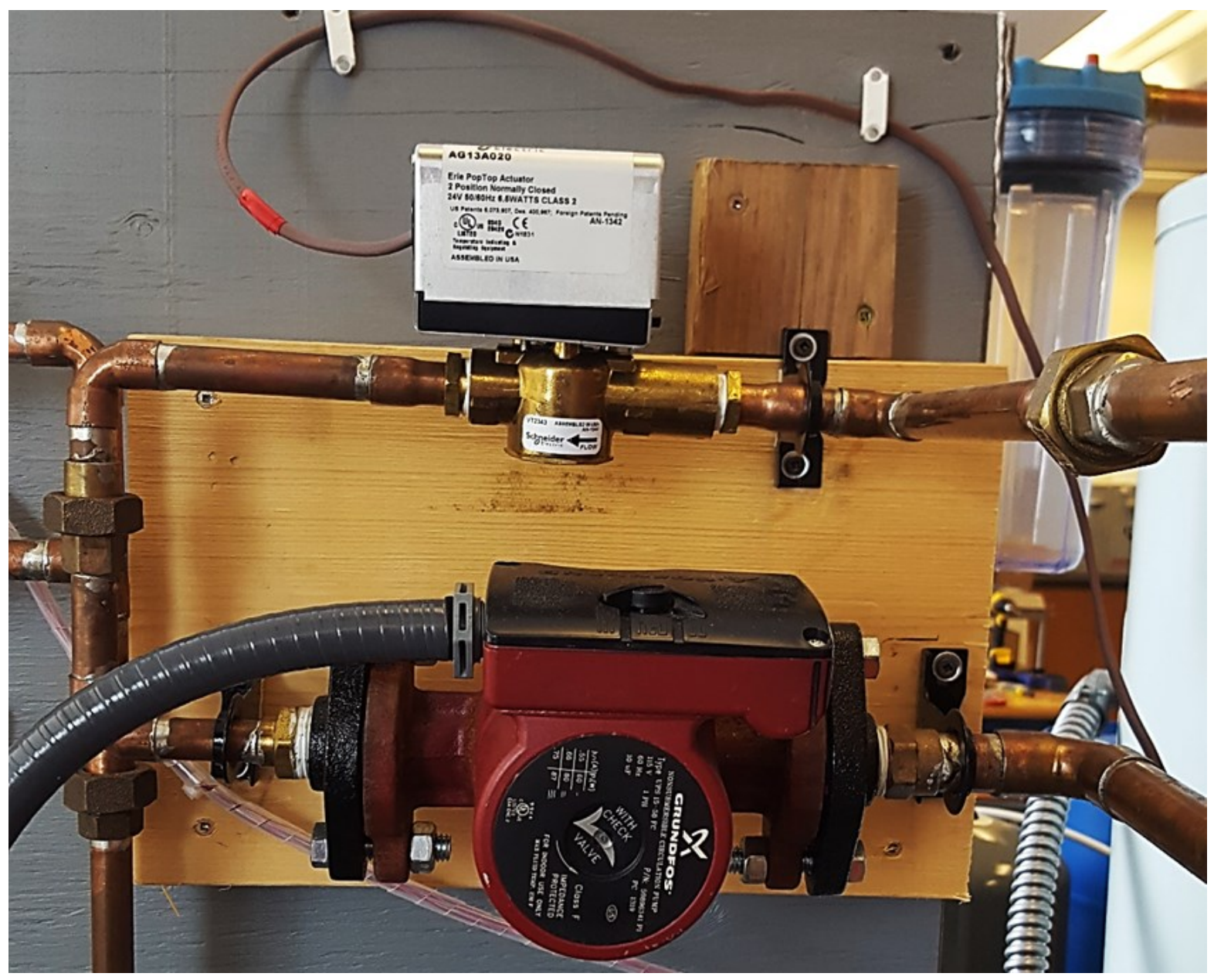

Figure 3-14: Recirculation loop for tank water de-stratification 


\subsubsection{Instrumentation}

The water draw system was instrumented with a thermowell at the exit of the HPWH to determine the temperature of the exiting water. A second thermowell was installed at the tempering valve to measure and control the delivery temperature of the water $\left(55^{\circ} \mathrm{C}\right)$. The thermowells used were constructed in the laboratory and are shown in Figure 3-15. The thermowells used a T-type thermocouple similar to the ones used in the water storage tank.

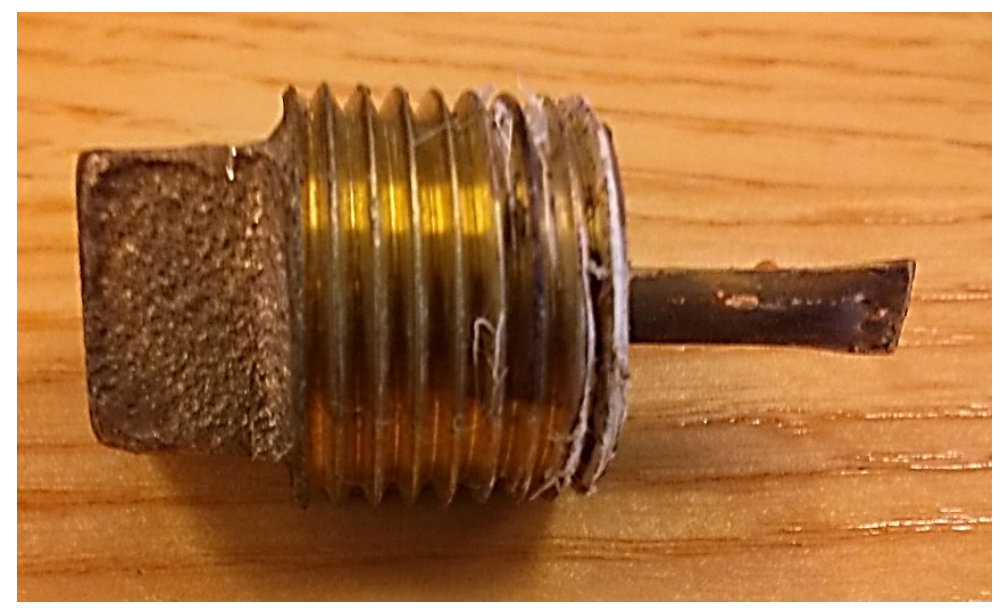

Figure 3-15: Thermowell for fluid stream temperature measurements

A positive displacement flow meter, Brooks BM-04, was installed in-line to the solenoid on the $1 / 2$ inch piping in order to regulate the draw-profile automation. The flow meter had a working temperature range of up to $80^{\circ} \mathrm{C}$, a flow rate range between 1 and $30 \mathrm{~L} / \mathrm{min}$ and an accuracy of $0.5 \%$ [47]. The positive displacement flowmeter works on triggering pulses as the oval gear rotats due to fluid motion. These generated pulses were communicated to the data acquisition system (DAQ), and converted to a flowrate reading in LabVIEW. The flow meter used in the experimental apparatus is shown in Figure 3-16. 


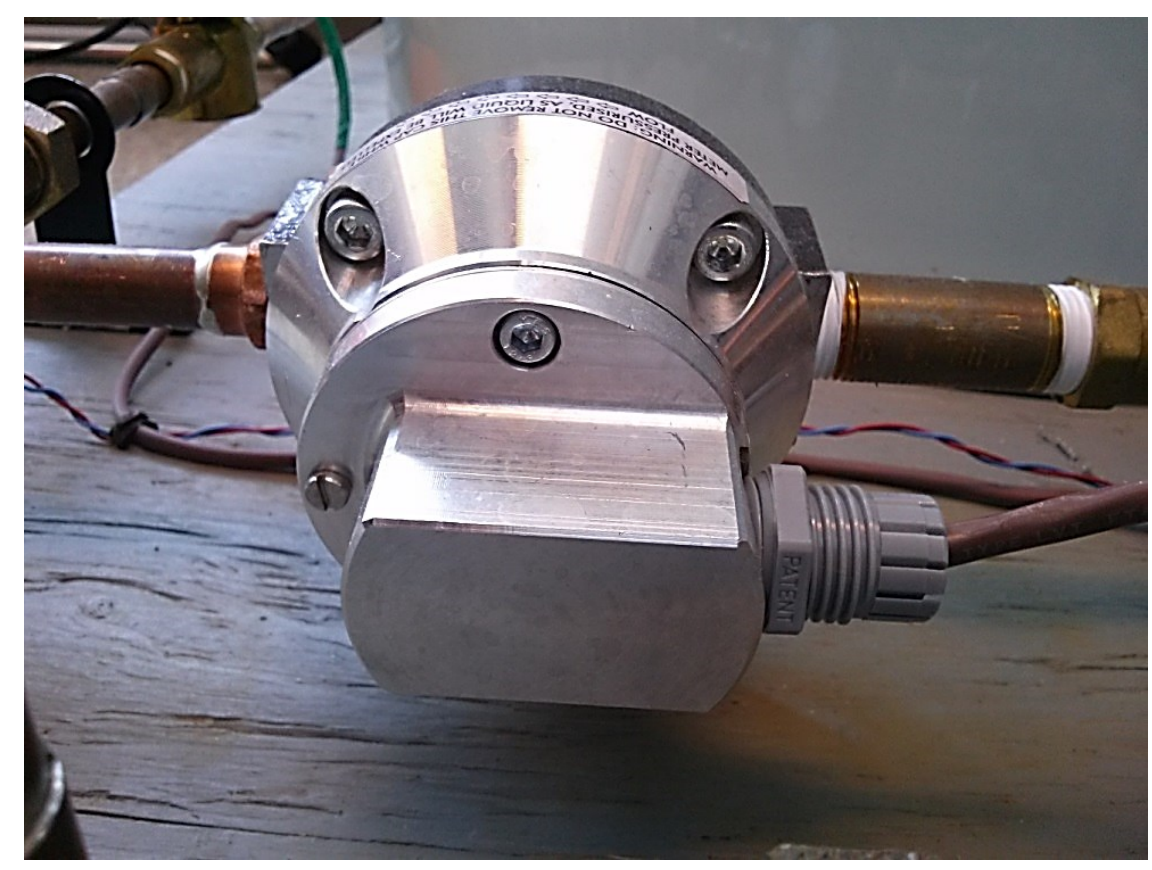

Figure 3-16: Flow meter for water flow regulation

\subsection{Data Monitoring and Collection}

In order to characterize the performance of the HPWH commercial unit, it was necessary to include a data monitoring and collection system. The data collected was then used to develop the performance map to be used for simulation and for calibration purposes. To accomplish this task, a compactDAQ, control cards and LabVIEW software were used to create a computer interface that monitors and controls the experimental apparatus.

\subsubsection{Data Acquisition System}

A compactDAQ (cDAQ) chassis was used to create a communication portal between various pieces of equipment and the external computer interface through I/O modules. This communication was established through multiple timing engines that can control up to eight different hardware modules at different sample rates. The cDAQ 9188 was used and connected to the laboratory computer through an Ethernet cable. This data acquisition system was chosen due to its simplistic communication graphical interface in LabVIEW that allows full control over 
the I/O modules, as opposed to a typical DAQ chassis which requires extra steps to set-up virtual inputs and outputs to acquire monitored data from the I/O modules. Figure 3-14 displays the cDAQ 9188 installation and the I/O modules.

Multiple different I/O modules were used to achieve the necessary controls and data collection required from the experiments. The I/O modules used were: binary input, binary output, analog input, analog output and thermocouple module. The binary input signals were required from the power monitoring system and other pulse generating equipment such as the water flow meter. These pulses were converted to power reading or flowrate readings in LabVIEW through conversion equations provided by the devices. The binary input signals were generated by the module and distributed to the components and instruments. They were mainly used for on/off controls. The analog input signals were communicated to the DAQ from the sensors either by current of voltage and were used for control purposes in the PID loops to collect data from all the sensors installed except for the thermocouples. Temperature readings were collected through a special module which has a prebuilt-in cold junction. This cold junction was used to compare the voltage generated by the two dissimilar metals, due to the temperature change from the thermocouple to the cold junction, and to create a temperature reading. The analog output signals were only used for control purposes. The signal generated through the PID controller was used for feedback to the equipment based on the required set-point. Table 3-6 provides a list of all the modules used for the experimental apparatus and the equipment monitored by each module. The data acquisition system used for the HPWH system is shown in Figure 3-17. 
Table 3-6: I/O used in the HPWH apparatus

\begin{tabular}{|l|l|c|c|l|}
\hline $\begin{array}{l}\text { I/O } \\
\text { Module }\end{array}$ & \multicolumn{1}{|c|}{ I/O Type } & Quantity & Channels & \multicolumn{1}{c|}{ Use } \\
\hline NI 9214 & $\begin{array}{l}\text { Isothermal Thermocouple } \\
\text { Input }\end{array}$ & 2 & 16 & $\begin{array}{l}\text { Thermocouple } \\
\text { measurement }\end{array}$ \\
\hline NI 9476 & 24VDC Binary Output & 1 & 32 & $\begin{array}{l}\text { Power control for } \\
\text { relays (on/off) }\end{array}$ \\
\hline NI 9422 & 24VDC Binary Input & 1 & 8 & $\begin{array}{l}\text { Pulse count for flow } \\
\text { and power readings }\end{array}$ \\
\hline NI 9207 & Voltage/Current Analog Input & 1 & 8 & $\begin{array}{l}\text { Data monitoring and } \\
\text { PID input }\end{array}$ \\
\hline NI 9264 & \pm 10 V Analog Output & 1 & 16 & PID output \\
\hline
\end{tabular}

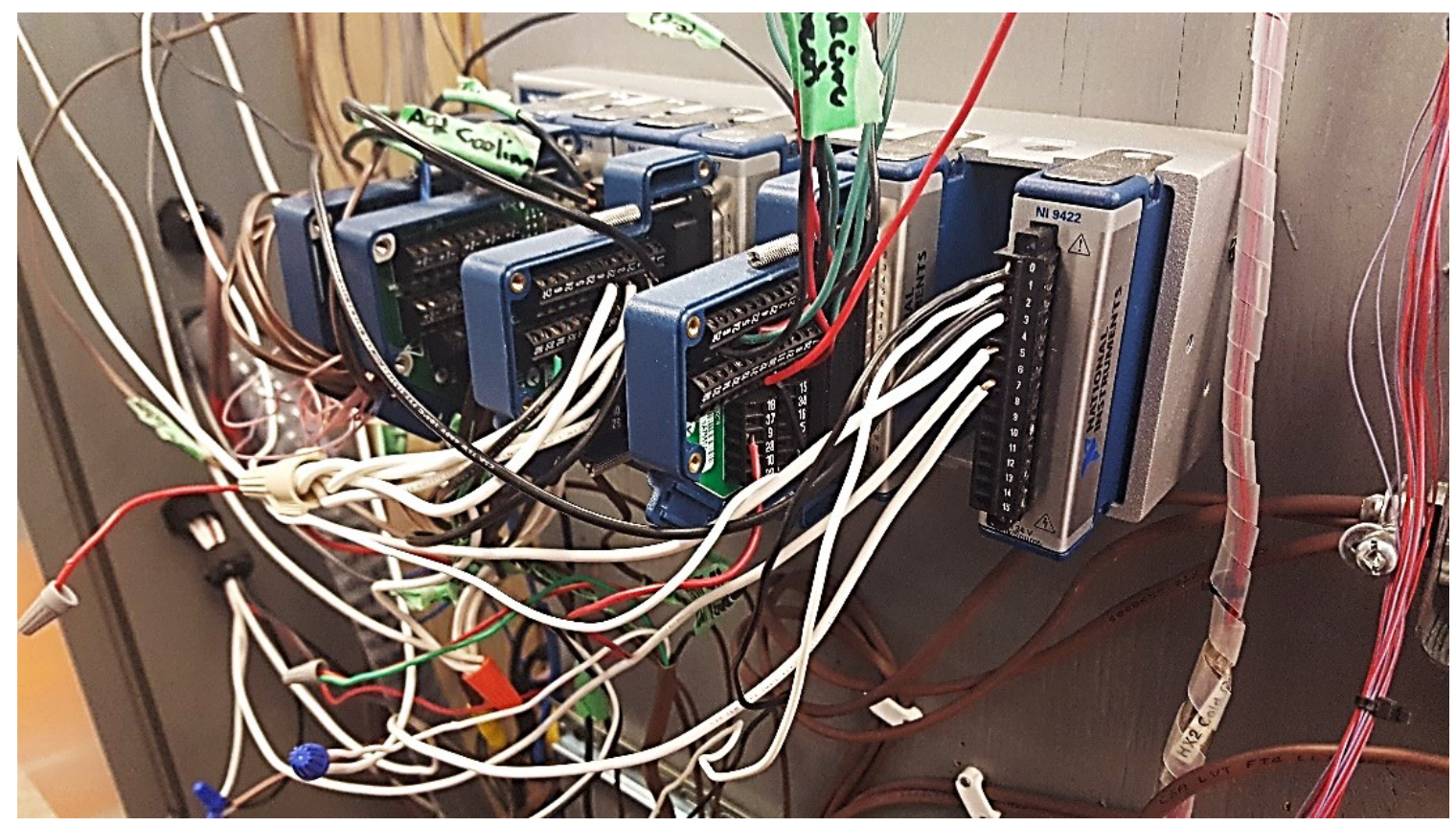

Figure 3-17: Data acquisition system and I/O cards for the HPWH apparatus

\subsubsection{LabVIEW}

LabVIEW is a program used to design and develop visual programing through a graphical language developed by National Instruments. LabVIEW uses a graphical user interface called a Virtual Interface (VI). The VI runs code in workflow-based language, which closely resembles block diagrams. This method allows user visualization during controls programming. 
In this study, a LabVIEW VI was used to develop a graphical interface for the experimental apparatus. The following two sections will provide details of the control strategies used to provide the test conditions in order to create the performance map and for water draw-profile testing.

\subsubsection{Performance Map VI}

A performance map VI was constructed to monitor the performance of the HPWH under different operating conditions (e.g., different supply air temperatures and humidities). The performance of the HPWH was monitored by measuring the change in water temperature which corresponds to heat rejected from the condenser and the compressor power. The evaporator's performance was monitored by measuring the change in air temperature and humidity across the unit. The LabVIEW VI outputted the collected data to an Excel sheet and the incoming air conditions into the AHU were adjusted based on the VI and measured conditions. The VI allowed a 20 minute period between tests for the PID loop to update to the new testing conditions. This involved the PID loop adjusting the temperature and humidity of the supply air, and draining the hot water storage tank, in order to start the new test at a uniform mains water temperature. During this time, the water storage tank was initialized by draining the tank and/or recirculating the water in the tank to obtain a uniform temperature. During the test, the data were logged to an Excel file at 60 second intervals until the tank reached the set-point temperature. The operation was then repeated for the next air conditions. Figure 3-18 shows the layout of the performance map VI. 


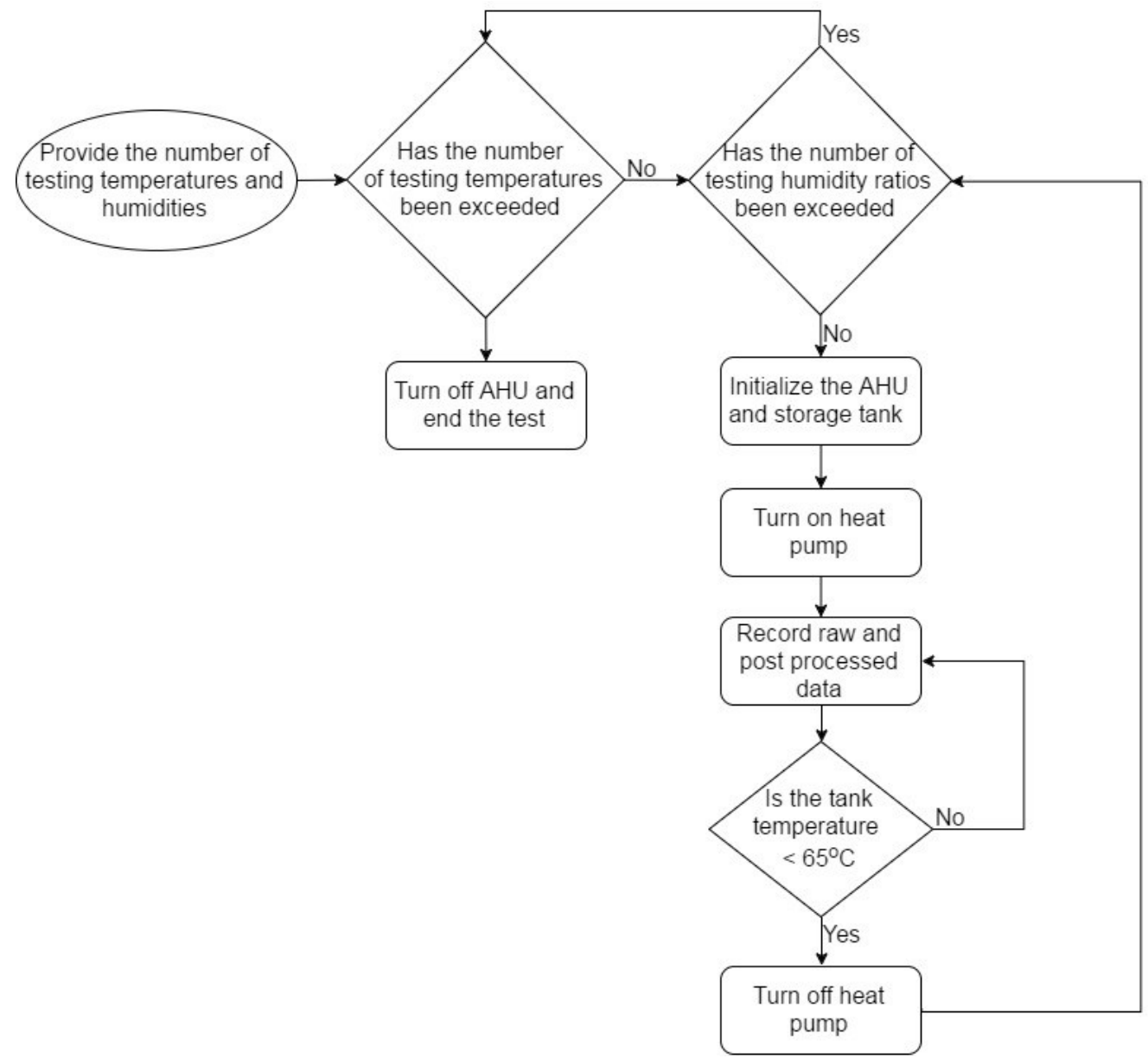

Figure 3-18: LabVIEW VI for performance map data collection

\subsubsection{Draw-profile VI}

The performance of the heat pump was tested through monitoring the change in the COP through the recovery period during the water draws in residential units. Therefore, a water draw VI was created in order to simulate a day long water draw-profile for a residential unit of different sizes based on the CSA-F379.1 standards. The solenoid was throttled to draw water at a rate of $4 \mathrm{~L} / \mathrm{min}$. The VI updated on hour to hour bases. Figure 3-19 shows the draw-profile VI. 


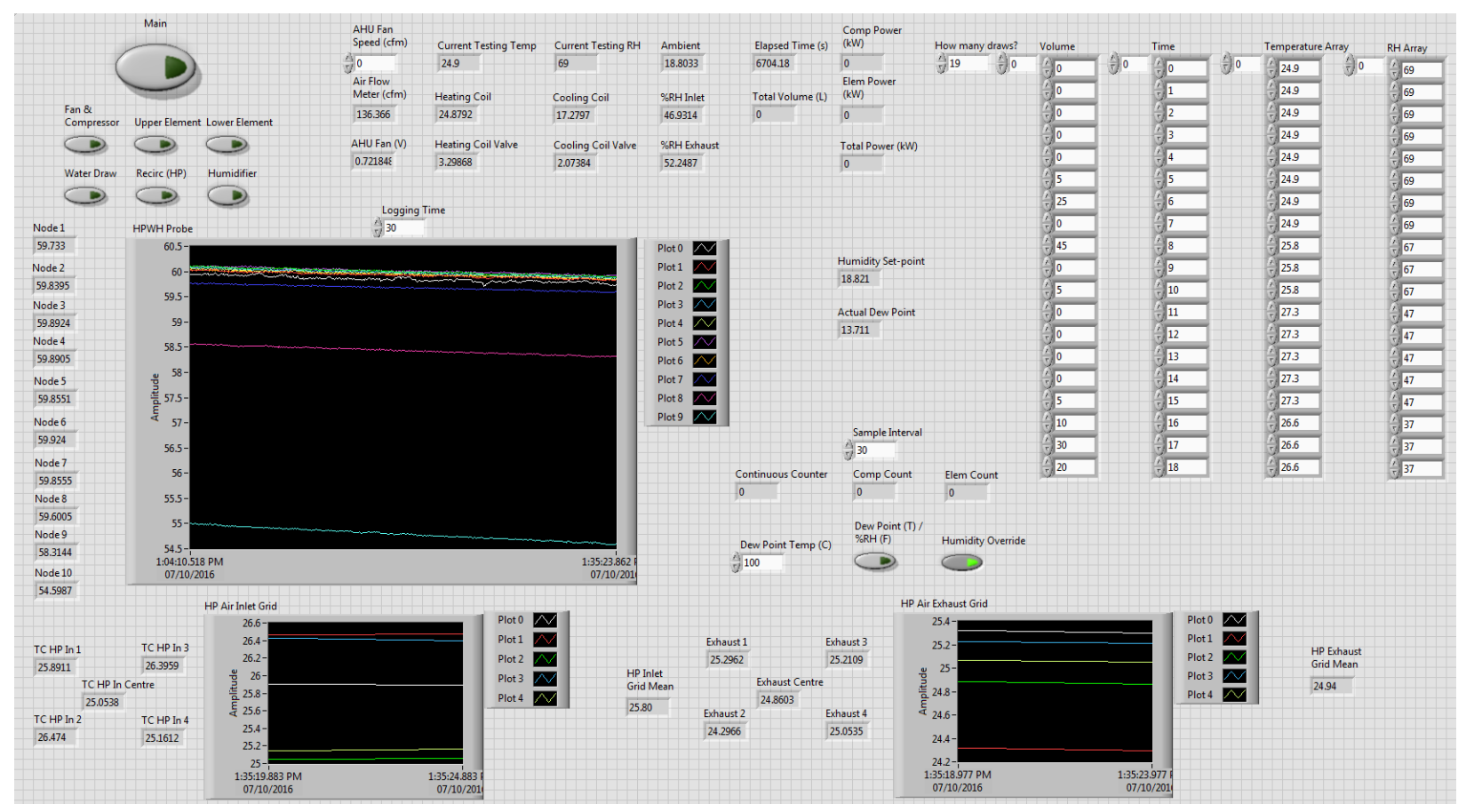

Figure 3-19: LabVIEW VI for water draw-profile testing

\subsection{Performance Map Methodology}

The performance map was constructed such that the performance of the unit could be determined given specific operating conditions. These operating conditions were regulated by the temperature and humidity of the supply air and the average temperature of the water storage tank. The performance of the unit was evaluated using the COP of the unit at specific operating conditions. The COP of the unit was dependent on the performance of the individual components in the thermal cycle.

Using the aforementioned power monitoring system outlined in Section 3.2, the pulse readings provided a power consumption value for the compressor. The heat exchange rate between the air and the evaporator was quantified by calculating the sensible and total cooling capacity across the evaporator. This was achieved by sampling the supply and exhaust air average temperature and humidity at a 60 second sampling period, while assuming a constant volumetric air flowrate and negligible specific heat of air for the range of the performance map. 
Finally, the heat delivery from the condenser wrap-around coil to the water storage tank was calculated by sampling the water temperature at 60 second intervals, and calculating the energy difference between the node at the current time-step and the previous times-step. This was calculated for both individual nodes and the average heat delivery of the tank as a whole. Each test was conducted over a 6 hour period, allowing the tank to charge from a uniform $10^{\circ} \mathrm{C}$ water temperature to a set-point of $60^{\circ} \mathrm{C}$. These tests were conducted for an air temperature range of 10 to $40^{\circ} \mathrm{C}$ at $10^{\circ} \mathrm{C}$ intervals. Due to the dry conditions in the laboratory, the tested humidity range was only achievable for 20 and $30 \%$ RH. During each test, the performance of the unit was logged for water temperatures at $10^{\circ} \mathrm{C}$ intervals. Additional details regarding the performance map and equations used are provided in Chapter 4.

\subsection{Instruments Calibration and Uncertainty}

An uncertainty analysis was conducted to determine the experimental error associated with the experimental set-up and associated sensors (e.g., thermocouples, flowmeters, etc.).

The National Institute of Standards and Technology [48] provides voltage to temperature conversion tables for thermocouples with an accuracy of $\pm 0.5^{\circ} \mathrm{C}$; however this relationship table does not take into account the error introduced by the data acquisition system or the cold junction compensation temperature reading. Therefore, in order to account for the latter, a temperature bath (Fluke 7102) was used to calibrate the thermocouples in the experimental set-up. A uniform temperature bath was maintained at a constant temperature and the temperature of the bath was varied incrementally from $5^{\circ} \mathrm{C}$ to $90^{\circ} \mathrm{C}$. The voltage reading from the data acquisition system for the submerged thermocouples was compared to a platinum resistance temperature detector (RTD), which is factory calibrated to an accuracy of $\pm 0.02^{\circ} \mathrm{C}$. Equation (3-1) shows the 
relationship between the RTD resistance and the temperature reading of the thermocouple for a range of $0^{\circ} \mathrm{C}$ to $100^{\circ} \mathrm{C}$.

$$
T=0.000997 R_{\mathrm{RTD}}^{2}+2.308 R_{\mathrm{RTD}}-240.845
$$

where $T$ is the temperature of thermocouple reading in ${ }^{\circ} \mathrm{C}$, and $R_{R T D}$ is the resistance of the RTD in ohms.

A coefficient of determination of 1 for Equation (3-1) was shown, indicating a good fit. Therefore, since the regression error was found to be in an order of magnitude smaller than the RTD's instrumentation error, it was neglected in the uncertainty analysis [49]. The National Instruments thermocouple card NI 9214 measured the cold junction temperature using a built-in thermistor with an instrumentation error of $\pm 0.25^{\circ} \mathrm{C}$ [50]. A thermocouple from a spool of 24-gauge thermocouple wires was immersed within the uniform temperature bath and connected to the thermocouple card used for curve fit calibration process. The test was carried on by increasing the bath temperature set-point from $5^{\circ} \mathrm{C}$ to $95^{\circ} \mathrm{C}$ at $2{ }^{\circ} \mathrm{C}$ intervals. The temperature test range was selected to cover the entire operational range of the experimental system. The thermocouple voltage, cold junction temperature and RTD reading were measured at five seconds intervals for three minutes for each temperature set-point.

A calibration equation was used to create the relationship between the temperature difference at the tip of the thermocouple, the temperature of the cold junction and the voltage produced. A sixth order polynomial equation was developed from curve fitting to a data set determined by subtracting the temperature of the cold junction from the temperature of the bath, and the voltage produce by the thermocouple. The data collected during the calibration test were curve fitted to a sixth order polynomial which provided a correlation coefficient of 0.9 according 
to Baldwin [49]. The sixth order calibration equation for the 24-gauge wire is shown in Equation $(3-2)$.

$$
\begin{gathered}
T=0.00258 V^{6}-0.00374 V^{5}-0.0633 V^{4}+0.227 V^{3} \\
-0.741 V^{2}+24.68 V+0.091+C J C
\end{gathered}
$$

where $T$ is temperature in ${ }^{\circ} \mathrm{C}, V$ is voltage produced by the thermocouple in $\mathrm{mV}$, and $C J C$ is cold junction temperature in ${ }^{\circ} \mathrm{C}$.

An uncertainty analysis was conducted on the thermocouple readings using the root mean square method, by taking the sum of the squares of the systematic and random errors as shown in Equation (3-3).

$$
u_{\mathrm{T}}=\sqrt{u_{\mathrm{s}}^{2}+u_{\mathrm{r}}^{2}}
$$

The uncertainty analysis had to consider the calibration of the thermocouples and the experimental measurement process. A summary of the uncertainty analysis is listed in Table 3-7. The uncertainty analysis showed the root mean squared error of the compounded error to be $\pm 0.46^{\circ} \mathrm{C}$ for the 24 -gauge wire.

Table 3-7: Summary of measurement and calibration error for temperature readings $\left({ }^{\circ} \mathrm{C}\right)$

\begin{tabular}{l|c}
\hline Sources of error & 24 Gauge wire \\
\hline Voltage error - calibration & 0.175 \\
\hline Voltage error - calibration & 0.175 \\
\hline Bath uniformity & 0.02 \\
\hline Resistance error & 0.0397 \\
\hline RTD & 0.02 \\
\hline Regression Error & 0.157 \\
\hline Cold junction temperature - experimental & 0.25 \\
\hline Cold junction temperature - calibration & 0.25 \\
\hline Total Uncertainty & 0.46 \\
\hline
\end{tabular}




\subsection{Summary}

Chapter 3 provided a detailed description of the experimental set-up consisting of the HPWH, AHU, and the water draw system, and provided information regarding the unit's controls and instrumentation, and the uncertainty analysis. Table 3-8 provides a summary of the equipment controlled by the experimental apparatus to obtain the data for the performance map. The $\mathrm{I} / \mathrm{O}$ list summarizes the output signals used in the control strategy, where BO is the binary output signal and AO is the analog output signal. The measurements recorded to develop the performance map were used in a computer model, which is discussed in Chapter 5. The following chapter outlines a detailed description of the HPHW Type created in TRNSYS and the house model used to determine the interaction between the space heating and cooling systems with the HPWH daily operations. 
Table 3-8: Summary of the control equipment in the experimental apparatus and their I/O list

\begin{tabular}{l|l|c}
\hline List of Equipment & \multicolumn{1}{|c}{ Description } & I/O \\
\hline HPWH compressor & Starts the heat pump cycle in the HPWH unit & BO \\
\hline HPWH fan & Always turns ON when the compressor is operating & BO \\
\hline HPWH upper element & A primary backup for the HPWH unit for high demand & BO \\
\hline HPWH lower element & $\begin{array}{l}\text { A secondary backup for the HPWH unit for high } \\
\text { demand }\end{array}$ & BO \\
\hline $\begin{array}{l}\text { AHU cooling digital } \\
\text { valve control (DVC) }\end{array}$ & $\begin{array}{l}\text { Proportional control valve which controls the flow of } \\
\text { the chilled water in the cooling coils }\end{array}$ & AO \\
\hline AHU heating DVC & $\begin{array}{l}\text { Proportional control valve which controls the flow of } \\
\text { the hot water in the heating coils }\end{array}$ & AO \\
\hline $\begin{array}{l}\text { AHU glycol cooling } \\
\text { DVC }\end{array}$ & $\begin{array}{l}\text { Proportional control valve which controls the flow of } \\
\text { the 50/50 gylcol/water solution (by volume) in the } \\
\text { second set of cooling coils }\end{array}$ & AO \\
\hline AHU fan & $\begin{array}{l}\text { Controls the fan speed to maintain constant supply air } \\
\text { volumetric flowrate }\end{array}$ & AO \\
\hline AHU humidifier & Used to humidify the supply air & BO \\
\hline Recirculation pump & $\begin{array}{l}\text { Recirculates the hot water from the exit of the HPWH } \\
\text { back into the inlet of the water storage tank }\end{array}$ & BO \\
\hline $\begin{array}{l}\text { Recirculation pump } \\
\text { solenoid }\end{array}$ & Acts as a flow switch for the recirculation loop & BO \\
\hline Water draw system & Acts as a flow switch for the recirculation loop & BO \\
\hline Pre-heat tank & $\begin{array}{l}\text { Haintains a constant mains water temperature to the } \\
\text { HPW }\end{array}$ & BO \\
\hline
\end{tabular}




\section{Chapter: System Modelling}

A computer model was created in the TRNSYS environment to study the effect of a HPWH on the space heating and cooling systems of a home. The TRNSYS software used in this study is capable of modelling complex, transient energy systems, and developing custom computer model using FORTRAN language compliers and built-in functions in the TRNSYS kernel. TRNSYS is made up of multiple libraries; each library is made up of components, such as physical components, control devices, utility component and weather files, called "Types". The Types are modelled such that the outputs are mathematical functions of the input and parameters of the Type. Finally, the TRNSYS software uses a simulation studio, which is a graphical interface where TRNSYS models are built by connecting components through links that transfer data between Types, where the output of one Type is the input to the next Type.

The TRNSYS software solves the computer model iteratively until convergence is achieved for a user-defined time step and simulation length. This process is initiated after TRNSYS creates an input file, called a "deck" file, which represents the components and their connections and initial conditions. Results are presented by TRNSYS both graphically and through an output file. This chapter provides a detailed description of the custom built TRNSYS Type for the HPWH to accurately predict the output of the warp-around coil (condenser) based on the performance of the unit and the level of stratification. Furthermore, a house model was developed and used to run an annual simulation and is described in detail. 


\subsection{Heat Pump Water Heater Type}

Type 938, from the TRNSYS Thermal Storage TESS library [51], is a single air-to-water heat pump water heater subroutine, which requires a performance map to simulate the performance of the HPWH. The HPWH performance map is presented in Appendix A. This Type was not suitable for our study as the condenser is modelled as a counter flow heat exchanger, which does not reflect the wrap-around coil technology used in the experimental apparatus. Also, the wrap-around coil within the laboratory system circulates the refrigerant fluid in the coil while the water is stationary in the tank, unlike Type 938. Furthermore, Type 938 does not consider the different operational modes of the HPWH commercial unit [51]. Within the Thermal Storage TESS library, a liquid storage tank with a wrap-around coil (Type 1237) also exists. The limitation of this Type consists of the fact that the wrap-around coil does not allow for phase change materials such as the refrigerant R134 used in HPWH units. Therefore, a new HPWH Type was developed using an object-oriented FORTRAN Compiler. The HPWH Type uses a modified code for Type 938 in combination with Type 534 which is a subroutine which represents a cylindrical storage tank.

\subsubsection{Methodology}

The new Type is a stand-alone component, built using the Ivf11x TRNSYS compiler, for the GeoSpring hybrid heat pump water heater. The new Type uses a performance map and experimentally derived relationships to model the heat rejected to the tank along the length of the wrap-around coil. The computer model has five main parts: interpolation, psychrometric equations, heat delivery, governing equations, and nodal heat input. 


\subsubsection{Interpolation}

The built-in TRNSYS function "InterpolateData" was used to read the experimentally developed performance map for the physical unit. The interpolation function assigns a logic unit to the performance map text file. The function then defines the number of independent and dependent variables for the file. The dependent variables are: the supplied air temperature and humidity, and storage tank water temperature. The independent variables are: the total and sensible cooling capacity, the compressor power, and the heat delivery to the water storage tank. Finally, the unit performs a three-dimensional linear interpolation for the four dependent variables. The interpolation function is not capable of extrapolating beyond the range of the provided data. The function will read the value for the highest independent variable if the data provided is outside of the range of the map [9]. Therefore, it was important to cover the whole operational range of the physical unit for the performance map to avoid code limitation. Equation (4-1) shows the code for the InterpolateData function.

$$
\text { InterpolateData }(L U, n I N D, n X, n Y, X, Y)
$$

where $L U$ is the FORTRAN logic unit number to access the performance map, $n I N D$ is the number of independent variables, $n X$ is the number of values for each independent variable, $n Y$ is the number of values for each dependent variable, $X$ is the independent variable input, and $Y$ is the dependent variable output.

Since the water temperature of the storage tank has the most variation, the performance map file is organized such that the water temperature is interpolated first, followed by the air temperature and finally the relative humidity of the supplied air. This will reduce the computational power requirement of the computer model, allowing it to converge at a better rate which is vital for long annual simulations. 
It must be noted that the performance of the unit is also dependent on other variables such as the specific heat capacity of air, the volume of the water storage tank, the length of the wrap-around coil, and the size of the evaporator. These independent variables were assumed to be constant and were not included in the performance map of the unit; however, these independent variables affect the values of the aforementioned dependent variables.

\subsubsection{Psychrometrics}

The TRNSYS Type uses psychrometrics to determine the air properties of the supply and exhaust air, by using the air temperature, relative humidity and pressure. This is required in order to calculate the mass flowrate of the supply air based on the air density and the volumetric flowrate of air supplied by the unit's fan. The mass flowrate is calculated using Equation (4-2).

$$
\dot{m}=\dot{V} \rho
$$

where $\dot{m}$ is the mass flowrate in $\mathrm{kg} / \mathrm{s}, \dot{V}$ is the volumetric flowrate in $\mathrm{m}^{3} / \mathrm{s}$, and $\rho$ is the density of air in $\mathrm{kg} / \mathrm{m}^{3}$.

Once the performance map is interpolated and the values for the total and sensible cooling capacity of the evaporator are obtained, the HPWH Type will calculate the exhaust air temperature and the exhaust enthalpy. This is done under the assumption that there is no pressure difference between the inlet and exhaust of the HPWH. The equations used to calculate the air temperature and specific heat are shown in Equations (4-3) and (4-4), respectively. The specific heat correlation is adapted from ASHRAE standards 2001 [52].

$$
\begin{gathered}
Q_{\text {Sens }}=\dot{m} C_{\mathrm{p}}\left(T_{\text {in }}-T_{\text {out }}\right) \\
C_{\mathrm{p}}=0.81764+0.0017855 T-5.6517 \times 10^{-6} T^{2}+6.0054 \times 10^{-9} T^{3}
\end{gathered}
$$


where $Q_{\text {sens }}$ is the sensible cooling capacity in $\mathrm{kJ} / \mathrm{h}, C_{\mathrm{p}}$ is the specific heat of air in $\mathrm{kJ} / \mathrm{kg} \mathrm{K}, T_{\mathrm{in}}$ is the inlet air temperature in $\mathrm{K}$, and $T_{\text {out }}$ is the exhaust air temperature in $\mathrm{K}$.

The enthalpy of the exhaust air is calculated using Equation (4-5).

$$
Q_{\text {Total }}=\dot{m}\left(h_{\text {in }}-h_{\text {out }}\right)
$$

where $Q_{\text {Total }}$ is the total cooling capacity in $\mathrm{kJ} / \mathrm{hr}, \mathrm{h}_{\text {in }}$ is the inlet air enthalpy in $\mathrm{kJ} / \mathrm{kg}$, and $h_{\text {out }}$ is the exhaust air enthalpy in $\mathrm{kJ} / \mathrm{kg}$.

Using the air temperature, enthalpy and pressure, the psychrometric equations and the ideal gas law are used to calculate the exhaust relative humidity and humidity ratio. The psychrometric equations used in the new HPWH TRNSYS Type are listed in Equations (4-6) through (4-12) based on ASHRAE standards [52].

$$
\begin{gathered}
v=\frac{0.2871(T+273.15)(1+1.6078 W)}{p} \\
\phi=\frac{\mu}{1-(1-\mu)\left(\frac{p_{\mathrm{ws}}}{p}\right)} \\
\mu=\frac{W}{W_{\mathrm{s}}} \\
W_{\mathrm{s}}=0.62198 \frac{p_{\mathrm{ws}}}{p-p_{\mathrm{ws}}} \\
\rho=(1 / v)(1+W) \\
W=0.6198 \frac{p_{\mathrm{w}}}{p-p_{\mathrm{w}}} \\
h=1.006 T+W(2501+1.805 T)
\end{gathered}
$$

where $\phi$ is the relative humidity, $v$ is the specific volume of dry air in $\mathrm{m}^{3} / \mathrm{kg}, \rho$ is the density of air in $\mathrm{kg} / \mathrm{m}^{3}, p$ is the atmospheric pressure in $\mathrm{kPa}, p_{\mathrm{w}}$ is the partial pressure of water vapor in $\mathrm{kPa}, W$ is the humidity ratio in $\mathrm{kg}_{\text {water }} / \mathrm{kg}_{\text {dryair }}, W_{\mathrm{s}}$ is the saturation humidity ratio, and $\mu$ is the 
degree of saturation. The psychrometric equations in the TRNSYS Type along with the performance map values for the total and sensible cooling values, will predict the exhaust air properties that will offset the space heating and cooling.

\subsubsection{Heat delivery}

The heat delivery to the water is determined by the model based on hard coded experimentally defined ratios of heat delivery per node of the total heat delivery to the tank. Due to the lack of access to the wrap-around coil in the experimental set-up, the heat delivery values were calculated according to the change in water temperature over a certain period of time. The heat delivery to the water was calculated using Equation (4-13).

$$
\begin{gathered}
\Delta E=E_{\mathrm{t}}-E_{\mathrm{t}-1} \\
H R=\frac{\Delta E}{t}=\frac{\left[\left[(V o l) \rho\left(T_{\mathrm{t}}\right) C_{\mathrm{p}}\left(T_{\mathrm{t}}-T_{\mathrm{ref}}\right)\right]-\left[(V o l) \rho\left(T_{\mathrm{t}-1}\right) C_{\mathrm{p}}\left(T_{\mathrm{t}-1}-T_{\mathrm{ref}}\right)\right]\right]}{t}
\end{gathered}
$$

where $\mathrm{Vol}$ is the volume of a node in $\mathrm{m}^{3}, t$ is the time-step to which the temperature of a node is monitored at in seconds, $T_{\mathrm{t}}$ is the temperature of the node at the current time-step in ${ }^{\circ} \mathrm{C}, T_{\mathrm{t}-1}$ is the temperature of the node at the previous time-step in ${ }^{\circ} \mathrm{C}, E$ is the energy stored in a water node at a specific time-step in $\mathrm{kJ}$, and $H R$ is the heat delivery to the water node in $\mathrm{kJ} / \mathrm{s}$.

The density of the water was determined to be a function of the water temperature. The correlation between the water temperature and the density is shown in Equation (4-14) [49].

$$
\rho=1.68 \times 10^{-5} T^{3}-0.0061 T^{2}+0.022 T+1000
$$

Furthermore, in order to understand the breakdown or distribution of the heat delivery values per node, the length of the wrap-around coil covering the water storage tank was required. However, due to the lack of access to the wrap-around coil, the length of the tank had to be experimentally determined. A series of stratification tests were conducted, such that the tank was stratified starting at the bottom node while keeping the rest of the nodes at the same temperature. 
Using this method, the heat delivered to the tank was monitored. The results of the stratification test will be discussed in Chapter 5. It was found that the wrap-around coil covers the tank starting at Node 5 from the top all the way to the bottom of the tank at Node 10 . The procedure for the stratification test is represented using Figure 4-1.
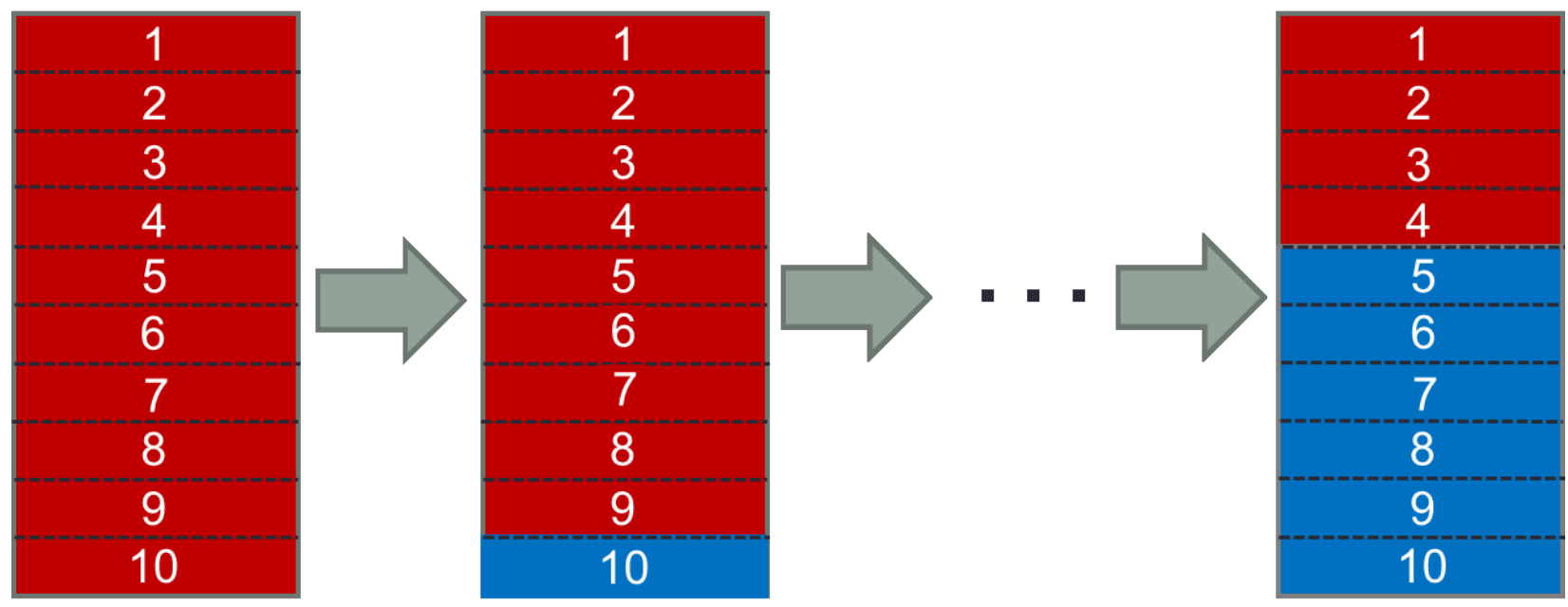

Figure 4-1: Stratification test conducted to determine the length of the wrap-around coil

It was found that heat delivery to the tank breaks down evenly over the tank nodes, either through direct heat input from the wrap-around coil for nodes five through ten or through heat diffusion for the nodes, mainly nodes one through four. The model determines the level of stratification between the nodes and accordingly determines the percent of heat transfer to each node. The Type will start by checking if the water storage tank is operating at the minimum level of stratification for the tank due to the wrap-around coil, then the heat transfer is divided equally between the nodes. However, if the tank is stratified beyond the minimum level of stratification (due to a water draw for example), the tank will divide the heat transfer value from the performance map over the nodes covered by the wrap-around coil until node five reaches the temperature of the node above (node 4), then the heat transfer will be divided equally over nodes four through ten. This process is repeated until node 5 reaches the temperature of node 1 , where 
the heat transfer will be divided equally over the entire number of nodes in the storage tank or the set-point of the water temperature has been achieved. The process is done in reverse if the tank temperature is uniform or below the minimum level of stratification due to the wrap-around coil, where the heat transfer value is divided equally over nodes one through five until the temperature between node five and node six reaches the required stratification level. The process is then repeated until the minimum level of stratification between the nodes is reached of the set-point of the water temperature is achieved. The process of breaking down the total heat delivery, provided by the performance at certain operating conditions, over the tank nodes is laid out in the flowchart shown in Figure 4-2.

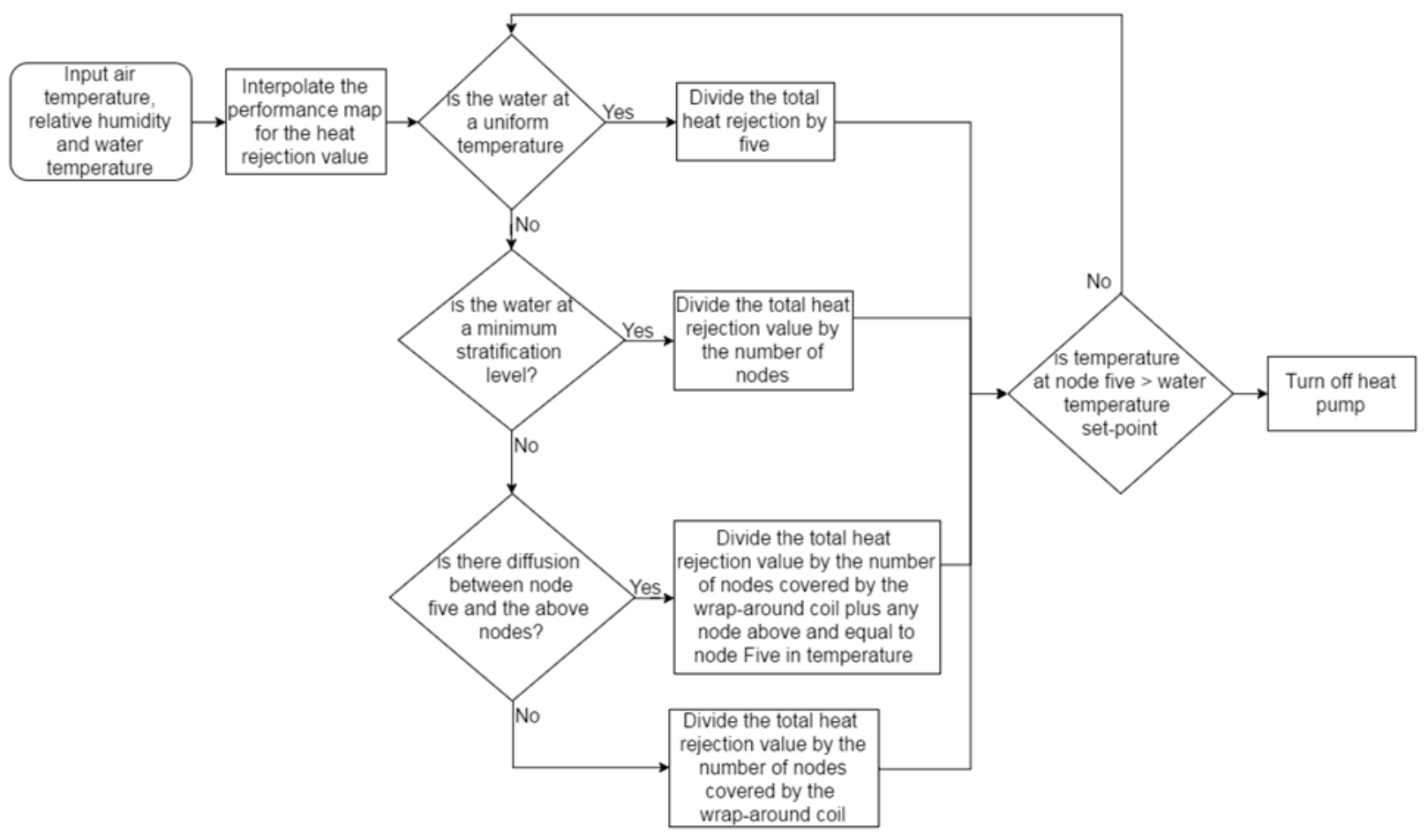

Figure 4-2: Heat delivery per node breakdown logic

The heat delivery values produced by the HPWH Type are used to calculate the change in the water temperature. Although the commercial HPWH unit is a stand-alone unit with a heat pump and storage tank, the new TRNSYS Type, Type 240, for the HPWH excluded the storage 
tank from the code and instead used a built-in component in the TRNSYS software for the storage tank. Type 534 was used for the water storage tank, and the heat delivery to the tank was introduced through auxiliary heat input for each node. This practice was valid since the heat delivery values were calculated based on the energy change in the water node from the temperature change over a period of time. Type 534 was sized to the height of the storage tank portion of the commercial unit, $1.015 \mathrm{~m}$ higher and has a volume of $189.3 \mathrm{~L}$. Furthermore, a cool-down test was conducted on the physical unit to determine the heat loss coefficient per node for the storage tank. The cool-down was initiated by heating the water storage tank to a uniform temperature of $60^{\circ} \mathrm{C}$. The $\mathrm{HPWH}$ unit was turned off and was allowed to lose heat to the surroundings. The temperature of each node was monitored for a 48 hour period, at 3 minute intervals. The temperature reading was used to calculate the heat loss coefficient for each node in the tank. The heat loss coefficient was calculated under the assumption that the tank was a perfect cylinder and all the nodes had the same volume. The heat loss coefficient for the water storage tank was calculated by Smith using Equation (4-15) [53]. The heat loss coefficients per node are listed in Table 4-1.

$$
U_{\mathrm{i}}=\frac{Q_{\text {loss }, \mathrm{i}}}{A_{\mathrm{s}, \mathrm{i}}\left(T_{\mathrm{i}}-T_{\mathrm{env}}\right)}
$$

where $U_{\mathrm{i}}$ is the heat loss coefficient in $\mathrm{W} / \mathrm{m}^{2} \mathrm{~K}, Q_{\text {loss,i }}$ is the heat loss to the environment in $\mathrm{kJ} / \mathrm{s}$, $A_{\mathrm{s}, \mathrm{i}}$ is the surface area of the node in $\mathrm{m}^{2}, T_{\mathrm{i}}$ and $T_{\mathrm{env}}$ are the temperatures of the measured node and environment, respectively, in ${ }^{\circ} \mathrm{C}$. 
Table 4-1: Loss coefficient to the environment per node [53]

\begin{tabular}{|c|c|}
\hline Node \# & Heat Loss Coefficient $\left(\mathrm{W} / \mathrm{m}^{2} \mathrm{~K}\right)$ \\
\hline Node 1 & 0.956569 \\
\hline Node 2 & 0.95919 \\
\hline Node 3 & 0.957596 \\
\hline Node 4 & 0.957691 \\
\hline Node 5 & 0.961579 \\
\hline Node 6 & 0.963551 \\
\hline Node 7 & 0.989515 \\
\hline Node 8 & 1.092323 \\
\hline Node 9 & 1.277035 \\
\hline Node 10 & 2.432742 \\
\hline
\end{tabular}

The storage tank Type was divided into 30 nodes. It was necessary to use a high number of nodes in order to accurately predict the water temperature change in the computer model. Therefore, for each experimental 'node', which was based on the location of the thermocouples in the tank, the modelled water storage tank used three nodes. Although a higher number of nodes would have produced a better prediction capability for the computer model, due to the high computational power required by the HPWH model, the storage tank was kept at 30 nodes. Type 534 computed the temperature of each water node by solving a first-order linear differential equation. The differential equations used in the computer code were introduced through a subroutine and have the form shown in Equation (4-16).

$$
\frac{d T}{d t}=a T+b
$$

where a and $b$ are coefficients which are dependent on the mass flow rate and heat capacity for each node.

Furthermore, the energy balance for the ith node is shown in Equation (4-17) and graphically in Figure 4-3. 


$$
\begin{gathered}
M_{\mathrm{i}} c_{\mathrm{p}} \frac{d T_{\mathrm{i}}}{d t}=\frac{(k+\Delta k) A_{\mathrm{s}, \mathrm{i}}}{\Delta x_{\mathrm{i}+1 \rightarrow i}}\left(T_{\mathrm{i}+1}-T_{\mathrm{i}}\right)+\frac{(k+\Delta k) A_{\mathrm{c}, \mathrm{i}}}{\Delta x_{\mathrm{i}-1 \rightarrow i}}\left(T_{\mathrm{i}-1}-T_{\mathrm{i}}\right)+U_{\mathrm{i}} A_{\mathrm{s}}\left(T_{\mathrm{env}}-T_{\mathrm{i}}\right) \\
+\dot{m}_{\text {down }} c_{\mathrm{p}} T_{\mathrm{i}-1}-\dot{m}_{\mathrm{up}} c_{\mathrm{p}} T_{\mathrm{i}+1}+\dot{m}_{\text {inlet }} c_{\mathrm{p}} T_{\text {inlet }}-\dot{m}_{\text {outlet }} c_{\mathrm{p}} T_{\text {outlet }}+\dot{Q}_{\mathrm{aux}}
\end{gathered}
$$

where $M_{\mathrm{i}}$ is the mass of the node in $\mathrm{kg}, k$ and $\Delta k$ are the tank fluid thermal conductivity and de-stratification conductivity in $\mathrm{W} / \mathrm{mK}, \Delta x_{\mathrm{i}+1 \rightarrow i}$ and $\Delta x_{\mathrm{i}-1 \rightarrow i}$ are the center-to-center distance between a node and node directly above and below in $\mathrm{m}, A_{\mathrm{s}, \mathrm{i}}$ and $A_{\mathrm{c}, \mathrm{i}}$ are the surface and the cross-sectional areas of a node in $\mathrm{m}^{2}$, respectively, $U_{\mathrm{i}}$ is the heat loss coefficient per unit area in $\mathrm{kJ} / \mathrm{h} \cdot \mathrm{m}^{2} \mathrm{~K}, \dot{m}_{\text {up }}$ and $\dot{m}_{\text {down }}$ are the mass flow rates circulating the tank in $\mathrm{kg} / \mathrm{h}, \dot{m}_{\text {inlet }}$ and $\dot{m}_{\text {outlet }}$ are the mass flow rates for the inlet and outlet in $\mathrm{kg} / \mathrm{h}, \dot{Q}_{\text {aux }}$ is the auxiliary heat in $\mathrm{kJ} / \mathrm{h}$, $T_{\mathrm{i}}, T_{\mathrm{i}+1}, T_{\mathrm{i}-1}, T_{\mathrm{inlet}}, T_{\text {outlet }}$, and $T_{\mathrm{env}}$ are the temperature for a specific node, the temperature for the node above, the temperature for the node below, the inlet and outlet temperature, and the environment temperature in ${ }^{\circ} \mathrm{C}$, respectively. 


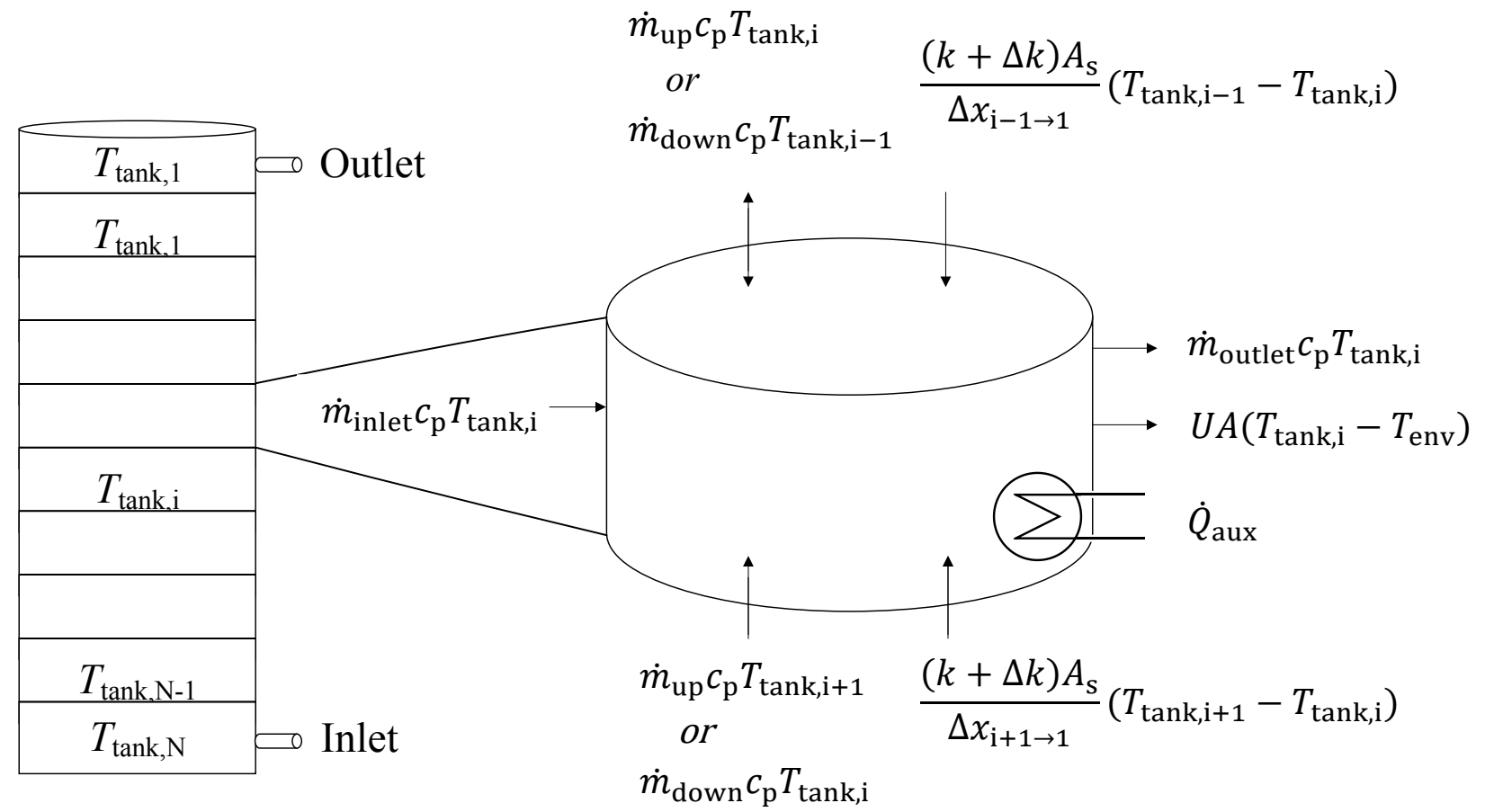

Figure 4-3: Schematic for a storage tank model and energy balance on a node (adopted from [54])

The HPWH Type will calculate the COP of the unit based on the total heat delivery value obtained from the performance map and the compressor power, plus any other added power consumption, such as the power consumed by the unit's controller and the fan. The COP equation is shown in Equation (4-18).

$$
C O P=\frac{H R_{\text {total }}}{P_{\text {fan }}+P_{\text {compressor }}+P_{\text {controls }}}
$$

where $H R_{\text {total }}$ is the total heat delivery to the storage tank in $\mathrm{kJ} / \mathrm{h}, P_{\text {fan }}, \mathrm{P}_{\text {compressor }}$, and $P_{\text {controls }}$ are the fan, compressor and controls power consumption, respectively. The FORTRAN code for the HPWH Type is presented in Appendix B. 


\subsubsection{System Overview}

For validation purposes, the experimental apparatus was modelled in TRNSYS. The TRNSYS model is shown in Figure 4-4. The activation of the HPWH Type (Type 240) was achieved using a control signal generated by Type 1502 Aquastat. The Aquastat uses the temperature of the storage tank at node 15 (node 5 experimentally), which is approximately where the thermostat is in the physical model, and a temperature dead band to determine the operation time of the unit. The Aquastat was used as a two-stage controller in order to accurately represent the unit in-situ. The first stage was set such that the signal is activated if there was no water draw and it was set to a $10^{\circ} \mathrm{C}$ dead band, meaning the $\mathrm{HPWH}$ is activated if the temperature of the unit at node 15 off by $5^{\circ} \mathrm{C}$ from the set-point. The second stage was set such that the signal is activated if there is a water draw activity taking place and it was set to $2^{\circ} \mathrm{C}$ dead band, therefore, the HPWH is activated if the temperature of the unit at node 15 is off by $1^{\circ} \mathrm{C}$ from the set-point.

A mains water diverter (Type 11) was used at the inlet of the storage tank to determine the amount of water used to deliver DHW at $55^{\circ} \mathrm{C}$ by using a tempering valve (Type 11) at the outlet of the storage tank. The tempering valve operates by using steady-state, steady flow assumptions in order to perform an enthalpy balance on the merging fluids [37]. Finally, the CSA-F379.1 draws shown in Table 4-2 were introduced to the model through a forcing function (Type14). The forcing function was used to determine the simulation time step needed to reach the desired draw at a specific time, based on a specified flowrate. The testing flowrate was set at $5 \mathrm{~L} / \mathrm{min}$; this was shown to be the average flowrate for residential equipment flowrate [55]; therefore, a maximum time step of $60 \mathrm{~s}$ was used to achieve the best accuracy. 
Table 4-2: CSA-F379.1 DHW draws schedule (for different level of occupancy) ( [56], modified)

\begin{tabular}{|c|c|c|c|}
\hline \multirow[b]{2}{*}{ Hour } & \multicolumn{3}{|c|}{ Draw Volume (L) } \\
\hline & Schedule A & Schedule B & Schedule C \\
\hline $1-6$ & 0 & 0 & 0 \\
\hline 7 & 5 & 10 & 10 \\
\hline 8 & 25 & 25 & 25 \\
\hline 9 & 0 & 5 & 25 \\
\hline 10 & 45 & 45 & 45 \\
\hline 11 & 0 & 5 & 25 \\
\hline 12 & 5 & 10 & 10 \\
\hline 13 & 0 & 5 & 5 \\
\hline 14 & 0 & 0 & 0 \\
\hline 15 & 0 & 0 & 0 \\
\hline 16 & 0 & 10 & 15 \\
\hline 17 & 5 & 25 & 25 \\
\hline 18 & 10 & 45 & 45 \\
\hline 19 & 30 & 25 & 25 \\
\hline 20 & 20 & 10 & 30 \\
\hline 21 & 0 & 5 & 10 \\
\hline 22 & 0 & 0 & 5 \\
\hline $23-24$ & 0 & 0 & 0 \\
\hline Total & 150 & 225 & 300 \\
\hline
\end{tabular}




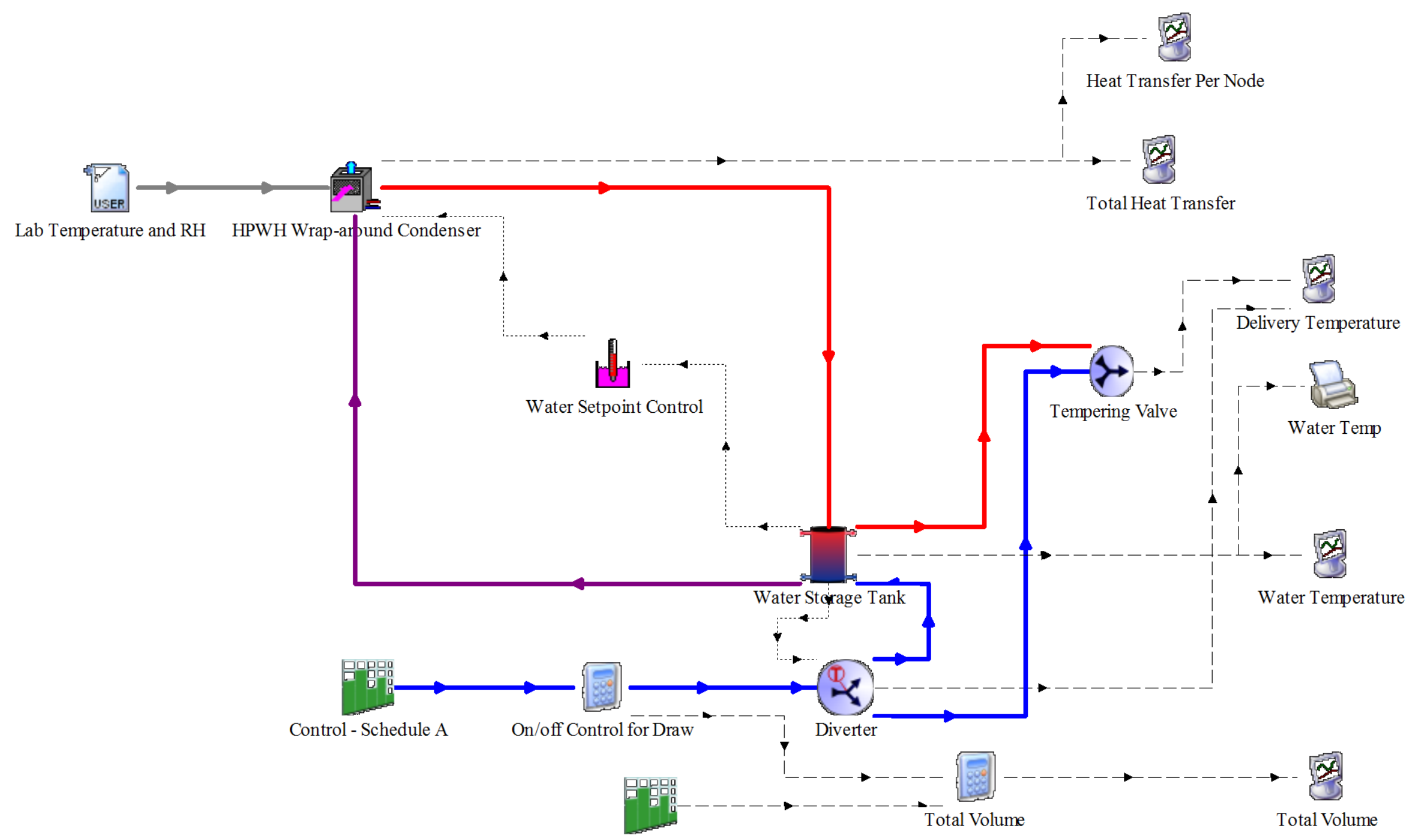

Water Draw - Schedule A

Figure 4-4: TRNSYS model for the HPWH experimental apparatus validation 
In addition to the HPWH and the water draw system, the TRNSYS computer model included an external data reader, printers, and plotters. The external file reader was used to introduce lab conditions (temperature and relative humidity) used for validation tests. Finally, the printers (Type 25) were used to create an Excel file for the output data, in order to be used for post-processing, while the plotters (Type 65) were used to visualize the result of the simulations.

\subsection{House Model}

As discussed in Chapter 1, the main purpose of this thesis was to understand the effect of the HPWH on the space heating and cooling systems of a home, and how this compares to the currently utilized technology for residential water heating. In order to accomplish this, a multi-zone building (Type 56) was developed using TRNBuild [13]. The building size and specifications used for this model were based on those provided by EnerGuide building standards [57]. The house Type was built such that one third of the total wall area was covered with windows. The windows had an overall heat transfer of $1.26 \mathrm{~W} / \mathrm{m}^{2} \mathrm{~K}$, and the solar heat gain was set to 0.624 . The house Type was built such that it consisted of four zones: the main floor where the thermostat to control the house temperature was placed; the basement where the HPWH or alternative water heating devices were installed; finally, the second floor and the attic. The floor area for each level was set to $110 \mathrm{~m}^{2}$ with a total volume of $835 \mathrm{~m}^{3}$ for the house. The thermal resistance used in the house model are summarized in Table 4-3. The infiltration was set to $0.05 \mathrm{ACH}$ [58]. The energy consumed by lights was introduced to the house model as a constant value of $24 \mathrm{kWh}$ per day added to the total energy consumption of the house. The value for the light loads energy consumption was based on specifications given by EnerGuide [57]. The house model was further split into two zones (east and west) but heating and cooling of the zones occurred simultaneously. The weather file used for the simulations was from the Typical 
Meteorological Year 2 (TMY2) for the selected city. The reader may refer to the work provided by Baldwin for further details on the house Type's assumptions [58].

Table 4-3: Thermal resistances used in TRNSYS house model [58]

\begin{tabular}{l|c}
\hline Parameter & Value $\left(\mathrm{m}^{2} \mathrm{~K} / \mathrm{W}\right)$ \\
\hline Above Grade Walls & 4.5 \\
\hline Attic & 11.5 \\
\hline Below Grade Walls & 2.7 \\
\hline Under Slab & 1.9 \\
\hline
\end{tabular}

To quantify the effect of the HPWH on the space heating and cooling systems, three space heating systems were modelled for the house Type. The modelled space heating systems were a furnace, baseboard electric heating and a heat pump. The furnace was modelled as a typical furnace unit at $17.6 \mathrm{~kW}$ heating capacity with an energy factor of 0.9 . The Electric baseboard heater was sized to a rated capacity of $10 \mathrm{~kW}$. Finally, the space heating heat pump used a performance map generated by Baldwin [36]. The heat pump was also used for space cooling for all three houses. It must be noted that the space heating and cooling heat pump is different than the HPWH unit used for DHW.

The HPWH was compared to two other common water heating technologies, EWH and natural gas boiler. The EWH was modelled using Type 1226-Elec, based on the electric-only mode where the $189 \mathrm{~L}$ uses two electric heating elements placed at Nodes 5 and 9. These two heating elements were modelled with a heating capacity of $4.5 \mathrm{~kW}$ each. The heating elements would not trigger simultaneously; that is, the upper heating elements would turn on if the temperature of Node 5 fell $5^{\circ} \mathrm{C}$ below the set-point. The lower heating element would only trigger if the temperature at Node 5 falls $15^{\circ} \mathrm{C}$ below the set-point. The lower element is simply a 
back-up in order to maintain high demand. The natural gas boiler was modelled using Type 1226-Gas with a heating capacity of $11.7 \mathrm{~kW}$ and a thermal efficiency of 0.67 for a typical natural gas boiler unit. The water storage tank Type 534 was modified to include a flue baffle to transfer the gases generated by the burner at the bottom of the tank throughout the length of the tank.

Heating was achieved using an air based system, where $20 \%$ of the distributed air was supplied to the basement, $35 \%$ to the main floor and $45 \%$ the 2 nd floor. The distribution was divided as such in order to allow the increased heating and cooling demands of the 2 nd floor to be met. The increased loads of the second floor were generated due to heat loss through the ceiling into the attic, which was maintained at a lower temperature than the house [58]. The space heating and cooling Types in TRNSYS used a bypass model, meaning that the air fraction bypassing the coils is user specified and it was set to 0.1 . In other words, $10 \%$ of the flow is not affected by the coils [25]. The space heating and cooling units were controlled using the Type 108 thermostat, which monitors the temperature of the main floor. The thermostat was set to $23^{\circ} \mathrm{C}$ with a dead-band of $1{ }^{\circ} \mathrm{C}$ for the summer, while the winter set-point was set to $20^{\circ} \mathrm{C}$ with a dead-band of $1{ }^{\circ} \mathrm{C}$. These set-points were used to reflect the comfort zone requirements for indoor air temperature according to ASHRAE standard 55 [59]. The air is conditioned and delivered to the house through an air handler unit (Type 52) with a fan rated flowrate of 1000 $\mathrm{kg} / \mathrm{h}$, and a heating coil (Type 753). Type 753 heats the supplied air using hot water produced using a liquid to liquid heat pump (Type 927). Similarly, the cooling of air is achieved through a cooling coil, included in Type 52, where the chilled water is supplied through the heat pump (Type 927), running in cooling mode, where the source is supplied through a dry fluid cooler (Type 511). 
The furnace and baseboard heating systems used in the modelling study had the same layout as the house with the heat pump model shown in Figure 4-5, except for the heating side of the air handling unit. A summary of the house models and cities used in this study is shown in Table 4-4.

Finally, the mains water temperature for the house is calculated using algorithms provided by Burch and Christensen from NREL [60]. The algorithm is shown in Equation (4-19).

$$
T_{\max }=\left(\bar{T}_{\mathrm{amb}}+\Delta T_{\mathrm{offset}}\right)+R\left(\Delta T_{\mathrm{amb}}\right) \sin \left(\frac{360}{365}(\text { day }-15-\text { lag })-90\right)
$$

where $T_{\text {mains }}$ is the mains water temperature in ${ }^{\circ} \mathrm{C}, \bar{T}_{\mathrm{amb}}$ is the annual average ambient temperature, $R$ is the ratio of the ground temperature at which the mains water temperature pipes are installed to the temperature of the surface, and day is the day of the year. The $\Delta T$ offset, R, and lag are shown in Equations (4-20) through (4-22).

$$
\begin{gathered}
\Delta T_{\text {offset }}=3^{\circ} \mathrm{C} \\
R=0.22+0.0056\left(\bar{T}_{\mathrm{amb}}-6.67\right) \\
l a g=1.67-0.56\left(\bar{T}_{\mathrm{amb}}-6.67\right)
\end{gathered}
$$

The reader may refer to the work provided by Berger for validation of the mains water temperature validation [41]. 
Table 4-4: House simulation set-up for different cities

\begin{tabular}{|c|c|c|}
\hline Cities & Space Heating System & Water Heating Systems \\
\hline \multirow{6}{*}{ Toronto } & \multirow{2}{*}{ Heat Pump } & Heat Pump Water Heater \\
\hline & & Electric Water Heater \\
\hline & \multirow{2}{*}{ Electric Baseboard Heater } & Heat Pump Water Heater \\
\hline & & Electric Water Heater \\
\hline & \multirow{2}{*}{ Furnace } & Heat Pump Water Heater \\
\hline & & Boiler \\
\hline \multirow{6}{*}{ Ottawa } & \multirow{2}{*}{ Heat Pump } & Heat Pump Water Heater \\
\hline & & Electric Water Heater \\
\hline & \multirow{2}{*}{ Electric Baseboard Heater } & Heat Pump Water Heater \\
\hline & & Electric Water Heater \\
\hline & \multirow{2}{*}{ Furnace } & Heat Pump Water Heater \\
\hline & & Boiler \\
\hline \multirow{4}{*}{ Montreal } & \multirow{2}{*}{ Heat Pump } & Heat Pump Water Heater \\
\hline & & Electric Water Heater \\
\hline & \multirow{2}{*}{ Electric Baseboard Heater } & Heat Pump Water Heater \\
\hline & & Electric Water Heater \\
\hline \multirow{4}{*}{ Vancouver } & \multirow{2}{*}{ Heat Pump } & Heat Pump Water Heater \\
\hline & & Electric Water Heater \\
\hline & \multirow{2}{*}{ Electric Baseboard Heater } & Heat Pump Water Heater \\
\hline & & Electric Water Heater \\
\hline
\end{tabular}




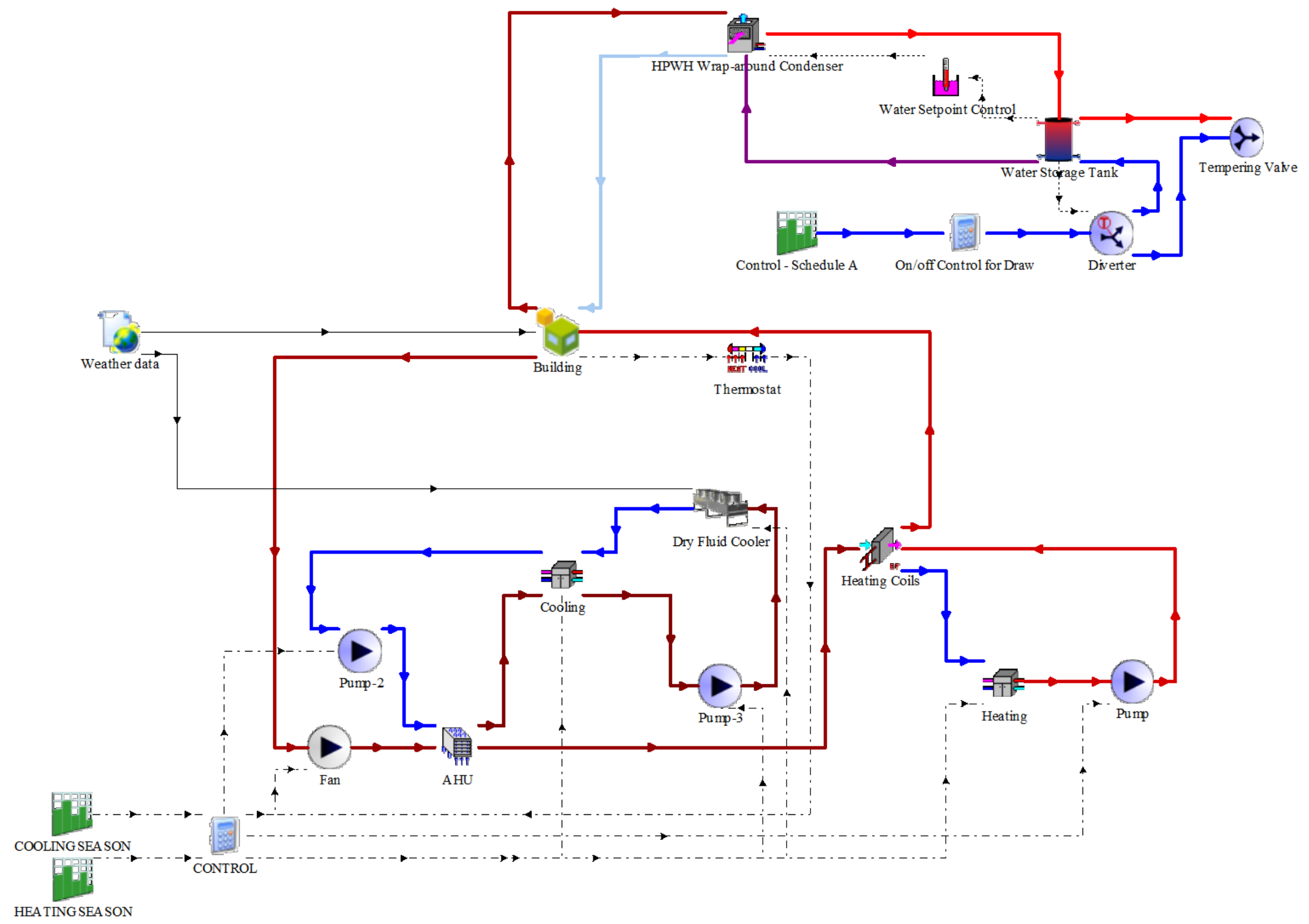

Figure 4-5: TRNSYS model for the HPWH integrated into a house Type 


\subsection{Simulation Control}

The TRNSYS control card was used to specify the time-step for the modelling study. In order to model the HPWH and water draws properly and accurately, the control was set for one minute time-step simulations. The length of the simulation was also set through the control card and varied depending on the length of the test and the season. The length of the simulations is discussed in more detail in Chapter 5. The utility rates for the cities using time-of-use billing were logged based on the time of the day and season using a forcing function (Type 14). Type 14 produces a 1 or 0 signal which is communicated to a calculator that decides whether it is a summer or a winter season, while the time of day and the day of the year is communicated to the calculator through the TMY2 weather file. The convergence tolerance for the simulations was determined by running the simulations for $24 \mathrm{~h}$ and monitoring the results. It was shown that there was no significant change in the results when running the simulations for convergence tolerances of $0.005,0.03$ and 0.08 . Therefore, 0.03 was chosen since it gave the best convergence speed without being close to the higher limit. The convergence criteria used for the current study are listed in Table 4-5.

Table 4-5: TRNSYS simulation convergence criteria

\begin{tabular}{|l|l|}
\hline Parameter & Value \\
\hline Simulation Time-step & 1 minute \\
\hline Max Iteration before 'WARNING' & 5000 \\
\hline Max Iteration before 'ERROR' & 5000 \\
\hline Max Iteration before 'TRACE' & 30 \\
\hline Integration Tolerance & 0.001 \\
\hline Convergence Tolerance & 0.03 \\
\hline
\end{tabular}




\subsection{Summary}

Chapter 4 described how the HPWH Type was created and discussed the interpolation routine required to read the performance map data, the psychrometric equations to calculate the temperature and relative humidity of air, and the heat delivery breakdown approach for the water storage tank. Finally, the house model used for integrating the HPWH with space heating and cooling was discussed, including the different components used and the simulation controls, which were used for the comparison study.

Once the computer model was completely developed, multiple modelling studies were conducted using the HPWH Type. The first was to validate the HPWH Type predictable capability for the performance of the unit in comparison to that of the physical unit. Once validated, a second study was conducted to determine the performance of the HPWH within the house model (when located in the basement) for different locations in Canada on an annual basis. Once the performance was determined, a comparison study was conducted using the house Type with different water heating technologies to determine the cost benefit of HPWH installation and $\mathrm{CO}_{2}$ emission reduction in comparison. The results of the modelling studies are presented and discussed in Chapters 5 and 6. 


\section{Chapter: Results}

This chapter provides the results from a sensitivity analysis involving the independent variables that provided a basis for the commercial unit's performance map development. Furthermore, results from the validation tests are given for different operating conditions and discrepancies between the model and the experimental results are shown. These results were used to justify extending the use of the model to simulate the behavior of the HPWH unit during seasonal simulations. Finally, the coefficient of performance of the HPWH water heater is given for a unit located in a basement during different seasons, and the effect of the unit installation on the space heating and cooling of the residence.

\subsection{Experimental Analysis}

Experimental testing was conducted to study the performance response of the HPWH unit to the change of the independent variables. The effect of the independent variables on the performance was vital for the construction of the performance map. Therefore, the unit was tested under various conditions for each independent variable while holding the other independent variables constant. The analysis was conducted for air temperature at $10^{\circ} \mathrm{C}$ intervals, relative humidity at 10 percent intervals and storage water temperature at $10^{\circ} \mathrm{C}$ intervals. These tests were conducted by initializing the storage tank at a uniform water temperature of $10^{\circ} \mathrm{C}$, which was then charged to $70^{\circ} \mathrm{C}$, covering the entire operational range of the $\mathrm{HPWH}$ unit.

Figure 5-1 shows the relative humidity effect on the total heat delivery to the water for varying water temperature (x-axis) from 20 to $70 \% \mathrm{RH}$ at $20^{\circ} \mathrm{C}$ air temperature. Figure $5-2$ shows the relative humidity effect on the compressor power consumption for varying water temperature. Determining the change in the heat delivery and compressor power consumption is important in order to understand the performance of the unit over the operational range of the 
unit. Contrary to what was initially expected, the heat delivery to the water did not increase at a higher relative humidity. On the other hand, the compressor power was nearly identical for 20 and $30 \% \mathrm{RH}$. However, past $30 \% \mathrm{RH}$, the compressor power increases with the increase in relative humidity.

Similarly, the analysis was conducted on the heat pump performance for a constant humidity and varying air inlet temperature. Figure 5-3 displays the heat delivery results for air temperatures of 10,20 and $30^{\circ} \mathrm{C}$ at $20 \% \mathrm{RH}$. As expected, the temperature increase results in a significant increase in heat delivery to the water which by itself causes an increase in the unit's COP based on Equation (4-18). Figure 5-4 displays the temperature effect on the compressor power consumption. Although there was a significant increase in heat delivery between 10 and $20^{\circ} \mathrm{C}$, the compressor power does not face a larger increase.

Finally, the performance of the unit was investigated at different air supply flowrates by adjusting the speed for the AHU. The unit was tested at air supply flowrates of 94, 142, 189 and $236 \mathrm{~L} / \mathrm{s}$ while holding temperature at $18^{\circ} \mathrm{C}$ and $20 \% \mathrm{RH}$. Although the physical unit was not capable of adjusting the fan speed, this test was conducted to include all the variables affecting the performance of the unit for future optimization of the unit. The result of the flowrate test on the heat delivery to the storage tank water, shown in Figure 5-5, concluded that there is a slight increase in the heat delivery value since a higher heat transfer is occurring at the evaporator. Accordingly, the higher air supply flowrate resulted in higher power consumption which is shown in Figure 5-6. It should be noted that the power reading for Figure 5-6 is the power consumption of the HPWH and not only the compressor, meaning it includes the power of the fan and the controllers. The result of the flowrate test concluded that the minimal added benefit 
to the heat delivery value will be offset by the space heating load of the conditioned space during HPWH operation. Thus, the flowrate of the air was neglected from the performance map.

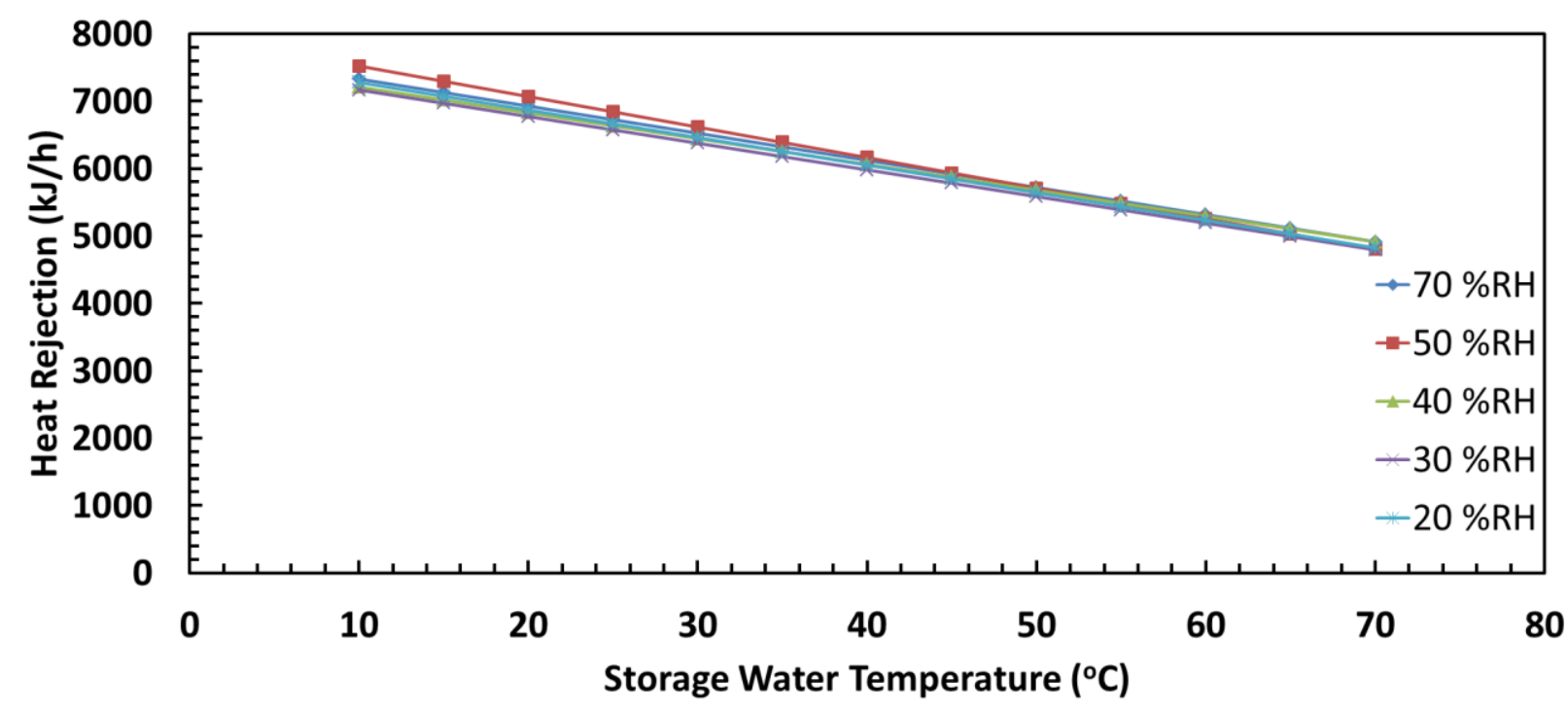

Figure 5-1: Heat delivery to water for a $20^{\circ} \mathrm{C}$ supply air temperature at varying humidities

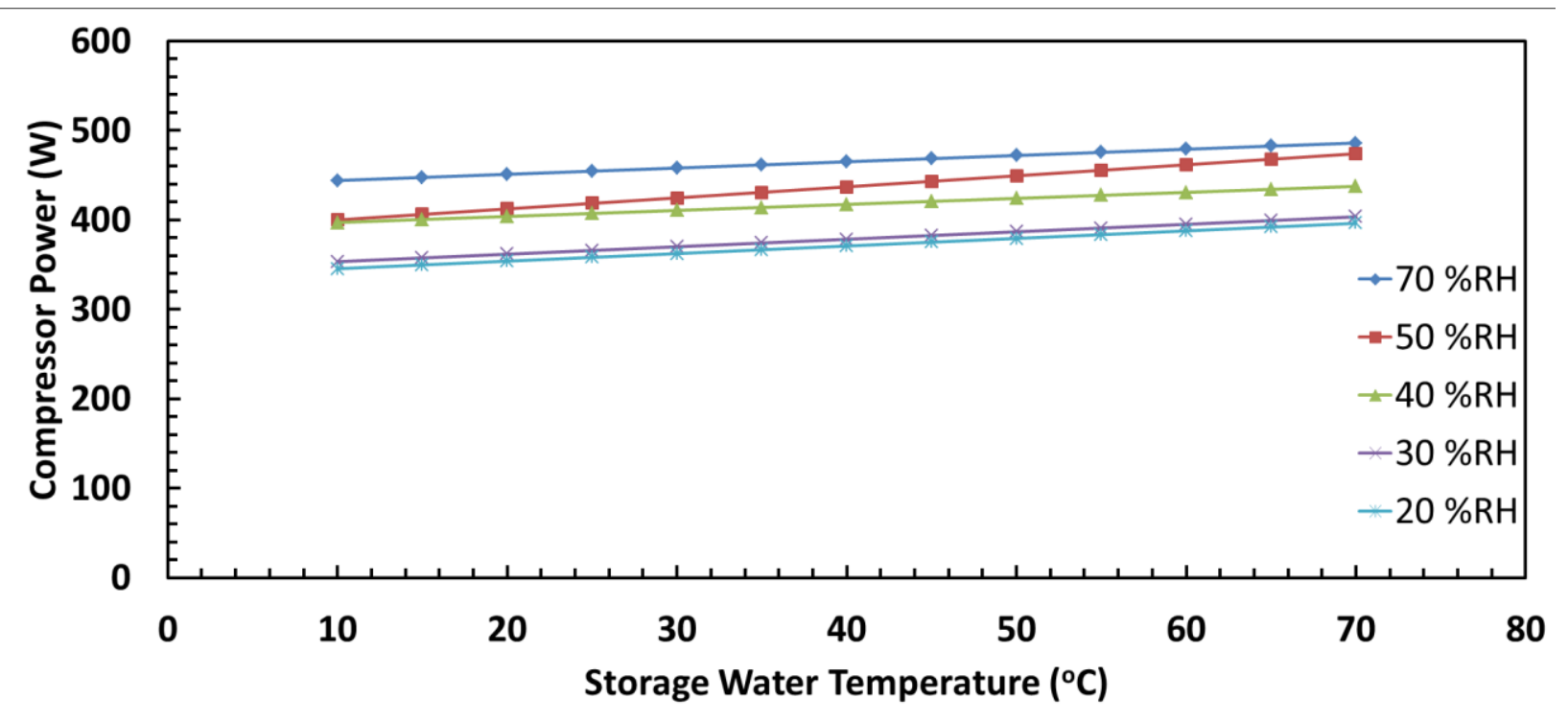

Figure 5-2: Compressor power for a $20^{\circ} \mathrm{C}$ supply air temperature at varying humidities 


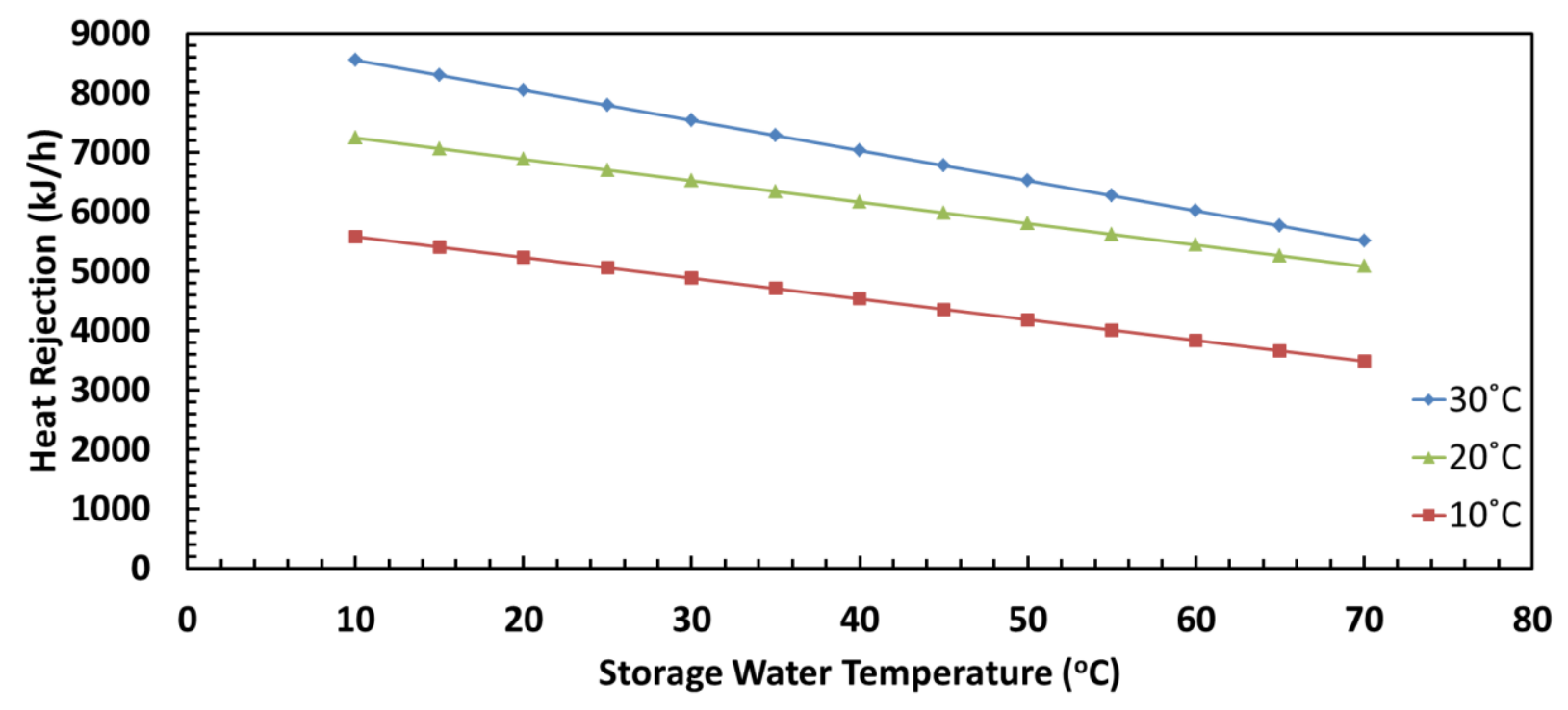

Figure 5-3: Heat delivery to water at a supply air relative humidity of $20 \%$ for varying temperatures

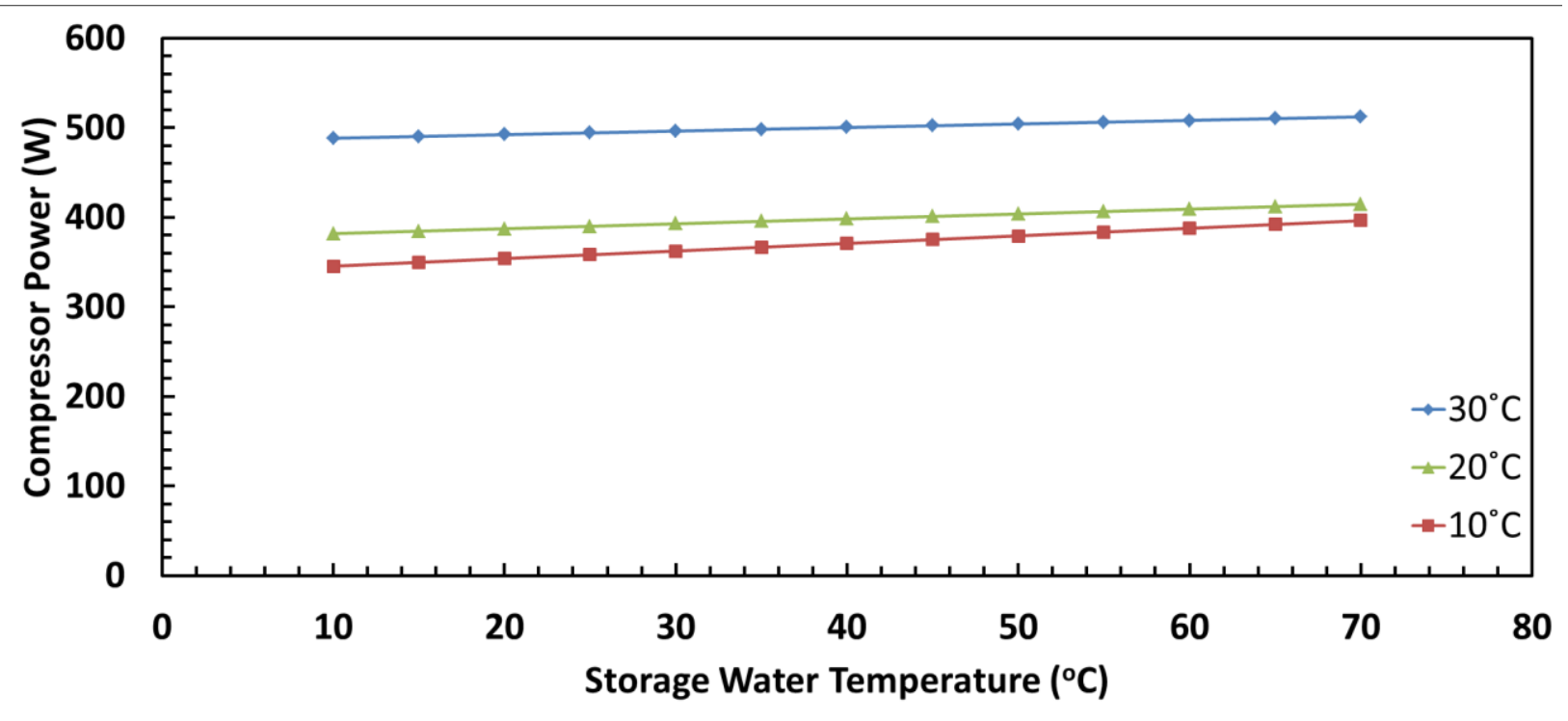

Figure 5-4: Compressor power at a supply air relative humidity of $20 \%$ for varying temperatures 


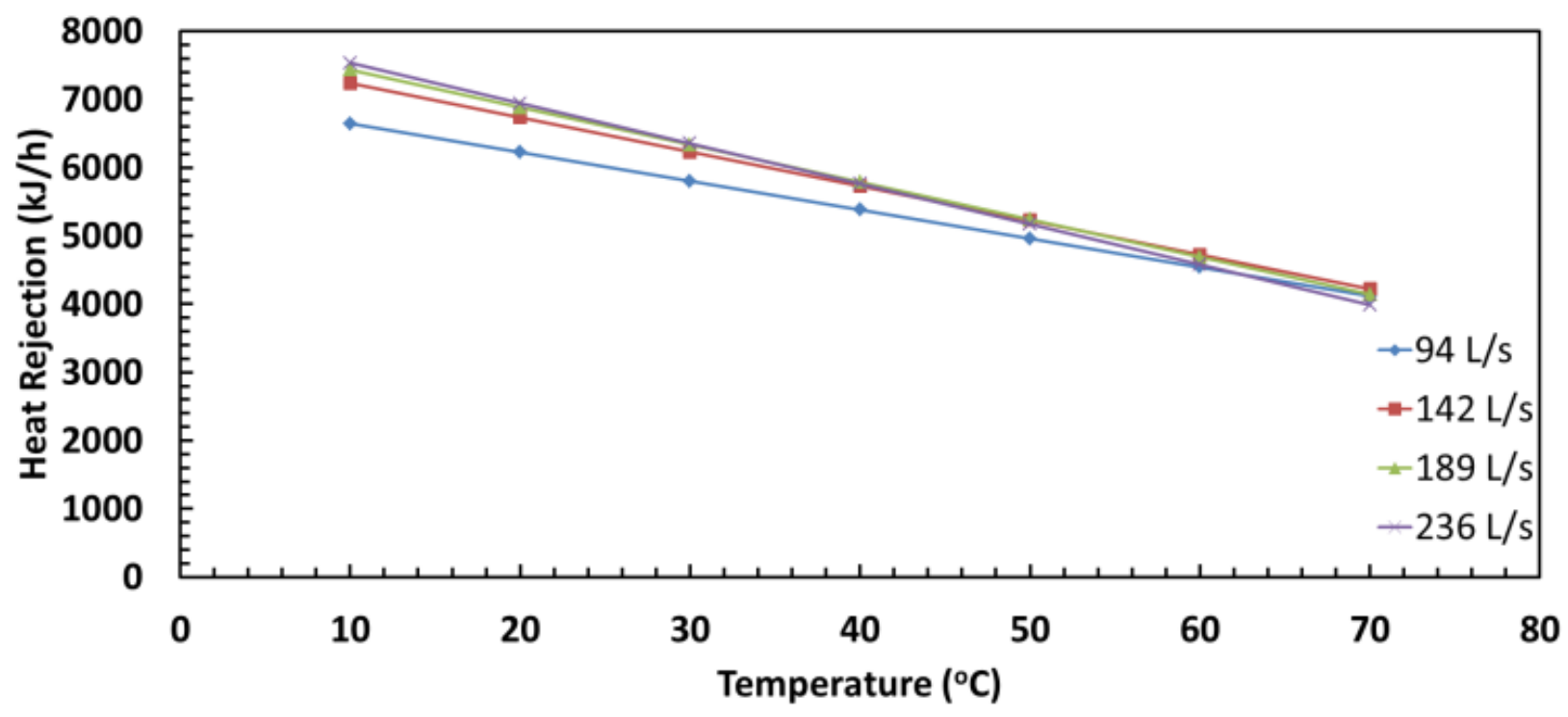

Figure 5-5: Heat delivery to water for an supply air temperature of $20^{\circ} \mathrm{C}$ and a relative humidity of $20 \%$ at varying flowrates

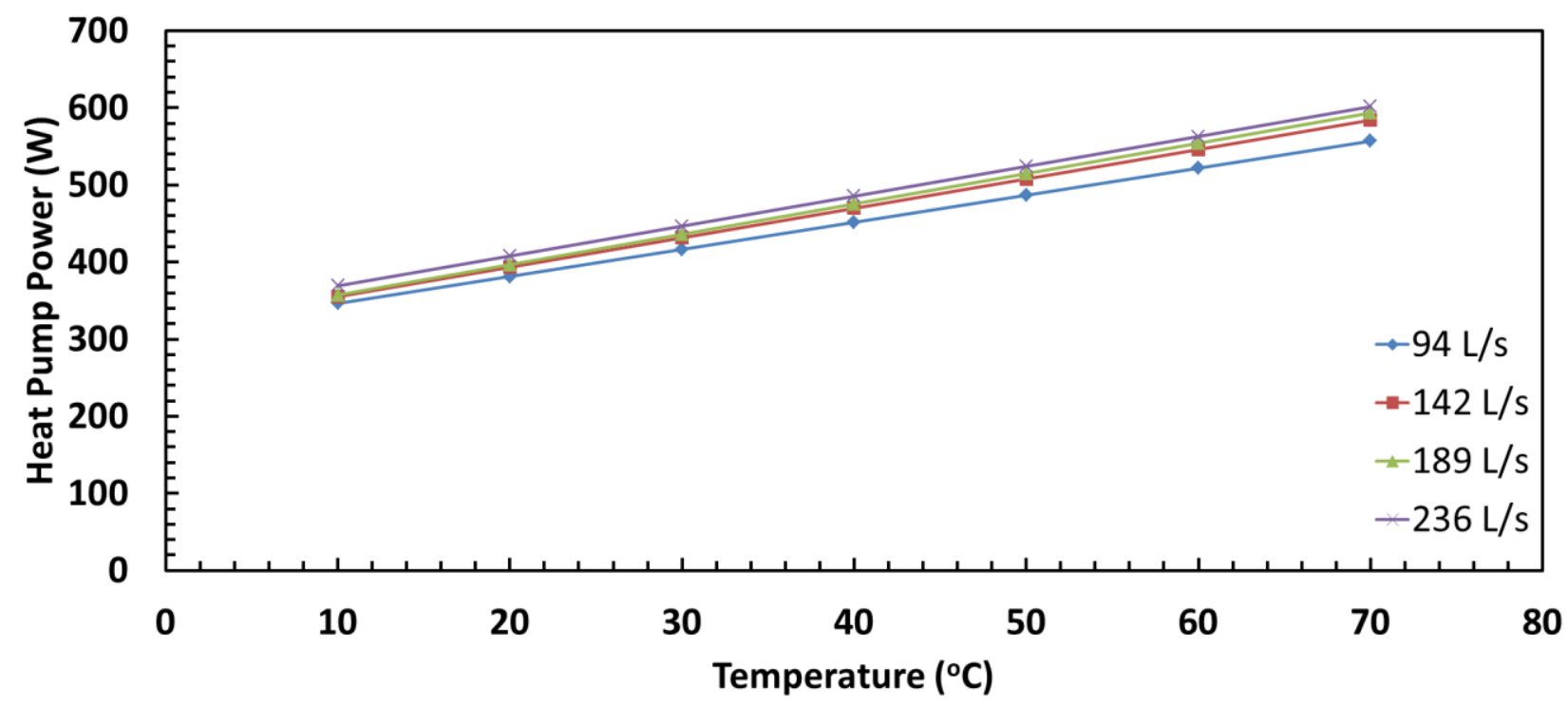

Figure 5-6: Compressor power for an supply air temperature of $20^{\circ} \mathrm{C}$ and a relative humidity of $20 \%$ at varying flowrates

\subsection{Simulations}

The modelling section results are provided in two parts. The first part of the modelling results includes the validation of the TRNSYS model to justify the use of the model to predict 
the unit's performance for extended testing under different operational conditions. The second part of the modelling results includes the performance monitoring of the HPWH Type when combined with the house model discussed in Chapter 4.

\subsubsection{Validation}

Annual simulations were conducted to test the heat pump performance in a conditioned space setting, and compare the performance of the house to the performance of the house with common water heating devices (electrical water heaters and high efficiency boilers). Therefore, the validation of the computer model was first required to simulate the performance of the unit according to the physical unit. The validation of the computer model, including the new TRNSYS Type, involved both an iteration process to calibrate the computer model to the properties of the experimental apparatus and testing the capability of the HPWH Type to determine the physical behavior of the commercial unit at a given operating conditions. These results were achieved through a series of tests, including: charging, discharging, charging and discharging, and draw tests. The validation tests were conducted under controlled laboratory conditions, with the supply air temperature and relative humidity fluctuating between 20 and $24^{\circ} \mathrm{C}$ and 10 and $30 \% \mathrm{RH}$ throughout the day, respectively.

The first validation test was a charging test which was conducted in order to evaluate the heat transfer between the HPWH Type and the water storage tank Type and predict the temperature change of the water temperature in comparison to the physical system. The result for the charging test is presented in Figure 5-13. It was observed that there are minor differences between the model and the experiment, mainly during the first 15 minutes of the test, where the model's temperature changes more rapidly than the experimental results. Error bars were added to the experimental results for Node 10 and it was observed that the temperature of this node 
obtained from the computer model falls within the error of the experimental results. It was also observed that the final temperature of Node 10 was $3^{\circ} \mathrm{C}$ lower in the model when compared with the experimental results. The temperatures for the remaining nodes match the experimental water temperatures over the same time length of four hours and 30 minutes.

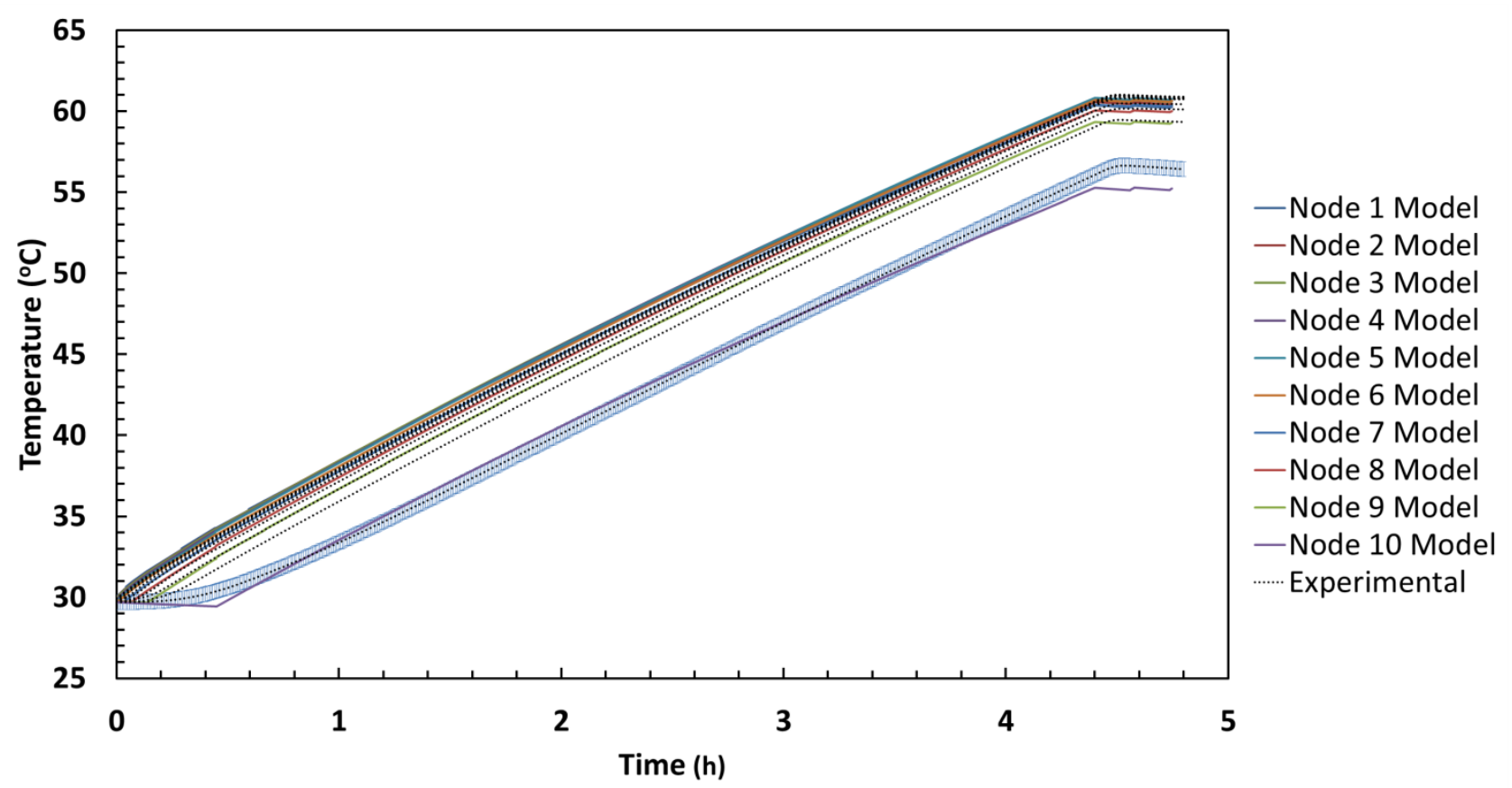

Figure 5-7: Charging test comparison between the experimental and model results for Nodes 1 through 10

To understand the discrepancies observed for the charging test between the experimental and modelling data, the heat transferred during the charging test was examined and is shown in Figure 5-8. The heat transfer graph shows a spike in energy injected into Node 5 which decreases toward the bottom of the tank, since the condenser will lose most of its energy to the first node covered by the wrap-around condenser coil. Furthermore, the figure shows that after a $15 \mathrm{oC}$ increase in the tank temperature, the heat delivery to the tank at each node reaches equilibrium, where the heat delivery is equal at each node. 


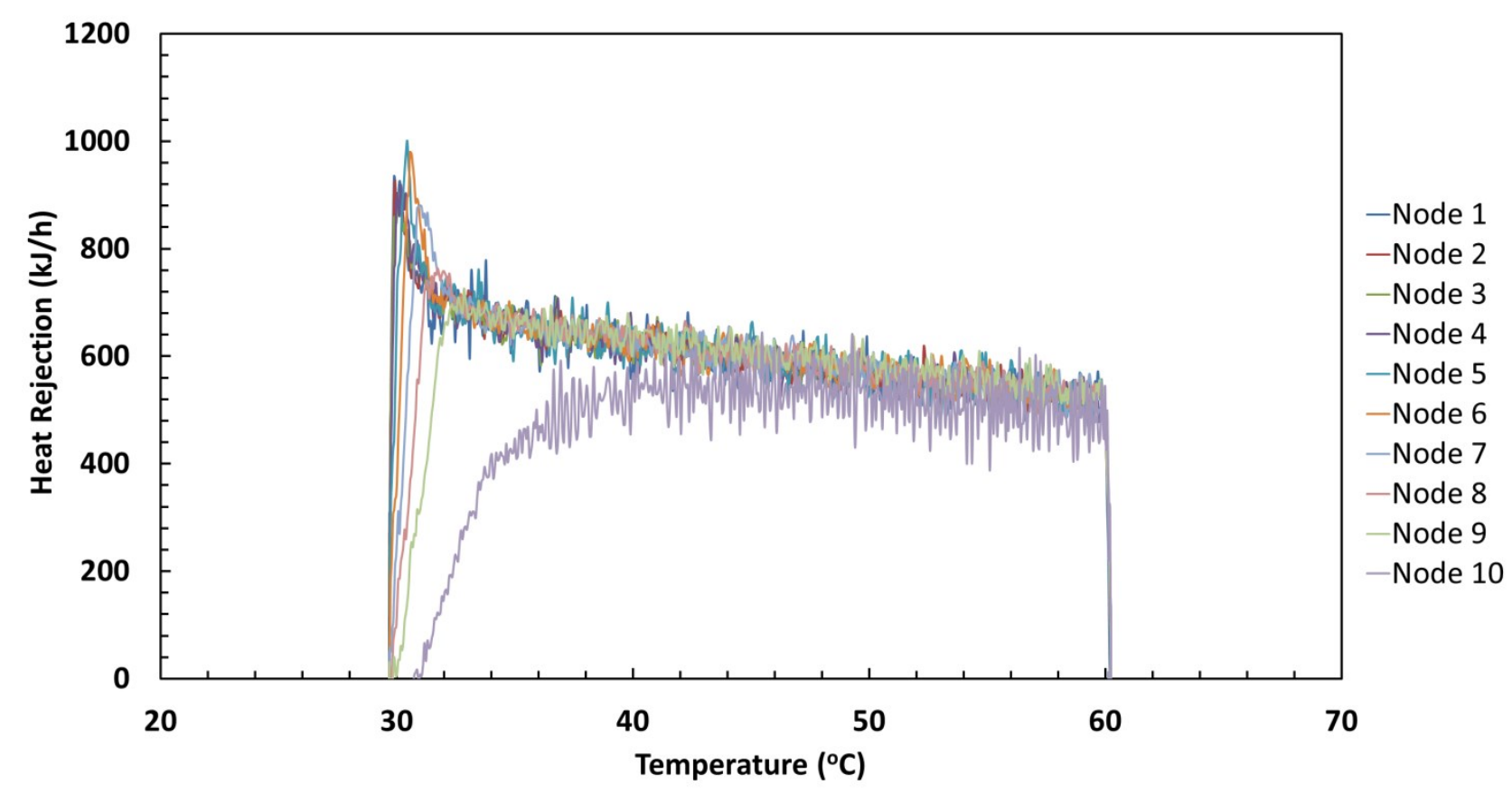

Figure 5-8: Experimental heat delivery per node during the charging procedure

Accordingly, the modelling results for the heat delivery values per node were validated against the experimental data shown in Figure 5-8. The results for the heat delivery validation were conducted for four nodes for clarity purposes, i.e., Nodes 1, 5, 8 and 10. These nodes were chosen to cover the entire range of the tank, while highlighting the discrepancies. The results of the heat delivery validation can be seen in Figure 5-9, Figure 5-10, Figure 5-11, and Figure 5-12, where the heat delivery value per node is plotted against the water temperature for the node. The results of the heat delivery validation showed that heat delivery per node for the four test nodes showed a high level of agreement in comparison to the experimental heat delivery data. It was evident that for Nodes 1,5 , and 8 , the heat delivery value for the initial spike is lower than that of the experimental data. However, past the initial spike, the heat delivery data generated by the TRNSYS Type follows the heat delivery values determined experimentally. Furthermore, it can be observed that the heat delivery for Node 10 stops $1{ }^{\circ} \mathrm{C}$ sooner than the heat delivery found experimentally for the same node which agrees with the modelling charging test results. 


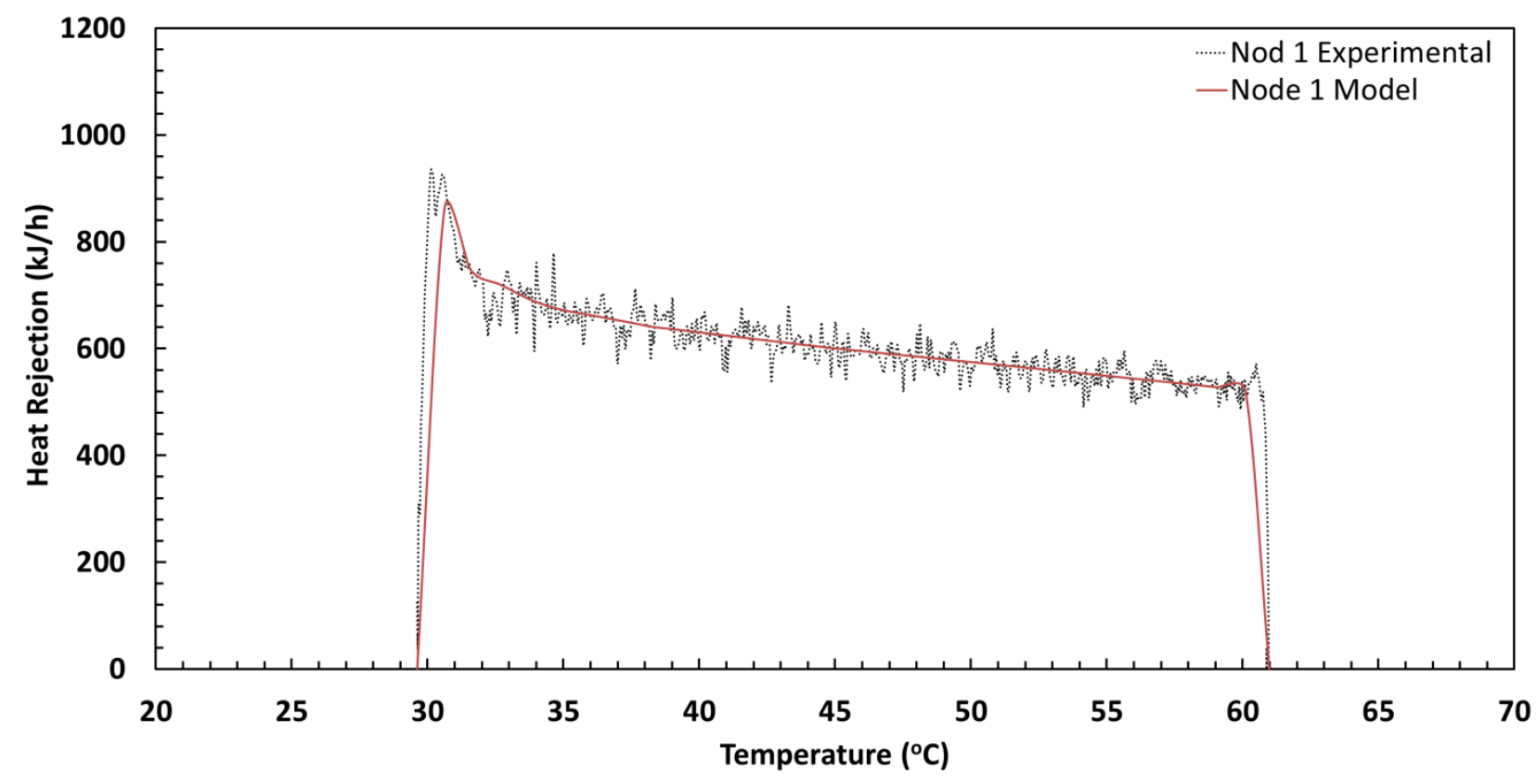

Figure 5-9: Charging test comparison between the experimental and model results for heat delivery to the water for Node 1

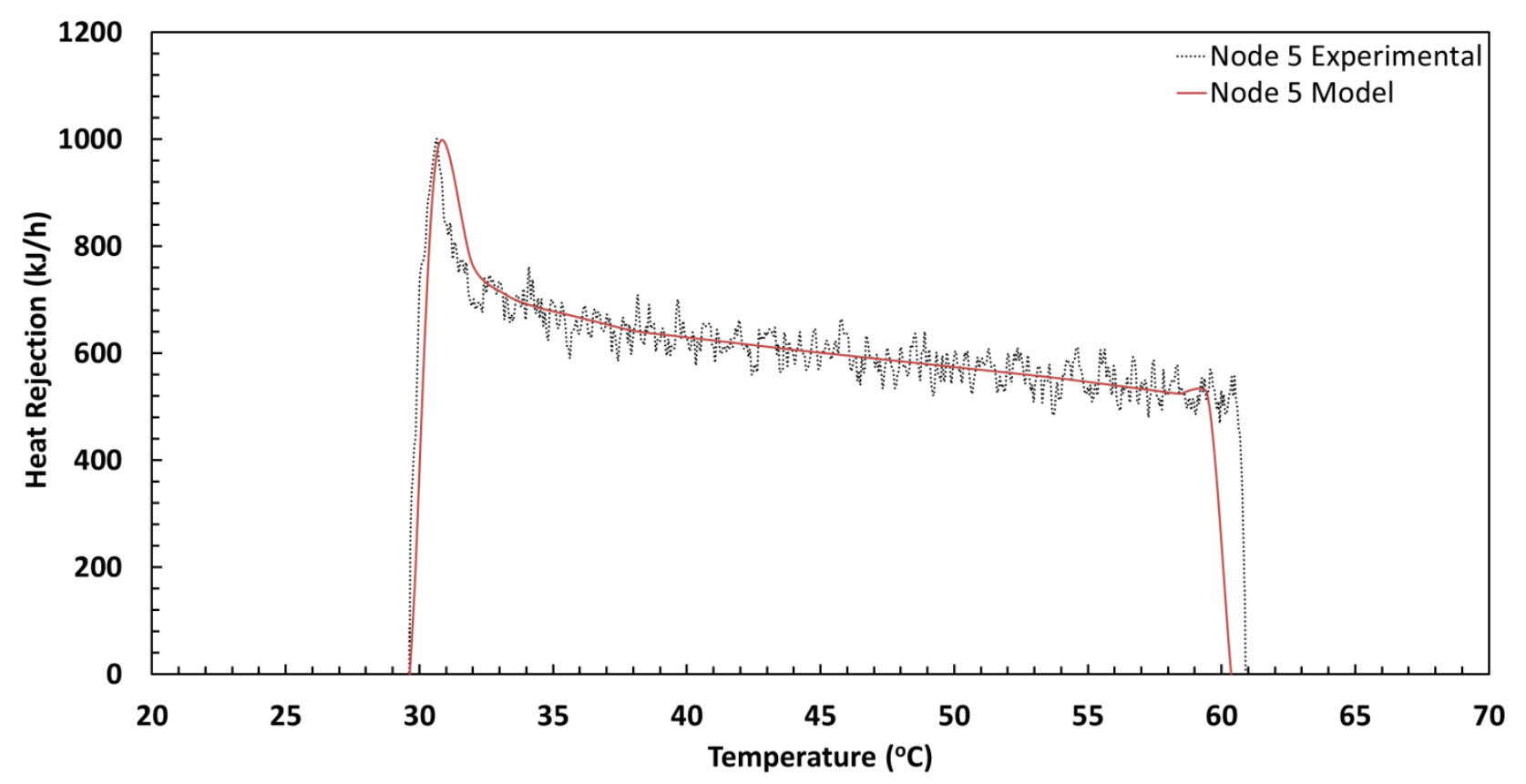

Figure 5-10: Charging test comparison between the experimental and model results for heat delivery to the water for Node 5 


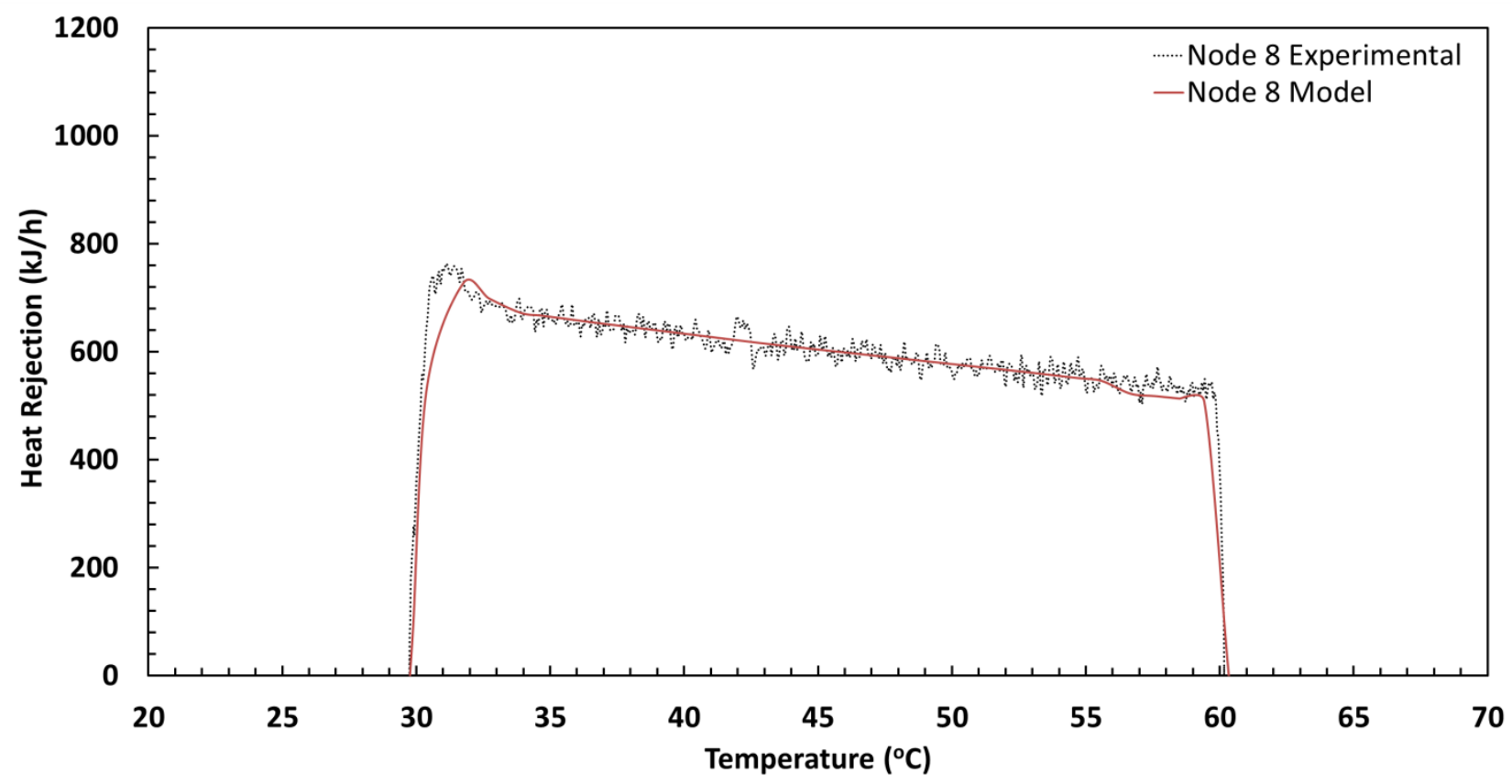

Figure 5-11: Charging test comparison between the experimental and model results for heat delivery to the water for Node 8

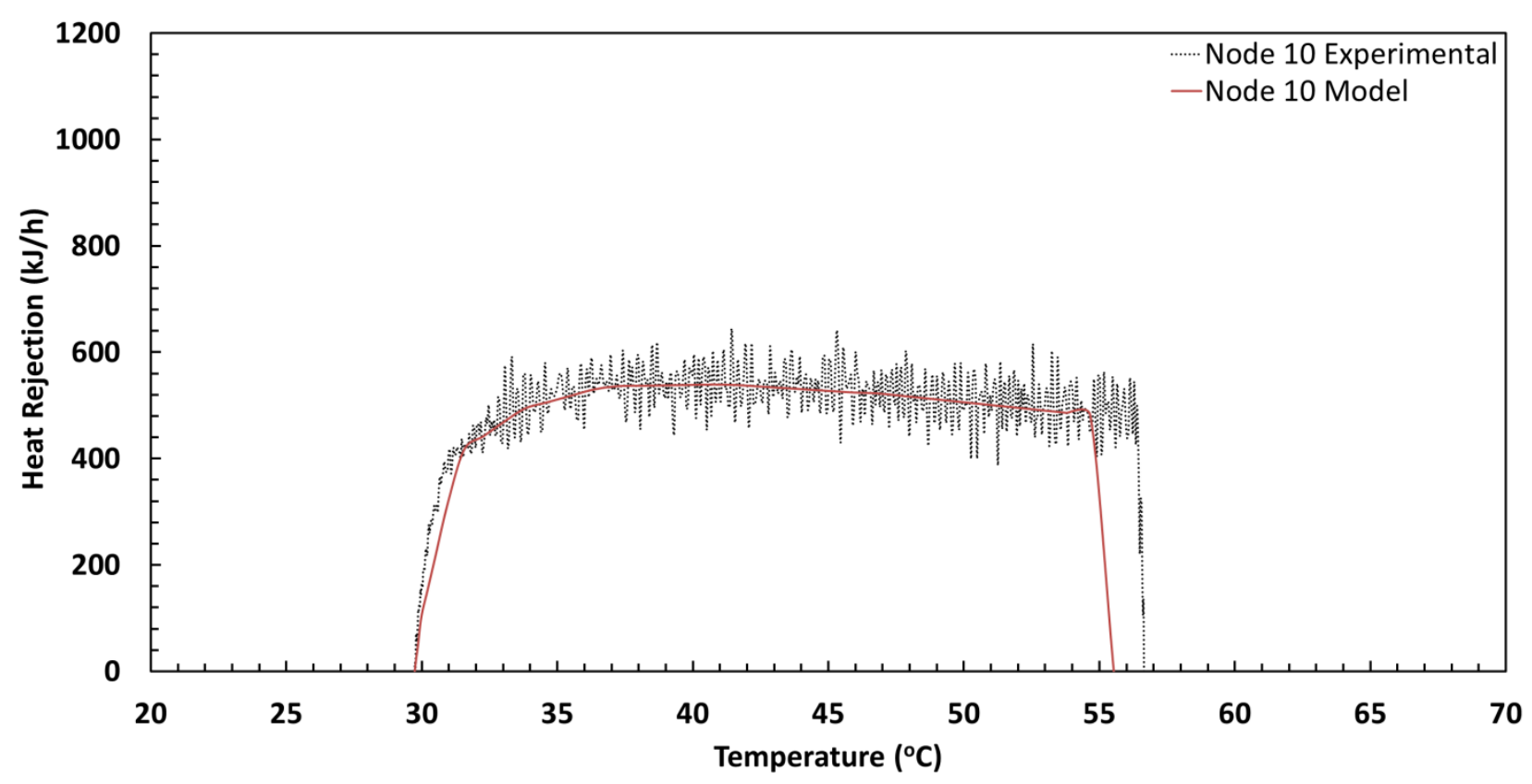

Figure 5-12: Charging test comparison between the experimental and model results for heat delivery to the water for Node 10 
The second validation test was a discharge test in order to evaluate the performance of the water storage tank by experiment and compare to the model. The test was started by charging and mixing the storage tank to a uniform water temperature of $60^{\circ} \mathrm{C}$, and then a water draw, at a rate of $3.8 \mathrm{~L} / \mathrm{min}$, was introduced with mains water at $26^{\circ} \mathrm{C}$, replenishing the drawn water. During the discharge test, the compressor was not operational. Figure 5-13 displays the results of the discharge test. A major discrepancy can be observed in the water temperature between the experimental and modelling results. The first discrepancy is similar to the charging test, in which Node 10 in the experimental set-up is not fully represented by the model. Furthermore, the temperature of each node is changing temperature over time although the temperature of the neighboring nodes is not changing due to the mains water refill. It is observed however that the tank reaches the same uniform water temperature at the same time.

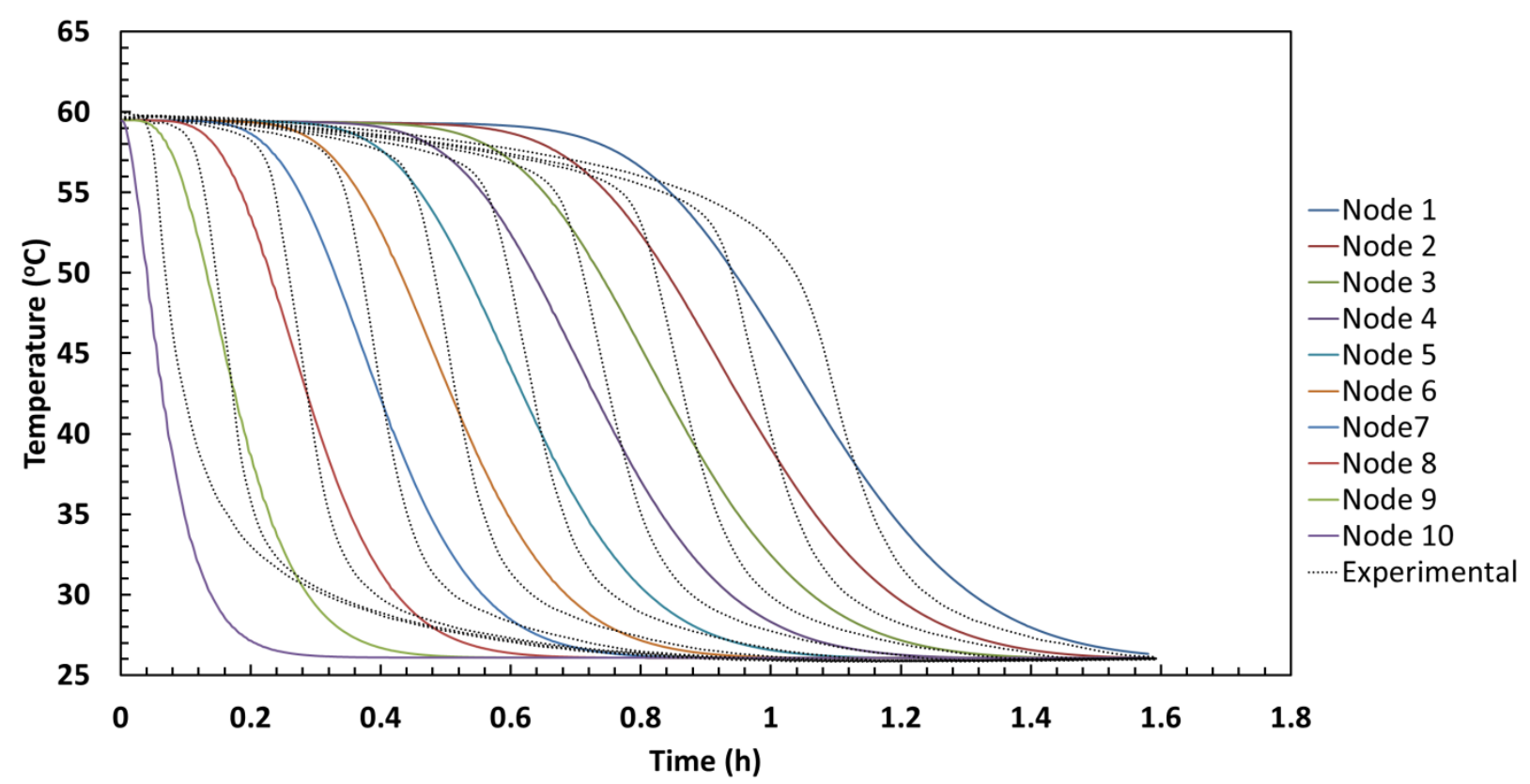

Figure 5-13: Discharging test comparison between the experimental and model results for Nodes 1 through 10 
Figure 5-14 displays the results for a combined charging and discharging test. The purpose of this test was to validate the response of the heat pump`s controls in the TRNSYS model, and calibrate the temperature sensor location in the model, as it is not perfectly aligned with the thermocouples in the tank within the experimental set-up. The test was initiated by fully mixing the tank to a uniform temperature of $22^{\circ} \mathrm{C}$ and charged to a set-point temperature of $60^{\circ} \mathrm{C}$. Once the set-point temperature was achieved, a water draw of $3.8 \mathrm{~L} / \mathrm{min}$ was introduced while allowing the heat pump to continue operating. As expected the heat pump was not capable of sustaining the temperature of the tank for the desired set-point. One important observation is the stratification between the nodes, introduced by the wrap-around coil. The stratification between the nodes confirms the calibration process of the TRNSYS type to represent the length and the covered tank area by the wrap-around coil. However, there was a large discrepancy between the temperature of the experimental tank and the computer model, mainly due to the limitation of the water storage tank during the discharging phase of the test.

Finally, a draw test to simulate a normal day to day operation of the HPWH unit was conducted using the CSA-F379.1 standards Schedule A, as described in Table 4-2, at a flowrate of $3.8 \mathrm{~L} / \mathrm{min}$. Schedule A is the only draw volume that the unit can support for a heat pump only operation. Therefore, it was the only schedule tested for validation purposes. The draw test essentially combines the previous three tests in order to test the response of the heat pump during normal operations. The temperature of the water nodes, the power consumption of the unit, the instantaneous COP and the rate of heat loss during non-operational periods were tested and compared to experimental values. The response of the HPWH Type determines the capability of the TRNSYS model to predict the performance of the physical HPWH unit when running annual simulations, or when combining the HPWH with different appliances. The results of the draw 
test are presented in Figure 5-15. Although there seems to be a discrepancy between the nodal temperature of the experimental results and the model, the model follows a similar trend and requires the same operation time to achieve the required temperature set-point. This is also shown in the power consumption and the unit's COP. The TRNSYS model predicts the power consumption and the COP accurately. However, there is an instant in the experimental results where the COP of the HPWH unit goes to zero, which occurs twice during the length of the operation (once during each time the compressor is on).

Before incorporating the HPWH unit into the house model as discussed in Chapter 4, the exhaust air temperature must be validated for the draw test in order to ensure the model can accurately determine the temperature being introduced to the space due to the HPWH operation. The exhaust temperature validation results are shown in Figure 5-16, which was recorded for the draw profile validation test shown in Figure 5-15. The exhaust temperature of the TRNSYS Type accurately represents the exhaust temperature of the experimental apparatus within $\pm 0.5^{\circ} \mathrm{C}$. The error between the TRNSYS model results and the experimental results falls within the error of the thermocouple calibration. Finally, it was observed that the temperature of the exhaust air during operation, between hour 3 and hour 7, and between hour 12 and hour 15, increase linearly. 


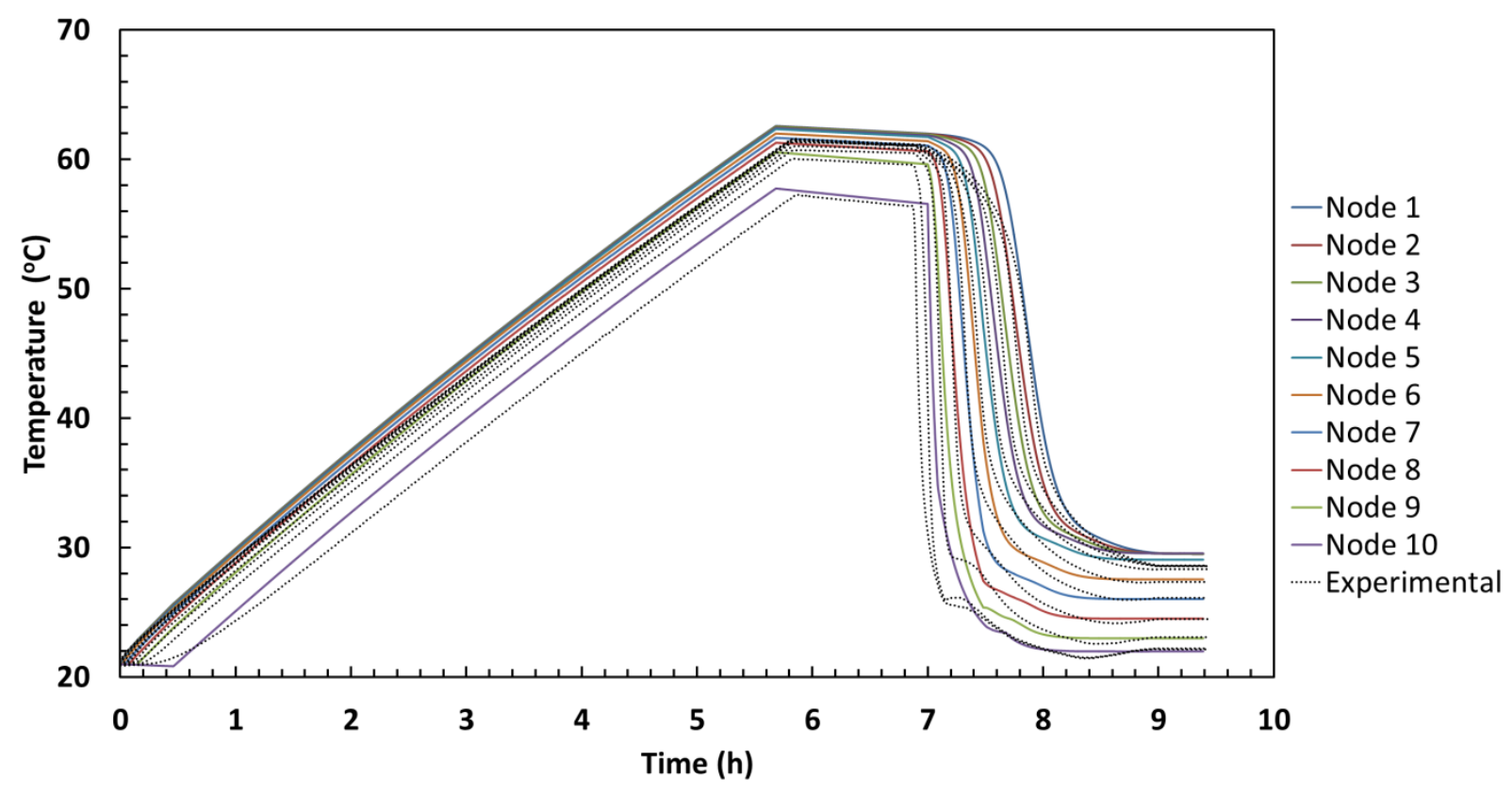

Figure 5-14: Charging-discharging test comparison between the experimental and model results for Nodes 1 through 10

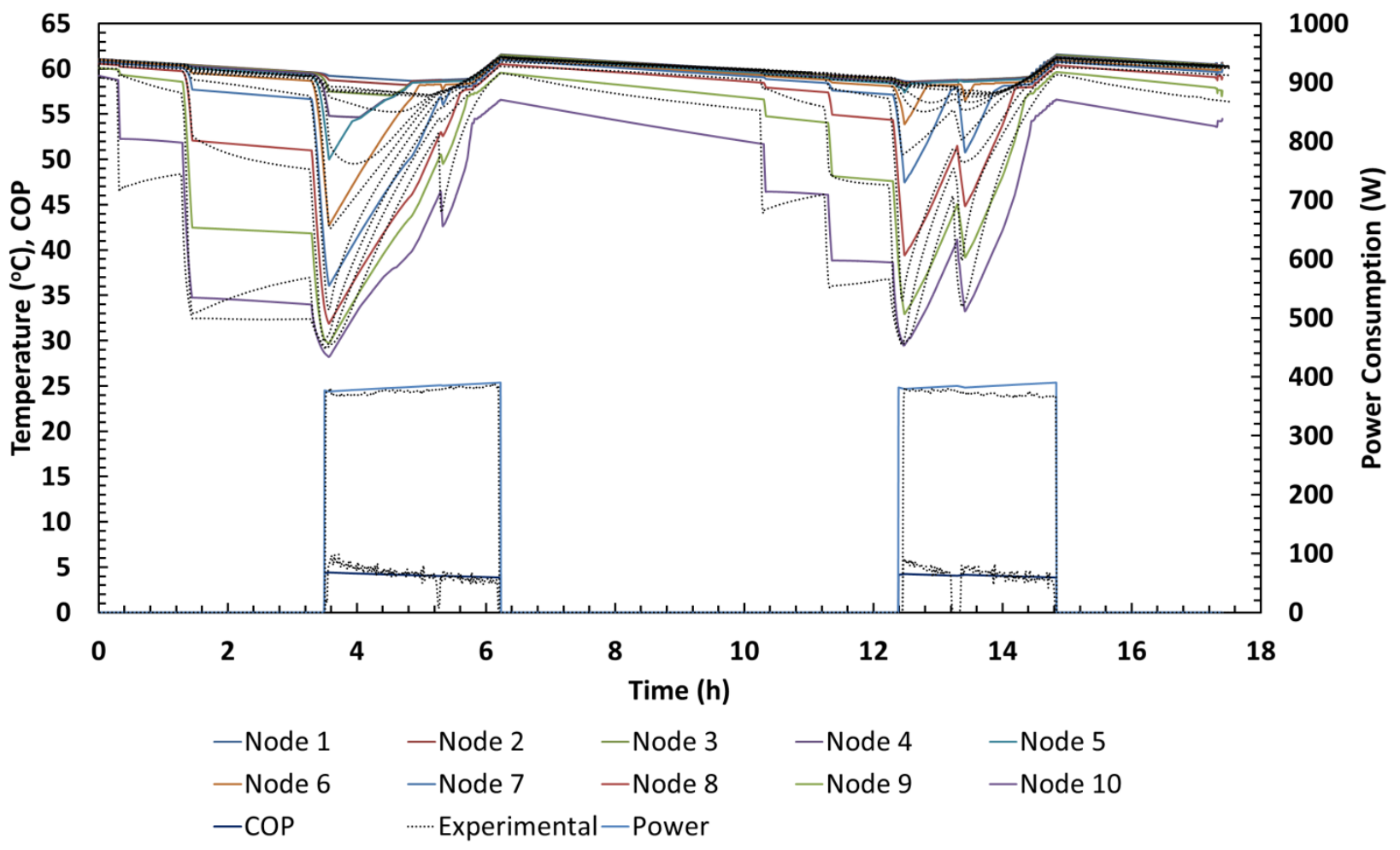

Figure 5-15: Draw profile test comparison between the experimental and model results for Nodes 1 through 10, the power consumption of the compressor, and the resulting instantaneous COP 


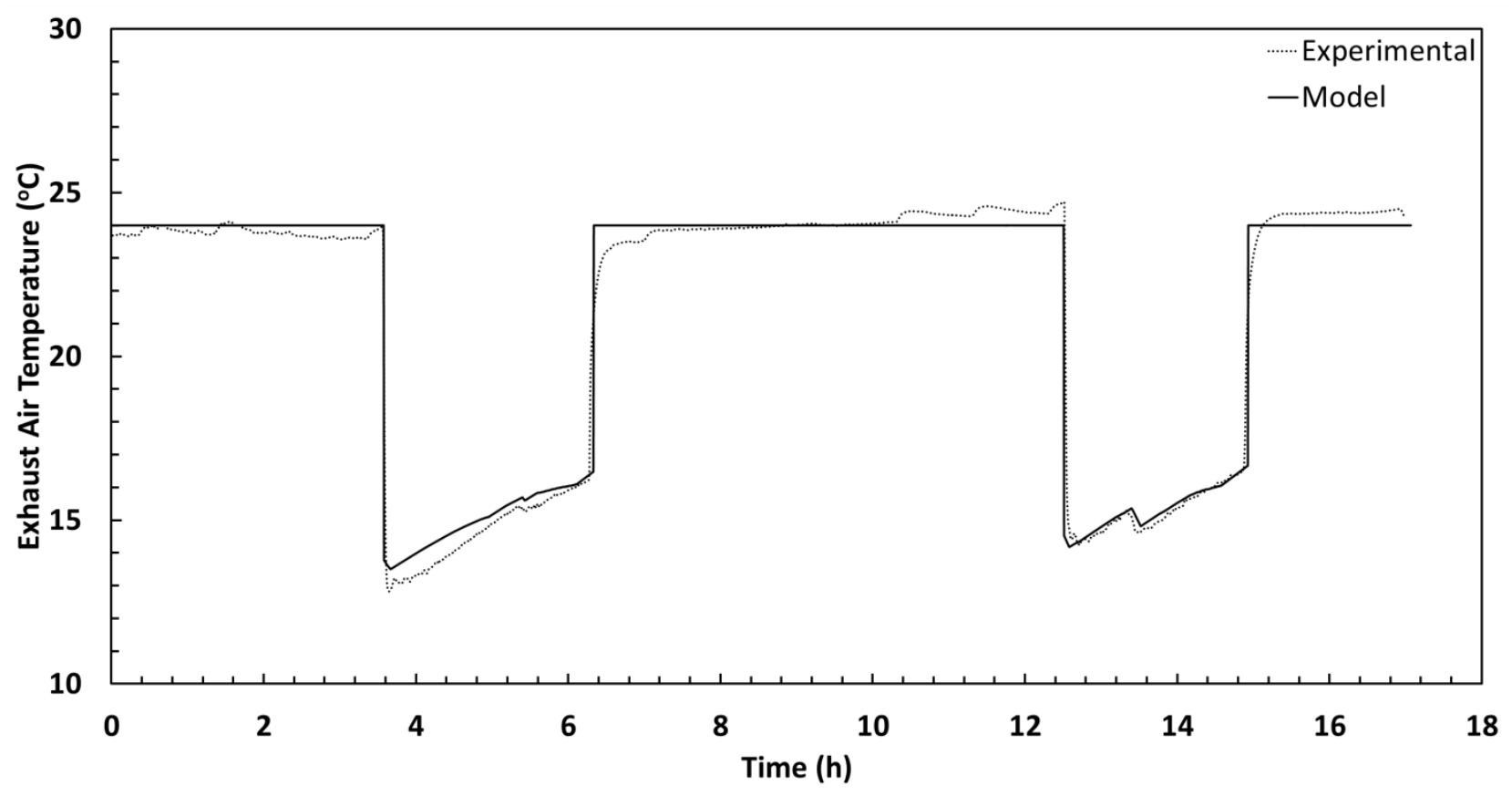

Figure 5-16: Comparison between the experimental and model results for the exhaust air temperature

\subsubsection{Performance}

Once the validation of the HPWH model was completed, the HPWH Type was incorporated into the TRNSYS house model. A modelling study was conducted such that the house and the performance of the HPWH were simulated for two days, one for each season to determine the effect of outdoor temperature on the operation of the HPWH and its interaction with the space heating and cooling systems. The results of this study are shown for October $20^{\text {th }}$ and $21^{\text {st }}$, since October falls in a transitional season where both heating and cooling are required.

Figure 5-17 shows the draw profile for the HPWH installed in a conditioned space. It can be observed that the DWH delivery temperature, which corresponds to the secondary axis, is maintained at $45^{\circ} \mathrm{C}$. It is required by the both the National Plumbing Code and the National Building Code that the DHW temperature does not exceed $49^{\circ} \mathrm{C}$ [61]. 
At the basement temperature of $18^{\circ} \mathrm{C}$, the $\mathrm{HPWH}$ operates at a maximum COP of 3.07 and a minimum COP of 2.46. The operation of the HPWH introduces a temperature drop across the HPWH which is delivered to the space at $70.8 \mathrm{~L} / \mathrm{s}$; the average air temperature drop across the heat pump throughout operation time is shown to be $9.9^{\circ} \mathrm{C}$. The effect of the temperature drop across the heat pump on the temperature of the basement was monitored for the two-day simulation period. It can be observed from Figure 5-18 that the air temperature of the basement with an installed HPWH unit is lower than that of a basement without HPWH unit. The temperature difference is shown to go as low as $15.8^{\circ} \mathrm{C}$ with a HPWH unit, where the basement air temperature, without a HPWH, only goes down to $16.8^{\circ} \mathrm{C}$. Furthermore, Figure 5-18 shows the ambient outdoor temperature. The ambient temperature range between 0 to $15^{\circ} \mathrm{C}$, however, as expected the ambient temperature has no effect on the HPWH operation when it is installed in a basement, as shown in Figure 5-17. The performance of the HPWH unit is only dependent on the condition of the basement. Therefore, the only link between the ambient outdoor temperature and the HPWH is the space heating and cooling, since the space heating and cooling is affected by both the HPWH unit operation and the ambient temperature.

The electricity rate for heating and cooling was used to quantify the effect of the HPWH installation in the basement. Figure 5-19 shows the total electricity rate for both the space heating and cooling. It should be noted that the reason why there is both heating and cooling is due to operating in a transitional season, where the temperature in the morning is high so the house requires cooling. This is shown on Figure 5-19 between hour 11 and 17 and between hour 38 and 40. On the other hand, heating is required at night when the ambient temperature goes down, which can be seen in Figure 5-19 between hour 0 and 6, between 21 and 30, and between 45 and 48. The electricity consumption for heating and cooling without a HPWH is shown to be 14.58 
and $5.65 \mathrm{kWh}$, respectively. Therefore, the results indicate that a house with a HPWH installation had a higher heating load; however, the cooling load for the house was decreased; these values were shown to be 16.32 and $5.38 \mathrm{kWh}$, respectively.

The effect of the HPWH operation on the space heating and cooling systems for different seasons (summer, winter and spring) is shown in Table 5-1. The ambient temperature for the time of year of interest had a marginal effect on the COP of the unit. The COPs of the unit for January, April, July, and October were shown to be $2.75,3.03,2.84$, and 2.76 , respectively. It can be observed that since there were no heating loads required in July, the space cooling experienced a decrease of $1.07 \mathrm{kWh}$ over the two days of simulation due to the HPWH operation. the space cooling savings were insignificant in a transitional month where the space heating is also required. Therefore, in October, the electricity consumption increased by $1.5 \mathrm{kWh}$. Finally, the month of January and April only require heating; thus, the HPWH operation causes the electricity consumption of the space heating to increase by 2.42 and $3.6 \mathrm{kWh}$, respectively. 


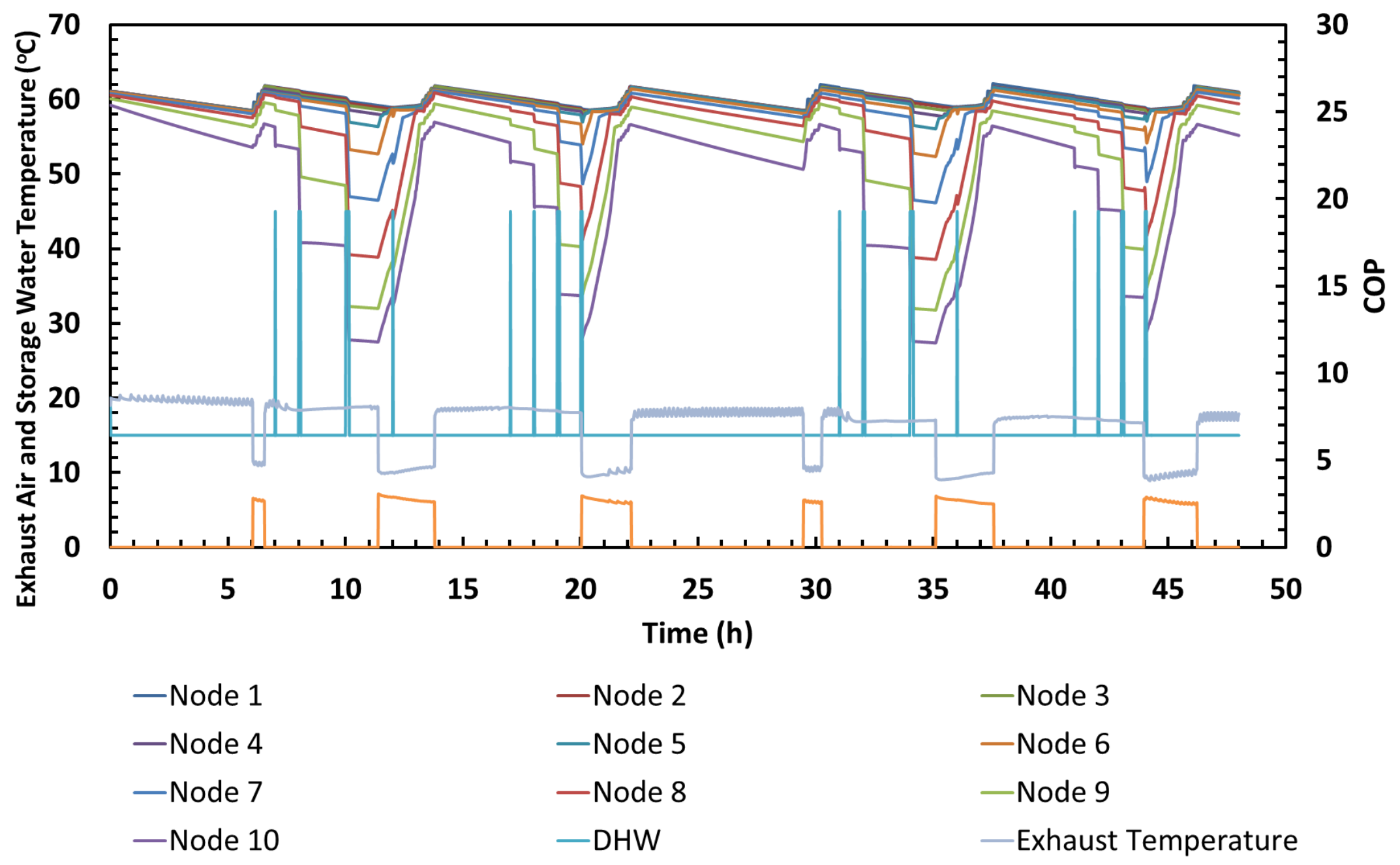

Figure 5-17: Performance of the HPWH in a basement set-up outlining the COP of the unit, the exhaust air temperature of the unit, the water supply temperature and the storage water temperature profile 


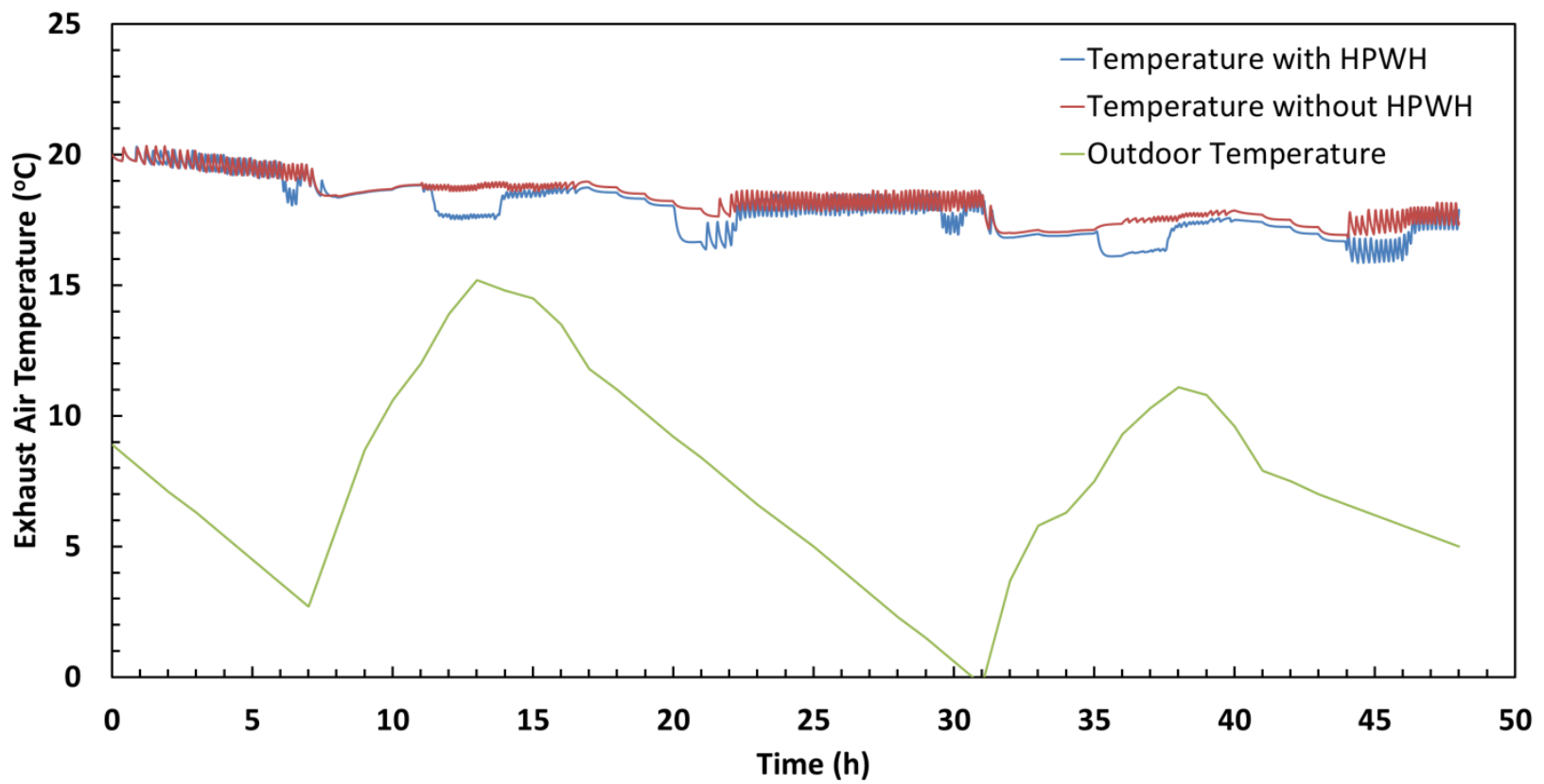

Figure 5-18: Effect of HPWH unit operation on the temperature of the basement in October

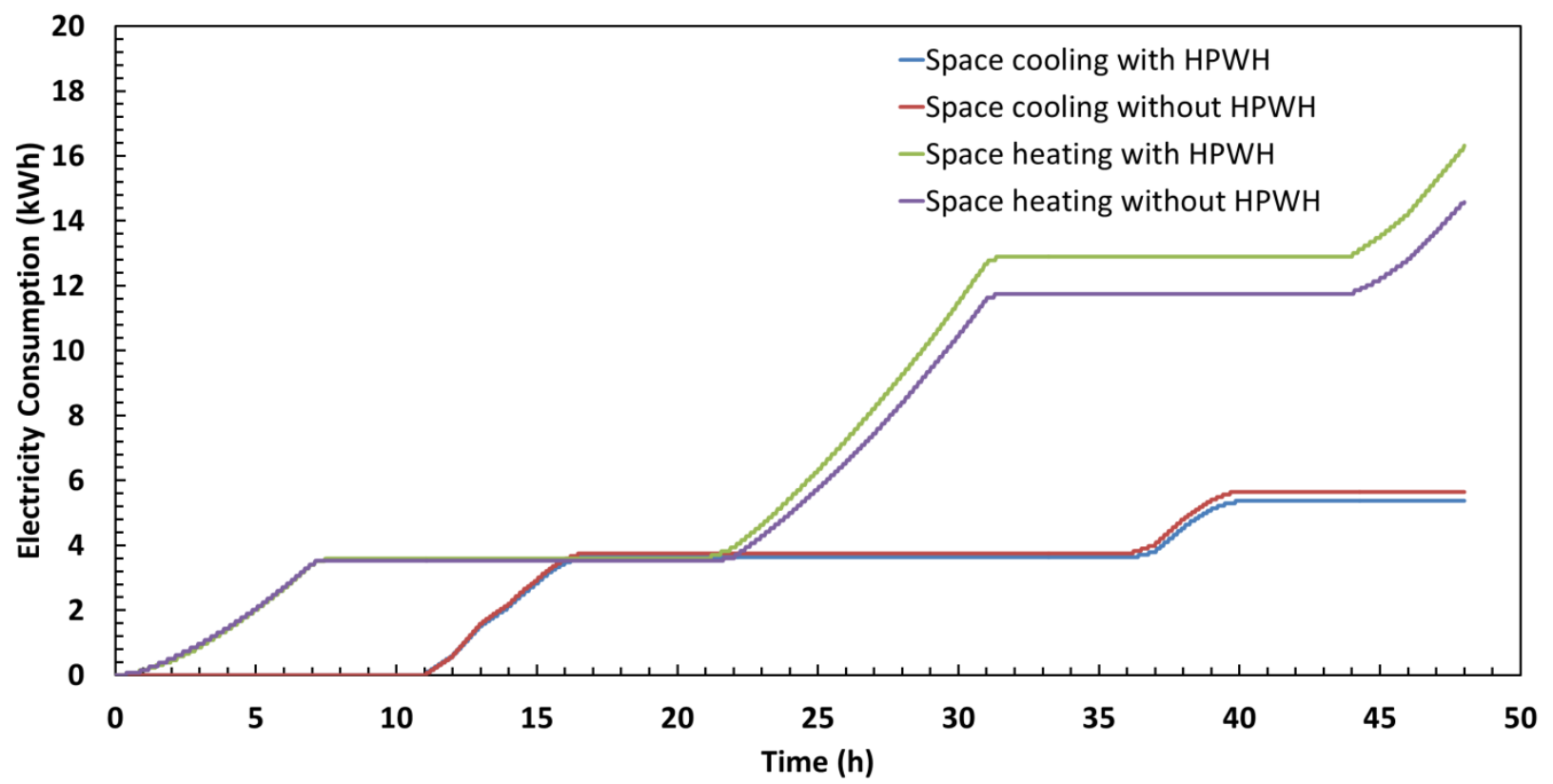

Figure 5-19: Space heating and cooling energy consumption comparison between a heat pump space heating operated house operating with and without a HPWH unit for two day period in October 
Table 5-1: Summary of the effect of the HPWH operation on the space heating and cooling for different seasons in Ottawa

\begin{tabular}{|c|c|c|c|c|c|c|c|c|c|}
\hline \multirow[b]{2}{*}{ Parameter } & & \multicolumn{2}{|c|}{ January } & \multicolumn{2}{|c|}{ April } & \multicolumn{2}{|c|}{ July } & \multicolumn{2}{|c|}{ October } \\
\hline & & $\begin{array}{l}\text { With } \\
\text { HPWH }\end{array}$ & $\begin{array}{l}\text { Without } \\
\text { HPWH }\end{array}$ & $\begin{array}{c}\text { With } \\
\text { HPWH }\end{array}$ & $\begin{array}{l}\text { Without } \\
\text { HPWH }\end{array}$ & $\begin{array}{c}\text { With } \\
\text { HPWH }\end{array}$ & $\begin{array}{l}\text { Without } \\
\text { HPWH }\end{array}$ & $\begin{array}{c}\text { With } \\
\text { HPWH }\end{array}$ & $\begin{array}{l}\text { Without } \\
\text { HPWH }\end{array}$ \\
\hline $\mathrm{COP}$ & - & 2.75 & - & 3.03 & - & 2.84 & - & 2.76 & - \\
\hline $\begin{array}{l}\text { Average Exhaust } \\
\text { Temperature }\end{array}$ & ${ }^{\circ} \mathrm{C}$ & 9.0 & - & 10.6 & - & 11.4 & - & 10.0 & - \\
\hline $\begin{array}{l}\text { Average Basement } \\
\text { Temperature }\end{array}$ & ${ }^{\circ} \mathrm{C}$ & 18.2 & 18.5 & 18.8 & 19.2 & 18.4 & 18.8 & 17.9 & 18.3 \\
\hline $\begin{array}{l}\text { Max Ambient } \\
\text { Temperature }\end{array}$ & ${ }^{\circ} \mathrm{C}$ & \multicolumn{2}{|c|}{2.10} & \multicolumn{2}{|c|}{11.30} & \multicolumn{2}{|c|}{33.60} & \multicolumn{2}{|c|}{15.20} \\
\hline $\begin{array}{l}\text { Min Ambient } \\
\text { Temperature }\end{array}$ & ${ }^{\mathrm{o}} \mathrm{C}$ & \multicolumn{2}{|c|}{-10.10} & \multicolumn{2}{|c|}{-6.19} & \multicolumn{2}{|c|}{18.30} & \multicolumn{2}{|c|}{-0.29} \\
\hline Heating Electricity Rate & $\mathrm{kWh}$ & 39.98 & 37.56 & 13.99 & 11.63 & - & - & 16.32 & 14.58 \\
\hline Cooling Electricity Rate & $\mathrm{kWh}$ & - & - & - & - & 45.16 & 46.23 & 5.38 & 5.65 \\
\hline Total Electricity Saving & $\mathrm{kWh}$ & \multicolumn{2}{|c|}{2.42} & \multicolumn{2}{|c|}{2.36} & \multicolumn{2}{|c|}{-1.07} & \multicolumn{2}{|c|}{1.5} \\
\hline
\end{tabular}




\subsection{Summary}

This chapter presented the result of the sensitivity analysis on the independent variables affecting the performance of the unit. The results of the sensitivity analysis were used to construct a performance map for the physical unit which was used in the computer model. The results for the both the HPWH Type and computer model for the experimental set-up validation results were presented showing a high-level agreement between the modelling and experimental results. Finally, the results of the HPWH unit in a conditioned space installation were presented outlining the effect of the unit on the space heating and cooling of the house for different seasons. 


\section{Chapter: Discussion}

\subsection{Experimental Analysis}

The sensitivity analysis conducted on the independent variables for the HPWH shows that there is no benefit in increasing the relative humidity of the air delivered to the unit at $20^{\circ} \mathrm{C}$. Also, it was observed that there was a lack of improvement in the performance of the unit when increasing the relative humidity (Figure 5-1), indicated by the minimal increase in heat delivery to the water storage tank. This effect is due to the low amount of condensation occurring on the evaporator coils during operation causing little to no latent heat transfer. The reason why condensation does not occur at lower temperatures is because the refrigerant fluid does not reach the dew-point temperature of the air in order to trigger condensation. Therefore, there is a drawback in running the HPWH unit at a higher RH with low air temperature, since the compressor power is higher at higher RH, as shown in Figure 5-2. The reason for the compressor power consumption increase is the decrease in convective heat transfer of air at a higher relative humidity [62]. Therefore, there was a lower heat transfer between the air and the evaporator coil. This meant that the compressor would need to operate at a higher operating point in order to meet the same operating set-point as the evaporator [63]. The unit would then experience degradation in the COP if it is operating at a higher humidity for a lower temperature set-point. This is mainly due to the increase in the power consumption of the unit for the minimal increase in the heat delivery values. These results are significant since the HPWH must be installed in basements in colder environments. Basements are commonly maintained at a lower RH than the rest of the house, generally between $20 \%$ and $30 \%$. This is in order to prevent condensation. As shown in Figure 5-1 and Figure 5-2, the unit will not experience any performance degradation in that range. 
The temperature of the supply air has a significant effect on the performance of the HPWH unit. As shown in Figure 5-3, a temperature increase in the air delivered to the heat pump results in a significant increase in the heat transfer between the air and the evaporator, which increases the heat delivery values at the condenser. The increase in heat delivery is coupled with an increase in compressor power consumption, as shown in Figure 5-4, which is necessary to increase the quality of the heat delivered to the condenser. The compressor power increase is the result of the higher heat transfer to the refrigerant causing a higher mass flowrate entering the compressor. Therefore, the compressor would need to operate at a higher operating point in order to maintain the pressure difference between the low and the high side of the compressor [63]. Since the basement has an approximate temperature of $18^{\circ} \mathrm{C}$, the unit will not experience any benefits from a temperature increase in colder environments. However, the HPWH unit could work well in a combined system such as a heating recovery ventilator system or a PV/T system where both units can benefit from each other.

The result of the sensitivity analysis on the flowrate of the supplied air on the heat delivery and power consumption shown in Figure 5-5 and Figure 5-6, respectively, concluded that there is a marginal increase in the heat delivery to the water, matched by a marginal increase in the power consumption. Therefore, the flowrate of the supply air was neglected from the performance map since it does not affect the performance of the unit. Furthermore, the increase of the supply air flowrate will result in a high exhaust flowrate which will significantly increase the loads on the space heating of the house. One application of increasing the flowrate is using the HPWH unit to support the space cooling system, which will require a control strategy to increase the fan speed when space cooling is required. 


\subsection{Simulations}

The discrepancies between the modelling and experimental results for the validation tests presented in Chapter 5 will be discussed here, outlining their causes. Additionally, the HPWH performance in a conditioned space is extended over multiple Canadian cities. These simulations were used to compare the performance of the unit in comparison to conventional water heating units such as EWH and natural gas boilers, discussing their effect on the overall performance of the house.

\subsubsection{Validation}

There are discrepancies that exist between the computer simulation results and the experimental results, as shown in Figure 5-7. These are mainly at the start of the charging process and the heat delivery to Node 10 . In the physical system, the rate of heat delivery to the tank ramps up over 5 minute periods as the refrigerant fluid slowly gains more energy while it is cycling between the evaporator and the condenser (transient response). However, due to the steady state performance map approach, the computer model negates the transient response of the HPWH and instantly injects the maximum heat delivery value for the tested air and water conditions. Due to the length of the test (5.5 hours), the transient response of the HPWH is insignificant and can be neglected. This is shown by the fact that both the experimental and modelling results reach the desired water set-point in the same amount of time. To further understand the discrepancies between the computer model and the experiments for the charging test, the heat delivery values produced by the model for Nodes 1, 5, 8 and 10 were plotted against the experimental data. Figure 5-9, Figure 5-10, Figure 5-11, and Figure 5-12 show that the model accurately determines the heat transfer per node given the total heat transfer to the tank from the performance map. However, it can be seen that the heat transfer into Node 10 stops 
around $3^{\circ} \mathrm{C}$ lower than the experimental results. This observation supports the lower temperature at Node 10 in the modelling results. The discrepancy between the water temperature of the experiment and the model Node 10 water temperature is due to the complex shape of the water storage tank. While the computer model uses a cylindrical shape for the water storage tank, the physical model has a convex bottom, causing less volume available for the bottom node. Therefore, less heat transfer is assumed to be introduced to the bottom node due to the larger volume node in the computer model, which explains the $3^{\circ} \mathrm{C}$ water temperature difference at the set-point for Node 10. These discrepancies are also the result of the estimated laboratory measurements of the water storage tank dimensions. Since no data for the dimensions of the water storage tank was provided by the manufacturer, the estimated measurements of the water storage tank dimensions introduced an error due to the inclusion of the insulation material between the water storage tank and the outside enclosure. Hence, the heat delivery values are calculated based on the node size approximation.

Node 10 in the discharging test, presented in Figure 5-13, displays similar issues, as the temperature in the experimental apparatus changes significantly faster than the TRNSYS model due to the smaller volume of the node. Moreover, the temperature of the nodes in the experimental results decreases simultaneously; each of the experimental nodes interacts with the rest of the nodes at the same time. This is caused by a jet-like behaviour at the inlet of the HPWH unit, resulting in large mixing of water between the nodes. Moreover, the present of the wrap-around coil causes mixing in the water storage tank, since the temperature increase in the node introduces a density change which causes the fluid warmer fluid to rise. This causes a discrepancy when using Type 534 because the mixing zone is pre-defined in the Type code for only the bottom section of the tank and the presence of the wrap-around coil in the physical tank 
sees mixing throughout the entire length of the tank [38]. Unlike the experimental results, during the discharging process, the nodes only interact with the top and bottom nodes, producing a much smoother discharging profile. The experimental tank can deliver a $45^{\circ} \mathrm{C}$ DHW temperature at the top of the tank for 45 minutes. However, the TRNSYS model can deliver a $45^{\circ} \mathrm{C}$ DHW for an hour at the same rate. Due to the nature of the draw profiles used in the study, there are no water draws longer than 10 minutes; therefore, the discrepancy between the modelling and experimental results can be neglected since it is insignificant for the length of time.

The charging-discharging test presented in Figure 5-14 validates the approximated length of the wrap-around coil since both the modelling and experimental results have the same level of thermal stratification. The wrap-around coil was concluded to cover the part of the tank between Nodes 5 through 10, while Nodes 1 through 4 received heat through diffusion only. The discrepancy at the end of the discharging process was generated due to the reconfiguration of the HPWH unit's controls. The safety controls produce an error if the unit cannot sustain the temperature of the tank while trying to switch to "electric-only" mode, which was disabled for the purpose of this experiment. The heat pump intermittently turned on and off, hence the reason for the unstable water temperature at the end of the discharging segment of the test.

Although there is a strong agreement between the TRNSYS model and the experimental results in the draw test presented in Figure 5-15, there are two instances where the COP of the unit goes to zero in the experimental results. The reason for this occurrence was that the heat delivery is calculated through the water temperature difference at a certain period of time; therefore, since the water was losing heat at a faster rate than heat gained from the condenser during water draw, the total heat delivery to the water is negative. The method to calculate the heat delivery to the water was adopted owing to the lack of access to the wrap-around coil of the 
unit, which does not allow the direct monitoring of the heat delivery from the refrigerant. This method already accounts for the losses to the environment. However, since the TRNSYS model uses the heat delivery values from the experimental data in the form of a performance map, the environmental losses of the model cause a slightly lower heat transfer value, hence the marginally lower COP.

This increase in the exhaust temperature, shown in Figure 5-16, is introduced by the higher temperature refrigerant operating through the evaporator, caused by the increase in temperature of the water storage tank. Therefore, the higher the temperature of the refrigerant entering the evaporator, the lower the rate of heat extraction exiting the evaporator. The validation test shows a slight discrepancy between the modelling and experimental results. These discrepancies were generated by the psychrometric equations in the computer model which were used to calculate the exhaust temperature. As shown in Equation (4-3) since the temperature is calculated using the sensible cooling capacity obtained from the performance map which contains the uncertainty values of the thermocouple readings. However, the temperature is adjusted when the enthalpy of the exhaust air is calculated from the total cooling capacity obtained from the performance map which is calculated using the humidity sensor readings. The reason for the discrepancy generated during the process is the low accuracy of the humidity accompanied by the mixing of the exhaust air with the room air which is at a higher temperature decreasing its relative humidity, affecting the calculated value of the total cooling capacity.

\subsubsection{System Performance Comparison}

In Chapter 5, the results of the HPWH performance showed that the effect of the ambient temperature on the performance of the unit is insignificant. However, on an annual basis, it was observed that the ambient temperature had a significant effect on the performance of the house, 
with an installed HPWH unit. It was shown that the house experiences a significant increase in the space heating loads during heating seasons. On the other hand, during the cooling season the decrease in the cooling loads was minimal. However, it was shown that most of the cooling load occurs during the on-peak billing hours. Consequently, the reduction in the cooling loads requirements of the house due to the heat pump results in higher savings than the increase in cost due to the increase in heating loads. This was mainly due to the heating loads increasing during the off-peak billing hours. These results could produce significant savings for house in provinces with time-of-use billing such as Ontario.

Therefore, the performance of the house with different space heating systems and different water heating technologies was studied for multiple Canadian locations to understand how the environment of the region, energy practices and cost compare between the different house set-ups. Ottawa was the first city to be tested. Figure 6-1 shows that the house with the heat pump space heating and cooling had a significantly lower cost with the HPWH installation in comparison to the house with EWH with a cost of $\$ 797$ and $\$ 1120$, respectively. Similarly, the HPWH for the DHW operated house produced significantly less $\mathrm{CO}_{2}$ emissions over the course of the year with $0.29 \mathrm{tCO}_{2} \mathrm{e}$ in comparison with the EWH house at $0.38 \mathrm{tCO}_{2} \mathrm{e}$. The house cost increased significantly when an electric baseboard heater was used for space heating, as expected. The HPWH house had significant savings in comparison to the EWH house where the annual operational cost for the house was found to be \$2214 and \$2398, respectively. Moreover, as expected, the $\mathrm{CO}_{2}$ emissions of the house with the EWH unit were higher due to the higher energy consumption with $0.90 \mathrm{tCO}_{2} \mathrm{e}$ than that of the house operating with a $\mathrm{HPWH}$ unit with $0.86 \mathrm{tCO}_{2} \mathrm{e}$. The reason for the lower difference in emissions between the HPWH unit and EWH unit house was due to the fact that the energy shifts from the HPWH to an electric board heater 
which consumes significantly higher energy to meet the required temperature set-point. The final house was simulated with a furnace acting as the space heating unit. The house running with the HPWH unit had an annual cost of $\$ 508$ in comparison to $\$ 422$ for the house running a natural gas boiler for water heating. The house with the natural gas boiler had a lower cost due to the cheap natural gas cost in the province of Ontario at $0.11 \$ / \mathrm{m}^{3}$ [64]. Accordingly, the $\mathrm{CO}_{2}$ emissions from utilization of natural gas for space heating are significantly higher in comparison to the house with heat pump space heating of the house with the electric baseboard heater. In 2014, GHG emissions from power generation in Ontario were the second highest, after Alberta. This was mainly due to the larger manufacturing industry in comparison to other provinces. However, power generation in Ontario is only $10 \%$ dependent on natural gas [4], hence, the generated emissions for the heat pump and electric baseboard space heating were significantly less in comparison to the house with the furnace space heating. The furnace space heating house still produces significantly fewer emissions when operating with a HPWH unit in comparison to boiler type water heater with $8.20 \mathrm{tCO}_{2} \mathrm{e}$ and $9.50 \mathrm{tCO}_{2} \mathrm{e}$, respectively. 


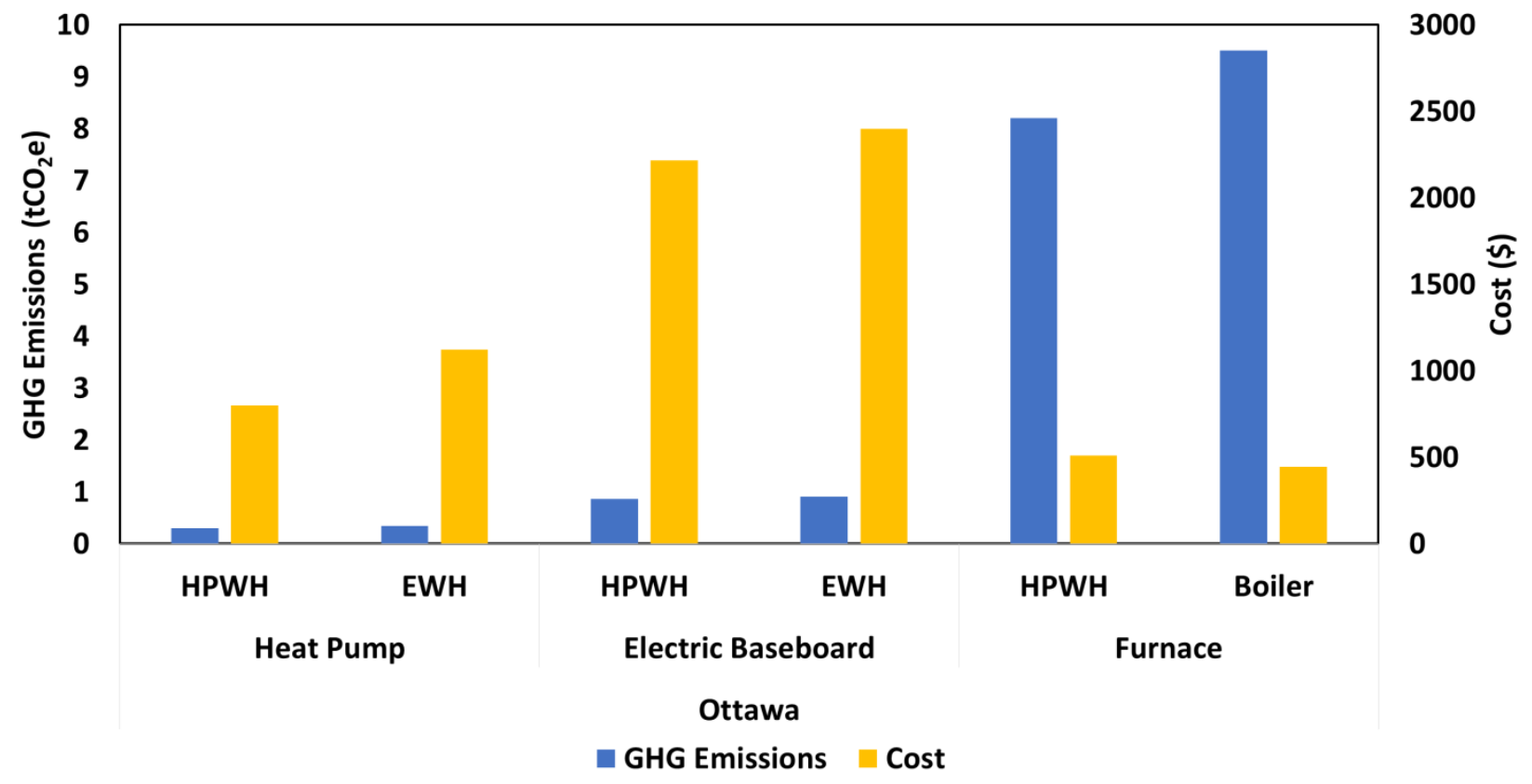

Figure 6-1: Annual cost and GHG emissions results for different house set-ups in Ottawa

Similar trends are seen in Figure 6-2, when using Toronto weather data because of the similarity in the energy cost billing in Ontario, natural gas prices and suppliers, and emission rates for electricity generation. However, the cost of operation for all the house types was cheaper in Toronto due to the higher ambient temperature throughout the year in comparison to Ottawa. Contrary to what was originally expected, it was found that the annual savings for the house in which a HPWH was installed and operated, changed from $\$ 323$ for Ottawa to $\$ 301$ for Toronto when operating the HPWH for DWH. That being said, it was observed that there were fewer emissions for a house located in Ottawa in comparison to Toronto $\left(0.045 \mathrm{tCO}_{2} \mathrm{e}\right.$ in Ottawa and $0.086 \mathrm{tCO}_{2} \mathrm{e}$ in Toronto). As for the electric baseboard operated house, Ottawa had higher savings at $\$ 184$ annually with an emission reduction of $0.037 \mathrm{tCO}_{2} \mathrm{e}$ compared to Toronto with $\$ 171$ annually with an emission reduction of $0.034 \mathrm{tCO}_{2} \mathrm{e}$. Finally, the furnace operated house had the same savings on emissions at $1.3 \mathrm{tCO}_{2} \mathrm{e}$ for both Ottawa and Toronto, but similar to 
Ottawa, the house operating with a natural gas boiler was cheaper to operate by $\$ 65$ annually in comparison to the house operating with a HPWH.

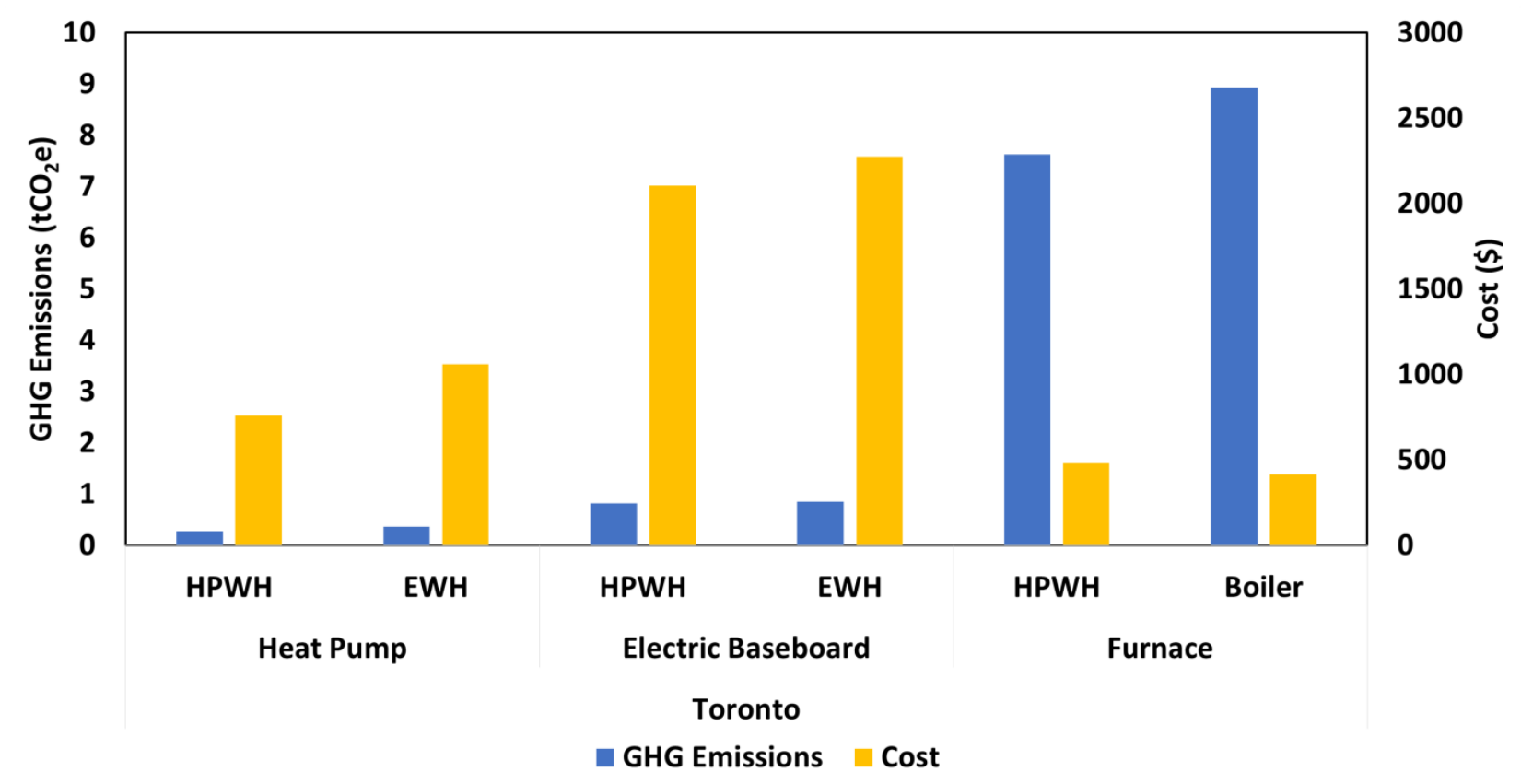

Figure 6-2: Annual cost and emissions results for different house set-ups in Toronto

Energy billing and electricity sources for the house types were also compared for different provinces. For Quebec, the city of Montreal was selected. It can be observed in Figure 6-3 that the annual energy cost for the house using a heat pump for space heating was \$565 when using a HPWH unit for DHW in comparison to same house with an EWH for DWH at $\$ 755$. The reduction in GHG emissions was found to be $0.02 \mathrm{tCO}_{2} \mathrm{e}$ for the house with a HPWH, and $0.015 \mathrm{tCO}_{2} \mathrm{e}$ for the house with the EWH. Furthermore, for the house operating with electric baseboard heaters for space heating, the annual energy costs for the HPWH and EWH were $\$ 1795$ and $\$ 1863$, respectively. Similarly, the lower energy consumption produced slightly lower emissions at $0.044 \mathrm{tCO}_{2} \mathrm{e}$ for the HPWH and $0.046 \mathrm{tCO}_{2} \mathrm{e}$ for the EWH. The house with the furnace space heating system was neglected for Montreal, since the province has a $99 \%$ dependency on electricity [65], due to the low cost of production. Consequently, the operation 
cost of the houses in Quebec was significantly lower than the houses simulated in Ontario due to the lower cost of electricity in Quebec. However, the savings potential for the HPWH was not as high as it was for Ontario. The reason for the higher saving potential in Ontario is due to the time-of-use billing on electricity which significantly increases the electricity rate at high-peak hours. Thus, when a HPWH operates in high-peak hours, it greatly reduces the operational cost in comparison to a EWH. On the other hand, Montreal has a flat electricity rate at $0.057 \$ / \mathrm{kWh}$ with a cap at $30 \mathrm{kWh}$ per day after which the electricity rate is increased to $0.087 \$ / \mathrm{kWh}$. Therefore, there is less potential for cost saving, because although the HPWH consumes less energy to operate, the length of time to reach the set-point is three times higher than an EWH.

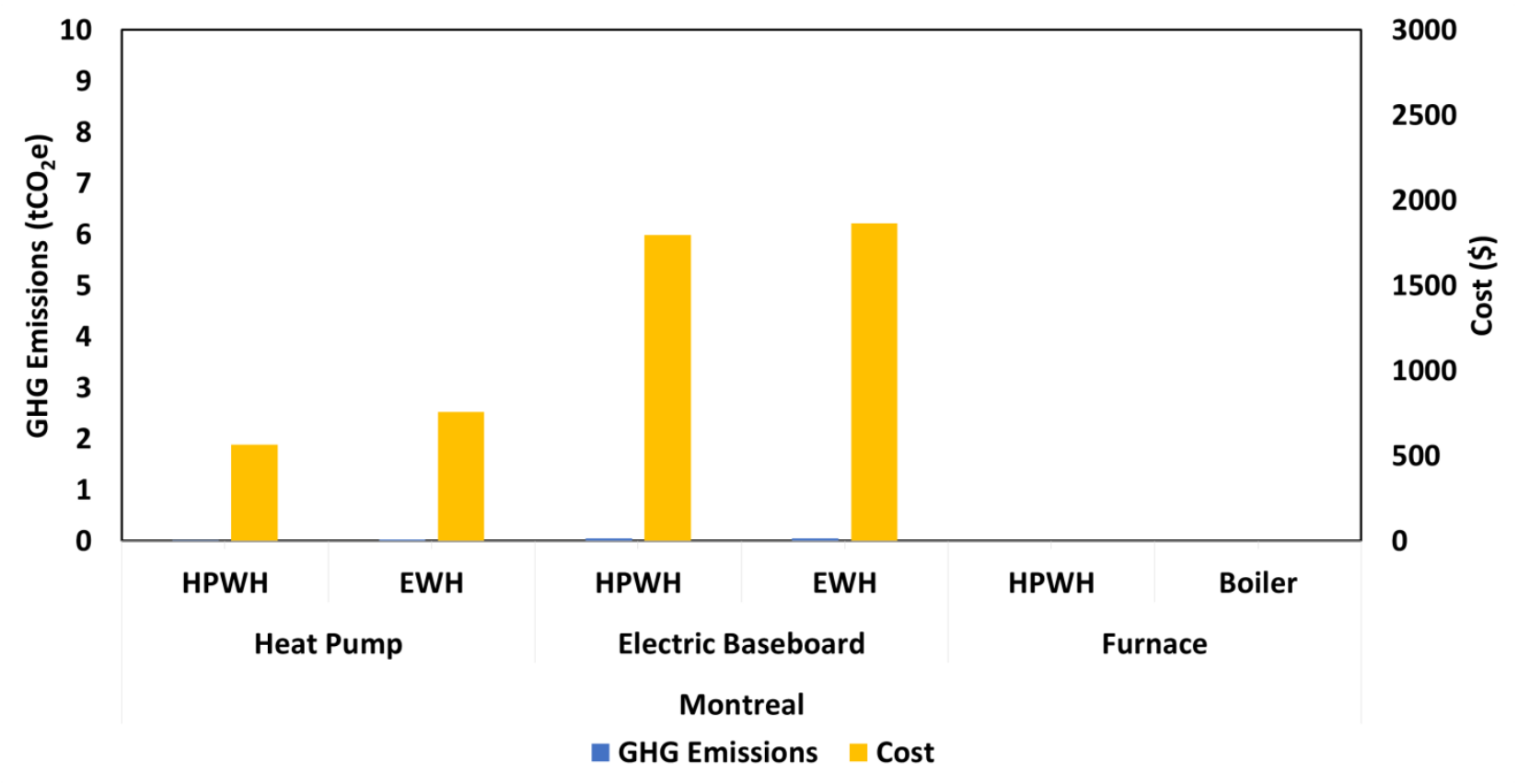

Figure 6-3: Annual cost and emissions results for different house set-ups in Montreal

Similar trends are shown in Figure 6-4 when the simulations were carried out for Vancouver. Vancouver has a high dependency on hydropower at $90 \%$ of the total production, and cheap electricity rates of $\$ 0.083 / \mathrm{kWh}$ up to a $1350 \mathrm{kWh}$, following by an increase to $\$ 0.124 / \mathrm{kWh}$. The high dependency on hydropower generation causes a low emissive power 
generation at $10.57 \mathrm{~g} / \mathrm{kWh}[66]$. It was less expensive to operate the houses in Vancouver in comparison to Montreal due to the mild weather throughout the year. However, the potential cost saving was similar to Montreal, due to the electricity rate billing practice. Finally, because of the higher emissions from electricity production in Vancouver, there was higher potential in $\mathrm{CO}_{2}$ emission savings; however, these savings were in significant compared to the savings in Toronto and Ottawa.

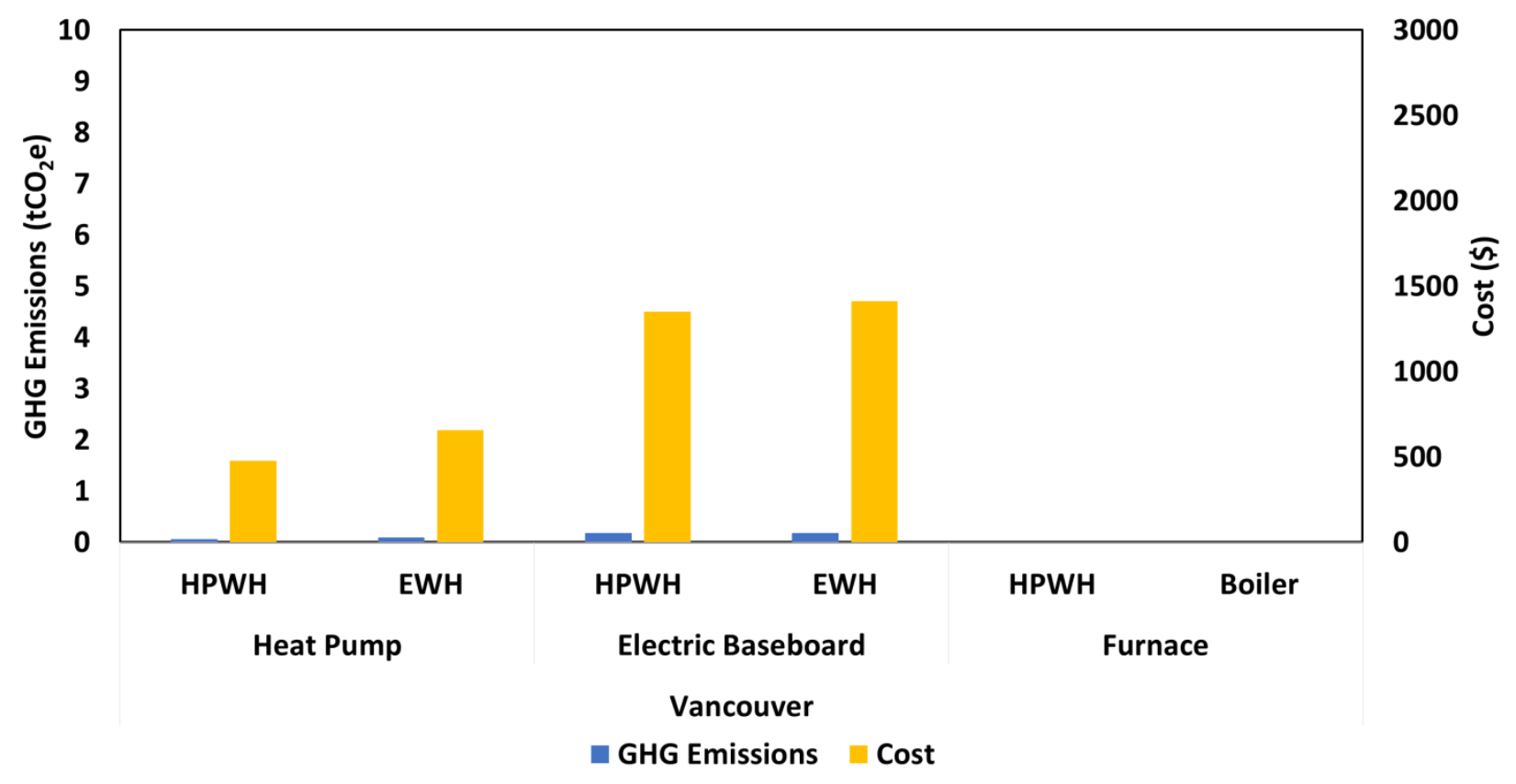

Figure 6-4: Annual cost and emissions results for different house set-ups in Vancouver

Before a conclusion can be made on the analysis, the payback period must be calculated to understand the potential of the unit installed in a conditioned space for cold environments. The $189 \mathrm{~L}$ GeoSpring hybrid heat pump water heater unit is sold for approximately $\$ 1400$. The pay-back period was calculated and is shown for each house set-up for the different cities in Table 6-1. The payback period was calculated either assuming the unit is installed brand new or as a replacement (generally either the boiler or the EWH) dependent on the house set-up. These units typically cost around $\$ 650$ on average. Furthermore, the payback period was compared to 
that of when the space cooling and heating was not taken into account. The results of the payback period analysis showed that the HPWH will generate savings after 4 years of operation in Ontario, if the unit is not replacing an existing water heating unit, and the effect on the space heating and cooling is neglected. For Montreal and Vancouver, the payback period was found to be significantly higher due to cheaper electricity rates. However, the payback period increases considerably when the effect of HPWH on the space heating and cooling is introduced, for newly installed HPWH units. However, when taken into account pre-exiting unit replacement, the payback period goes down from 8 to 4 years in Ottawa, and down from 9 to 5 years in Toronto. For Montreal and Vancouver, the electricity costs are low enough to use a EWH, as the payback period of the HPWH was higher than the life expectancy of the unit (8-12 years).

Table 6-1: Payback period summary for different Canadian cities

\begin{tabular}{|c|c|c|c|c|}
\hline \multirow[b]{2}{*}{ City } & \multirow[b]{2}{*}{ Space Heating } & \multicolumn{3}{|c|}{ HPWH Payback Period (Years) } \\
\hline & & New Installation & $\begin{array}{l}\text { Replacement } \\
\text { Installation }\end{array}$ & $\begin{array}{l}\text { Only DWH } \\
\text { (new unit) }\end{array}$ \\
\hline \multirow{3}{*}{ Ottawa } & Heat Pump & 5 & 3 & \multirow{2}{*}{ ( } \\
\hline & Electric Baseboard & 8 & 4 & \\
\hline & Furnace & - & - & - \\
\hline \multirow{3}{*}{ Toronto } & Heat Pump & 5 & 3 & \multirow{2}{*}{4} \\
\hline & Electric Baseboard & 9 & 5 & \\
\hline & Furnace & - & - & - \\
\hline \multirow{3}{*}{ Montreal } & Heat Pump & 8 & 4 & \multirow{2}{*}{12} \\
\hline & Electric Baseboard & 21 & 12 & \\
\hline & Furnace & - & - & - \\
\hline \multirow{3}{*}{ Vancouver } & Heat Pump & 8 & 5 & \multirow{2}{*}{9} \\
\hline & Electric Baseboard & 24 & 13 & \\
\hline & Furnace & - & - & - \\
\hline
\end{tabular}




\subsection{Summary}

This chapter commenced by discussing the results of the unit's performance with different independent variables. Furthermore, the reasons behind the discrepancies observed between the experimental and modelling results, as seen in Chapter 5, were discussed, concluding that the HPWH Type had good performance predictability for the physical variables of the unit. Most of the discrepancy occurred due to water mixing in the storage tank Type in TRNSYS. Finally, the performance of the HPWH in basement installations was expanded for different space heating systems. This was performed to compare the results of the cost savings and the reduction in emissions with other existing water heating technologies for different Canadian locations. The final chapter will provide concluding remarks and an outline of the future work that is recommended. 


\section{Chapter: Conclusions and Future Work}

\subsection{Conclusions}

The largest challenge in HPWH unit installation in conditioned spaces arises from the shift of energy from water heating to space heating and cooling, due to the colder exhaust air exiting the HPWH unit during operation. To facilitate penetration in the Canadian market, HPWH technology must be evaluated for different climatic and house conditions in order to understand the savings potential and limitations of the units. This thesis focused on the design, construction and instrumentation of an experimental set-up to evaluate a commercial HPWH unit. A performance map was developed to characterize the performance of the HPWH for a range of operating conditions. A TRNSYS model, using a new HPWH Type, was developed to accurately predict the performance of the condenser coil for the HPWH and the overall unit performance. Finally, the energy and cost savings, emission reduction and payback period were calculated using the TRNSYS model for the HPWH, coupled with a house model for different Canadian cities.

The experimental testing apparatus was designed to investigate the performance sensitivity of the HPWH unit for different independent variables. The design of the apparatus allowed the variation of three variables: the supply air temperature, humidity and flowrate. The experimental apparatus was used to calibrate the TRNSYS Type for the HPWH unit and determine the length of the condenser coil. The apparatus was then used to test the thermal and electrical performance of the HPWH unit using CSA-F379.1 water draw profiles for validation purposes of the computer model.

The modelling study was carried out by creating a TRNSYS Type for the HPWH unit in order to accurately model the behavior of the wrap-around coil condenser and the unit as a 
whole. The TRNSYS Type used psychrometric equations, interpolation routines and heat transfer equations to simulate the energy consumption of the unit and the exhaust temperature introduced into the space. The modelling study used three different types of heating systems: a heat pump, electric baseboard and furnaces, as well as two alternative water heating units, boilers and EWH. Therefore, a comparison between the energy saving potential and $\mathrm{CO}_{2}$ emissions of the HPWH in the different house set-ups in to the current DWH technologies could be made.

The sensitivity analysis on the HPWH unit showed that the unit's performance is significantly affected by the temperature of the supplied air. The humidity of the supplied air played a lesser role on the performance of the unit due a lower range in humidity in a basement setting, since a basement generally has low humidity in order to prevent condensation. The validation test of the computer model provided good agreement between the computer model and the physical model. Most of the discrepancies between the model and the physical unit were due to the storage tank Type in TRNSYS having a limited ability to predict the change in water temperature during a water draw event.

The performance of the unit was found to be independent of the ambient temperature of the region throughout the year, with a COP fluctuating between 2 and 3 . The unit showed a lower basement temperature during HPWH operations, which required an adjustment by the space heating and cooling. It was shown that the house is still capable of generating energy savings with the HPWH unit installation in comparison to houses with a EWH unit in all the tested cities. However, cities with dominant natural gas dependency had a negative energy saving when using the HPWH unit. These houses benefited from the immense reduction in $\mathrm{CO}_{2}$ emissions. The unit payback period was calculated to be 4 years in Ontario, when only considering the energy involved in DWH. Due to the effect on the space heating and cooling, the 
payback period was calculated using the energy saved by the house as a whole giving a payback period of 8 to 9 years for a new unit installation and 4 to 5 years for an old unit replacement. However, due to both Quebec and British Columbia's cheap and clean energy, the saving potential of the HPWH unit was insignificant to the energy consumption using EWH units. The study concluded that the unit's potential was significantly dependent on the locations' energy cost and billing practices. Ontario's time-of-use billing had a significant effect on increasing the energy saving potential of the unit in comparison to that of Quebec and British Columbia. However, due to the dominant natural gas dependency of Ontario, the HPWH will struggle to penetrate the market until more rebates on emissions reduction and natural gas price increases occur.

\subsection{Future Work}

The work conducted for this thesis is part of a larger project intended to understand the potential and feasibility of the HPWH units in the Canadian climate. This thesis concluded that installation of the HPWH unit in Ontario may lead to both cost and GHG emission savings. The downfall of these units is their negative effect on the space heating system of the house. Therefore, to study the potential of these units when coupled to a ducting system, which diverts the exhaust air to the outside, eliminating the energy shift on the space heating. This can be expanded to an optimization strategy study to expel exhaust air from the HPWH to the outside, while making use of the cold exhaust air in summer, allowing a shift in some of the cooling loads to the HPWH unit's exhaust air. Moreover, the study only examined the performance of the unit for $150 \mathrm{~L}$ with heat pump-only operations. The study can be extended by testing the $225 \mathrm{~L}$ daily draw for the $189 \mathrm{~L}$ unit, in order to test the feasibility of the unit when it is operating in hybrid mode, to maintain the higher DHW demands. The TRNSYS model for the house can be 
extended to simulate the performance enhancement of the HPWH when coupled with photovoltaic and solar thermal technology. Previous studies were conducted on the comparison between these technologies, for water heating purposes, resulting in significant saving potential. Coupling solar collectors with HPWH units can result in a benefit in the performances of both units. Finally, a first principle computer model can be developed in order to further optimize the performance of the HPWH unit on component bases, such as the evaporator, condenser and compressor size. Moreover, the unit can be optimized based on an operating refrigerant which can provide a wider range of operating temperatures. 


\section{References}

[1] Southern Baptist Convention, "Clean Energy Act," 31 May 2013. [Online]. Available: goo.gl/aHkHm0.

[2] Ministry of Finance Tax Bulletin, "Tax Rates on Fuels Motor Fuel Tax Act and Carbon Tax Act," Augest 2016. [Online]. Available: http://www2.gov.bc.ca/assets/gov/taxes/salestaxes/publications/mft-ct-005-tax-rates-fuels.pdf. [Accessed February 2017].

[3] Natural Resources Canada, "Overview - Residential energy use and GHG emissions," in Energy Efficiency Trends in Canada, 1990 to 2007, Ottawa, NRCan, 2010.

[4] Natural Resources Canada, "Energy Use Handbook - 1990 to 2013," Office of Energy Efficiency, Ottawa, 2013.

[5] Natural Resources Canada, "Water Heater Guid," Office of Energy Efficiency, Ottawa, 2012.

[6] A. Hepbasli and Y. Kalinci, "A review of heat pump water heating systems," Renewable and Sustainable Energy Reviews, vol. 13, p. 1211-1229 , 20 February 2009.

[7] J. Maguire, X. Fang and E. Wilson, "Comparison of Advanced Residential Water Heating Technologies in the United States," NREL, Golden, 2013.

[8] Enviroment Canada, "Temperature Climatology Map," Government of Canada, Ottawa, 2017.

[9] Solar Energy Laboratory, "Volume 7 Programmer's Guide," TRNSYS 17, Madison, WI, 2012. 
[10] Y. A. Cengel and A. B. Michael, Thermodynamics: An Engineering Approach, 6th ed., New York: McGraw Hill Companies, Inc, 2006.

[11] V. Stevens, C. Carven and R. Garber-Slaght, "Air Source Heat Pumps in Southeast Alaska: A review of the literature, a market assessment, and preliminary modeling on residential air source heat pumps in Southeast Alaska," Cold Climate Housing Research Center, Fairbanks, 2013.

[12] A. S. Vieira, R. A. Stewart and C. D. Beal, "Air source heat pump water heaters in residential buildings in Australia: Identification of key performance parameters," Buildings and Energy, vol. 91, pp. 148-162, 2015.

[13] Solar Energy Laboratory, "Volume 4 Mathematical Reference," in TRNSYS, Madison, WI, 2012.

[14] K. Hudon, B. Sparn, D. Chistensen and J. Maguire, "Heat Pump Water Heater Technology Assessment Based on Laboratory Research and Energy Simulation Models," in ASHRAE Winter Conference, Colorado, 2012.

[15] B. Sparn, K. Hudon and D. Christensen, "Laboratory Performance Evaluation of Residential Integrated Heat Pump Water Heater," National Renewable Energy Laboratory, Colorado, 2014.

[16] S. Widder, G. Parker, J. Petersen and M. Baechler, "Demand Response Performance of GE Hybrid Heat Pump Water Heater," Pacific Northwest National Laboratory, Richland, Washington, 2013.

[17] K. Roth, J. Dieckmann and J. Brodrick, "Heat Pumps for Cold Climates," ASHRAE Journal, vol. 51, no. 2, pp. 69-72, 2009 ". 
[18] J. Bursill and C. A. Cruickshank, "Heat Pump Water Heater Control Strategy Optimization for Cold Climates," in PowerEnergy2015, California, USA, 2015.

[19] M. Lei, H. Zhang, F. Wang and X. You, "Experimental study of an instantaneous-heating air source heat pump water with a temperature stratified water tank," Advances in Mechanical Engineering, vol. 8, no. 9, pp. 1-9, 2016.

[20] R. S. Kamel, A. S. Fung and P. R. Dash, "Solar systems and their integration with heat pumps: A review," Energy and Buildings, vol. 87, pp. 395-214, 2014.

[21] M. Chandrashekar, N. T. Le, H. F. Sullivan and K. G. T. Hollands, "A comparative study of solar assisted heat pump systems for canadian locations," Solar Energy, vol. 28, no. 3, pp. 217-226, 1982.

[22] Y. W. Li, R. Z. Wang, J. Y. Wu and Y. X. Xu, "Experimental performance analysis on a direct-expansion solar-assisted heat pump water heater," Applied Thermal Engineering, vol. 27, p. 2858-2868, 2007.

[23] A. G. Bridgeman, Experimental Analysis of an Indirect Solar Assisted Heat Pump for Domestic Hot Water Heating, Kingston, ON: Queen’s University, 2010.

[24] S. J. Sterling and M. R. Collins, "Feasibility analysis of an indirect heat pump assisted solar domestic hot water system," Applied Energy, vol. 93, pp. 11-17, 2012.

[25] J. Chu, "Evaluation of a Dual Tank Indirect Solar-Assisted Heat Pump System for a High Performance House by," in Master's Thesis, Carleton University, Ottawa, 2014.

[26] K. G. Hollands and M. F. Lightstone, "A review of low-flow, stratified-tank solar water heating systems," Solar Energy, vol. 43, no. 2, pp. 97-105, 1989. 
[27] T. L. Freeman, J. W. Mitchell and T. E. Audit, "Performance of combined solar-heat pump systems," Solar Energy, vol. 22, no. 2, pp. 125-135, 1979.

[28] S. Li, S. Li and X. Zhang, "Comparison analysis of different refrigerants in solar-air hybrid heat source heat pump water heater," International Journal of Refrigeration, vol. 57, pp. 138-146, 2015.

[29] A. Ibrahim, M. Othman, M. Ruslan, M. Sohif and S. Kamaruzzaman, "Recent advances in flat plate photovoltaic/thermal (PV/T) solar collectors," Renewable and Sustainable Energy Reviews, vol. 15, no. 1, pp. 352-365, 2011.

[30] M. D. Bazilian, H. Kamalanathan and D. K. Prasad, "Thermographic analysis of a building integrated photovoltaic system," Renewable Energy, vol. 26, no. 3, pp. 449-461, 2002.

[31] H. A. Zondag, D. W. DE Vries, W. G. J. Van Helden, R. J. C. Van Zolingen and A. A. Van Steenhoven, "the Thermal and Electrical Yield of a Pv-Thermal Collector," Solar Energy, vol. 72 , no. 2 , pp. 113-128, 2002.

[32] G. Pie, J. Ji, K. Liu, H. He and A. Jiang, "Numerical study of PV/T-SAHP system," Journal of Zhejiang University SCIENCE A, vol. 9, no. 7, pp. 970-980, 2008.

[33] R. Kamel and A. Fung, "Modeling, simulation and Feasibility analysis of Residential bipv/t+ashp System in cold climate-Canada," Energy and Buildings, vol. 82, pp. 758-770, 2014.

[34] J. Berger and S. J. Harrison, "Modelling of photovoltaic, solar thermal, and photovoltaic/thermal domestic water systems," in eSim Building Perfromance Simulation Conference, Hamilton, 2016. 
[35] H. Zondag, "Recommended Standard for the Characterization and Montoring of PV/Thermal Systems," International Energy Agency Solar Heating \& Cooling Programme., Paris, 2009.

[36] C. Baldwin and C. A. Cruickshank, "Using TRNSYS Types 4, 60, 534 to model residential cold thermal storage using water and water/glycol solutions," in eSim Building Performance Simulation Conference, Hamilton, 2016.

[37] J. Bursill , "Evaluation of Heat Pump Water Heater Performance and Optimization Strategies In Canadian Climates," in Master's Thesis, Carleton University, Ottawa, 2015.

[38] Y. Allard, M. Kummer, M. Bernier and A. Moreau, "INTERMODEL COMPARISON AND EXPERIMENTAL VALIDATION OF ELECTRICAL WATER HEATER MODELS IN TRNSYS," in 12th Conference of International Building Performance Simulation Association, Sydney, 2011.

[39] C. A. Cruickshank and S. J. Harrison, "Heat loss characteristics for a typical solar domestic hot water storage," Energy and Buildings, vol. 42, no. 10, pp. 1703-1710, 2010.

[40] C. Tran, P. Riviére and P. Waide, "Energy Efficiency Modelling of Residential Air Source Heat Pump Water Heater," Journal of Sustainable Development of Energy, Water and Environment Systems, vol. 4, no. 1, pp. 69-88, 2016.

[41] J. Berger, "The Modelling of Photovoltaic, Solar Thermal, and Photovoltaic/thermal Domestic Hot Water Systems," in M.A.Sc Thesis, Queen's University, Queens, 2016.

[42] Stiebel Eltron, Operation and Installation, Germany: Stiebel Eltron, 2011.

[43] GE Appliances, Technical Service Guide - GE Hybrid Water Heater, Kentucky: GE Appliances, 2012. 
[44] Omega, "HX94A SERIES RH/Temperature Transmitter," Omega, Biel/Bienne, Switzerland, 2016.

[45] Dent Instruments, "Operator's Guide PowerScout 24 Power Meter," Dent Instruments, Oregon, 2014.

[46] Skuttle, "Model 592 Spray Humidifier," $20 \quad 01 \quad 2017 . \quad$ [Online]. Available: http://skuttle.com/wp1/?page_id=210. [Accessed 0505 2017].

[47] Brooks-Oval, "Brooks-Oval Models: BM04, BM07, BM10, BM40 \& BM50," Brooks-Oval, [Online]. Available: goo.g1/A3V0CN. [Accessed 2202 2017].

[48] Omega Controls, "Revised Thermocouple Reference Tables - Type T Refence Tables," [Online]. Available: http://www.omega.ca/temperature/Z/pdf/z207.pdf. [Accessed 2202 2017].

[49] C. Baldwin, "Design and Construction of an Experimental Apparatus to Assess the 108," in Master's Thesis, Carleton University, Ottawa, 2013.

[50] National Instruments, "NI 9214 High-Accuracy Thermocouple Module," National Instruments, 2409 2014. [Online]. Available: http://www.ni.com/datasheet/pdf/en/ds-314. [Accessed 2202 2017].

[51] "Technical Service Guide," GE Appliances, 2012.

[52] ASHREA, "Handbook of Fundamentals (SI)," in Psychrometrics, Atlanta, Ga, American Society of Heating Refrigeration and Air Conditioning Engineers, 2001, pp. 6.1-6.17.

[53] P. Smith, Interviewee, Cooldown Test Data. [Interview]. 1102016.

[54] S. A. Klein, "A Design Procedure for Solar Heating Systems," in Ph.D. Thesis, Department of Chemical Engineering, University of Wisconson-Madison, Madison, WI, 1976. 
[55] B. Swistock, "Water System Planning—Estimating Water," U.S. Department of Agriculture, Pennsylvania, 2017.

[56] Canadian Standards Association, "CAN/CSA-F379.1-88: Solar Domestic Hot Water Systems (Liquid to Liquid Heat Transfer)," CSA, Mississauga, ON, 2004.

[57] Natural Resources Canada, "EnerGuide in Canada," Natural Resources Canada, Ottawa, ON, 2016.

[58] C. Baldwin and C. A. Cruickshank, "Assessing the Potential for Reduction in Peak Residential Electrical Loads Using a Heat Pump and Thermal Storage Systems," in International High Performance Buildings Conference, West Lafayette, IN, 2016.

[59] F. C. McQuiston, J. D. Parker and J. D. Spilter, Heating, Ventilating and Air Conditioning Analysis and Design, 6th edition, New Delhi: Wiley India Pvt. Ltd., 2014, pp. 89-92.

[60] J. Burch and C. Christensen, "Towards Development of an Algorithm for Mains Water Temperature," National Renewable Energy Laboratory, Golden, Colorado, 2009.

[61] C. Aguilar, D. J. White and D. L. Ryan, "Domestic Water Heating and Water Heater Energy," CBEEDAC, Ottawa, 2005.

[62] C. R. Iskra and J. Simonson, "Effect of air humidity of the convective mass transfer coefficient in a rectangular duct," Departnment of Mechanical Engineering, University of Saskatchewan, Saskatoon, SK, 2006.

[63] SWEP, "Refrigerant handbook," SWEP, Landskrona, Sweden, 2016.

[64] Ontario Society of Professional Engineers, "Ontario's Energy Dilemma: Reducing Emissions at an Affordable Cost," Ontario Society of Professional Engineers, Toronto, ON, 2016. 
[65] Quebec Hydro, "GHG emissions and Hydro-Québec electricity," Quebec Hydro, Quebec, 2016.

[66] Ministry of Environment, "2016/17 B.C. best practices methodology for quantifying greenhouse gas emissions," Ministry of Environment, Victoria, B.C., 2016. 


\section{Appendix A}

\section{Heat Pump Water Heater Performance Map}

The performance map data required for Type 240 is provided in Table B-7-1, Table

B-7-2, Table B-7-3, and Table B-7-4. These data tables were created from experimental testing on the HPWH and used in the simulations for the HPWH operation.

Table B-7-1: Total cooling capacity in $\mathrm{kJ} / \mathrm{h}$

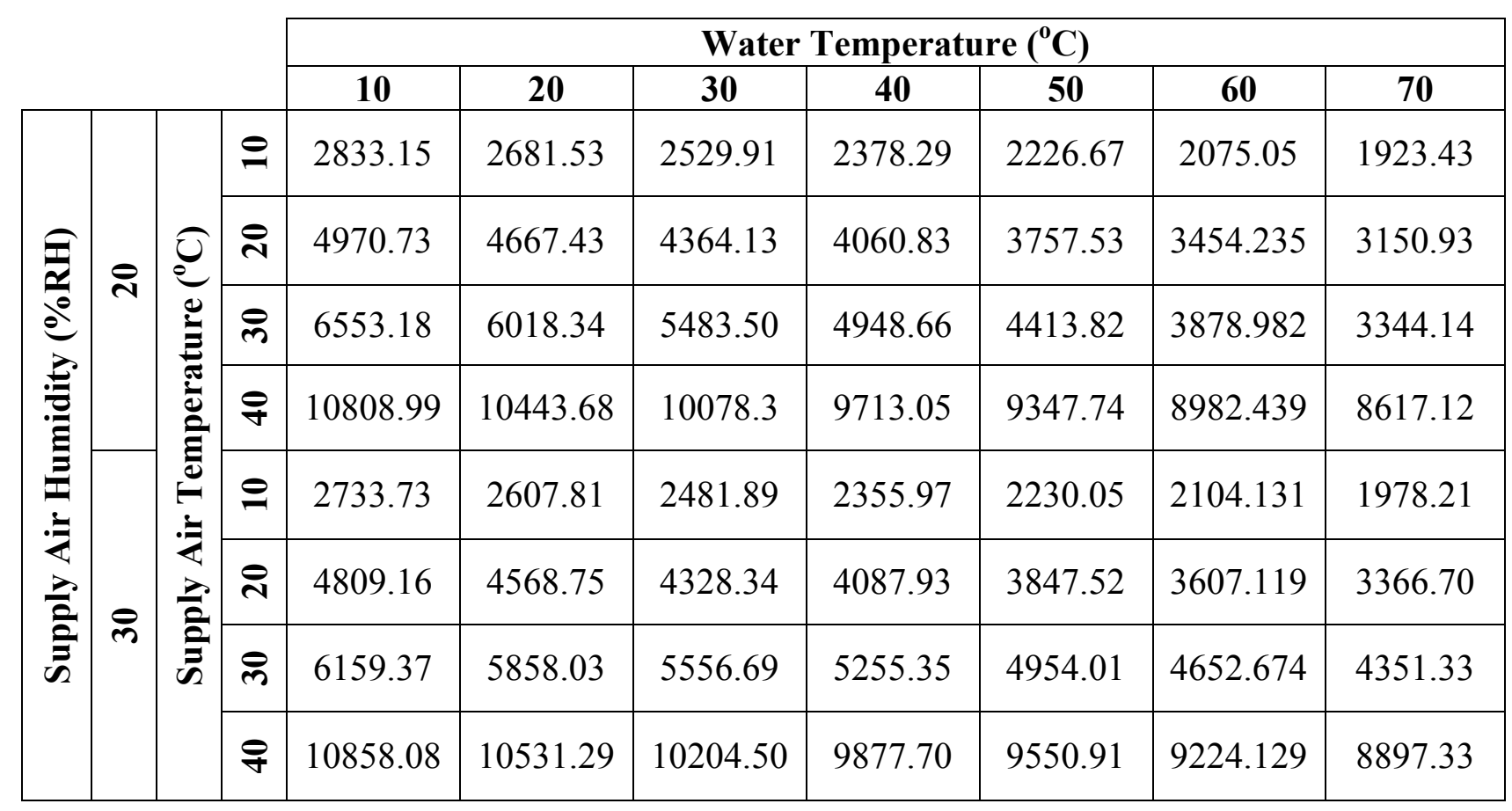


Table B-7-2: Sensible cooling capacity in $\mathrm{kJ} / \mathrm{h}$

\begin{tabular}{|c|c|c|c|c|c|c|c|c|c|c|}
\hline & \multicolumn{7}{|c|}{ Water Temperature $\left({ }^{\circ} \mathrm{C}\right)$} \\
\hline & & & & 10 & 20 & 30 & 40 & 50 & 60 & 70 \\
\hline \multirow{8}{*}{$\frac{\frac{\lambda}{2}}{\frac{2}{2}}$} & \multirow{4}{*}{ 구 } & \multirow{8}{*}{ 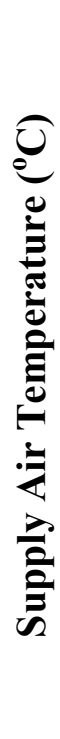 } & $\underline{\theta}$ & 2732.78 & 2581.16 & 2429.54 & 2277.92 & 2126.3 & 1974.68 & 1823.06 \\
\hline & & & ిㅗ & 4514.20 & 4210.90 & 3907.60 & 3604.30 & 3301.00 & 2997.70 & 2694.40 \\
\hline & & & ले & 6146.06 & 5611.22 & 5076.38 & 4541.54 & 4006.70 & 3471.86 & 2937.02 \\
\hline & & & \& & 7046.89 & 6681.58 & 6316.27 & 5950.96 & 5585.65 & 5220.34 & 4855.03 \\
\hline & & & 은 & 2619.88 & 2493.96 & 2368.04 & 2242.12 & 2116.20 & 1990.28 & 1864.36 \\
\hline & & & ชิ & 4744.79 & 4504.38 & 4263.97 & 4023.56 & 3783.15 & 3542.74 & 3302.33 \\
\hline & & & ले & 5557.46 & 5256.12 & 4954.78 & 4653.44 & 4352.10 & 4050.76 & 3749.42 \\
\hline & & & P & 7197.31 & 6870.52 & 6543.73 & 6216.94 & 5890.15 & 5563.36 & 5236.57 \\
\hline
\end{tabular}

Table B-7-3: Compressor power consumption in $\mathrm{kJ} / \mathrm{h}$

\begin{tabular}{|c|c|c|c|c|c|c|c|c|c|c|}
\hline & \multicolumn{7}{|c|}{ Water Temperature $\left({ }^{\circ} \mathrm{C}\right)$} \\
\hline & & & & 10 & 20 & 30 & 40 & $\mathbf{5 0}$ & 60 & 70 \\
\hline \multirow{8}{*}{ 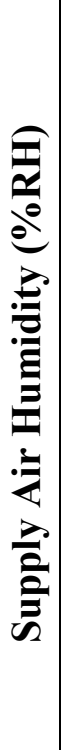 } & \multirow{4}{*}{ 고 } & \multirow{8}{*}{ 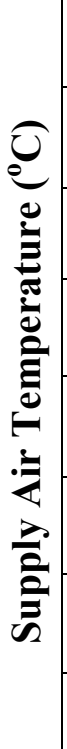 } & $\underline{\theta}$ & 1380.99 & 1399.77 & 1418.55 & 1437.34 & 1456.12 & 1474.91 & 1493.69 \\
\hline & & & 고 & 1229.04 & 1263.86 & 1298.67 & 1333.49 & 1368.30 & 1403.12 & 1437.93 \\
\hline & & & ஜ & 1749.43 & 1766.62 & 1783.80 & 1800.99 & 1818.18 & 1835.36 & 1852.55 \\
\hline & & & $\stackrel{\vartheta}{q}$ & 1272.12 & 1234.71 & 1197.23 & 1159.74 & 1122.26 & 1084.78 & 1047.29 \\
\hline & & & 으 & 1281.61 & 1326.92 & 1372.21 & 1417.52 & 1462.82 & 1508.12 & 1553.42 \\
\hline & & & ีำ & 1405.22 & 1411.51 & 1417.80 & 1424.09 & 1430.38 & 1436.68 & 1442.97 \\
\hline & & & ஜ & 2223.28 & 2265.06 & 2306.84 & 2348.63 & 2390.41 & 2432.20 & 2473.98 \\
\hline & & & \& & 1155.06 & 1129.39 & 1103.72 & 1078.05 & 1052.38 & 1026.72 & 1001.05 \\
\hline
\end{tabular}


Table B-7-4: Heat delivery in $\mathrm{kJ} / \mathrm{h}$

\begin{tabular}{|c|c|c|c|c|c|c|c|c|c|c|}
\hline & \multicolumn{7}{|c|}{ Water Temperature $\left({ }^{\circ} \mathrm{C}\right)$} \\
\hline & & & & 10 & 20 & 30 & 40 & 50 & 60 & 70 \\
\hline \multirow{8}{*}{ 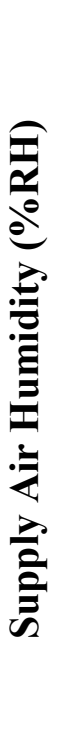 } & \multirow{4}{*}{ 로 } & \multirow{8}{*}{ 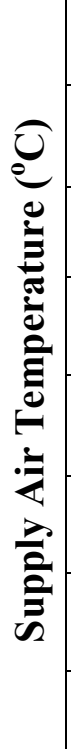 } & 은 & 5453.58 & 5146.26 & 4838.94 & 4531.62 & 4224.30 & 3916.98 & 3609.66 \\
\hline & & & ్ㅗ & 8026.75 & 7689.80 & 7352.85 & 7015.90 & 6678.95 & 6342.00 & 6005.05 \\
\hline & & & లి & 8729.28 & 8190.46 & 7651.64 & 7112.82 & 6574.00 & 6035.18 & 5496.36 \\
\hline & & & $\stackrel{9}{q}$ & 8303.84 & 7943.08 & 7582.32 & 7221.56 & 6860.80 & 6500.04 & 6139.28 \\
\hline & \multirow{4}{*}{ હે } & & $\Theta$ & 5545.39 & 5197.28 & 4849.17 & 4501.06 & 4152.95 & 3804.84 & 3456.73 \\
\hline & & & 고 & 7141.89 & 6820.08 & 6498.27 & 6176.46 & 5854.65 & 5532.84 & 5211.03 \\
\hline & & & లి & 8155.61 & 7715.22 & 7274.83 & 6834.44 & 6394.05 & 5953.66 & 5513.27 \\
\hline & & & f & 10015.41 & 9597.82 & 9180.23 & 8762.64 & 8345.05 & 7927.46 & 7509.87 \\
\hline
\end{tabular}




\section{Appendix B}

\section{Type 240 Heat Pump Water Heater FORTRAN Code}

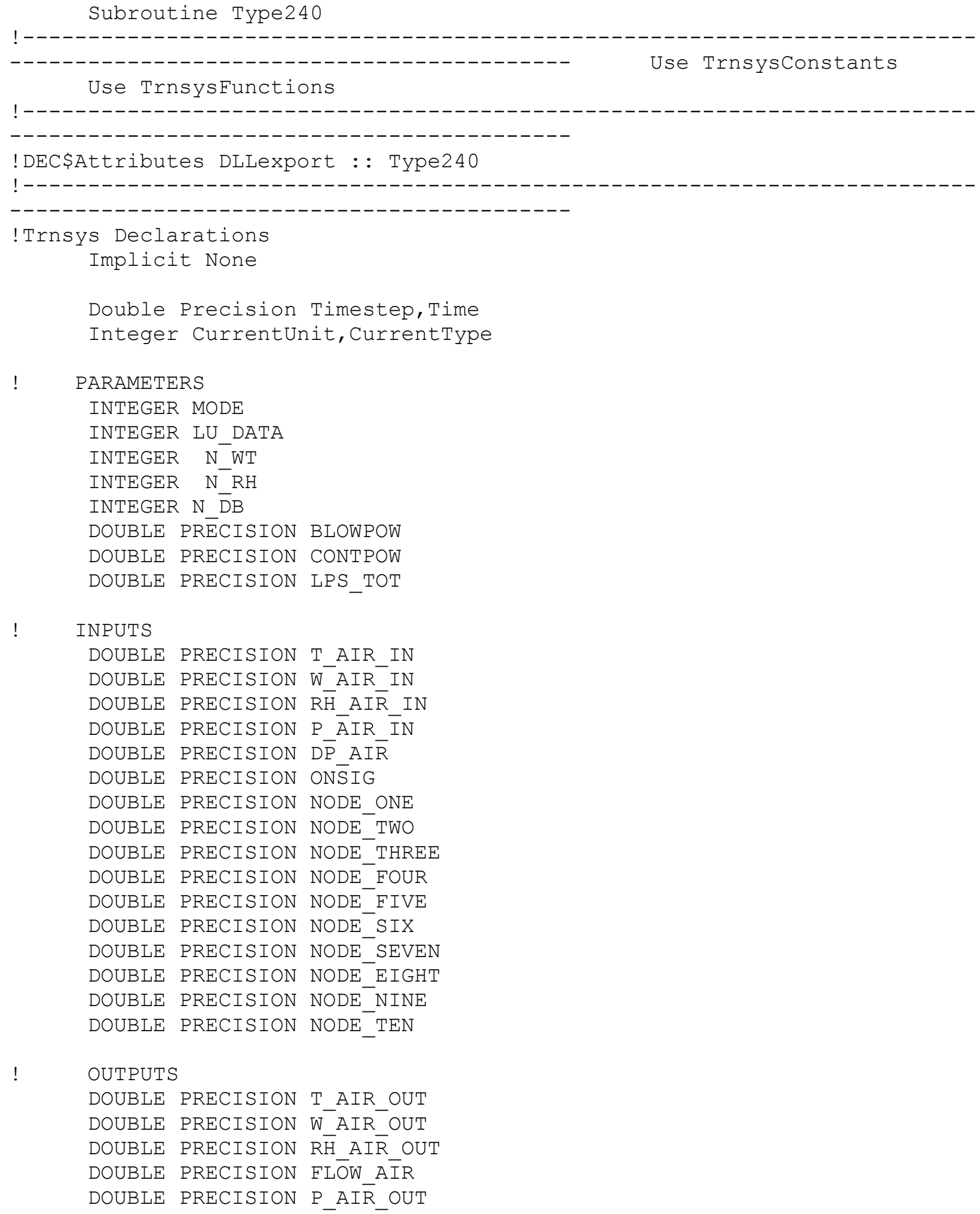




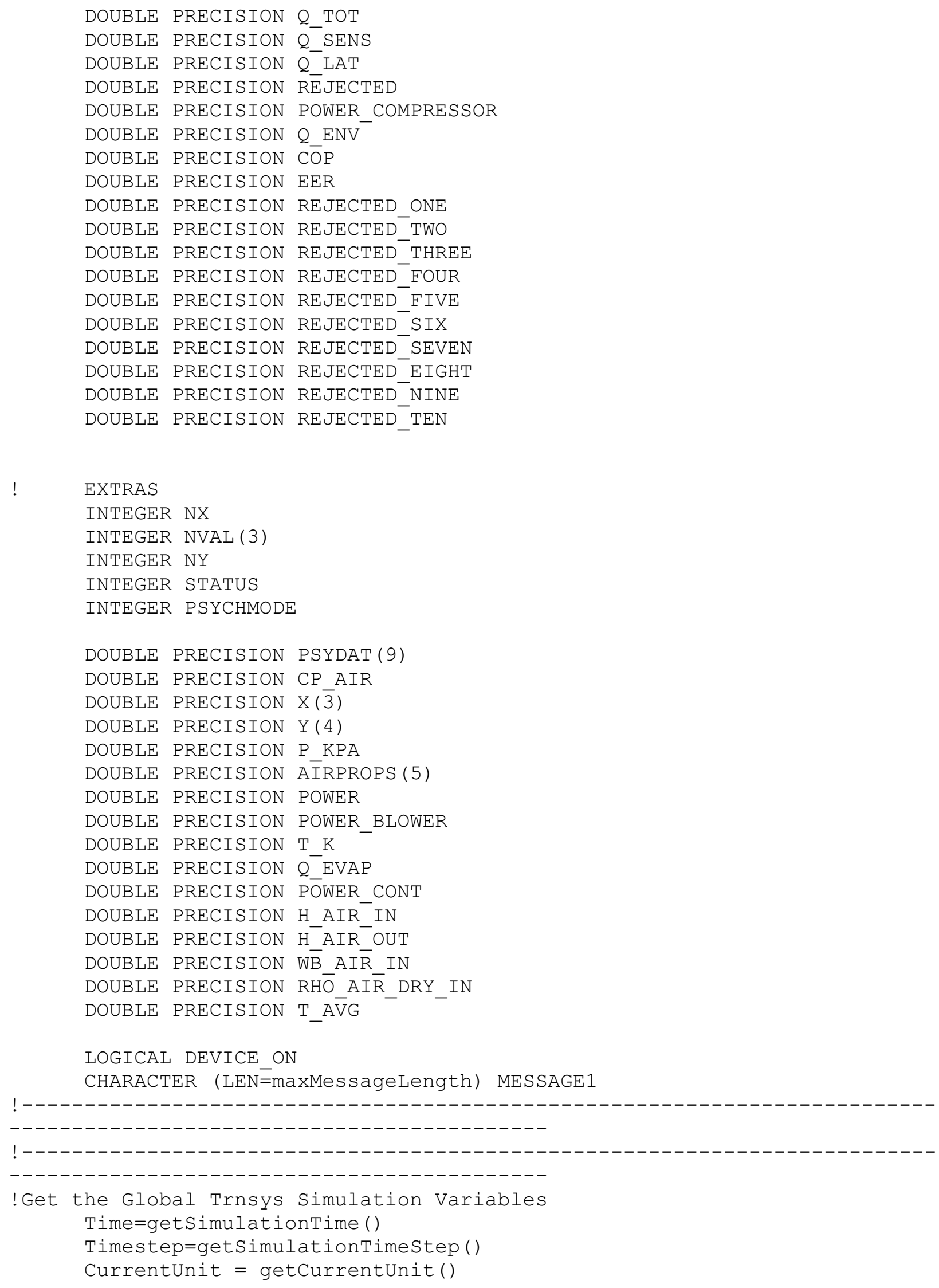


CurrentType = getCurrentType()

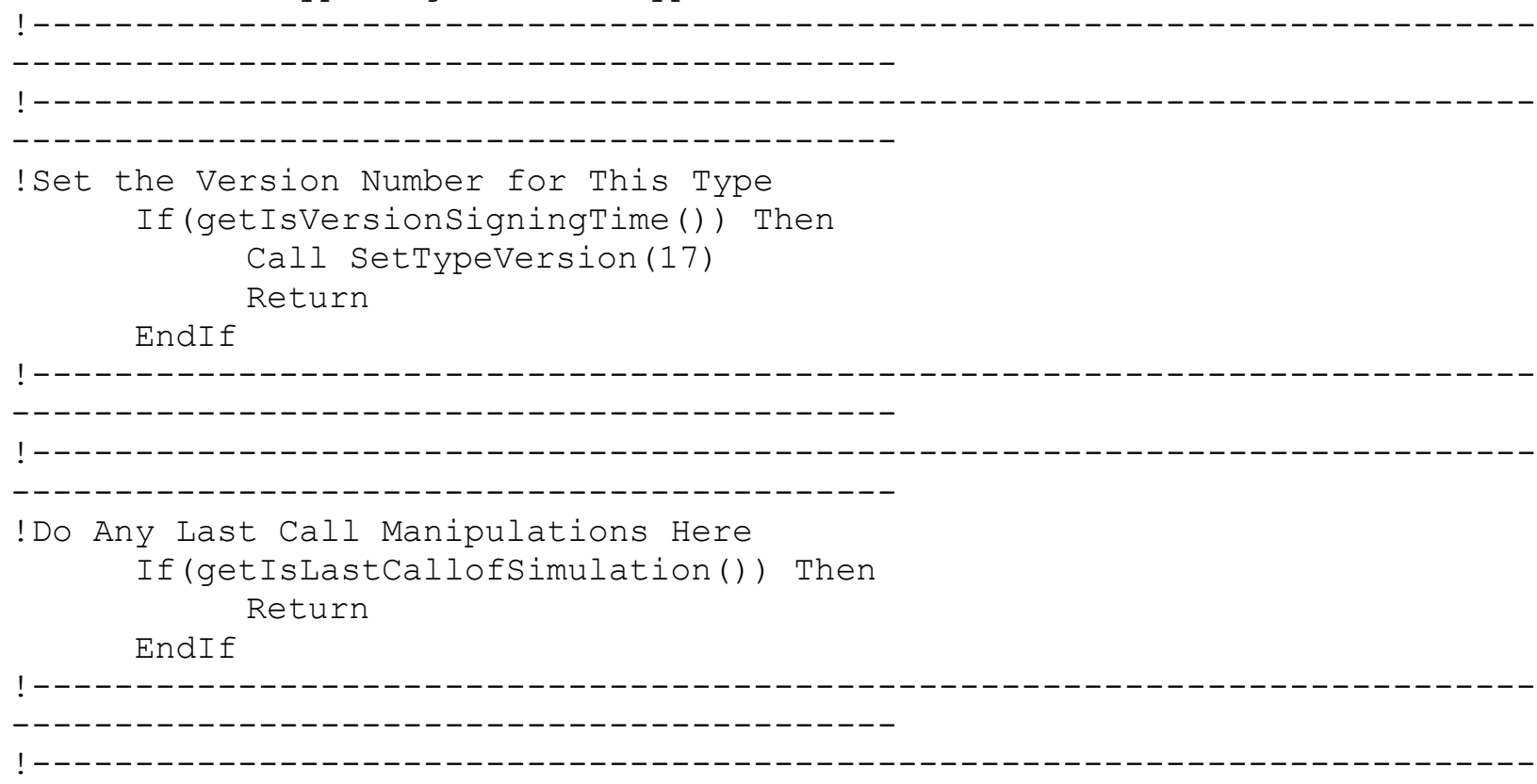

!Perform Any "After Convergence" Manipulations That May Be Required at the End of Each Timestep

If (getIsEndOfTimestep()) Then

Return

EndIf

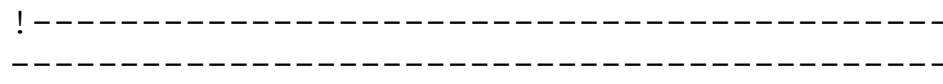

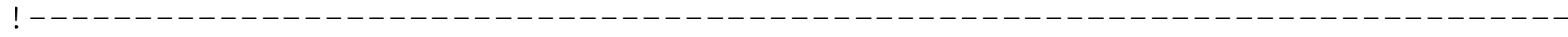

$-------------------------------------------$

!Do All of the "Very First Call of the Simulation Manipulations" Here If(getIsFirstCallofSimulation()) Then

! Tell the TRNSYS Engine How This Type Works

Call SetNumberofParameters(8) ! The number of

parameters that the the model wants

Call SetNumberofInputs(16) !The number of

inputs that the the model wants

Call SetNumberofDerivatives(0) !The number of

derivatives that the the model wants

Call setNumberofOutputs (24) ! The number of

outputs that the the model produces

Call SetIterationMode (1) ! An

indicator for the iteration mode (default=1). Refer to section 8.4.3.5 of the documentation for more details.

Call SetNumberStoredVariables $(0,0)$ ! The

number of static variables that the model wants stored in the global storage array and the number of dynamic variables that the model wants stored in the global storage array

Call SetNumberofDiscreteControls(0) !The number

of discrete control functions set by this model (a value greater than zero requires the user to use Solver 1: Powell's method) 
Return

EndIf

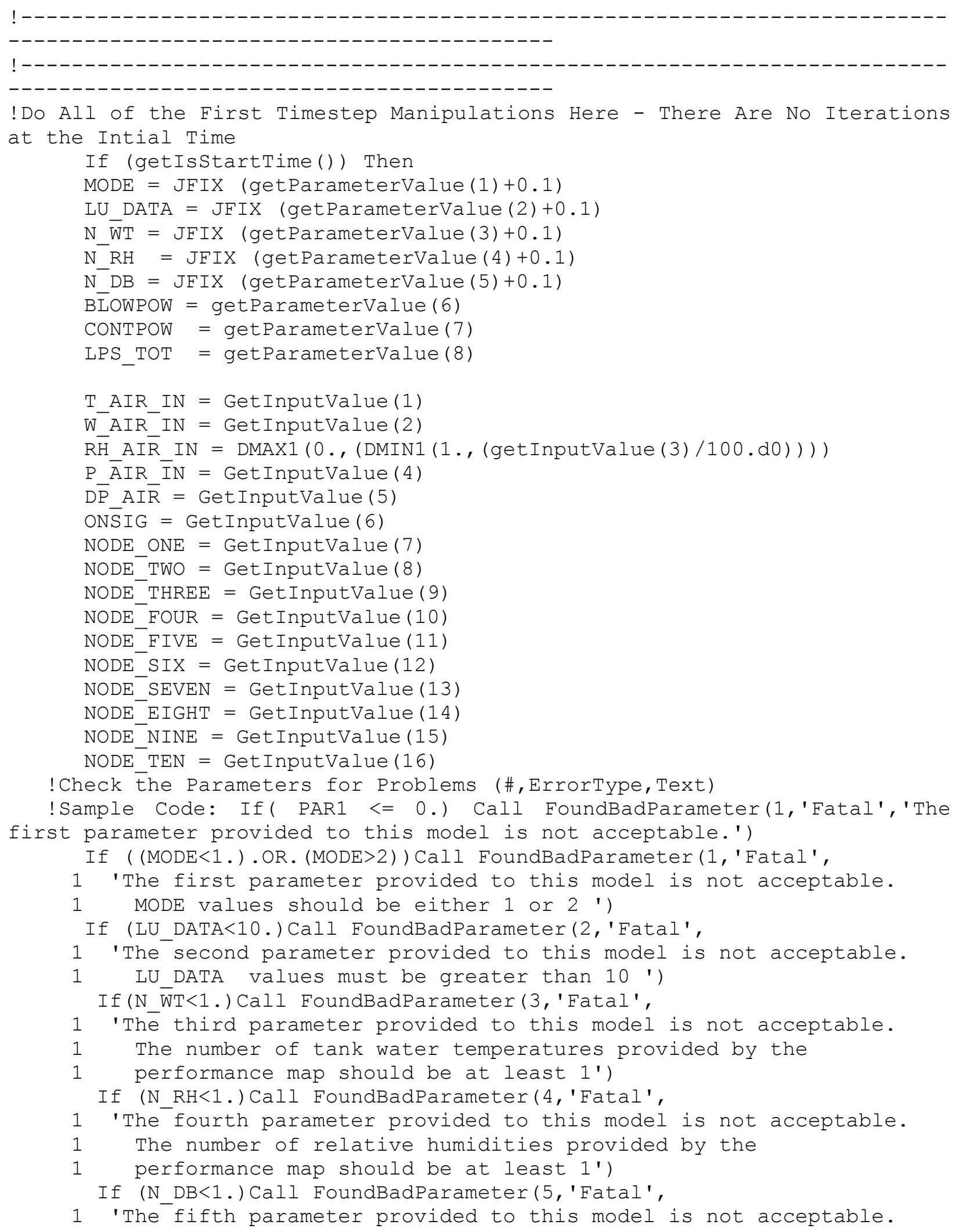




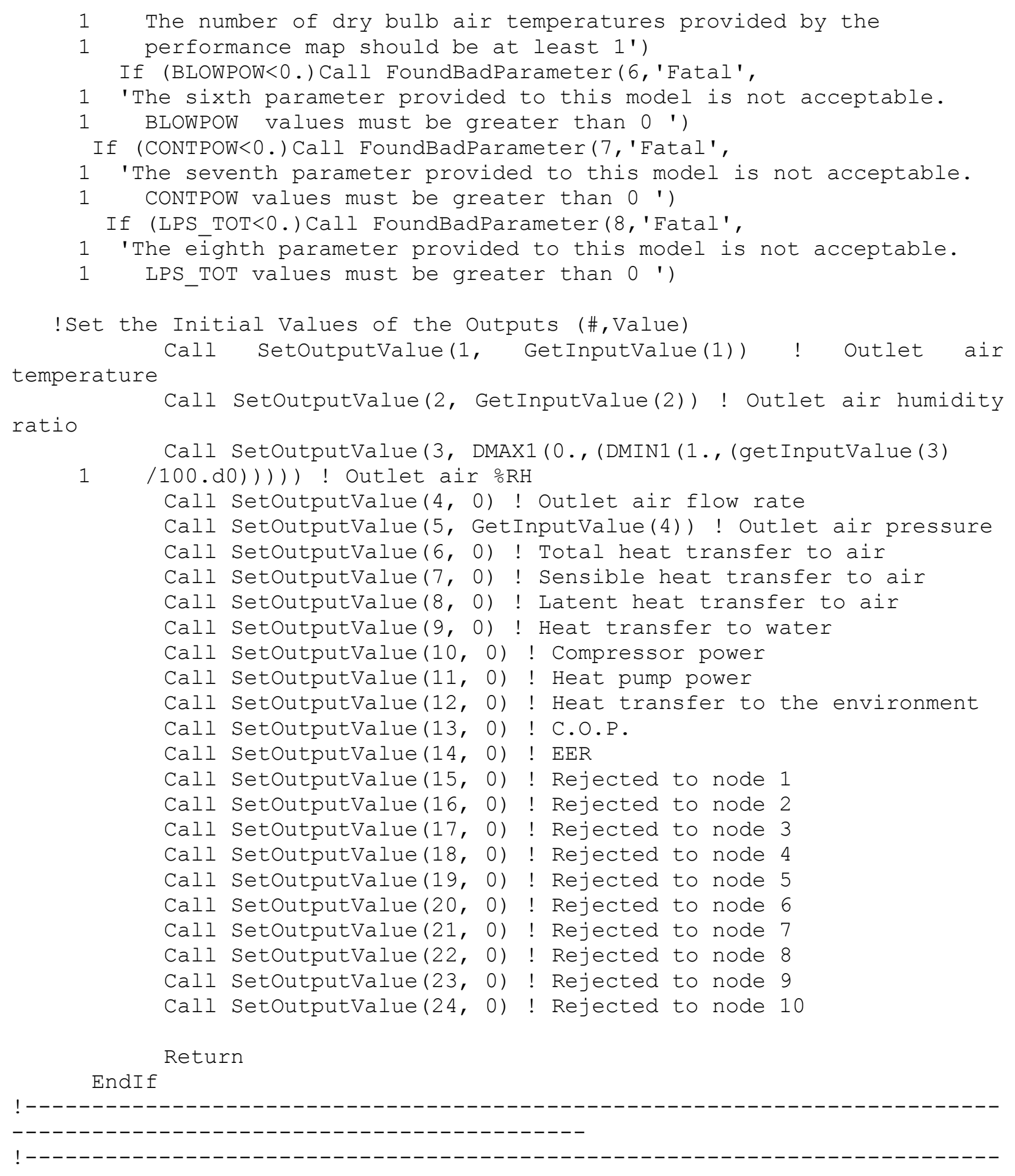

!ReRead the Parameters if Another Unit of This Type Has Been Called Last If (get IsReReadParameters ()) Then

!Read in the Values of the Parameters from the Input File MODE = JFIX (getParameterValue $(1)+0.1$ )

LU_DATA = JFIX (getParameterValue (2) +0.1 )

$\mathrm{N} \_\overline{\mathrm{W} T}=$ JFIX (getParameterValue $(3)+0.1$ )

$\mathrm{N}_{-}^{-} \mathrm{RH}=\mathrm{JFIX}$ (getParameterValue $(4)+0.1$ ) 
$\mathrm{N} \_\mathrm{DB}=$ JFIX (getParameterValue $(5)+0.1$ )

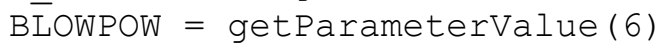

CONTPOW = getParameterValue (7)

LPS_TOT = getParameterValue (8)

EndIf

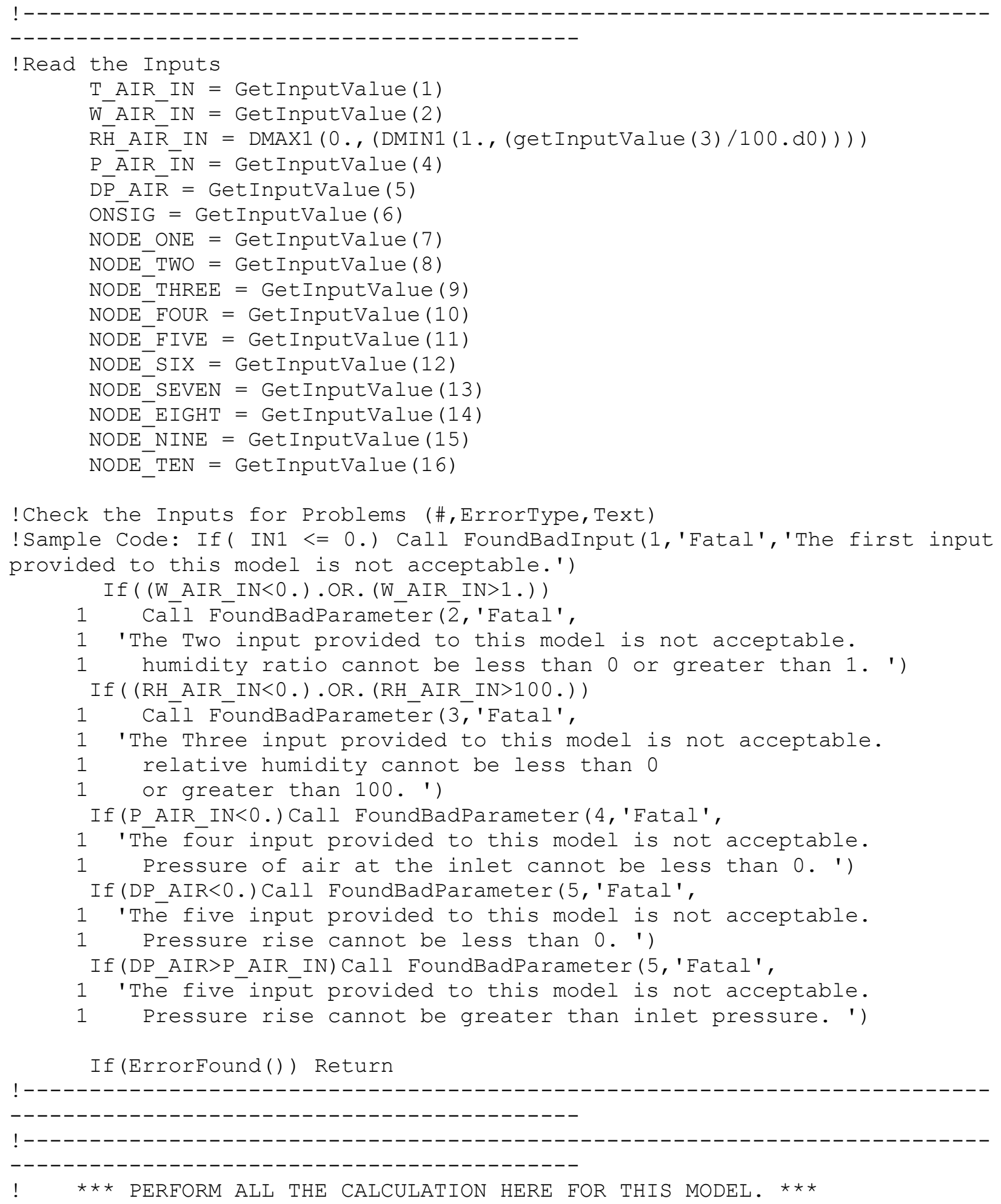




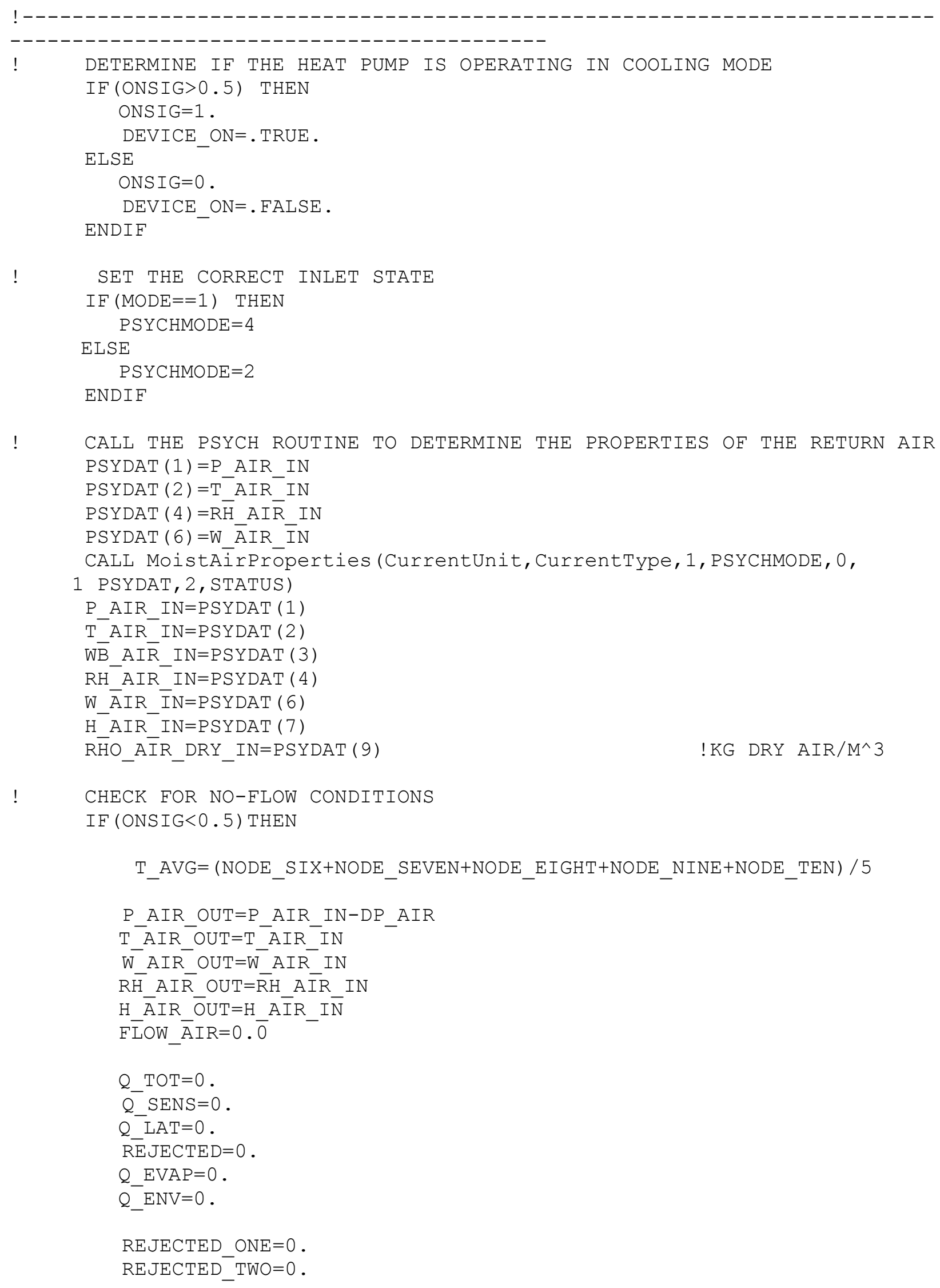




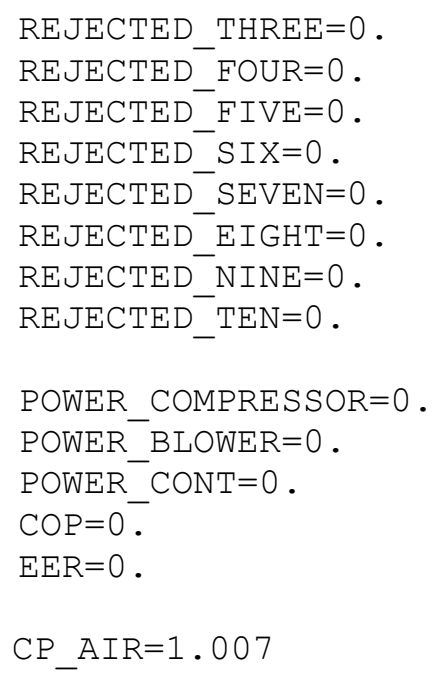




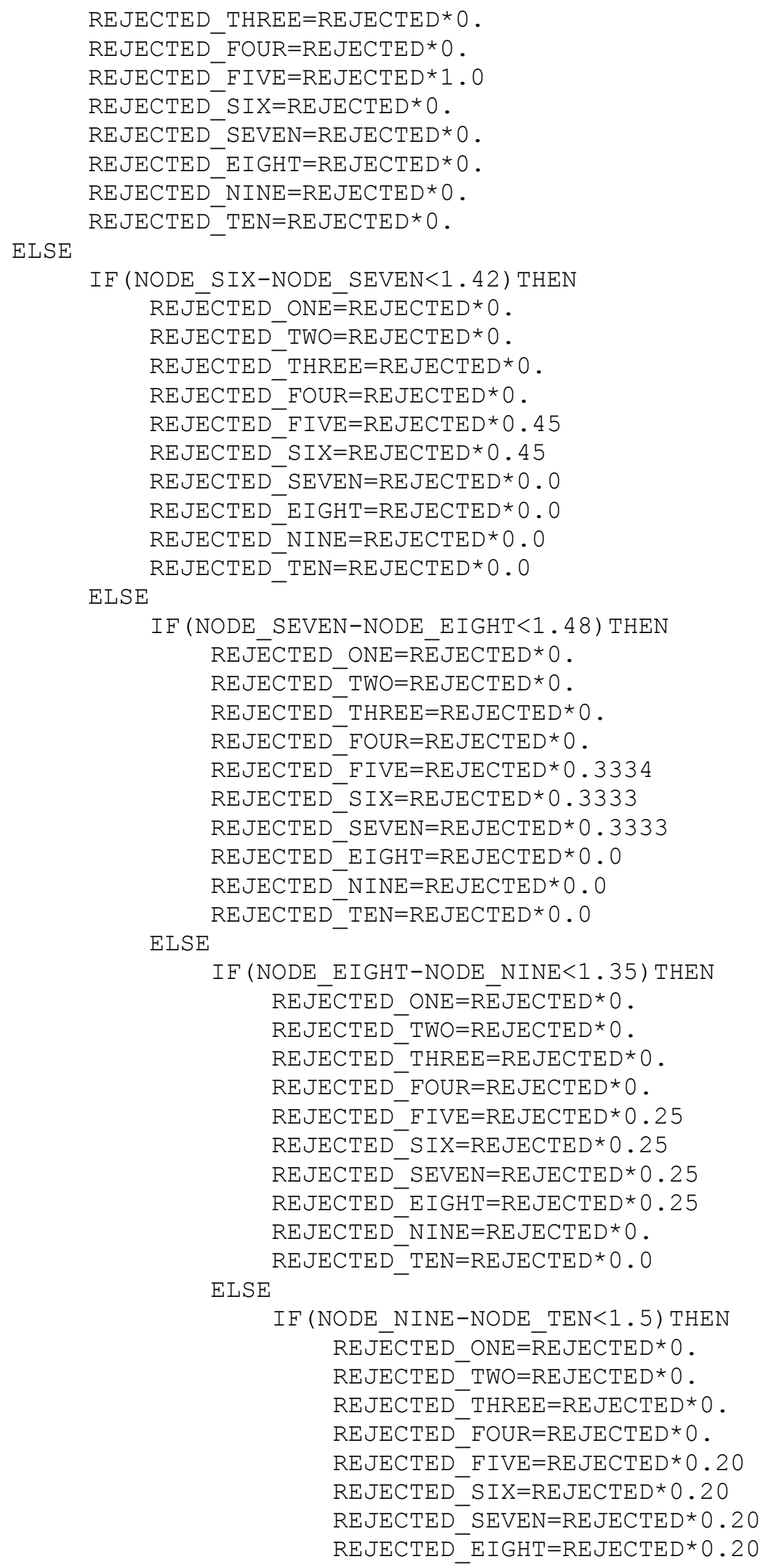




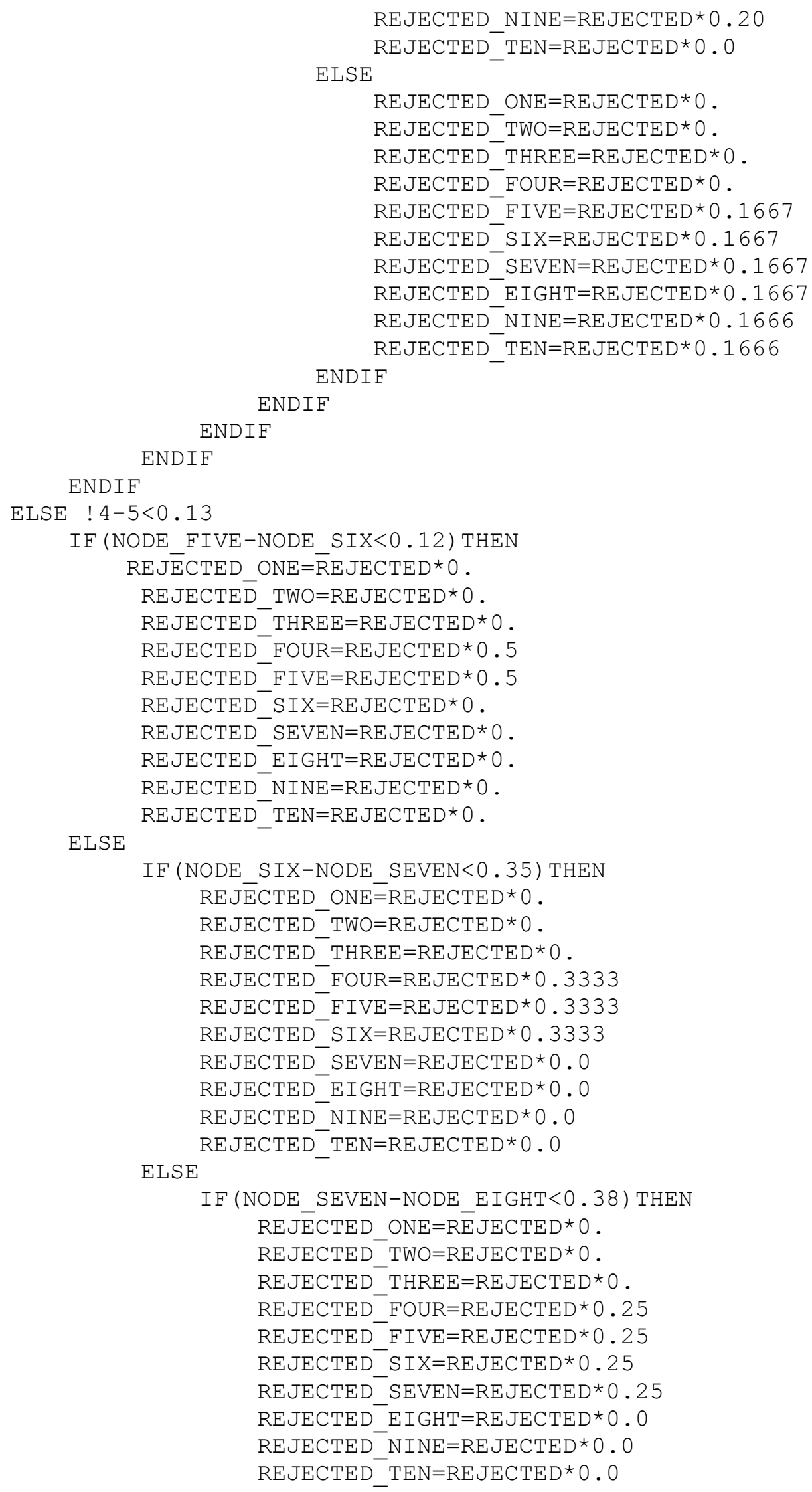


ELSE

IF (NODE EIGHT-NODE NINE<0.73) THEN

REJE CTED ONE $=R \bar{E} J E C T E D * 0$.

REJECTED TWO=REJECTED*0 .

REJECTED_THREE=REJECTED*0.

REJECTED_FOUR=REJECTED*0.20

REJECTED_FIVE $=$ REJECTED*0.20

REJECTED_SIX $=$ REJECTED*0.20

REJECTED SEVEN=REJECTED*0.20

REJECTED_EIGHT $=$ REJECTED 0.20

REJECTED_NINE $=$ REJECTED*0.

ELSE

REJECTED_TEN=REJECTED*0.

IF (NODE NINE-NODE TEN $<1.5$ ) THEN

REJECTED ONE $=\bar{R} E J E C T E D * 0$.

REJECTED_TWO=REJECTED*0.

REJECTED THREE $=$ REJECTED*0 .

REJECTED_FOUR $=$ REJECTED*0.1667

REJECTED_FIVE $=$ REJECTED*0.1667

REJECTED_SIX $=$ REJECTED*0.1667

REJECTED_SEVEN=REJECTED*0.1667

REJECTED_EIGHT $=$ REJECTED*0.1666

REJECTED NINE $=$ REJECTED*0.1666

ELSE

REJECTED_TEN $=$ REJECTED 0.0

REJECTED ONE $=R E J E C T E D * 0$.

REJECTED $T W O=R E J E C T E D * 0$.

REJECTED THREE $=$ REJECTED*0 .

REJECTED_FOUR=REJECTED*0.15

REJECTED_FIVE=REJECTED*0.15

REJECTED_SIX=REJECTED*0.15

REJECTED_SEVEN=REJECTED*0.15

REJECTED_EIGHT $=$ REJECTED*0.15

REJECTED_NINE $=$ REJECTED*0.15

ENDIF

REJECTED_TEN=REJECTED*0.10

ENDIF

ENDIF

ENDIF

ENDIF

ENDIF

ELSE $! 3-5<0.18$

IF (NODE_FIVE-NODE_SIX<0.12) THEN

REJECTED ONE $=\bar{R} E J E C T E D * 0$.

REJECTED TWO=REJECTED* 0 .

REJECTED THREE $=$ REJECTED*0.3334

REJECTED_FOUR=REJECTED $* 0.3333$

REJECTED_FIVE $=$ REJECTED 0.3333

REJECTED SIX $=$ REJECTED*0 .

REJECTED SEVEN=REJECTED*0.

REJECTED_EIGHT $=$ REJECTED*0.

REJECTED_NINE $=$ REJECTED*0.

ELSE

REJECTED_TEN=REJECTED*0. 


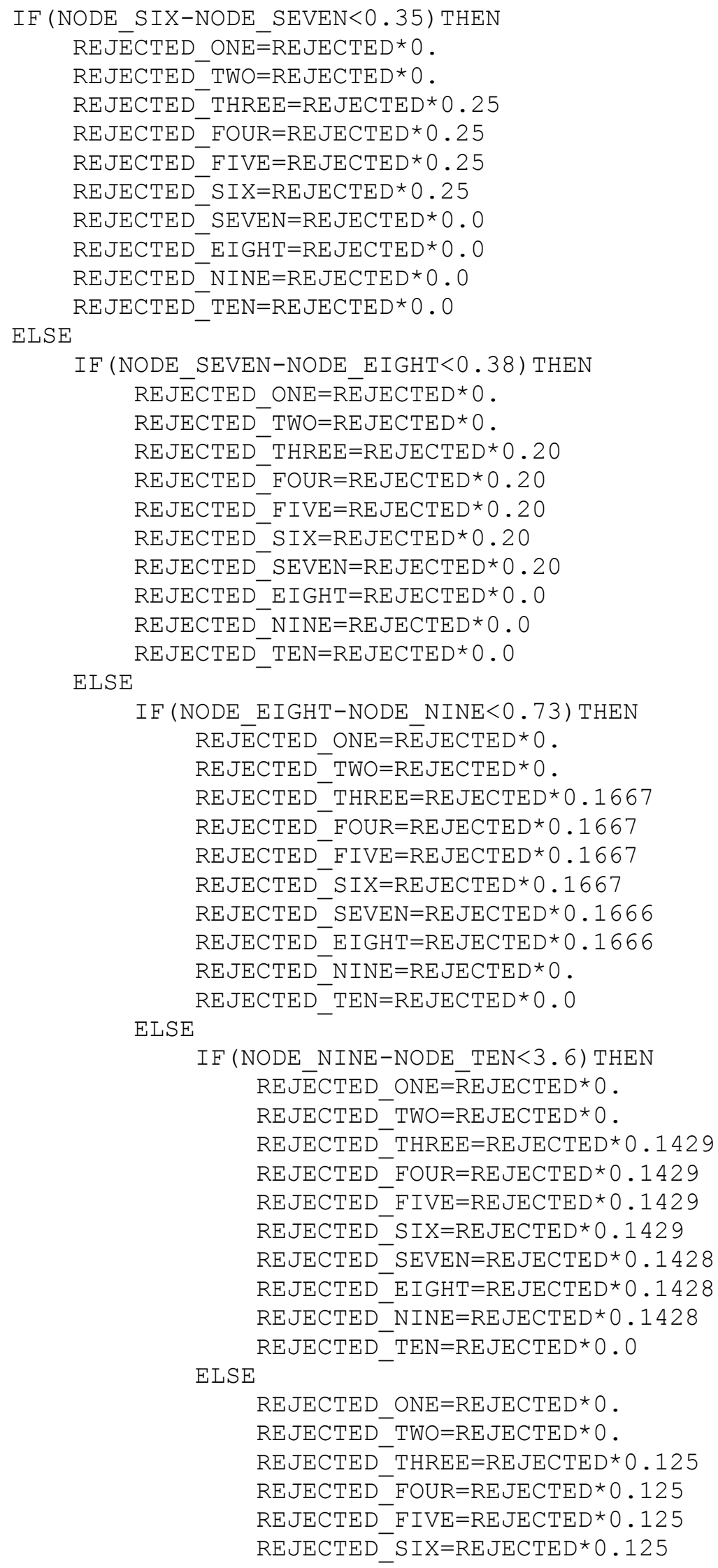




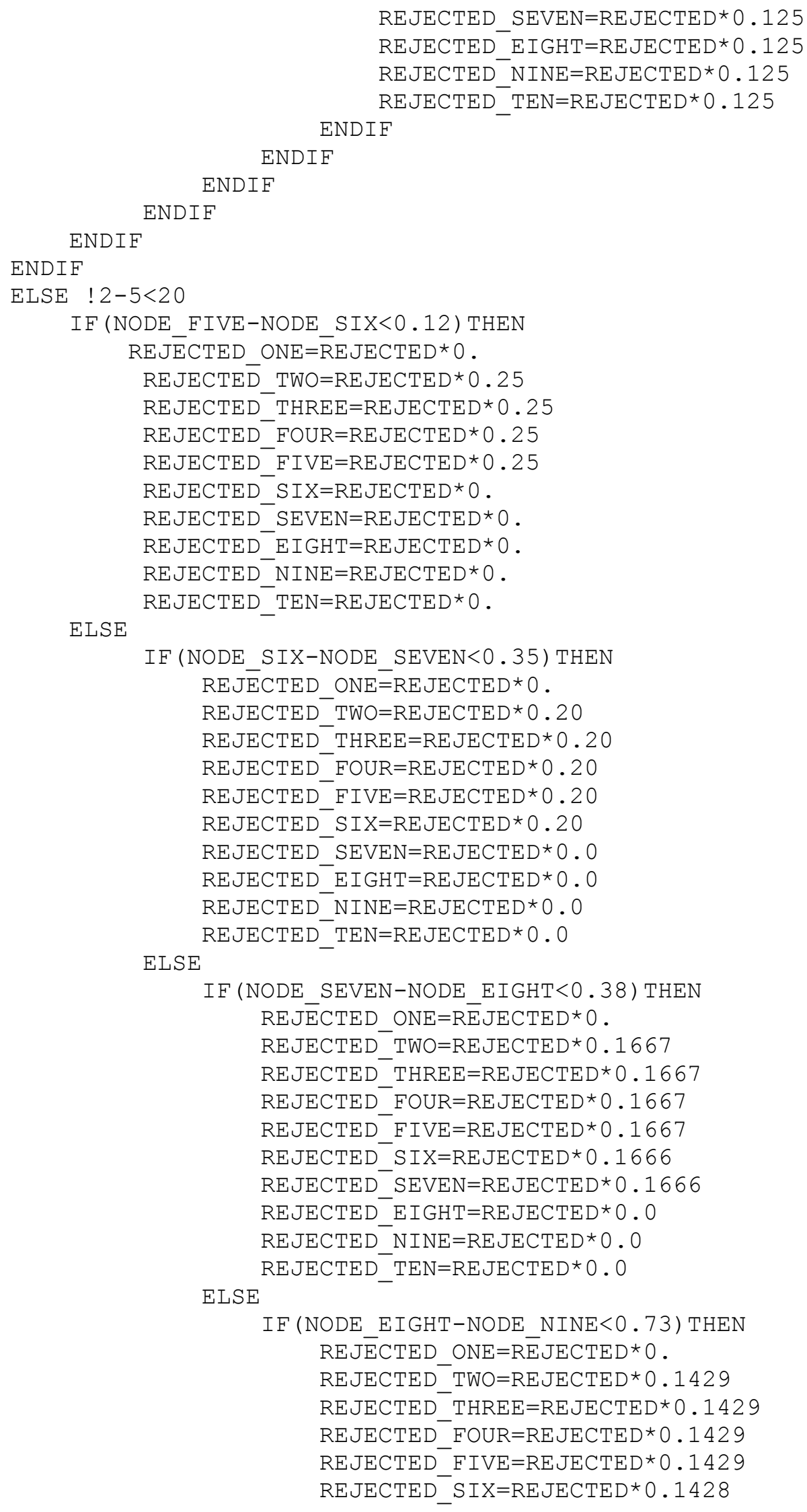




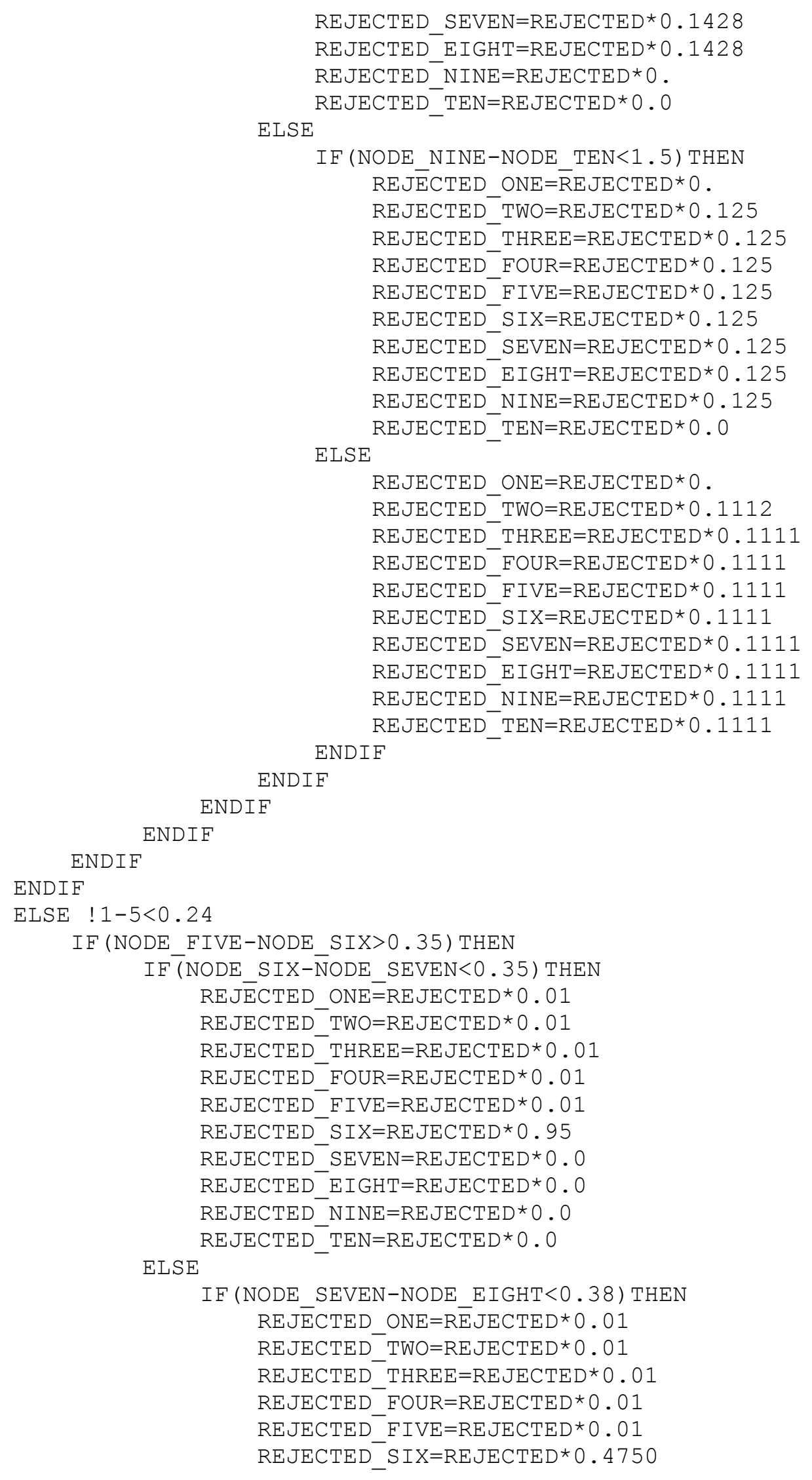




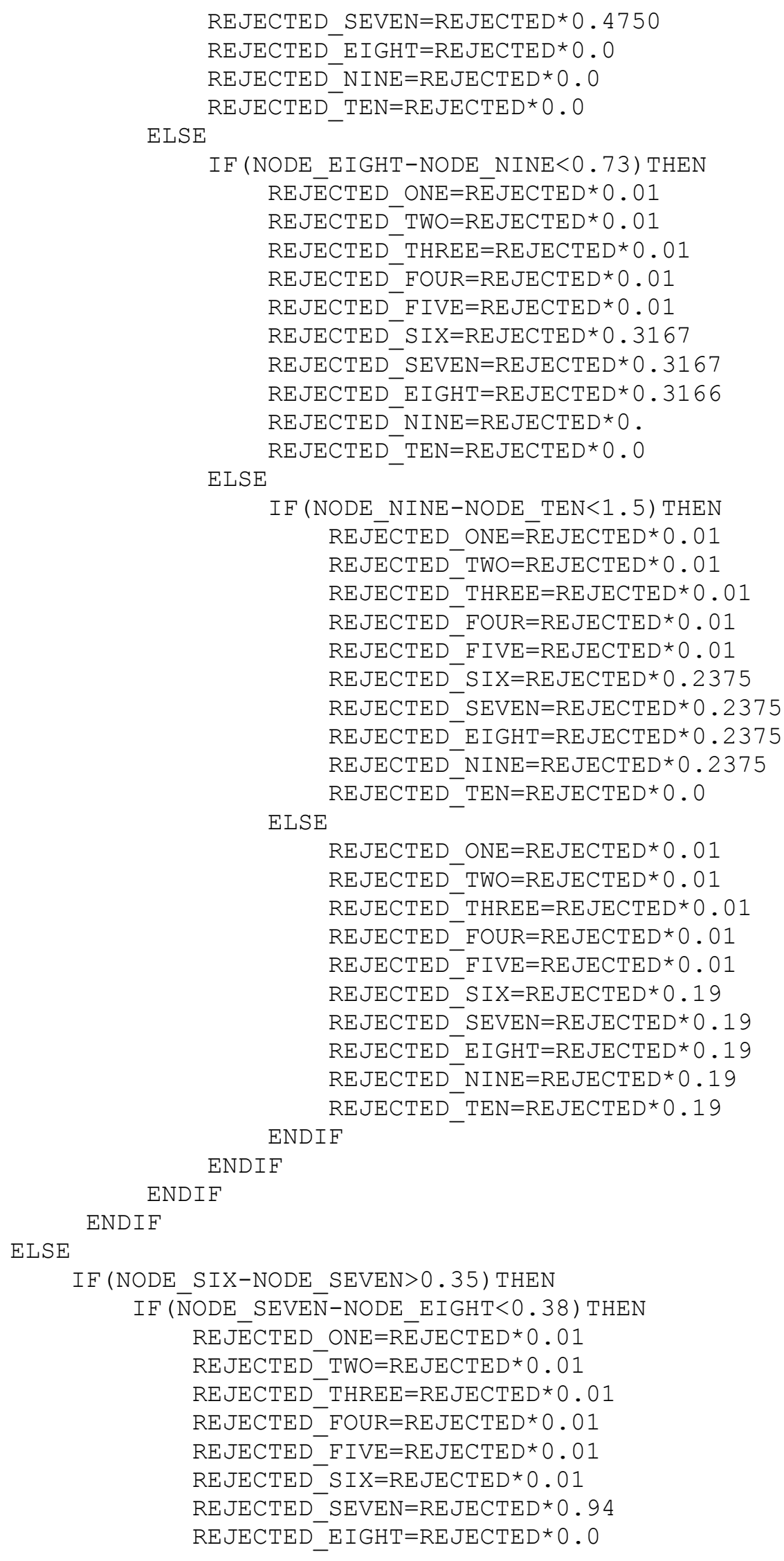

REJECTED_SEVEN=REJECTED*0.4750

REJECTED NINE $=$ REJECTED *0.0

E

IF (NODE EIGHT-NODE NINE<0.73) THEN

REJECTED ONE $=$ REJECTED*0.01

REJECTED TWO=REJECTED* 0.01

REJECTED THREE $=$ REJECTED*0.01

REJECTED SEVEN=REJECTED*0.3167

REJECTED EIGHT $=$ REJECTED*0.3166

REJECTED NINE $=$ REJECTED*0.

IF (NODE NINE-NODE TEN 1 . 5) THEN

REJECTED ONE $=$ REJECTED*0.01

REJECTED TWO $=$ REJECTED*0.01

$E * 0.01$

REJECTED $F I V E=R E J E C T E D * 0.01$

REJECTED SIX=REJECTED*0.2375

REJECTED SEVEN=REJECTED*0.2375

REJECTED EIGHT $=$ REJECTED*0.2375

REJECTED NINE=REJECTED*0.2375

REJECTED ONE $=$ REJECTED*0.01

REJECTED TWO $=$ REJECTED*0.01

REJECTED_THREE $=R E J E C T E D * 0.01$

REJECTED SEVEN=REJECTED*0.19

REJECTED EIGHT $=$ REJECTED*0.19

REJECTED NINE $=$ REJECTED *0.19

REJECTED TEN=REJECTED*0.19

ENDIF

NDIF

F(NODE_SIX-NODE_SEVEN>0.35) THEN

IF (

REJECTED ONE $=$ REJECTED*0.01

REJECTED TWO=REJECTED $* 0.01$

REJECTED THREE $=$ REJECTED*0.01

REJECTED FOUR=REJECTED*0.01

REJECTED FIVE $=$ REJECTED*0.01

REJECTED_EIGHT $=$ REJECTED*0.0 


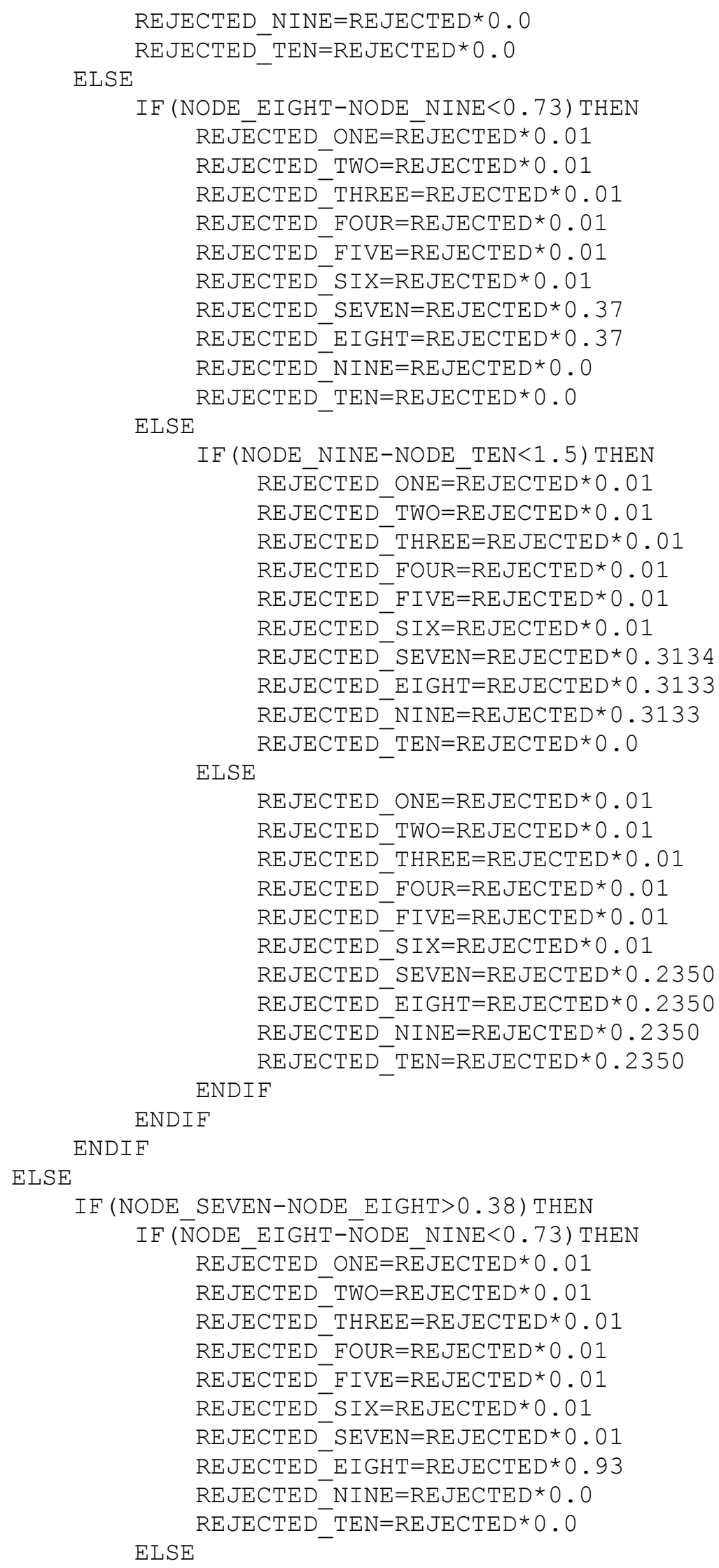




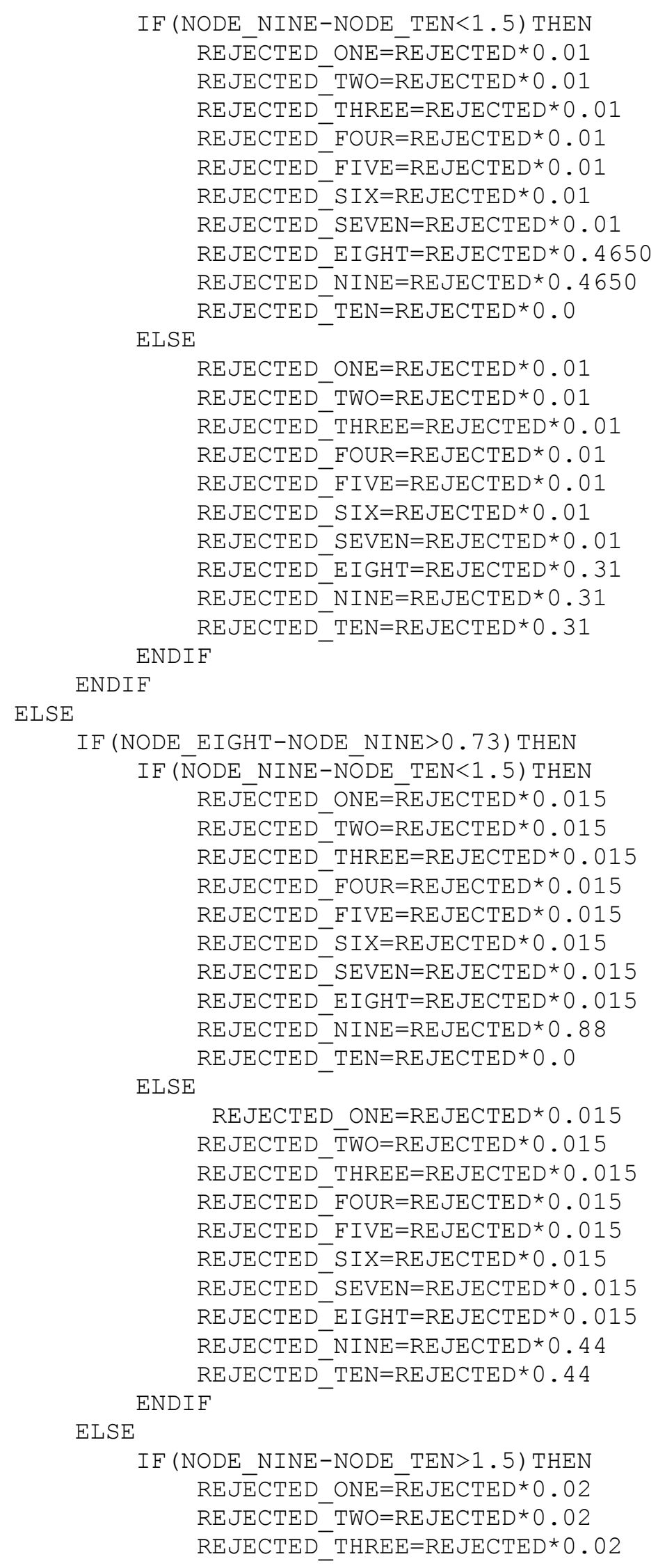




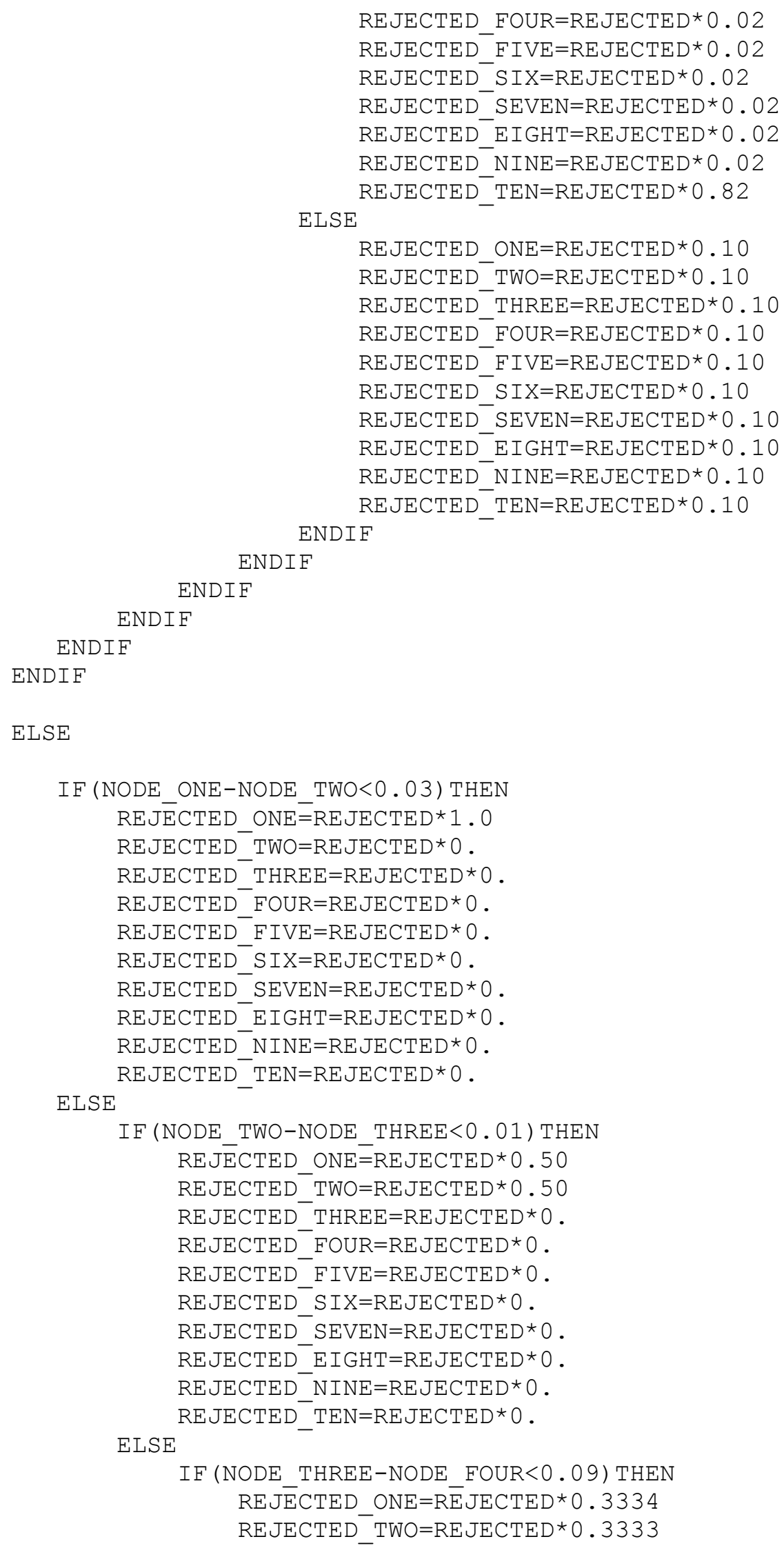




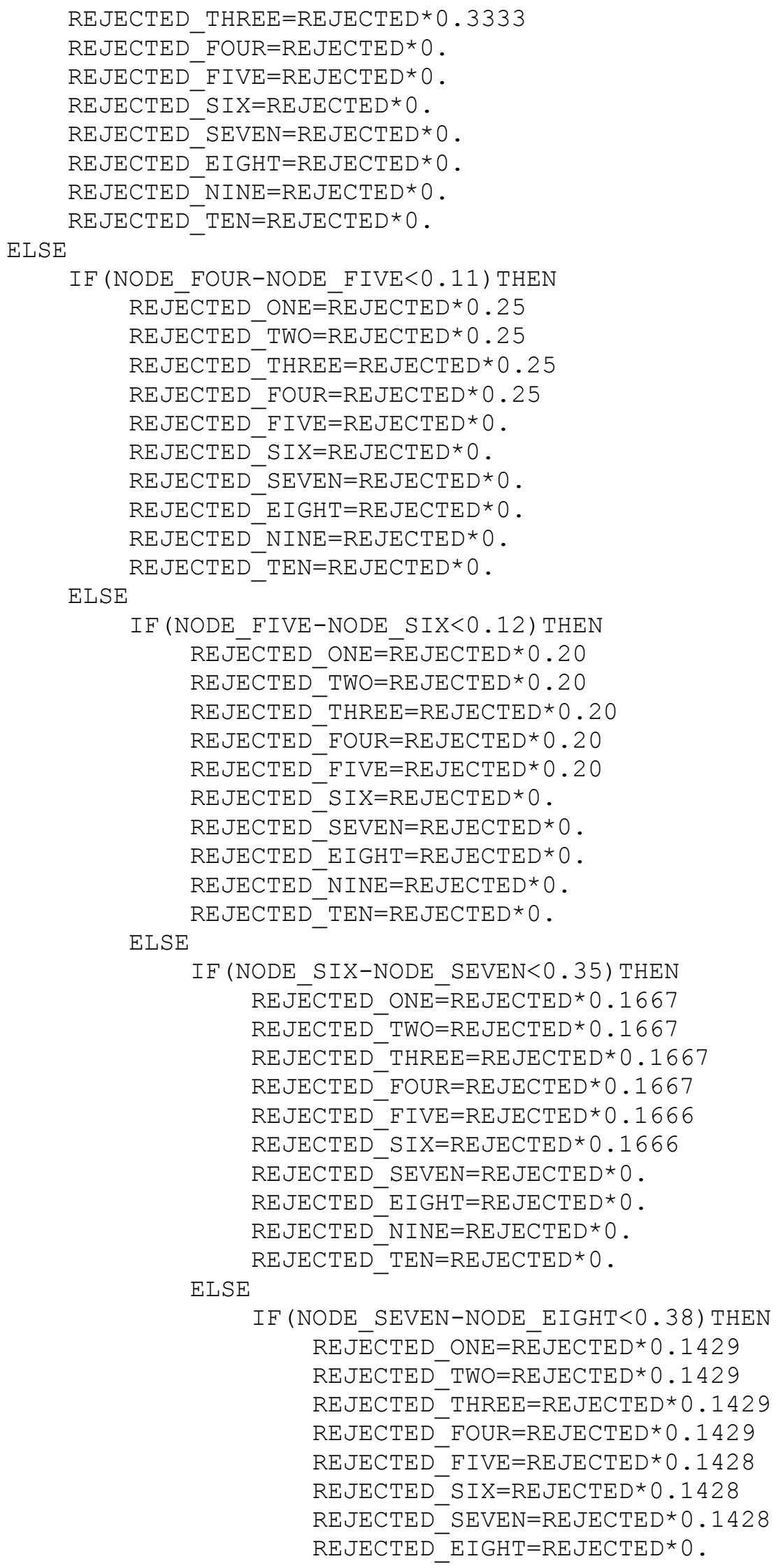



ELSE

REJECTED_NINE $=$ REJECTED $* 0$

REJECTED_TEN=REJECTED*0.

IF (NODE_EIGHT-NODE_NINE $<0.73$ ) THEN

REJECTED ONE $=$ REJECTED $* 0.1250$

REJECTED_TWO=REJECTED 0.1250

REJECTED_THREE=REJECTED*0.1250

REJECTED FOUR=REJECTED*0.1250

REJECTED_FIVE $=$ REJECTED*0 0.1250

REJECTED_SIX=REJECTED*0.1250

REJECTED SEVEN=REJECTED*0.1250

REJECTED_EIGHT=REJECTED*0.1250

REJECTED - NINE $=$ REJECTED*0.

ELSE

REJECTED_TEN=REJECTED*0.

IF (NODE NINE-NODE TEN<3.06) THEN

REJECTED ONE $=$ REJECTED*0.1112

REJECTED_TWO=REJECTED*0.1111

REJECTED_THREE $=$ REJECTED*0.1111

REJECTED_FOUR=REJECTED*0.1111

REJECTED_FIVE=REJECTED*0.1111

REJECTED SIX $=$ REJECTED*0.1111

REJECTED_SEVEN=REJECTED*0.1111

REJECTED EIGHT=REJECTED*0.1111

REJECTED_NINE $=$ REJECTED*0.1111

REJECTED_TEN=REJECTED*0.

ELSE

REJECTED ONE $=$ REJECTED*0.10

REJECTED ${ }^{-}$TWO $=$REJECTED $* 0.10$

REJECTED_THREE $=$ REJECTED 0.10

REJECTED_FOUR=REJECTED*0.10

REJECTED_FIVE $=$ REJECTED*0.10

REJECTED_SIX=REJECTED *0.10

REJECTED SEVEN=REJECTED*0.10

REJECTED ${ }^{-} I G H T=R E J E C T E D * 0.10$

REJECTED NINE $=$ REJECTED*0.10

REJECTED_TEN=REJECTED*0.10

ENDIF

ENDIF

ENDIF

ENDIF

ENDIF

ENDIF

ENDIF

ENDIF

ENDIF

ENDIF

! CALCULATE THE ENERGY THAT IS LOST FROM THE COMPRESSOR TO THE SURROUNDINGS

Q_ENV $=$ Q_TOT+POWER-REJECTED 
CALCULATE THE OUTLET AIR CONDITIONS FROM THE CAPACITIES

T_AIR_OUT $=T$ T_AIR_IN-(Q_SENS/ (CP_AIR*FLOW_AIR))

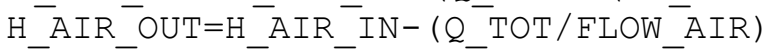

$P_{-}^{-} A I R-O U T=P_{-}^{-} A I R+I N+D_{-}^{-}{ }_{-}^{-} A I R$

CALL PSYCH TO GET THE REMAINING PROPERTIES $\operatorname{PSYDAT}(1)=\mathrm{P}$ AIR_OUT $\operatorname{PSYDAT}(2)=\mathrm{T}^{-}$AIR_OUT $\operatorname{PSYDAT}(7)=\mathrm{H}^{-}$AIR_OUT

CALL MoistAir̄Properties (CurrentUnit, CurrentType, 1, 5, 1,

1 PSYDAT, 0 , STATUS )

T AIR OUT $=$ PSYDAT (2)

WAAR_OUT $=$ PSYDAT ( 6 )

$\mathrm{R} \overline{\mathrm{H}}$ AI $\overline{\mathrm{R}}$ OUT=PSYDAT (4)

H_

CHECK TO MAKE SURE THE ROUTINE RETURNED A REASONABLE ANSWER IF (W_AIR_OUT $>$ W_AIR_IN) THEN

W_AIR_OUT $=W \_A I R \_I N$

H_AIR_OUT $=\mathrm{H}_{-}{ }_{-}^{-} \mathrm{AIR}{ }_{-}^{-} \mathrm{IN}-\mathrm{Q} \_\mathrm{TOT} / \mathrm{FLOW}$ _AIR

$\operatorname{PSYDAT}(1)=\mathrm{P}$ AIR OUT

$\operatorname{PSYDAT}(6)=\mathrm{W}-{ }^{-} \mathrm{AIR}$ OUT

$\operatorname{PSYDAT}(7)=\mathrm{H}^{-}$AIR OUT

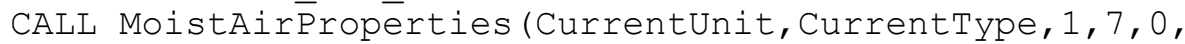

1 PSYDAT, 0 , STATUS )

T_AIR_OUT $=$ PSYDAT (2)

W-AIR_OUT $=$ PSYDAT ( 6 )

$\mathrm{R} \overline{\mathrm{H}} \mathrm{AI} \overline{\mathrm{R}} \mathrm{OUT}=\mathrm{PSYDAT}(4)$

H_

ELSE IF (RH_AIR_OUT>0.999) THEN

$\mathrm{H} \_\mathrm{AIR} \_\mathrm{OUT}=\mathrm{H} \_\mathrm{AIR} \_\mathrm{IN}-\mathrm{Q} \_\mathrm{TOT} / \mathrm{FLOW} \_\mathrm{AIR}$

$\operatorname{PSYDAT}(1)=\mathrm{P}$ AIR_OUT

$\operatorname{PSYDAT}(4)=\bar{R} \bar{H}$ AI $\bar{R}$ OUT

$\operatorname{PSYDAT}(7)=\mathrm{H}$ A IR OUT

CALL MoistAirPיproperties (CurrentUnit, CurrentType, 1, 8, 0 ,

1 PSYDAT, 0, STATUS )

T_AIR_OUT $=$ PSYDAT $(2)$

W'AIR_OUT $=$ PSYDAT ( 6 )

$\mathrm{R} \overline{\mathrm{H}} \mathrm{AI} \overline{\mathrm{R}} \mathrm{OUT}=\mathrm{PSYDAT}(4)$

H_

ENDIF

ADD IN THE FAN POWER

W_AIR_OUT $=W \_A I R \_O U T$

H_AIR_OUT $={ }^{-}{ }_{-}{ }_{-}$AIR_OUT + BLOWPOW $/$FLOW_AIR

$\operatorname{PSYDAT}(1)=\mathrm{P} \_$AIR_OUT

$\operatorname{PSYDAT}(6)=W-A I R \_$OUT 


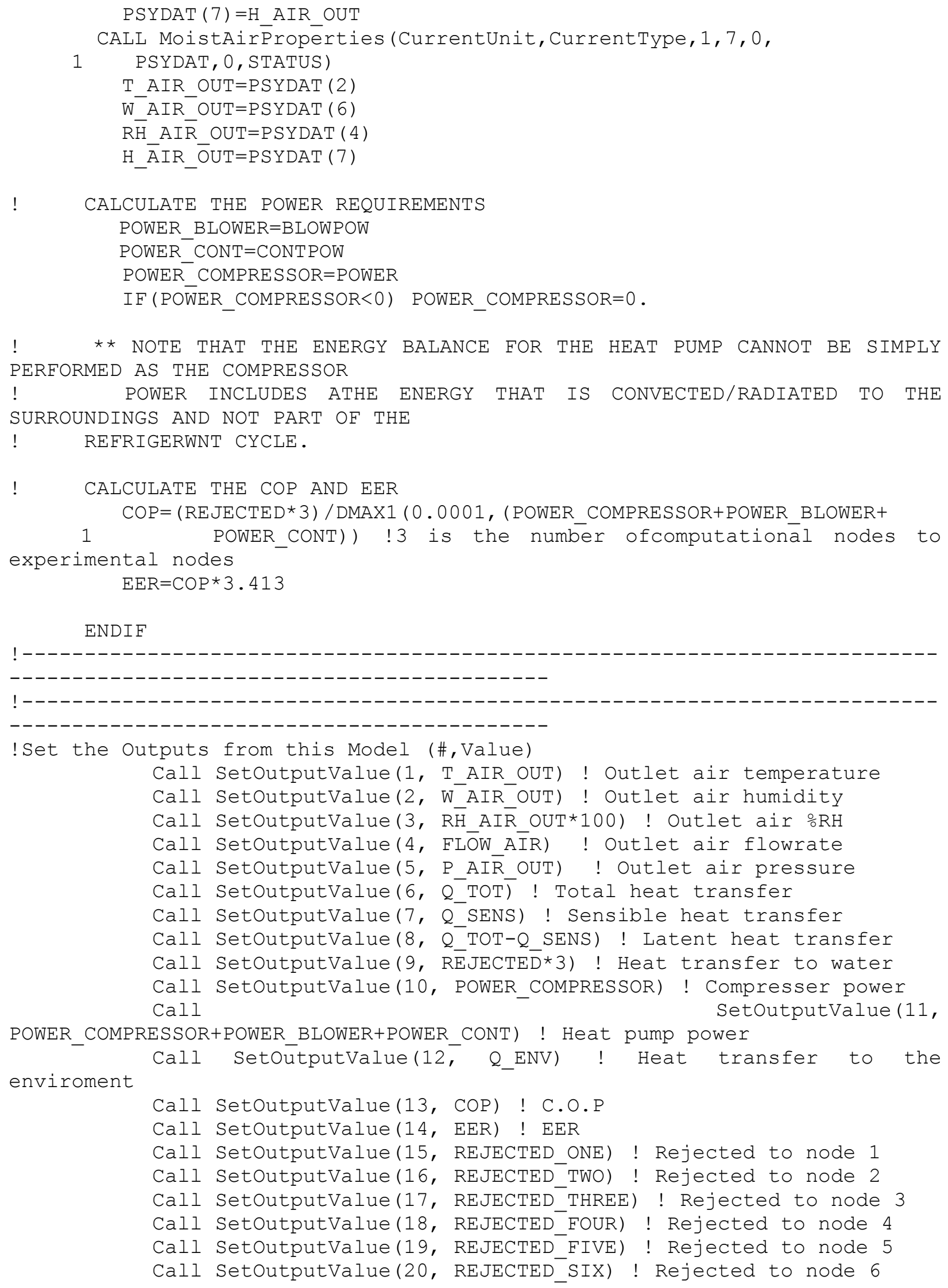


Call setoutputValue(21, REJECTED_SEVEN) ! Rejected to node 7

Call SetoutputValue(22, REJECTED EIGHT) ! Rejected to node 8

Call setoutputvalue (23, REJECTED NINE) ! Rejected to node 9

Call SetoutputValue(24, REJECTED_TEN) ! Rejected to node 10

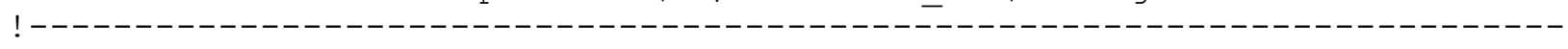

Return

End

! - - - - - - - - - - - - - - - - - - - - - - - - - - - - - - - - - - 